\title{
Heavy Metal Pollutants in Snow and Ice from Roosevelt Island, Antarctica
}

By

\section{Andrea Jean Tuohy \\ 300104536}

A thesis submitted to the Victoria University of Wellington in fulfilment of the requirements for the degree of Doctor of Philosophy

Victoria University of Wellington

2015 


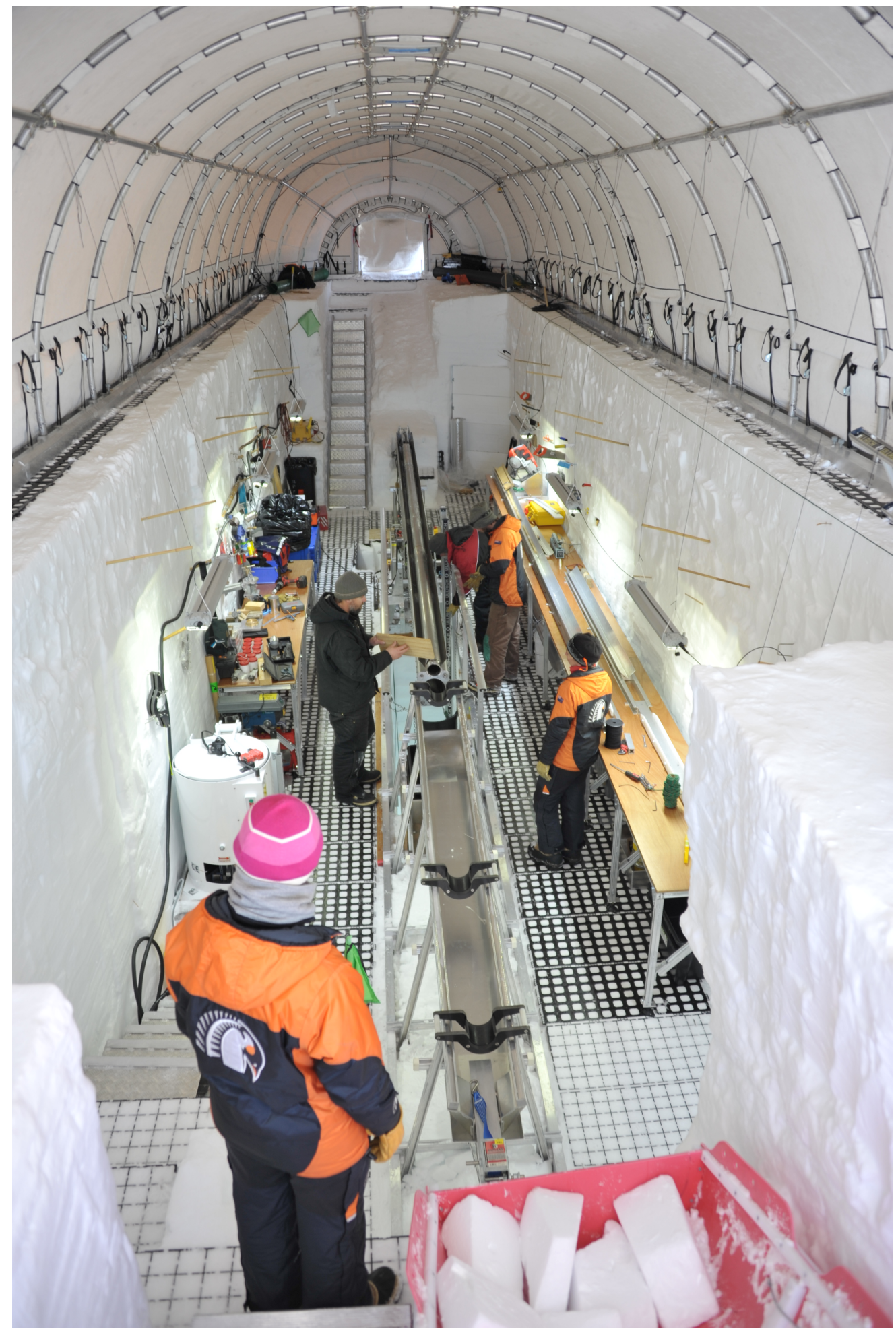

Frontispiece - Setting up for ice core drilling at Roosevelt Island, during field season 20112012. Photo: Sepp Kipfstuhl. 


\section{Abstract}

Global industrialization has led to emissions of heavy metal pollutants that are transported to the most remote areas of the planet. Elevated concentrations of heavy metals are ecological toxins in soils, water, and air. Monitoring has only been implemented during the last few decades with anthropogenic emissions superimposed over natural sources. Furthermore, most monitoring programs generally target local sources of emissions near cities rather than largescale impacts. Thus quantifying safe limits and controlling industrial emissions is complicated by a lack of knowledge about natural sources and variability on regional, hemispheric, and global scales. New baseline studies are needed to determine i) natural background concentrations of heavy metals, ii) contributions of anthropogenic emissions, and iii) the degree to which atmospheric transport affects background heavy metal concentrations. Due to the remoteness of Antarctica, ice cores can be used as sensitive recorders of background heavy metal atmospheric concentrations over thousands of years. This provides the opportunity to determine natural variability and contributions to the atmosphere on a hemispheric scale, as well as dating the onset of anthropogenic emissions.

This thesis presents a 2,300-year time-series record of six heavy metals from a new highresolution coastal ice core from the Ross Sea region of Antarctica. Roosevelt Island is an ice dome located in the north-eastern Ross Ice Shelf, and a $763 \mathrm{~m}$ deep ice core was collected over two field seasons as part of the Roosevelt Island Climate Evolution (RICE) project. In addition to 31 other trace elements, concentrations of iron, aluminium, manganese, lead, arsenic, and thallium were measured using inductively coupled plasma mass spectrometry (ICPMS) in the RICE ice core, snow pit, and snow precipitation samples. Sample resolution over the $20^{\text {th }}$ century is extremely high $(\sim 1.6$ months per sample), with $\sim$ four-year resolution extending the record back to 2,300 years ago.

We use this record to first determine the representativeness of the RICE ice core to Southern Hemisphere atmospheric concentrations of heavy metals, and find that concentrations in snow precipitation are strongly linked to meridional air mass pathways from the South Pacific. Local deposition characteristics and heavy metal seasonality are also examined in the surface snow. The natural sources and variability of the six heavy metals are explored through the last $\sim 2,000$ years, and this provides the context for examining changes over the $20^{\text {th }}$ century. We find that iron, aluminium, and manganese are strongly associated with crustal dust and do not exhibit source changes over the $20^{\text {th }}$ century, though significant 
increases in concentration may be due to anthropogenically induced increases in atmospheric dust. Even when increased variability due to recent increased efficiency of atmospheric transport is taken into account, the change in source emission strength dominates the concentration increases in these elements recorded in the RICE ice core. Thallium concentrations do not increase over the $20^{\text {th }}$ century, and are likely linked to local volcanism. Both lead and arsenic concentrations increase significantly over the $20^{\text {th }}$ century, with the pattern in lead concentrations closely matching existing Antarctic records. These increases are linked to anthropogenic emissions, with peaks during the 1970 s and 1980s up to $400 \%$ higher than pre-industrial concentrations - well outside the natural variability. However, the ice core record shows a decreasing trend in concentrations of these elements from the mid1990s to the present. Arsenic concentrations return to within pre-industrial variability, and the timing of this trend coincides with increasing efforts of policy makers in Southern Hemisphere countries to regulate industrial emissions and to promote public awareness of heavy metal pollutants. 


\section{Acknowledgements}

First thanks go to my supervisors Nancy Bertler, Ross Edwards, and Dan Sinclair, for both the opportunity to work on this project and for all the support throughout it. This has been a great experience for me, and has challenged me to learn many new skills. In particular, thanks to Nancy for your unquestioning support and confidence, and to Ross for your generosity with time, expertise, and lab equipment.

Special thanks go to Peter Neff. I couldn't have asked for a better colleague or friend to share all the sample prep, lab time (failures and successes) and analyses. I would also like to thank my other office mates Heidi Roop, Molly Patterson and Daniel Emanuelsson for sharing your friendship and support and beer.

Thanks to the 2011-2012 RICE field team for making my first season in Antarctica such a great experience; and also to the 2012 and 2013 ice core processing teams for your comradeship through the months of shift work.

I would also like to acknowledge the wider RICE community; I've enjoyed working with you on the age scale and sharing results. I also want to thank the other staff and students in the ARC for your support and good advice both around the lunch-table and for being available whenever I had questions.

Finally thanks to my all family, both in Christchurch and Wellington, and particularly to Oliver Tuohy for your love, understanding, support and advice. You are the foundation from which I draw happiness and strength. 


\section{Table of Contents}

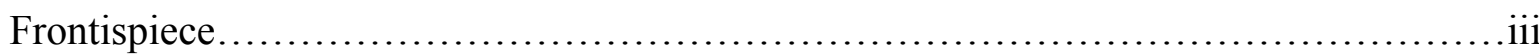

Abstract.............................................................................

Acknowledgements...............................................................

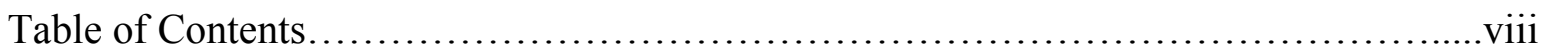

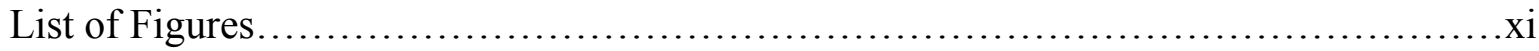

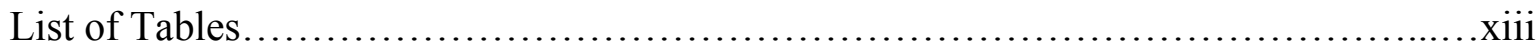

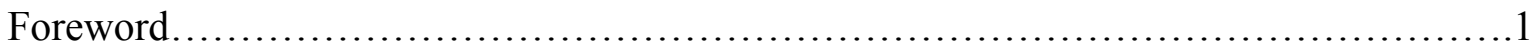

Chapter 1: Introduction and Background

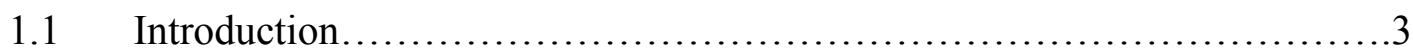

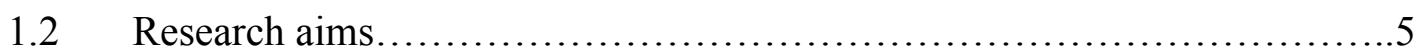

1.3 Background concepts from the literature............................5

1.3.1 Antarctic climate...............................................

1.3.2 Atmospheric transport........................................... 10

1.3.3 Major and trace elements..........................................

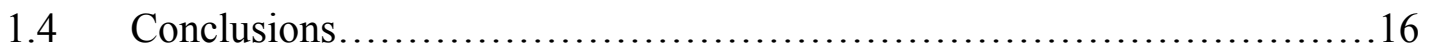

Chapter 2: Roosevelt Island Climate Evolution Project

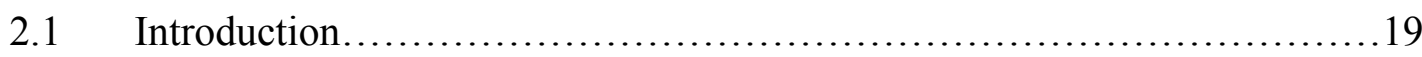

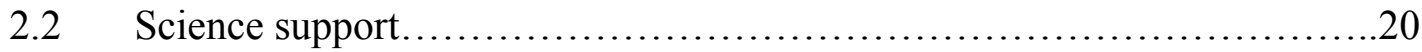

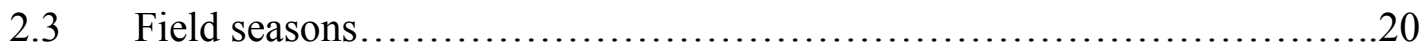

$2.4 \quad$ RICE ice core analysis over view................................... 21

2.5 RICE ice core processing summary..................................22

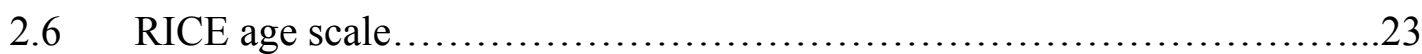

Chapter 3: Analytical Methods and Data Processing

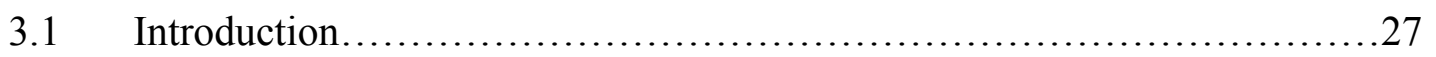

3.2 Sample and standard preparation...................................27

3.3 Acidification and leaching experiment...............................28

3.3.1 Results..............................................................

$3.4 \quad$ ICPMS set up and sample analysis.................................. 34

3.4.1 Quality of ICPMS measurements......................................

3.4.2 Limits of quantification and concentration in Antarctic ice samples.......40

3.5 Analysis of plutonium isotopes....................................43

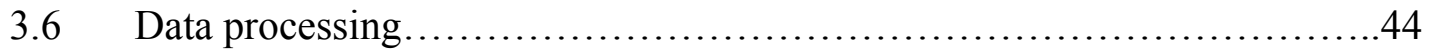


Chapter 4: Transport and Deposition of Toxic Heavy Metals in the Ross Sea Region, Antarctica

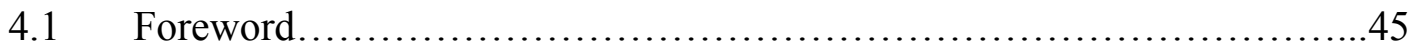

$4.2 \quad$ Abstract............................................................46

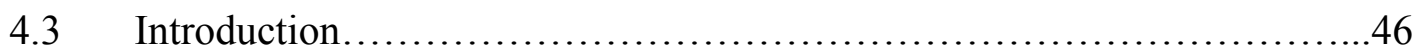

$4.4 \quad$ Methods........................................................ 48

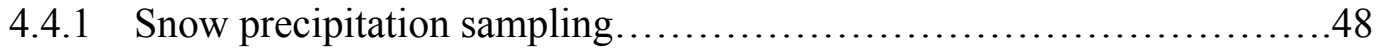

4.4.2 Snow pit sampling methods.......................................49

4.4.3 ICPMS analysis of snow precipitation and snow pit samples.............50

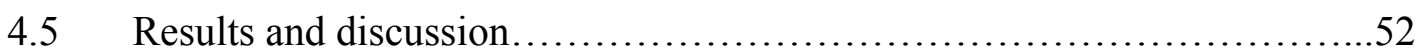

4.5.1 Snow precipitation at Roosevelt Island............................52

4.5.2 Scavenging efficiency of different snow precipitation..................54

4.5.3 Back trajectory modelling......................................56

4.6 Snowpack dating .................................................60

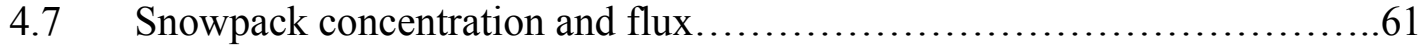

4.8 Conclusions.......................................................66

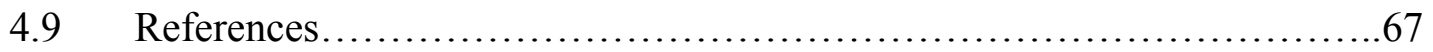

4.10 Supplementary information........................................ 72

Chapter 5: $20^{\text {th }}$ Century Arsenic Pollution: A record of anthropogenic emissions and recent decreases

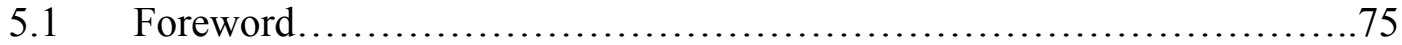

$5.2 \quad$ Introduction....................................................... 75

$5.3 \quad$ Results and discussion............................................. 77

5.3.1 Sources of pre-industrial arsenic .................................79

5.3.2 Arsenic over the $20^{\text {th }}$ Century................................... 81

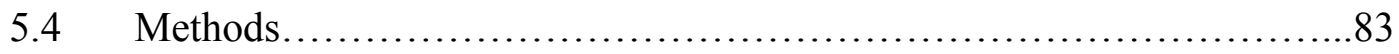

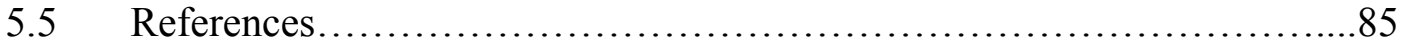

5.6 Supplementary Figures and Tables..................................88

Chapter 6: Heavy Metal Pollutants over the last 2,000 years at Roosevelt Island, Antarctica

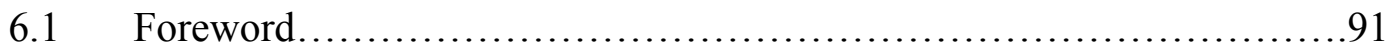

$6.2 \quad$ Abstract.......................................................... 91

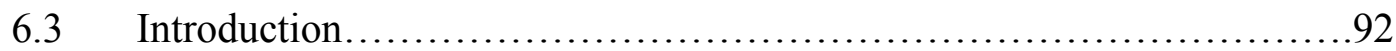

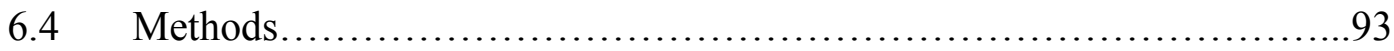

6.4.1 RICE age scale....................................... 95 
$6.5 \quad$ Results and discussion..........................................96

6.5.1 Metal concentrations and variability.............................98

6.5.2 Heavy metal sources............................................ 99

6.5.3 $20^{\text {th }}$ Century Source Changes.................................... 101

6.6 Conclusions......................................................... 105

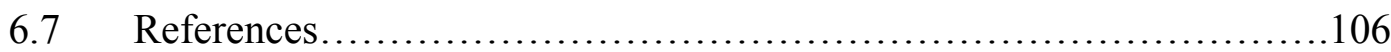

Chapter 7: Summary and Conclusions.......................................... 111

7.1 Future Directions.............................................. 115

Thesis References........................................................... 117

Appendix A.................................................................. 127 


\section{List of Figures}

Figure 1.1 - Location map of Antarctica.........................................6

Figure 2.1 - Outline of ice core cutting plan, with divisions of analyses and contributions from participating nations.

Figure 2.2 - Example of RICE 1.0 age scale layer counting based on ice

Chemistry

Figure 2.3 - RICE 1.0 age scale over the top $350 \mathrm{~m} / 2,500$ years

Figure 3.1 - Change in concentration over time since acidification for $\mathrm{Fe}, \mathrm{Mn}$, and La....

Figure 3.2 - Percent concentration changes following acidification in trace

elements analysed in RICE snow.

Figure 3.3 - QC stability through time for selected rare earth elements and heavy metals.

Figure 3.4 - RICE sample mean values compared to instrumental and procedural

Blanks

Figure 3.5 - ICPMS counts per second on $\mathrm{Pu}^{239}$ in RICE ice core samples.

Figure 4.1 - Location map of Roosevelt Island, Antarctica...........................48

Figure 4.2 - Concentrations of heavy metal elements in RICE snow precipitation........52

Figure 4.3 - Hysplit clustered atmospheric back trajectories for summer $2011 / 2012$.

Figure 4.4 - Comparison of average heavy metal concentrations per clustered atmospheric pathway.

Figure 4.5 - Seasonal clustered atmospheric back trajectories between 2006

and 2012 .

Figure 4.6 - Chemistry data contributing to snow pit age model.

Figure 4.7 - Concentrations of heavy metals in the RICE snow pit

Figure 4.8 - RICE snow pit density and annual accumulation.

Figure 4.S1 - Annual average flux for heavy metals in RICE snow....

Figure 5.1 - Changes in arsenic concentration through time from the RICE

ice core

Figure 5.2 - High-resolution concentrations of S and As in the RICE ice core. .80 
Figure 5.S1 - Spectral analysis of As, S, and $\mathrm{Pb}$ between 1890 and 1991

Figure 5.S2 - Comparison of RICE Pb concentrations with those published in McConnell et al. 2014 over the $20^{\text {th }}$ Century...

Figure 6.1 - Heavy metal concentrations over the last 2,000 years in the RICE ice core

Figure 6.2 - Comparison of RICE Pb concentrations with those published in McConnell et al. 2014 over the $20^{\text {th }}$ Century.

Figure 6.3 - Spectral frequencies for selected heavy metal elements during the pre-industrial period and the $20^{\text {th }}$ Century 


\section{List of Tables}

Table 3.1 - Trace elements analysed in leaching experiment with comparisons between sample precision, accuracy, and external standard values.

Table 3.2 - List of analysed isotopes and calibration standard concentrations.

Table 3.3 - Known concentrations of QC samples vs analytical mean and standard deviation.

Table 3.4 - Concentrations of RICE samples, instrumental and procedural blanks

Table 4.1 - Heavy metal data statistics .54

Table 4.2 - Correlation coefficients between snow pit annual accumulation, wind speed, and annual element flux, and heavy metal concentration with density

Table 4.ST1 - Daily snow concentrations and field observations.

Table 5.1 - Statistical characteristics of arsenic over the last 2,000 years.

Table 5.2 - Correlation coefficients between arsenic and other elements analysed in the RICE ice core

Table 5.ST1 - Analytical mean, standard deviation and blank concentration of Arsenic in RICE samples.

Table 6.1 - Heavy metal concentrations and crustal enrichment values over the last 2,000 years

Table 6.2 - Correlation coefficients between RICE pre-industrial and $20^{\text {th }}$ Century trace elements

Table 6.3 - Frequency intervals of spectral peaks for heavy metal elements over the pre-industrial and the $20^{\text {th }}$ Century....

Table 6.4 - Comparison of trace element variability between the last

2,000 years and the $20^{\text {th }}$ Century 


\section{Foreword}

This thesis focuses on the $20^{\text {th }}$ century record of heavy metal pollutants in Antarctic snow and ice, in the context of the last 2000 years. The work was conducted as part of the international Roosevelt Island Climate Evolution (RICE) project. Hence, there has been significant collaboration with many others in the collection and processing of samples, and the generation of large datasets, of which the results presented here are a subset.

The collaborative nature of the RICE program and my role as a PhD candidate necessitates an outline of my contributions to the project.

- Field work - I was a member (ice core processor) of the 2011/2012 field team, which spent two months at Roosevelt Island setting up the drill site and equipment, and drilling the first $130 \mathrm{~m}$ of the main ice core. During this time I also worked within a team to sample a $3 \mathrm{~m}$ deep snow pit for geochemical analysis, to collect daily precipitation for stable isotope and trace element analyses, to take hourly weather observations, and to maintain and repair the RICE automatic weather station.

- Equipment preparation and ice core processing - PhD student Peter Neff and I carried out the preparation (cleaning) of the first 20,000 vials for trace element analyses. During the 2012 and 2013 ice core processing campaigns I led the 12 hour day-shift operation of the fraction collectors for trace element, major ion, and stable isotope samples $(>50,000$ discrete samples) in the clean laboratory; assisted with core preparation for the continuous melter system in the cold laboratory, and managed the discrete sample labelling and storage of all discrete water samples.

- Laboratory set up - I carried out the set-up, testing, and preparation of a new ThermoFisher Element 2 Inductively Coupled Plasma Mass Spectrometer (ICPMS) in the Victoria University of Wellington Geochemistry laboratory for low concentration trace element analyses. Unfortunately, extensive malfunctions occurred following earthquakes and unplanned power outages. For this reason we shifted the analysis in April 2014 to the John de Laeter Centre Trace Research Advanced Clean Environment (TRACE) facility at Curtin University in Perth, Australia. 
- Sample preparation and analyses - Peter Neff and I carried out all preparation of over 2000 samples for trace element analyses, including combining over 10,000 samples into averaged samples. Analysis for concentrations of 35 different trace elements on over 2000 samples spanning the top $320 \mathrm{~m}$ of the RICE ice core was conducted at Curtin University, Perth, Australia; and required 24hr supervision over four weeks, split between Peter Neff and I.

- Data processing - I carried out the majority of ICPMS data processing from the raw data counts generated at Curtin University to final sample concentrations.

- RICE age scale - Peter Neff, Daniel Emanuelsson, Thomas Beers and I individually developed the first layer counts on the top 40m of the RICE ice core, and combined these to produce the first age scale for the top $40 \mathrm{~m}$. This was adopted as the RICE 1.0 age scale for the top $40 \mathrm{~m}$ by the international RICE community in 2014 . Since then the age model was updated using high resolution continuous-flow methane measurements which were matched to the WAIS Divide ice core record by Dr. James Lee, Prof. Ed Brook, Prof. Thomas Blunier, and the identification of the 1252 AD volcanic eruption at $165 \mathrm{~m}$ depth by Dr. Andrei Kurbatov.

\section{Thesis Outline:}

This thesis is structured around three manuscripts prepared for peer-reviewed publication. The introductory chapter contains the thesis research aims and a discussion of the literature for context and background. A separate chapter discusses the overall RICE project including field seasons, ice core processing and the development of the RICE age scale. The methods chapter states the methodology used for sample preparation and trace element analysis. This chapter is followed by three chapters consisting of individual manuscripts presenting results and discussions related to the research questions. Each chapter includes an introduction stating author contributions and the stage of the manuscript in the publication process. As each manuscript includes a discussion of the results, the final chapter is a summary of the findings presented in this thesis and future directions arising from this work. Two appendices are included to present the data pertaining to the results presented in this thesis, and the MATLAB scripts used for processing the data. 


\section{Chapter 1 - Introduction and Background}

\subsection{Introduction}

Heavy metals encompass the transition metal elements in the periodic table, which have physical and chemical properties that are essential for many industrial processes. The occurrence of the industrial revolution during the $19^{\text {th }}$ century has drastically changed our use of natural resources. Over the last 150 years there have been large increases in the emissions of pollutants to the environment (Pacyna and Pacyna, 2001). Heavy metals are biological toxins (Hughes, 2002), which not only contaminate local soil and water near areas of industrial activity, but are transported long-distances in the atmosphere. However, the extent to which background concentrations of heavy metals have increased in the environment is still relatively unknown. This is in part due to the lack of data preceding significant human emissions, and also due to local input from population centres. There are few long-running pollutant observational monitoring programmes and none record pollutant concentrations prior to the industrial revolution (Pilgrim and Hughes, 1994; Torseth et al., 2012). Antarctic ice cores provide an opportunity to a) provide baseline measurements of natural variability and concentrations, b) quantify anthropogenic emissions and assess success of recent policy changes to reduce pollutants, and c) assess the efficiency of long-distance atmospheric transport and local deposition processes.

Ice cores from Antarctica capture annual accumulation and aerosol concentrations of pollutants. As snow accumulates it traps both soluble and insoluble trace element impurities, and these layers have been accumulating for many thousands of years (Legrand and Mayewski, 1997). There have been a considerable number of Antarctic ice core records analysed for heavy metal concentrations, but these records either span very long periods of time with discontinuous samples (i.e. (Gabrielli et al., 2005; Marteel et al., 2008)), or continuous records covering only the last 500 to 1000 years (i.e. (Planchon et al., 2003; Vallelonga et al., 2002)). Here we present the first high-resolution 2,000-year record of heavy metal concentrations in coastal Antarctica which will add to the emerging array of heavy metal emission reconstructions. Reconstructions for the past 2,000 years are particularly useful as they capture not only the important transition from natural baseline concentrations to anthropogenic pollution levels of these elements, but also permits the investigation of natural variability across climate transitions (such as the medieval warm period and little ice age). Moreover, the exceptional resolution of the RICE record permits us to investigate the influence of high frequency climate drivers such as the El Nino Southern Oscillation or the 
Southern Annular Mode. This makes the RICE data a useful contribution to the 2,000 year arrays used by the IPCC, Past Global Changes (PAGES), and International Partnerships in Ice Core Sciences (IPICS) communities (IPCC, 2013).

Ice core records from Antarctica are unique in that the continent is both isolated from local anthropogenic sources of heavy metals and, due to the relatively small percentage of rock outcrops, the contribution from local sources is low. This makes them an ideal monitoring station for Southern Hemisphere emissions, but also creates technical challenges due to extremely low concentrations of heavy metals in Antarctic snow and ice from low parts per billion (ppb) to low parts per trillion (ppt) (Planchon et al., 2001). Some heavy metals have only recently become possible to measure, such as thallium $(\mathrm{Tl})$ which is present in concentrations lower than 200 parts per quadrillion (ppq) (Hong et al., 2012). Such low concentrations requires extremely careful sample handling to avoid contamination, both in the field and in the laboratory (Rodushkin et al., 2010). However, the low natural concentrations allow changes in either natural source emission strength or anthropogenic input to stand out above the background concentrations in snow and ice. Hence, ice core records can provide an indication of changes in hemispheric-wide background concentrations of heavy metals, and possible sources of those changes.

In addition to quantifying the timing and extent of changes in heavy metal concentrations, studying these elements in coastal Antarctic snow and ice allows the atmospheric transport of heavy metals to be investigated. Coastal locations in Antarctica receive the highest accumulation of snow, and hence contain the highest-resolution records. Heavy metals have complex chemical behaviour and while some elements, such as Fe, are always transported as particulates, others such as arsenic ( $\mathrm{As}$ ) and lead $(\mathrm{Pb})$ may be transported either bound to particulates or in a soluble phase (Grotti et al., 2011). Thus changes in atmospheric transport can affect the concentrations measured in snow and ice, in addition to source changes.

Understanding and quantifying past changes in heavy metal concentrations is an important step in assessing our footprint on the environment. Developing quantitative estimates of the extent to which pollutant emissions are transported world-wide is essential for developing regulation and mitigation policies. Furthermore, continued monitoring of Antarctic snow may be able to quantify efforts to reduce emissions of heavy metal pollutants. 


\subsection{Research Aims}

The aim of this thesis is to reconstruct anthropogenic pollution characteristics by investigating the changes in heavy metal concentrations in coastal Antarctic snow and ice, with an emphasis on quantifying changes over the $20^{\text {th }}$ century, in the context of the last 2,000 years.

To achieve this the concentrations of six heavy metal elements ( $\mathrm{Fe}, \mathrm{Al}, \mathrm{Mn}, \mathrm{Pb}, \mathrm{Tl}$, and $\mathrm{As}$ ), along with 31 other trace and major element species, were analysed in snow and ice from Roosevelt Island as part of the Roosevelt Island Climate Evolution (RICE) project. The heavy metal time-series data, with reference to other crustal and sea-salt related elements, are used to address the following research questions:

1. What are the modern concentrations and seasonal variability of heavy metals at Roosevelt Island, and what are the major atmospheric transport paths of these elements? Is the RICE ice core likely to contain a record of heavy metal concentrations that is representative of the wider South Pacific region?

2. How have arsenic concentrations changed in Antarctic snow and ice over the last 2,000 years, what are the major sources, when did anthropogenic emissions become significant, and can anthropogenically-derived arsenic increases and policy-related reduction be quantified?

3. How do $20^{\text {th }}$ Century concentrations of heavy metals at Roosevelt Island compare to concentrations and variability during natural climate events over the last 2,000 years, and how significant are changes in atmospheric transport compared to source changes?

\subsection{Background concepts from the literature}

Polar ice cores are a cornerstone of our knowledge about past global climate. They have been used to construct some of the highest resolution records of past climate, and some of the longest annually resolved records of changes in both atmospheric gas composition and proxy records of climate related processes (EPICA Community Members, 2004). Ice cores are unique in that they trap bubbles of air in the ice, which preserve snap-shots of the concentrations of atmospheric gases such as $\mathrm{CO}_{2}$ and $\mathrm{CH}_{4}$ through time (MacFarling Meure et al., 2006). In this way they present the opportunity to develop both direct measurements and proxy measurements of environmental conditions throughout the last 1 million years (EPICA Community Members, 2004). 
The analysis of heavy metal concentrations in polar ice has been a topic explored for several decades. Originally some of these analyses were plagued by issues with contamination $(\mathrm{Ng}$ and Patterson, 1981), with samples being contaminated from equipment used during the drilling and processing of ice. Moreover, the concentrations of heavy metals in ice from polar regions are so low that any contamination usually overprints the record preserved in the ice.

The climate record preserved in ice cores from Antarctica has served to extend our knowledge of global climate change back almost 1 Ma (EPICA Community Members, 2004). In addition, they have extended our knowledge of climatic changes across the Antarctic continent (Mayewski et al., 2005). Despite the increase in ice core records from Antarctica, the deeper ice core records are commonly spatially distant (Figure 1.1). In particular there are a lack of coastal core sites, and a lack of sites from the West Antarctic Ice Sheet (WAIS). The RICE ice core from Roosevelt Island (Figure 1.1, circle) is ideally situated to fill a crucial gap, and aims to improve our understanding of change in the Ross Sea region and of the WAIS (Figure 1.1). Roosevelt Island receives high annual snow accumulation of $\sim 0.25 \mathrm{~m}$ water equivalent, which permits annual to sub-annual resolution of samples over the Holocene and recent periods. The RICE ice core site has the potential to provide proxies of South Pacific atmospheric transport and trace elements impurities, as the topography of the Ross Sea Region captures synoptic scale cyclonic systems (Hoskins and Hodges, 2005; Sinclair et al., 2010).

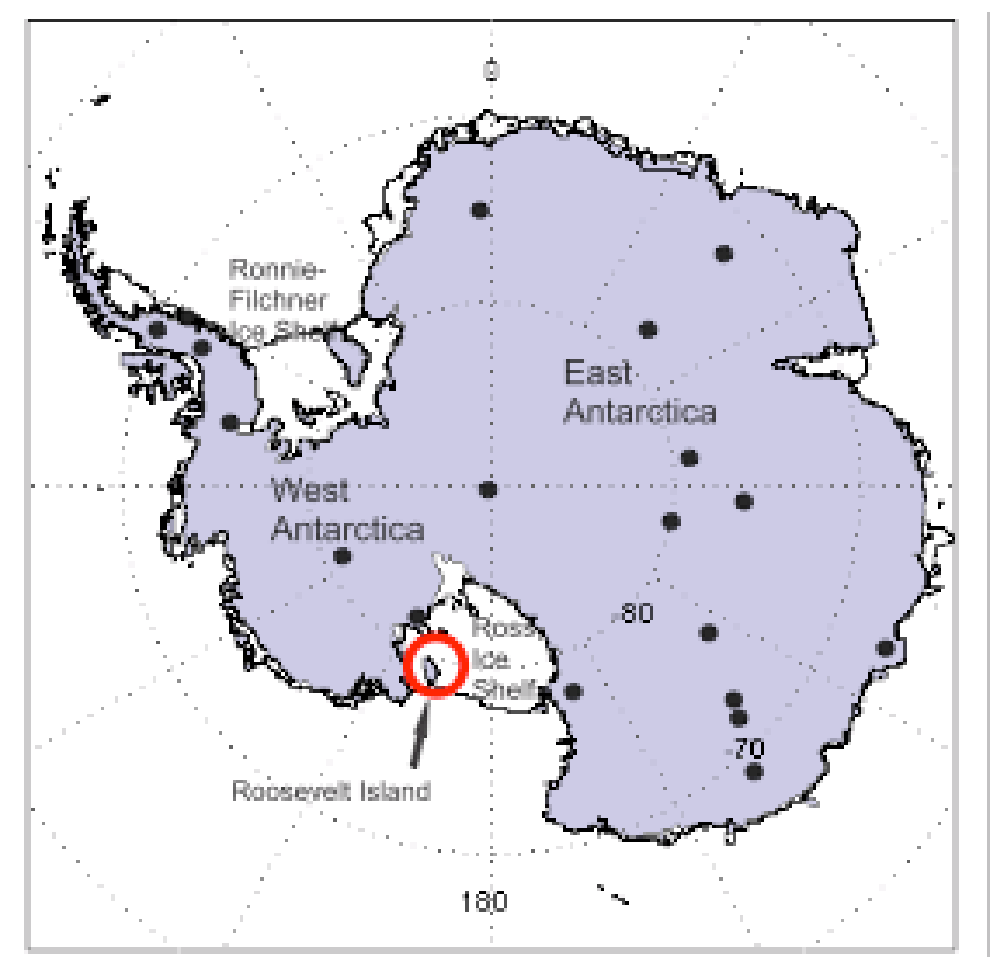

Figure 1.1. Location map of Antarctica with approximate locations of ice core sites from US ITASE (http://www2.maine.edu/USITASE/figures/fig6.html). Roosevelt Island is circled. 


\subsubsection{Antarctic Climate}

The processes governing the transport of impurities (such as wind strength, temperature, sea ice extent and more) are variable through time, so the climatic and environmental past of West Antarctica needs to be explored. In Antarctica the trace element impurities in the ice are derived from a variety of sources, such as crustal dust and volcanic emissions, both local to Antarctica and from lower latitudes. However, even terrestrial Antarctic sources of trace elements have to be transported through the atmosphere to the study site and deposited in the snow. The full RICE ice core is expected to capture at least 60,000 years. This thesis focuses on the last 2,000 years, which is contained in the top $320 \mathrm{~m}$. This time period is particularly important because high-resolution (annual-resolved) climate records from ice cores can be compared to other proxy records such as tree rings, speleothems and lake sediments to draw conclusions on recent climate variability and drivers.

Antarctica is an integral component of the global climate system. Since the last glacial maximum (LGM) global average temperatures have increased about $5^{\circ} \mathrm{C}$ (von Deimling et al., 2006). However, the change in climate has not been linear, with abrupt changes that have been linked to different feedback mechanisms. Many of these changes are recorded in Antarctic ice and the development of ice core records has increased our understanding of many of the environmental drivers of global climate.

During the LGM the WAIS reached the mid to outer continental shelf, while parts of the East Antarctic Ice Sheet (EAIS) reached the mid-shelf (Anderson et al., 2002). Overall ice volume increased by about 13\% (Fretwell et al., 2013; Golledge et al., 2013; Lythe et al., 2001), with global sea level reduced by about $120 \mathrm{~m}$ and polar temperature about $8 \mathrm{~K}$ cooler than today (Lambeck et al., 2014; Lambert et al., 2013). Temperatures were colder in the polar regions than the global average due to polar amplification which is primarily caused by feedback mechanisms due to the expansion (and retreat) of ice sheets and sea ice (Holland and Bitz, 2003; Masson-Delmotte et al., 2006). In general, retreat from LGM maximal positions began $\sim 18 \mathrm{ka}$, but was asynchronous across different regions (Anderson et al., 2002). Retreat histories around Antarctica have been developed from ice core records and sedimentary profiles from ocean sediment cores; while on the Antarctic continent ${ }^{10} \mathrm{Be}$ exposure dating of glacial boulders and nunataks has allowed calculation of ice sheet thinning rates (Mackintosh et al., 2011; McKay et al., 2008). 
Despite strong post-LGM warming ice core records have shown the climate trend during this time continued to oscillate between warmer and colder periods (Stenni et al., 2010). Changes in water isotopes coupled with trace chemistry and gas $\left(\mathrm{CO}_{2}\right.$ and methane) measurements show a reversal in the temperature trend from $\sim 14.6 \mathrm{ka}$ to $\sim 13.1 \mathrm{ka}$ (Pedro et al., 2011). This period, known as the Antarctic Cold Reversal (ACR), saw cooling or a pause in warming throughout Antarctica and the southern mid-latitudes (Moreno et al., 2009; Putnam et al., 2010), which pre-dates the Northern Hemisphere reversal - the Younger Dryas ( 12.6-11.6 ka) (Blunier and Brook, 2001). As higher resolution records from Antarctica became available (i.e. EDML, Law Dome) to match the Greenland ice core data (GRIP, GISPII, NGRIP, NEEM), the relative dating improved and the see-saw behaviour of the two hemispheres could be accurately dated (Andersen et al., 2004).

The causes of the phase relationship between the two polar regions are still subject to much scientific debate (Severinghaus, 2009), but it has become apparent that the Southern Ocean might play a major role (Barker et al., 2009). The Southern Ocean and westerly winds strongly couple Antarctica to the rest of the world, and the changes in Antarctic bottom water (AABW) formation are a major driver of some of the world's largest ocean currents (Pahnke and Zahn, 2005; van Sebille et al., 2013). Cooling in the Antarctic driven by freshening of the southern polar ocean, is dated to just prior to strengthening of the northern Atlantic deep water formation, and strong warming in the Bolling-Allerod period. Resumption of warming in the Antarctic follows this by about 300 years (Blunier and Brook, 2001; Pedro et al., 2011).

The Holocene encompasses the most recent period of time, from $\sim 11.7 \mathrm{ka}$ to the present. The early Holocene includes the final stages of the warming transition out of the LGM, with average global temperature and mean sea level reaching modern values around 8,000 years ago (Lambeck et al., 2014). In general, temperature and sea level have remained close to the modern average throughout the Holocene, although there have been several globally significant warmer and cooler periods (Wanner et al., 2008). These include the Holocene climatic optimum (6-3 ka) and, during the last 2,000 years, events such as the Medieval Warm Period (MWP) and Little Ice Age (LIA).

The Holocene climatic optimum is recorded in Antarctic ice cores as an increase in water isotope values, indicating an increase in temperatures. Several Antarctic records indicate both an early optimum period at the peak of deglacial warming, followed by a second peak 
between 6,000 and 3,000 years ago (Masson et al., 2000). The MWP is primarily a Northern Hemisphere phenomenon, and is not strongly observed in Antarctic ice core records, however, climate modelling and high-latitude proxy records do suggest that warmer temperatures were experienced in the southern high-latitudes and the timing of peak warmth lagged about 150 years behind the Northern Hemisphere (Goosse et al., 2004; Mann, 2003). The LIA is also primarily observed in Northern Hemisphere records, but there are also several Antarctic records that suggest anomalously cold and stormy conditions were prevalent, including in the Ross Sea region (Bertler et al., 2011; Mayewski et al., 2004; Orsi et al., 2012; Rhodes et al., 2012).

The $20^{\text {th }}$ Century is a unique time period where we have observational records of Antarctic climate conditions (e.g. temperature, precipitation, wind speed), some of which span over 50 years (Steig et al., 2009). We also have reliable satellite records covering much wider regions of Antarctica (and the globe) from the 1970s onwards (Bromwich et al., 2007). However, despite these detailed records, we are also beginning to see that $20^{\text {th }}$ Century climate is anomalous compared to the last 2,000 years, and probably for much longer. The occurrence of the industrial revolution in the late $19^{\text {th }}$ Century is linked to rapid, global-scale changes in atmospheric greenhouse gases, as well as many other trace elements and pollutants (Brailsford et al., 2012; Solomon et al., 2009). Changes in $\mathrm{CO}_{2}$ are well known to be strongly coupled to changes in temperature (Petit et al., 1999), and global temperatures have been observed to increase over the $20^{\text {th }}$ Century (Karl and Trenberth, 2003).

$20^{\text {th }}$ Century trends in Antarctic climate differ spatially. Observational records have shown that the Antarctic Peninsula region is one of the fastest warming regions on the planet (Vaughan et al., 2003). In contrast, East Antarctica regions show no trend or weak cooling, while West Antarctic regions show statistically significant warming (Bromwich et al., 2013; Steig et al., 2009). In addition, during the winter months (June-August), the mid-troposphere across all of Antarctica is warming at a rate faster than anywhere on Earth with a rate of 0.5$0.7^{\circ} \mathrm{C}$ per decade (Turner et al., 2006). Although station observation datasets are spatially distant with low coverage of the Antarctic continent, modelling studies coupled with satellite records have improved our understanding of temperature changes over Antarctica (Steig et al., 2013; Turner et al., 2005). In addition to temperature changes, studies have observed an intensification of the polar vortex coupled with increases in Southern Ocean wind strength (Arblaster and Meehl, 2006), as well as opposing trends in sea ice extent in regions of Antarctica (Holland and Kwok, 2012). 
It is only by examining the Antarctic observational records in the context of the longer climate records that we can evaluate the magnitude and rate of environmental changes and the anthropogenic impact on our climate.

\subsubsection{Atmospheric Transport}

Atmospheric circulation plays an important role in transporting trace element impurities over the Antarctic continent. Hence, it is necessary to outline the processes involved in atmospheric transport to the Southern high latitudes, as well as the inherent variability. The vigorous nature of atmospheric circulation leads to oscillations in transport efficiency that occur over timescales of months to decades. This variability can be reflected in the concentrations of trace element impurities recorded in Antarctic snow and ice.

The polar regions of the Earth are the location of important feedback mechanisms that regulate the circulation of heat around the globe. In the simplest terms, the poles act as a heat sink for solar radiation concentrated around the equator, hence the transfer of energy from the equator towards the high latitudes is a fundamental driver of atmospheric and ocean circulation (Broecker, 1997; Oort, 1971). However, the Antarctic is unique in that the Southern Ocean circumnavigates the globe, creating strong ocean currents and winds. The huge amount of energy in this system drives significant atmospheric transport, cyclogenesis, and extensive oceanic upwelling/overturning (Sigman et al., 2010).

The coastal regions of Antarctica receive significantly more precipitation than the interior, due to enhanced moisture delivery from cyclonic systems. The generation of cyclonic systems occurs more frequently in areas near the mid-latitude continents such as South America and South Africa, and in the Pacific/Indian oceans (Carraso et al., 2003; Hoskins and Hodges, 2005). The combination of jet streams and topographic changes enhances the formation of low pressure systems, such as in the lee of the Andes mountains, and the resulting sub-tropical jet is associated with active cyclogenesis (Hoskins and Hodges, 2005). In summer the storm tracks cluster close to the Antarctic continental margin, while in winter the storm tracks are more asymmetric, with tracks tending to spiral in towards the pole from the southern Atlantic, Indian and Pacific oceans (Hoskins and Hodges, 2005). In general, cyclonic systems near the Antarctic coast have travelled in from lower latitudes, but there are areas of enhanced local cyclogenesis. In particular the Ross Sea region has been found to have significant mesoscale cyclone activity, resulting from synoptic-scale storm paths 
entering the region from the South Pacific (Carraso et al., 2003). Mesoscale cyclogenesis is closely related to the behaviour of synoptic-scale cyclone tracks, and to interaction with katabatic air flow from major outlet glaciers (Bromwich, 1991; Carraso et al., 2003).

The change in movement of cyclonic systems over Antarctica affects Antarctic climate, as the mild, moist air is heavily contrasted with the usual cold, dry continental polar troposphere (Nicolas and Bromwich, 2011). In general the steep topography of Antarctica blocks intrusion of cyclonic systems, however, in certain areas of Antarctica the topography allows delivery of moisture further inland over the ice sheets (Dixon et al., 2012; Naithani et al., 2002; Nicolas and Bromwich, 2011). The West Antarctic in particular receives synoptic intrusions through the Ross Sea region and the Amundsen-Bellingshausen Sea (Nicolas and Bromwich, 2011). In the Ross Sea region synoptic scale cyclonic systems are observed to travel in from the east, but then are deflected northwards by the Transantarctic Mountains, creating strongly curved airflow (Sinclair et al., 2010; Sinclair et al., 2013).

Within the circumpolar trough semi-permanent lows exhibit a zonal wave-3 pattern (Raphael, 2004; Turner et al., 2013). West Antarctic climate is particularly sensitive to the variability in depth and location of the Amundsen Sea Low (ASL) in the Amundsen-Bellingshausen Sea (ABS) (Turner et al., 2013). On intra-annual time scales, the ASL moves west from January through June as waves 1-3 amplify and their phases shift to the west (Turner et al., 2013). This strongly affects cyclone density in the ABS, and therefore influences the delivery of precipitation and temperature over much of Western Antarctica (Fogt et al., 2012).

Atmospheric meridional transport to Antarctica is associated with the jet streams and Rossby wave pattern in the atmosphere (Inatsu and Hoskins, 2004). This flow is an important mechanism for long-range transport to the Southern Ocean and Antarctica. Polewards transport in the troposphere allows particulates to arrive in Antarctica within 5-6 days from mid-latitude sources (Krinner and Genthon, 2003; Li et al., 2008). Particularly strong meridional transport can occur where a deep low located in the mid-latitudes is coupled with a blocking high, creating a long corridor that can intrude over continental Antarctica (Hirasawa et al., 2000). These types of events have been associated with anomalously high accumulation and warmer temperatures (Gorodetskaya et al., 2014; Massom et al., 2004).

Cyclone density around the Antarctic continent is linked to oscillations in the strength and position of the Southern Ocean westerly winds, which follow the phase of the Southern 
Annular Mode (SAM) (Irving et al., 2010; Jones et al., 2009). The SAM is the principal mode of variability in the high-latitude atmospheric circulation, and describes annual fluctuations in the eddy-driven jet (Jones et al., 2009; Mayewski et al., 2009). During the last 50 years the SAM phase has become more positive, leading to the intensification and southward displacement of the westerly winds (Mayewski et al., 2009). The positive trend appears strongest in the austral summer months, and it is becoming apparent that these trends are the strongest observed over the last 150 years (Fogt et al., 2009).

Superimposed upon the sub-annual and annual variations in cyclonic activity are longer scale climate oscillations. The Southern Ocean and the Antarctic are not isolated from global climate, and teleconnections exist through the Rossby wave patterns (Turner, 2004). The El Niño Southern Oscillation (ENSO) describes the 2 to 7 year variability in tropical Pacific sea surface temperatures, although through atmospheric feedback cycles, the anomalously warm and cold cycles of ENSO affect precipitation and temperature around the world (McPhaden et al., 2006). The connection between ENSO and the southern high-latitudes is variable in strength. The ENSO signal is strongly transmitted to high-latitudes when the SAM is in phase (i.e. a La Nina event occurs during a positive SAM phase, or El Nino and negative SAM), or when a strong ENSO event occurs during a weak SAM event (Fogt et al., 2011). These inphase events have been linked to strong changes in sea ice duration and extent (Stammerjohn et al., 2008), and are also observed in snow and ice records from the Ross Sea Region and West Antarctica (Bertler et al., 2004a; Bertler et al., 2006; Gregory and Noone, 2008; Patterson et al., 2005).

Decadal-scale oscillations also modulate climate variability in the Pacific, identified as "ENSO-like" features occurring over 15-30 years (Salinger et al., 2001). There have been three phases of this Interdecadal Pacific Oscillation (IPO - also referred to as the Pacific Decadal Oscillation) identified over the $20^{\text {th }}$ century, oscillating between positive and negative phase (Salinger et al., 2001). These phases appear to enhance/weaken teleconnections between tropical sea surface temperature variations and the Antarctic region on decadal to interdecadal time-scales (Okumura et al., 2012). Though there are few observational records long enough to investigate this, ice core records indicate oscillations exist in accumulation and atmospheric transport on decadal to centennial timescales (Delmonte et al., 2005; Frezzotti et al., 2005; Okumura et al., 2012). 


\subsubsection{Major and Trace Elements in Ice Cores}

Impurities, both soluble and insoluble, in polar snow and ice are derived from aerosols. Sources can be either primary aerosols such as sea salt or terrestrial dust, or secondary aerosols produced in the atmosphere through oxidation of trace gases (Legrand and Mayewski, 1997). The interaction between the atmosphere and ocean water means oceanic chemistry has an important effect on the concentrations of many impurities, especially at sites near the coast. The concentrations of major ions such as $\mathrm{Na}+$ and $\mathrm{Cl}-\mathrm{can}$ be used as proxies of the marine salt contribution of aerosols to ice after adjustments are made for any potential terrestrial sources (Wolff et al., 2010; Wolff et al., 2006). Maxima in sea-salt related aerosols are either related to the proximity of open ocean (summer peaks, i.e. (Bertler et al., 2005; Bertler et al., 2004b)), or enhanced atmospheric circulation and the development of frost flowers on sea ice (winter peaks, i.e. (Legrand and Mayewski, 1997; Rankin et al., 2002)). Other elements which form sea salts include $\mathrm{Ca}, \mathrm{Mg}$, and $\mathrm{K}$; however, these can also have significant terrestrial inputs, so the interpretation of their concentrations in an ice core is site specific (Wolff et al., 2010).

Sea ice extent, in conjunction with summer temperatures, also affects Antarctic biological productivity. Productivity in the Southern Ocean is known to be iron (Fe) limited, so variation in the deposition of dust from atmospheric transport has a large effect on the extent and duration of algal blooms. There are many species of algae that thrive in the sea ice/ocean environment around Antarctica, and they are an active component in the production and removal of trace species from the atmosphere. The biogenic component of sulphate concentrations (methanesulfonate or MS) in ice cores can provide a useful proxy for marine biogenic input, and also for sea ice extent, because it is derived from the oxidation of dimethylsulfide (DMS) by marine phytoplankton found in close association with sea ice (Rhodes et al., 2009; Wolff et al., 2010). DMS accounts for 50-60\% of the total natural reduced sulfur flux to the atmosphere, and is a key metabolic pathway in the Antarctic microbial food-web (Stefels et al., 2007). Hence, measurements of methansulfonic acid (MSA) in ice cores can be used as a proxy for both biological productivity and sea ice extent in coastal regions (Rhodes et al., 2009).

Volcanic emissions are an important contribution to aerosol trace element concentrations over Antarctica (Matsumoto and Hinkley, 2001). Volcanic emissions are thought to contribute about $15 \%$ of non-sea salt sulfate $\left(\mathrm{nss}^{\left.-\mathrm{SO}_{4}\right)}\right.$ and to be a significant source of other elements, particularly heavy metals, such as $\mathrm{Pb}, \mathrm{Sb}, \mathrm{Cd}, \mathrm{Bi}, \mathrm{Tl}$, and $\mathrm{As}$ (Boutron and 
Patterson, 1986; Gabrielli et al., 2005; Hong et al., 2013; Hur et al., 2013). Analysis of volcanic layers in ice cores highlights the importance of emissions from volcanoes situated on the Antarctic continent, and trace element and major ion analyses of the tephra can fingerprint these to specific events (Basile et al., 2001; Rhodes et al., 2012). Tephra layers tend to be sourced from local Antarctic volcanic events, however, some layers can be due to large eruptions that have occurred elsewhere in the Southern Hemisphere (Basile et al., 2001; Sigl et al., 2013).

Terrestrial dust is the final main natural source of impurities to Antarctic snow and ice. Insoluble dust particles are entrained in the wind and can be transported thousands of kilometres across both hemispheres (Delmonte et al., 2008; Delmonte et al., 2004; Lambert et al., 2008; Li et al., 2008). Both the dust particle concentration and the concentration of certain elements found mainly in dust can be used as proxies for the dust flux over time (Ruth et al., 2008). Typically $\mathrm{Al}$ or $\mathrm{Ca}$ are used after a correction has been made for the sea salt derived fraction (Ruth et al., 2008). Studies of dust and dust-derived trace elements in ice cores from EPICA Dome $\mathrm{C}$ and Vostok have shown that glacial periods were characterised by stronger winds than interglacial periods, with a predominantly South American source (Delmonte et al., 2008; Lambert et al., 2008).

The Rare Earth Elements (REEs) are comprised of the lanthanide and actinide groups of the periodic table, and can also be used to identify different potential source areas of terrestrial dust (Gabrielli et al., 2010). This is because the natural abundance of the different REEs varies with major rock type and this pattern is preserved in dust that has been deflated into the atmosphere (Gabrielli et al., 2010). The isotopic ratio of certain elements, such as $\mathrm{Sr} / \mathrm{Nd}$ or $\mathrm{Pb}^{206} / \mathrm{Pb}^{208}$ found in ice cores is another method for determining the predominant source of the dust particles due to unique isotopic ratios that are found in many locations worldwide (Vallelonga et al., 2010). Further research involving lead isotopes and other modelling studies have suggested some dust in Antarctic ice may also come from Australia during interglacials due to the glacial/interglacial changes in atmospheric transport patterns (De Deckker et al., 2010; Markle et al., 2012; Vallelonga et al., 2010).

In addition to atmospheric transport and emission source changes, local deposition mechanisms also affect concentrations of heavy metals and other impurities in polar snow. In coastal Antarctic regions snowfall is the dominant form of trace element deposition into surface snow, whereas clear sky precipitation (diamond dust) dominates in the Antarctic 
interior (Bromwich, 1988; Wolff et al., 1998). Wet deposition describes the removal of trace element impurities from aerosols along with water (in any form), and in Antarctica this is primarily as snow although fog and rime ice are also known to contribute significant quantities where these occur regularly (Blas et al., 2010; Davidson et al., 1981; Duncan, 1992). Trace element concentrations in surface snow can also be increased through dry deposition mechanisms (contribution without water or ice), such as wind pumping, diffusion of dissolved/vapour phase elements, and impaction of particulates (Davidson et al., 1981; Wolff et al., 1998). Dry deposition mechanisms dominate the transfer of trace elements into snow in the Antarctic interior, while wet deposition mechanisms predominate in coastal locations (Cunningham and Waddington, 1993; Grotti et al., 2011). However, it seems likely that the aerosol phase of trace element species (dissolved vs particulate) would also impact the proportion of wet to dry deposition in coastal areas (Grotti et al., 2011).

Heavy metals have been analysed in ice cores for several decades. Early work highlighted the importance of clean sampling and handling techniques, as the low concentrations (parts per trillion and lower) present in ice are easily contaminated (Patterson et al., 1985). Initially only metals such as $\mathrm{Pb}, \mathrm{Fe}, \mathrm{Cd}, \mathrm{Zn}$, and $\mathrm{Cu}$ were measured, however, as mass spectrometric technology has improved other metals and metalloids such as $\mathrm{Sb}, \mathrm{Hg}, \mathrm{Tl}$ and $\mathrm{As}$ have been recently included. However, only few such records currently exist, and at low resolution or over short time periods (Hong et al., 2013; Hur et al., 2007a; Marteel et al., 2008).

Snow and firn core studies of heavy metals in Antarctica suggest that most metals show two maxima per year (Burn-Nunes et al., 2011; Hur et al., 2007b). At Law Dome Ba and Pb concentrations are reported to show spring and autumn maxima with winter minima, attributed to seasonal variability in atmospheric transport (Burn-Nunes et al., 2011). A snow study from the Lambert Glacier Basin area suggests there are differences in seasonality depending on the dominant source and transport pathways of the heavy metal element (Hur et al., 2007b). Du Hur et al (2007) observe spring/summer and occasional winter maxima for $\mathrm{Al}, \mathrm{Fe}, \mathrm{Mn}, \mathrm{Pb}$, and $\mathrm{Ba}$ while $\mathrm{Bi}$ and $\mathrm{As}$ generally show spring/summer peaks only. In addition to seasonal variability, spatial variability in heavy metal concentrations is also observed to be high through the US-ITSE transects, particularly in locations with extensive dunes and glazed (re-crystallised) snow surfaces where accumulation is low (Dixon et al., 2013). In coastal locations, major ion concentrations are known to decrease with distance and elevation from the coast, though they remain higher where synoptic circulation allows regular intrusion of marine air masses to occur (Bertler et al., 2005; Kreutz and Mayewski, 1999). At 
coastal locations such as Roosevelt Island it seems likely that both accumulation rate and atmospheric transport paths will affect the seasonality of heavy metal concentrations.

Most metals have natural sources from volcanic emissions and crustal dust, although over the $20^{\text {th }}$ century anthropogenic emissions have also contributed to concentrations in polar snow and ice (Ng and Patterson, 1981; Rosman et al., 1994). These records clearly attribute the large increases in polar pollutant concentrations to industry, and as such they contributed to policy changes to reduce emissions. Ice core records from Greenland were able to link changes in heavy metal concentrations to the rise and fall of Northern Hemisphere civilizations (Hong et al., 1994). Recent studies of $\mathrm{Pb}$ in Antarctic ice have shown that concentrations first showed signs of anthropogenic emissions from 1889 (McConnell et al., 2014). These concentrations decreased during 1920-1940, coinciding with the Great Depression and Second World War, then increased from $\sim 1950$ s to a peak during the 1980s (McConnell et al., 2014). This peak is attributed to widespread use of motor vehicles and the use of leaded petrol. More recent concentrations in snow and firn during the 1990s and 2000s have decreased, coinciding with the phase-out of leaded petrol (Barbante et al., 1997; McConnell et al., 2014). These records confirm that policy driven decisions to regulate and reduce emissions of pollutants have measureable effects in the environment.

\subsection{Conclusions}

Recent research has highlighted the complexity of the processes involved in the transport and deposition of impurities in polar ice. While many studies have shown that trace element concentrations in ice can be used as proxies of environmental change, the controlling processes/factors can vary from site to site. The local temperature and annual snow accumulation are first order controls, and influence the ratio of wet deposition to dry deposition of impurities (Wolff et al., 1998). The elevation of the ice core site and the distance from the ocean change the fraction of sea salt derived impurities (Kreutz et al., 2000). Hence, in order to interpret proxy records and trace element time series from new ice core sites the atmospheric transport patterns and local deposition mechanisms in surface snow and precipitation need to be characterized.

This thesis focuses on the Southern Hemisphere emissions of heavy metal and their transport to the Ross Sea region of Antarctica. This region connects strongly with the South Pacific, New Zealand, South American, and Australian land-masses and the RICE ice core results are the first such record from West Antarctica. There is also a requirement to investigate the 
background changes in environmental heavy metal pollutants and anthropogenic emissions over recent time, particularly making use of new technological capability to analyse extremely low concentration elements such as As and Tl. Furthermore, a focus is needed on high-resolution records over the last 2000 years because as yet, there are no Antarctic records of heavy metal concentrations that continuously cover this time span. These records are needed to place the changes over the $20^{\text {th }}$ century into the context of recent natural climate events. 


\section{Chapter 2 - Roosevelt Island Climate Evolution Project}

\subsection{Introduction}

The Roosevelt Island Climate Evolution (RICE) Project is a New Zealand-led international collaboration aiming to investigate the stability of the Ross Ice Shelf and the West Antarctic Ice Sheet (WAIS) in a warming world. There are representatives from 21 different institutions, from nine different countries (New Zealand, USA, Denmark, UK, Germany, Australia, Italy, China and Sweden) contributing to drill and analyse a $763 \mathrm{~m}$ deep ice core from Roosevelt Island. The project seeks to determine the timescales over which the Ross Ice Shelf changes, as this has a fundamental impact on the stability of the WAIS. If the Ross Ice Shelf should collapse in the future it would not impact sea level, however, the ice shelf buttresses the majority of the WAIS - and loss of the ice shelf would accelerate the loss of ice from the WAIS into the ocean.

The well-established strong correlation between greenhouse gases such as $\mathrm{CO}_{2}$ and temperature indicate that when atmospheric concentrations of $\mathrm{CO}_{2}$ rise, so does global temperature. Over the past (150 years) atmospheric $\mathrm{CO}_{2}$ has risen from $\sim 280 \mathrm{ppm}$ (prior to the industrial revolution) to just over $400 \mathrm{ppm}$ today. The ANDRILL program showed from sediment cores that the last time atmospheric $\mathrm{CO}_{2}$ levels were similar to today was 3-5 million years ago (Naish et al., 2009). The ANDRILL core also showed evidence that the Ross Ice Shelf disintegrated and the WAIS collapsed during this warm interval (Naish et al., 2009). However, this record was not high-enough resolution to indicate how quickly the Ross Ice Shelf and the WAIS responded to the warmer conditions.

The ice core from Roosevelt Island will provide an annually resolved record of environmental change over at least the past $\sim 60,000$ years for the Ross Sea sector. This record will provide the opportunity to closely investigate how the Ross Ice Shelf changed over the Last Glacial Maximum (LGM) to the present, through the deglacial warming. After the LGM the global average temperature rose by $6^{\circ} \mathrm{C}$ and global sea level rose by $\sim 120 \mathrm{~m}$ over a timescale of around 8000 years. The RICE ice core will provide a high-resolution record of changes throughout this time period, and this information can be used by modellers to improve predictions of future change in a world that will warm further. 


\subsection{Science Support}

The New Zealand Science funding is provided through research contracts with the New Zealand Ministry for Business, Employment and Innovation through GNS Science (Global Change through Time (GCT) Principle Investigator Dr Chris Hollis, 540 GCT32), and through the Antarctic Research Centre, Victoria University of Wellington (Roosevelt Island Climate Evolution (RICE) Project, Rutherford Discovery Fellowship, Principle Investigator Dr. Nancy Bertler, RDF-VUW-1103).

Support for Antarctic field logistics is provided by Antarctica New Zealand for K049, and the New Zealand Intermediate Depth Ice Core Drilling System has been built by the Science Drilling Office at Victoria University's Antarctic Research Centre.

\subsection{Field Seasons}

A preliminary RICE field season for site investigation was carried out in 2010/2011, during which several short firn cores were recovered, along with snow pit samples, and sites for ground penetrating radar measurements were set up. Also, an automatic weather station was installed, and some fuel and equipment were winterised.

During the summer field season of 2011/2012 a team of 12 people worked towards setting up the drilling equipment and drilling the first part of the RICE ice core. This involved setting up the purpose built tent and preparing the drill trench, which measured $3 \mathrm{~m}$ deep, $3 \mathrm{~m}$ wide and $\sim 16 \mathrm{~m}$ long. A core buffer cave was also dug along a corridor off the drill trench. A slot was added to the trench to allow movement of the drill a further $6 \mathrm{~m}$ below the base of the trench, so drilling started $\sim 8.4 \mathrm{~m}$ below the $2011 / 2012$ snow surface. Processing of the ice core in the field involved marking orientation and metre lengths, cutting the core runs into $1 \mathrm{~m}$ sections, and recording weight, temperature, and any extra breaks/cracks. The cut cores were packaged in pre-cut lay-flat bags, and 6 cores were packed into ice core boxes then stored in the core buffer cave. After dry drilling $126 \mathrm{~m}$ the hole was reamed and casing was installed to a depth $64 \mathrm{~m}$, past the firn-ice transition at $54 \mathrm{~m}$. Final drilled depth for the season was $130.4 \mathrm{~m}$. In addition to the main core, three further firn cores were drilled varying between $10 \mathrm{~m}$ and 14 $\mathrm{m}$ depth, snow pit samples from a $3 \mathrm{~m}$ pit were collected, as well as surface snow collected on trays staked out $\sim 300 \mathrm{~m}$ upwind of the camp.

The field team for 2012/2013 aimed to complete drilling the rest of the RICE ice core (bedrock estimated at $760 \mathrm{~m}$ depth). Drilling fluid (a mixture of ESTISOL and COASOL the 
same density as ice to maintain the drill hole open) was pumped into the hole and drilling began 19/11/2012. In preparation for core storage, the core buffer was enlarged, and a refrigeration unit installed above the cave to keep the cave temperature below $-20^{\circ} \mathrm{C}$. Drilling was completed on 20/12/2012 at 763 m depth (bedrock). The second to last run recovered a single piece $(2 \mathrm{~m})$, which contained a few sand-sized grains in the lower section, and the final run only recovered $25 \mathrm{~cm}$. The final piece showed a facebreak, with a distinct cloudy band and visible sediment. The last run of the drill to confirm that there was no more ice recovered a small amount of sediment stuck to the drill head and final cuttings. The drill tent was removed and the drill-hole casing extended to allow for further borehole measurements to be made. Two further shallow firn cores were drilled, one to $20 \mathrm{~m}$ depth the other to $10 \mathrm{~m}$. The ice cores and all other samples were shipped to New Zealand in the same manner as the samples from the previous field season. The overall core quality was good.

A reduced team of 6 personnel returned to the field in 2013/2014 to return all the remaining camp and drilling equipment to Scott Base/New Zealand. Borehole measurements were undertaken during 2014/2015 field season.

\subsection{RICE Ice Core Analysis Overview}

Comprehensive analysis of the RICE ice core is ongoing, with contributions from all participating research scientists. An outline of all contributions is available on the RICE webpage (http://www.victoria.ac.nz/antarctic/research/research-prog/rice).

The ice was processed at the National Isotope Centre of GNS Science in Lower Hutt, Wellington, New Zealand over three ice core processing campaigns. In preparation for processing by continuous flow analysis (CFA) the ice was cut into rods, measuring $0.34 \mathrm{~m} \mathrm{x}$ $0.34 \mathrm{~m}$ x $1 \mathrm{~m}$. Major analytical sections are described in Figure 2.1, along with country flags indicating major contributions to these analyses. The deeper ice cores from $500 \mathrm{~m}$ to $760 \mathrm{~m}$ were rested at $-16^{\circ} \mathrm{C}$ for one year prior to cutting into rods. The basal ice $760-763 \mathrm{~m}$ are embargoed pending decisions on final analytical priorities. 


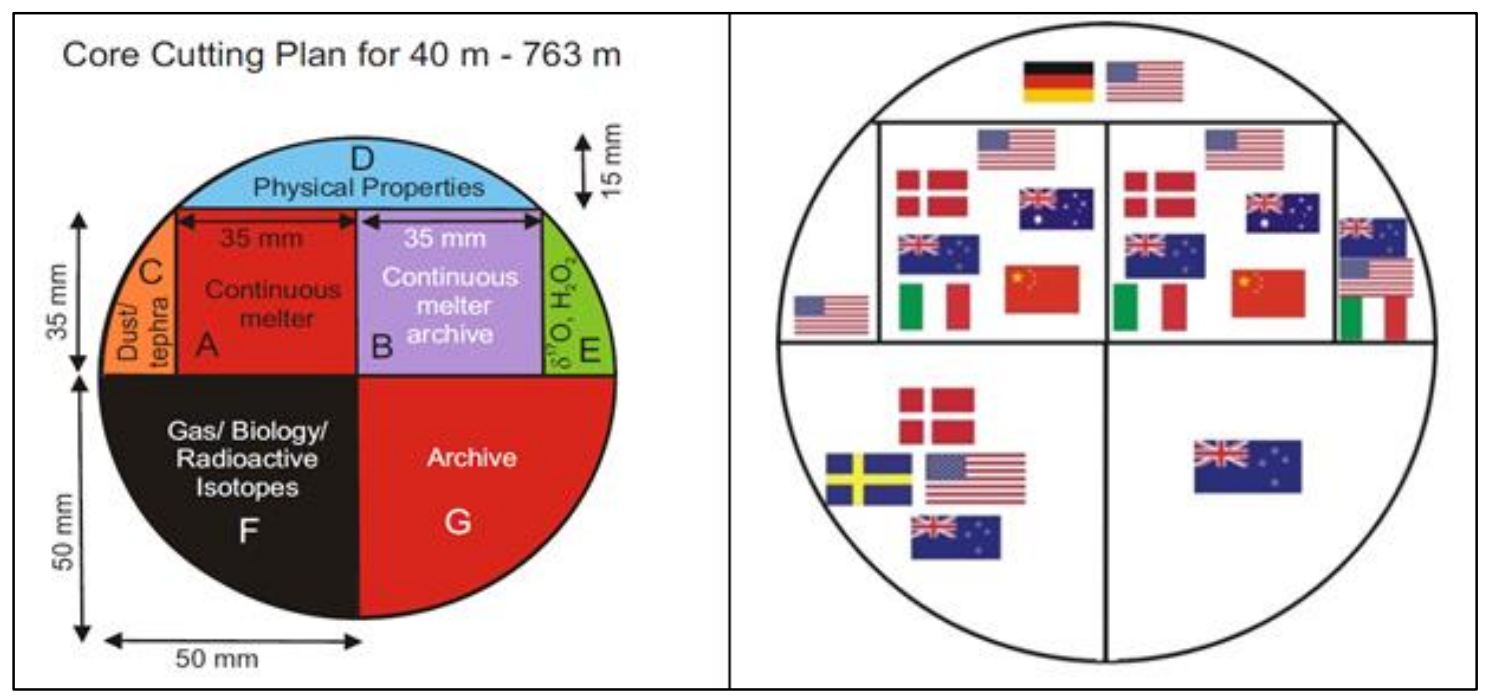

Figure 2.1. Outline of core cutting plan for analytical measurements and contributions from participating nations.

Originally, the New Zealand contribution of ICPMS data was to be analysed at Victoria University of Wellington, utilising the Element 2 ICPMS in the Geochemistry Laboratory. To further increase the capability of this instrument for high-sample throughput/lowconcentration trace element analyses, an ESI SC-2 FAST autosampler system was purchased and installed. Unfortunately the loss of two staff members early in 2012 left the Department without the specific expertise in operating the Element 2. Consequently the tuning and testing of the Element 2 system took significantly longer to establish the analytical limits with respect to ice core samples. Following this, the Element 2 was used to analyse samples from a leaching experiment testing the effect of acidification upon trace element concentrations in Antarctic snow samples, as well as procedural blanks from the 2012 and 2013 processing campaigns.

Unfortunately a significant number of problems developed in the Element 2 following several strong earthquakes occurring near Wellington in late 2013, and these were exacerbated by several unplanned power cuts. The analysis of samples from the top $300 \mathrm{~m}$ of the RICE ice core had been planned for the end of 2013, however, with the delay reaching several months, the decision was made to analyse all VUW-RICE snow samples at Curtin University, Perth, Australia. These analyses took place in March 2014.

\subsection{RICE Ice Core Processing Summary}

The first campaign took place in July-August 2012, and involved comprehensive set-up and testing of the continuous flow analysis (CFA) system. Only the top $40 \mathrm{~m}$ of ice were 
processed during this campaign and due to contamination issues this ice was re-processed during the 2013 campaign.

The second ice core processing campaign took place from May to August 2013, and involved $24 \mathrm{hr}$ shift work for much of this time to successfully process the RICE ice core to $500 \mathrm{~m}$. The ice core melter was built into a freezer inside a class-1000 clean room, and cores were melted in stacks of four. The CFA systems were installed around the ice core melter and flow of water was regulated using peristaltic pumps. A number of analyses were included in the CFA system, including stable water isotopes (Emanuelsson et al., 2014), black carbon, pH, conductivity, $\mathrm{Ca}^{2+}$, and gases methane and $\mathrm{CO}_{2}$. Discrete samples for major ions, trace elements, and stable water isotopes were collected using fraction collectors. Water from the clean inner section of the ice core was pumped to the vials for major ion analysis by Ion Chromatograph (IC) and to the pre-cleaned vials for trace element analysis by Inductively Coupled Plasma Mass Spectrometer (ICPMS); while water from the outer section was pumped to the stable water isotope vials. We aimed to collect high-resolution samples over the top $500 \mathrm{~m}$ of the RICE ice core, resulting in over 20,000 discrete samples each for IC and water stable isotopes and more than 10,000 samples for ICPMS analysis. Ice core processing was halted after $500 \mathrm{~m}$ to allow the more brittle deeper ice to relax.

The final ice core processing campaign took place in May-July 2014, and the final $260 \mathrm{~m}$ of the RICE ice core were successfully processed. This campaign followed a similar set-up to the 2013 campaign, and the final $260 \mathrm{~m}$ of ice were successfully cut into the melter rods following 12 months of storage at $-18^{\circ} \mathrm{C}$ to allow it to relax.

\subsection{RICE Age Scale}

The first estimate of the age captured in the RICE ice core was based on modelled parameters of firn densification and ice flow, performed by T.J. Fudge. This model suggested that the firn-ice transition would occur at $\sim 54 \mathrm{~m}$ and that ice at $\sim 320 \mathrm{~m}$ depth would be about 2000 years old, with basal ice estimated at $>60,000$ years old. We observed the firn-ice transition at $55 \mathrm{~m}$ depth in the ice core, constraining the upper part of the age model.

The RICE 1.0 age scale was developed in early 2014 (following trace element analysis of samples by ICPMS) from layer counts. The dataset used for layer counts comprised the chemistry analyses over the top $38 \mathrm{~m}$ of the RICE deep ice core and the RICE 12/13B firn core. This included the CFA stable water isotope measurements, sulfate measurements by IC, 
and a suite of trace elements from ICPMS analyses, principally S, Na, Sr, and Iodine (I). Summers ( $1^{\text {st }}$ January) were designated where peaks in total $\mathrm{S}$ and $\mathrm{SO}_{4}$ aligned with a peak or shoulder of a peak in the $\delta^{18} \mathrm{O}$ value, followed by a peak in $\mathrm{I}$ - which appeared to have a strong winter peak in concentration (Figure 2.2). Layer counts were independently compiled by Peter Neff, Daniel Emanuelsson, Andrea Tuohy, and Thomas Beers and then combined into one layer count. This was presented to the principal investigators in the RICE project and the final annual layer count for the top $40 \mathrm{~m}$ was agreed upon. The RICE 1.0 age scale indicates that the top $38 \mathrm{~m}$ captures annual layers from 1900 to the present, with an age uncertainty of \pm 1 year.

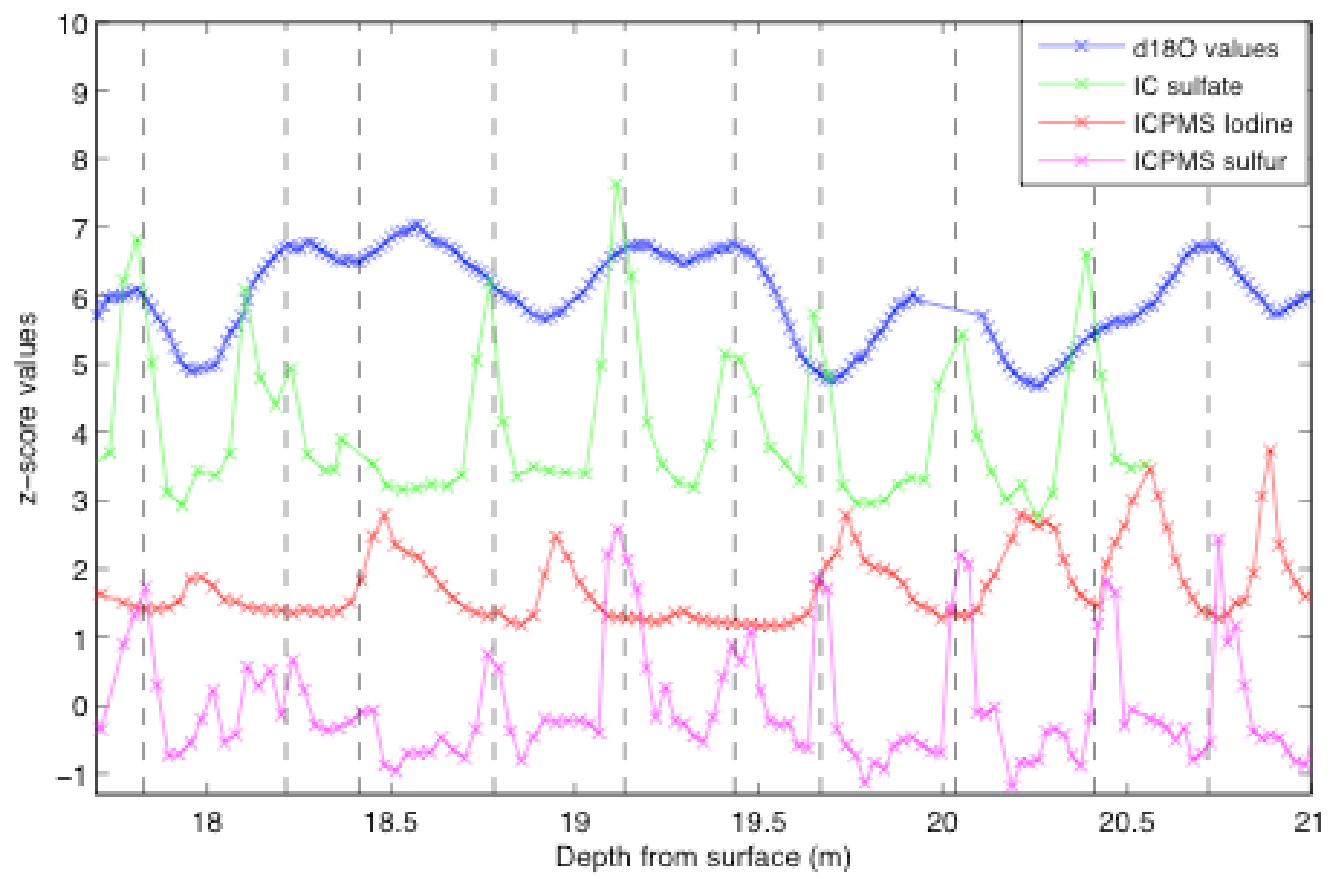

Figure 2.2. Example of RICE 1.0 summer layer picks (black vertical dashed lines).

The age scale from $40 \mathrm{~m}$ to $320 \mathrm{~m}$ is based on seven points where methane measurements have been tied to the well-dated WAIS divided ice core (Lee, Brook, Blunier, personal communication) (Members, 2013), and a tephra layer at $165 \mathrm{~m}$ that is identified as the 1252 CE Unknown volcanic event (Kurbatov, Lee, personal communication). The age scale has been interpolated between these age-tie points using a Nye-interpolation, has been adjusted for accumulation changes, and the delta ice-air age has been kept constant at 150 years (Lee, Fudge, Blunier, Brook, personal communication) (Figure 2.3). The snow pit age was also based on summer and winter layer counting of $\delta 18 \mathrm{O}$ values and total S concentrations, and was matched to the RICE 1.0 age scale. The three metre deep snow pit (150 ICPMS samples) spans five years from late 2006 to January 2012, with an age uncertainty of one year. All 
trace element data published in this thesis include depth measurements so that when the RICE community releases an updated age scale for the deeper ice the data can be re-plotted.

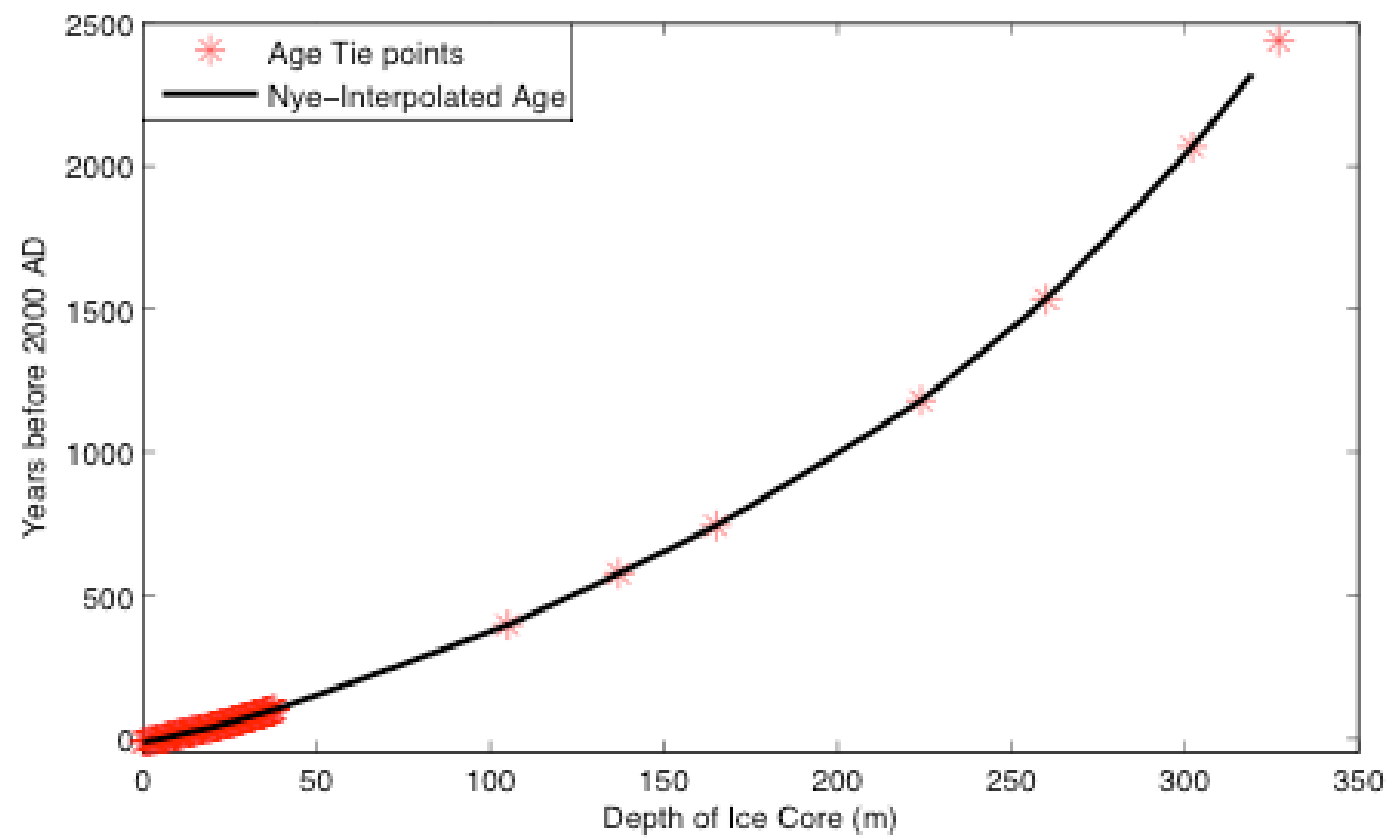

Figure 2.3. RICE 1.0 age scale with all tie points (layer counts, methane age ties, $165 \mathrm{~m}$ tephra layer) plotted as red points, and interpolated ages between as a black line. 


\section{Chapter 3 - Analytical Methods and Data Processing}

\subsection{Introduction}

This chapter discusses the trace element analytical methods and processing of the acquired data. This includes a summary of the clean-handling procedures, sample preparation and acid leaching, set-up of sector-field inductively coupled plasma mass spectrometers (SF-ICPMS), and structure of the analytical runs. The statistical processing of the data is presented, with references to the scripts used in Appendix A, as well as the heavy metal data in Appendix B (on $\mathrm{CD}$ ). Not all the data generated as part of this $\mathrm{PhD}$ is published in this thesis, however, new collaborators wishing to work with it are asked to contact Dr. Nancy Bertler for access. All the data presented in the three manuscripts included in this thesis are available in electronic form in Appendix B. This chapter includes a section discussing the effect of acidification and long-term acid leaching on melt-water trace element concentrations. The acid leaching experiments were used to determine the time required to reach stable trace element concentrations and included results for both a rock reference material and Antarctic snow.

\subsection{Sample and Standard Preparation}

All lab equipment used for sample preparation was acid cleaned prior to use, including a 10 $\mathrm{mL}$ column, all vials and all pipette tips. The procedure for cleaning the polypropylene vials and caps involved three rinses in ultra-pure MQ water followed by five days in an acid bath of reagent grade $5 \% \mathrm{HNO}_{3}$. The vials were rinsed three times following the acid bath and soaked in MQ ultra-pure ( $>18.2 \mathrm{M} \Omega$ ) water for at least 48 hours. They were then rinsed with ultra-pure MQ water three more times prior to capping. Clean empty vials were frozen and kept in storage at $-30^{\circ} \mathrm{C}$ until a few days before use to prevent any bacterial growth. All cleaning of equipment was carried out in the Victoria University of Wellington Geochemistry Facility, inside a class 100 clean room.

Pipette tips were used to acidify the samples and for sub-sampling. The cleaning procedure for all pipette tips followed the vial cleaning procedure with an additional conditioning step prior to use. Two vials of ultra-pure trace element-grade nitric acid, and one vial of MQ ultrapure $>18.2 \mathrm{M} \Omega$ water were used to condition pipette tips before use. A $10 \mathrm{~mL}$ column was used to prepare larger quantities of ultra-pure $\mathrm{HNO}_{3}$ at various concentrations (usually $10 \%$ or $1 \%$ ), and after initial acid-soaking cleaning was rinsed three times with MQ water both before and after use. 
More than 13,000 vials were collected for ICPMS analysis during the melting campaigns from the top $320 \mathrm{~m}$ of the RICE ice core. We decided to analyse all samples over the top 40 $\mathrm{m}(\mathrm{n}=784)$, and to combine samples from $40 \mathrm{~m}$ to $\sim 320 \mathrm{~m}$. Based on the modelled age of the ice, $320 \mathrm{~m}$ was expected to cover the last 2,000 years. This allowed the creation of a dataset with very high (1.6 month) resolution over the top $40 \mathrm{~m}$, and lower resolution ( $\sim 4 \mathrm{yr}$ average) below $40 \mathrm{~m}$, to a maximum age of 2,300 years ago at $320 \mathrm{~m}$.

We created composite samples, each covering four years, and avoided sample bias by using the modelled age of the ice to assign an estimated age based on the depth of each vial. Hence, fewer vials were combined from the deeper parts of the ice core. Towards $40 \mathrm{~m}$ between 11 and 16 vials were combined to make one $\sim 4$ yr-averaged sample, requiring $\sim 0.3 \mathrm{~mL}$ from each vial, and towards $320 \mathrm{~m}$ between 4 and 6 vials were combined, requiring $\sim 0.8 \mathrm{~mL}$ from each vial. In total, 621 combined vials were made, sub-sampling all vials $(\sim 10,800$ vials $)$ between $40 \mathrm{~m}$ and $320 \mathrm{~m}$. Composite samples were acidified following the combining process. The preparation of these samples was carried out in a class 1000 clean room, inside class 100 laminar flow hoods. Procedural blanks consisting of clean room blanks, acid blanks, pipette tip blanks, laminar flow hood blanks, MQ >18.2 M $\Omega$ water blanks, were collected throughout the stages of sample preparation.

\subsection{Acidification and Leaching Experiment}

All samples to be analysed for concentrations of trace elements by ICPMS must be acidified to prevent precipitation of insoluble species (Koffman et al., 2014), and to prevent adsorption into the vial walls, and to leach elements from insoluble particles in the samples (Knüsel et al., 2003). $\mathrm{HNO}_{3}$ is commonly used due to the stability of a large number of elements in solution and because it creates few polyatomic interferences in the ICPMS spectra. One percent $(1 \%)(\mathrm{v} / \mathrm{v} \%) \mathrm{HNO}_{3}$ was used to be comparable with previous studies and because of the potential for the introduction of contamination from higher acid concentrations. Commercial Seastar ultra-pure trace element-grade nitric acid, certified to $<10 \mathrm{ppt}$ for most elements, was used to acidify samples. Ultra-pure (TRACE-2D) $\mathrm{HNO}_{3}$ prepared in the Curtin University Trace Research Advanced Clean Environment (TRACE) facility was used to prepare standards and reagents for the analytical runs, standards and instrumental blanks. This acid was prepared by double sub-boiling distillation in perfluro alkoxy alkane (PFA) stills and captured in PFA bottles that had been used for the distillation for several years. The 
acid was prepared in better than class 100 clean conditions in an ultra-trace metal clean laboratory module.

To be quantitative, elements introduced to the SF-ICPMS should be in solution. While elements bound in particulates may still be determined, their analysis is dependent on the total particle vaporisation in the ICP plasma and the scanning rate and dwell-time of the SFICPMS (Knüsel et al., 2003). Another problem arises if particles in samples are adsorbed on to vial walls and are not transferred to the plasma. Continuous ice core melter methods avoid the problem of particles adsorbing to vial walls since the particles are in continuous motion (McConnell et al., 2002), however, they suffer from quantification issues resulting from incomplete particle vaporisation and shot-noise arising from scanning rates (R. Edwards, personal communication). Capturing ice core melter samples in discrete vials is an alternative that allows for sample treatment to bring elements into solution. Several recent papers have highlighted the effect of long acidification times on trace element concentrations in ice core samples (Edwards et al., 2006; Grotti et al., 2011; Koffman et al., 2014; Rhodes et al., 2011). The solubility and stability of metal species in water are $\mathrm{pH}$ and ligand dependent (Byrne et al., 1988). Dissolved metal ions are present in ultra-pure water as aqua ions with water molecules acting as ligands (other ligands may also be present in natural waters). Many metal aquo ions can donate protons (Brønsted acids), while other metal aquo ions may be amphoteric. For example $\left[\mathrm{Fe}\left(\mathrm{H}_{2} \mathrm{O}\right)_{6}\right]^{3+}$ is an acid, while $\left[\mathrm{Al}\left(\mathrm{H}_{2} \mathrm{O}\right)_{6}\right]^{3+}$ is amphoteric. Metal aquo ions can therefore display complex redox equilibria in solution and form insoluble oxides and salts. This equilibria and thus solubility is highly $\mathrm{pH}$ dependent. The elements typically studied in ice cores are usually stable at low $\mathrm{pH}$. The presence of low concentrations of alumino-silicate minerals (typically $\sim 3$ micron in diameter) presents an analytical challenge for Antarctic ice core and snow samples. If collected in vials, the particles tend to disappear out of solution onto the walls of the vial and this may not even be partially vaporised or determined in the ICP. Total digestion of the particles requires the use of time consuming and dangerous hydrofluoric acid based digestion procedures, which may introduce contamination, particularly when heavy metal elements are an analytical priority. Acid leaching of elements from the particles into solution is an alternative.

The decrease in $\mathrm{pH}$ causes the solubility of many elements to increase, and as melted ice core water contains particulates, the concentration of trace elements present in solution in an ice core sample changes over time following acidification. In addition, the lithology and size of particles also affect the measured concentration of many elements (Koffman et al., 2014; 
Rhodes et al., 2011). Some methods of analysing ice core samples bypass this issue, by analysing samples for trace element concentrations in a continuous flow arrangement where the ice core water is acidified and injected directly into an ICPMS (McConnell et al., 2014). This method results in trace element concentrations that are representative of the watersoluble concentrations, although vaporisation of any particulates present in the samples can affect these measurements. However, a drawback to this method is that the water-soluble concentrations of many trace elements (particularly rare earth elements, REE) in Antarctic ice are so low they are below the detection limits of most instruments. Allowing time to pass following acidification of samples results in increased concentrations of most trace elements, which is useful when attempting to analyse low concentration elements. However, these concentrations must be stable and reproducible.

In polar snow, Koffman et al. (2014) find that water-soluble elements such as $\mathrm{Mg}, \mathrm{S}, \mathrm{K}, \mathrm{Ca}$ and $\mathrm{Na}$ minimally increase over time, while elements associated with insoluble particulates such as $\mathrm{Al}, \mathrm{Mn}, \mathrm{Fe}, \mathrm{La}$ and $\mathrm{Pb}$ increase substantially $(>100 \%)$. The concentrations of some elements, such as $\mathrm{Al}$ and $\mathrm{Fe}$ continue to increase after three weeks, implying continued leaching from particulates (Koffman et al., 2014; Rhodes et al., 2011). Both these authors conclude that ice core samples should be acidified to $1 \% \mathrm{HNO}_{3}$ for at least one month prior to analysis to ensure that concentrations of target elements are stable.

To determine the extent to which these processes might affect our samples - from a new Antarctic location, we both replicated the experiment of Rhodes et al. (2011) and included snow from Roosevelt Island and two other Antarctic locations. Two different rock standards were chosen for comparison to the study by Rhodes et al. (2011), and these were made up into base solutions of two different dust concentrations each. BHVO-2 is Hawaiian basalt, and W2 is a diabase. Both standards are predominantly comprised of clinopyroxene and plagioclase feldspar, while $\mathrm{BHVO} 2$ has minor amounts of magnetite and W2 has minor amounts of muscovite, quartz and opaque minerals (Rhodes et al., 2011). The grain size fraction of the two standards span $\sim 1 \mu \mathrm{m}$ to $100 \mu \mathrm{m}$, with the main peak of W2 at $\sim 1.2 \mu \mathrm{m}$, and BHVO-2 at $\sim 11.5 \mu \mathrm{m}$ (Rhodes et al., 2011). The bottles used for the solutions were 500 $\mathrm{mL}$ and $250 \mathrm{~mL}$ PFA Teflon bottles, all refluxed with alternating concentrated ultra-pure $\mathrm{HNO}_{3}$ and $\mathrm{HCl}$ for at least one week, and then thoroughly rinsed with ultra-pure (MQ) water $(>18.2 \mathrm{M} \Omega$ ) prior to the experiment being started, to ensure no contamination could occur through leaching from the containers. The powdered rock standards were weighed using a micro-balance giving a $0.1 \mathrm{mg}$ error, to make a $500 \mathrm{~mL}$ solution of ultra-pure water (MQ, > 
18.2 $\mathrm{M} \Omega$ ) plus rock powder. The final base solutions had the following concentrations: BHVO-2 $100 \mathrm{ppm}$ and $10 \mathrm{ppm}, \mathrm{W} 2100 \mathrm{ppm}$ and $10 \mathrm{ppm}$. These four solutions were then acidified to $1 \mathrm{wt}$ \% \% with ultra-pure Optima $\mathrm{HNO}_{3}$.

Snow and ice samples from three different Antarctic sites were available for this study. Ice samples from Mt Erebus Saddle (MES) and Whitehall Glacier (WHG) were made up of combined ICPMS samples that had been prepared from cores from those locations but were surplus to requirements. Surface snow from Roosevelt Island was collected during the 2010/2011 field season using a pre-cleaned scraper to scoop snow into pre-cleaned acid washed Nalgene bottles. These were made into $1 \% \mathrm{HNO}_{3}$ acidified solutions in the $250 \mathrm{~mL}$ PFA Teflon bottles.

Once acidified each of the base solutions (including blanks) were sampled at set times past the initial acidification time to allow the changes in trace element concentrations to be examined. All sampling was carried out in a class 1000 clean lab, inside class 100 laminar flow hoods, to minimise potential contamination of the samples. The sampling intervals were 15 minutes, 1 hour, 2 hours, 4 hours, 6 hours, 8 hours, 12 hours, 24 hours, 48 hours, 3 days, 5 days, 8 days, 2 weeks, 3 weeks, 5 weeks, 8 weeks; with replicates taken on four of the intervals. At each sampling time $10 \mathrm{ml}$ of the base solution were pipetted off into an acid cleaned vial, and $10 \mathrm{ml}$ of $1 \mathrm{wt} \% \mathrm{HNO}_{3}$ were added back to the base solution to ensure it remained at the same acid concentration. The $10 \mathrm{ml}$ vials were then centrifuged at $4500 \mathrm{rpm}$ for 5 minutes to separate supernatant from any particles in order to prevent continuation of any leaching, and then $6 \mathrm{ml}$ were pipetted off into new acid cleaned vials for storage at room temperature prior to ICPMS analysis.

The centrifuged samples were analysed for 21 trace elements using a Thermo Scientific Element 2 ICPMS in August 2013, at the VUW Geochemistry laboratory. An Elemental Scientific Inc (ESI) SC-2 FAST autosampler was used for sample introduction coupled with a peristaltic pump, and the built-in 'loop-rinse' method was used to reduce the wash-out time between samples. A low-flow Teflon micro-nebuliser was used in conjunction with a double by-pass quartz spray chamber with a Peltier cooler. Standard nickel sample and skimmer cones were used. Calibration of the samples was achieved using a set of eight serial dilutions from a certified (custom) multi-element standard purchased from Inorganic Ventures. Instrumental blanks consisting of $1 \mathrm{wt} . \% \mathrm{HNO}_{3}$ and an external standard purchased from the National Research Council of Canada (SLRS4-riverine water) were included to bracket every 
9 samples, and were used to provide instrument background correction, to assess overall accuracy and reproducibility of results, and to validate the methodology. Detection limits were defined as three standard deviations of the blank measurements (Table 3.1). The mean uncertainty range of most elements was within the accepted error for the certified values of the SLRS4 standard, except for $\mathrm{Ca}$ and $\mathrm{P}$, which had calibration problems. A dilution correction was made to leaching experiment samples to correct for the addition of the $10 \mathrm{~mL}$ $\mathrm{HNO}_{3}$ to the bulk solutions at each sampling interval, and this correction was more significant for the smaller volume $250 \mathrm{~mL}$ Antarctic samples, than for the $500 \mathrm{~mL}$ rock standard solutions, but did not affect the overall quality of the data.

\begin{tabular}{|c|c|c|c|c|c|c|c|}
\hline \multirow[b]{2}{*}{ Isotope } & \multicolumn{2}{|c|}{ GeoReM Values } & \multirow{2}{*}{$\begin{array}{l}\text { Average } \\
\text { SLRS4 } \\
\text { Concentration } \\
(\mathrm{ppb})\end{array}$} & \multirow{2}{*}{$\begin{array}{l}\text { Precision } \\
\text { RSD \% }\end{array}$} & \multirow{2}{*}{$\begin{array}{l}\text { Accuracy } \\
\text { \% Error* }\end{array}$} & \multirow{2}{*}{$\begin{array}{l}\text { Detection } \\
\text { Limits } \\
\text { (ppt) }\end{array}$} & \multirow{2}{*}{$\begin{array}{l}\text { Rhodes et } \\
\text { al. } 2011 \\
\text { Detection } \\
\text { limit (ppt) }\end{array}$} \\
\hline & $\mathrm{ppb}$ & std dev & & & & & \\
\hline Cr52(MR) & 0.33 & 0.02 & 0.305 & 6.68 & 1.49 & 2.842 & 8.8 \\
\hline $\mathrm{Pb} 208(\mathrm{LR})$ & 0.086 & 0.007 & 0.071 & 5.14 & 13.03 & 0.436 & 14.7 \\
\hline Ce140(LR) & 0.36 & 0.012 & 0.334 & 4.51 & 3.08 & 0.792 & 0.2 \\
\hline As75(HR) & 0.68 & 0.06 & 0.746 & 6.70 & -2.35 & 1.535 & 1.2 \\
\hline La139(LR) & 0.287 & 0.008 & 0.265 & 5.17 & 2.99 & 0.373 & 0.1 \\
\hline Nd146(LR) & 0.269 & 0.014 & 0.243 & 5.43 & 4.77 & 0.601 & \\
\hline Th232(LR) & 0.018 & 0.003 & 0.018 & 6.77 & 1.91 & 0.044 & 0.2 \\
\hline Bi209(LR) & 0.002 & 0.0001 & 0.002 & 6.83 & -2.13 & 0.034 & 0.3 \\
\hline Gd157(LR) & 0.034 & 0.002 & 0.035 & 7.49 & -3.05 & 0.125 & 0.6 \\
\hline Yb172(LR) & 0.012 & 0.0004 & 0.011 & 5.99 & 3.61 & 0.046 & 0.5 \\
\hline U238(LR) & 0.05 & 0.003 & 0.042 & 7.42 & 8.86 & 0.010 & 0.2 \\
\hline Na23(MR) & 2400 & 200 & 2203.03 & 7.49 & 1.33 & 4566.51 & 763 \\
\hline Mg24(MR) & 1600 & 100 & 1591.97 & 6.51 & 0.50 & 673.17 & 49.1 \\
\hline S34(MR) & NA & NA & 2510.70 & 7.65 & & 6817.18 & \\
\hline $\mathrm{Ca} 44(\mathrm{HR})$ & 6200 & 200 & 8365.35 & 13.19 & -17.12 & 4799.20 & 874 \\
\hline K39(HR) & 680 & 20 & 677.48 & 7.68 & 0.37 & 4607.49 & \\
\hline Ti47(MR) & 1.46 & 0.08 & 1.220 & 8.28 & 9.51 & 21.65 & 23.5 \\
\hline Mn55(MR) & 3.37 & 0.18 & 3.281 & 5.81 & 2.66 & 3.359 & 15.1 \\
\hline Ba137(LR) & 12.22 & 0.6 & 11.61 & 5.66 & -0.35 & 2.896 & 3.3 \\
\hline A127(MR) & 54 & 4 & 56.78 & 6.94 & 2.15 & 915.28 & 48.6 \\
\hline Fe56(MR) & 103 & 5 & 102.57 & 7.58 & 0.42 & 246.20 & \\
\hline P31(MR) & 9.13 & 0.78 & 6.838 & 7.84 & 19.24 & 113.42 & \\
\hline Sr88(LR) & 26.3 & 3.2 & 26.80 & 5.27 & -1.90 & 4.731 & 0.9 \\
\hline
\end{tabular}

*Minimum percent difference from the GeoReM value taking into account the measured RSD

Table 3.1: List of elements analysed in leaching experiment samples, the GeoReM preferred values of the SLRS-4 Riverine water used as an external standard. Precision and accuracy of the external standard samples (average over all runs), and detection limits based on the $3 \sigma$ of the average blank samples, are compared to the detection limits from Rhodes et al. (2011). 


\subsubsection{Results}

Measured values of SLRS-4 for most analytes were within $5 \%$ of accepted values (GeoReM, http://georem.mpch-mainz.gwdg.de/), with the exception of $\mathrm{Pb}^{208}$ (13\% accuracy), $\mathrm{U}^{238}$ (9 $\%), \mathrm{Ca}^{44}(17 \%)$, and $\mathrm{Ti}^{47}(10 \%)$.

In the rock standards and Antarctic snow samples almost all elements show a significant increase in concentration over the 8-week sampling interval (Figures 3.1 and 3.2). All the rock standard solutions show exponential increases in trace element concentration over time, with the alkaline earths showing the largest overall change, followed by the transition metals, then the lanthanides and actinides. Both the rates of concentration change and the magnitude of element concentration changes for the rock standards agree well with the results presented by Rhodes et al. (2011).

The concentration of trace elements in the three Antarctic samples are lower than the rock standards, suggesting that lower concentrations of dust are present in solution than in the 10 ppm rock standard solutions. However, all three Antarctic solutions also show significant change over time following acidification. Of the three Antarctic samples, the RICE sample has the lowest overall concentration of trace elements, because of the distance to local outcrops and differences in particle size. The rate of element concentration change following acidification of the solutions is mostly the same in all three Antarctic samples. Moreover these results agree very well with those reported in the $1 \% \mathrm{HNO}_{3}$ test in Koffman et al. (2014). The transition metals show the largest overall concentration changes over the 8-week period before stabilising, followed by the actinides and lanthanides (Figure 3.1). La and some other rare earth elements show complex behaviour, decreasing in concentration during the first several days following acidification, increasing after 10 days and stabilising after 5 to 8 weeks of acidification (Figure 3.1). The majority of concentration change for all elements occurs within the first 48 hours of acidification, with smaller changes occurring after 3 weeks (Figure 3.2). For some elements $(\mathrm{Cr}, \mathrm{Ca}, \mathrm{Al}$, and $\mathrm{Fe})$ an increasing concentration trend is still present at 8 weeks after acidification, similar to Edwards et al. (2006) (Figure 3.2), indicating that these elements can be expected to increase in concentration further, however, the trend is weaker from 3-5 weeks onward.

Our results replicate the findings presented in both Rhodes et al. (2011) and Koffman et al. (2014), and confirm that acidification time longer than 8 weeks is necessary to allow all elements to stabilize to a point where leaching effects on measured sample concentration 
become negligible. While it is clear that a minimum acidification time of one month will avoid unstable sample concentrations in most elements, we chose to acidify samples from the RICE project for a minimum of three months in order to ensure target elements such as the transition metals and rare earth elements were stable in solution.

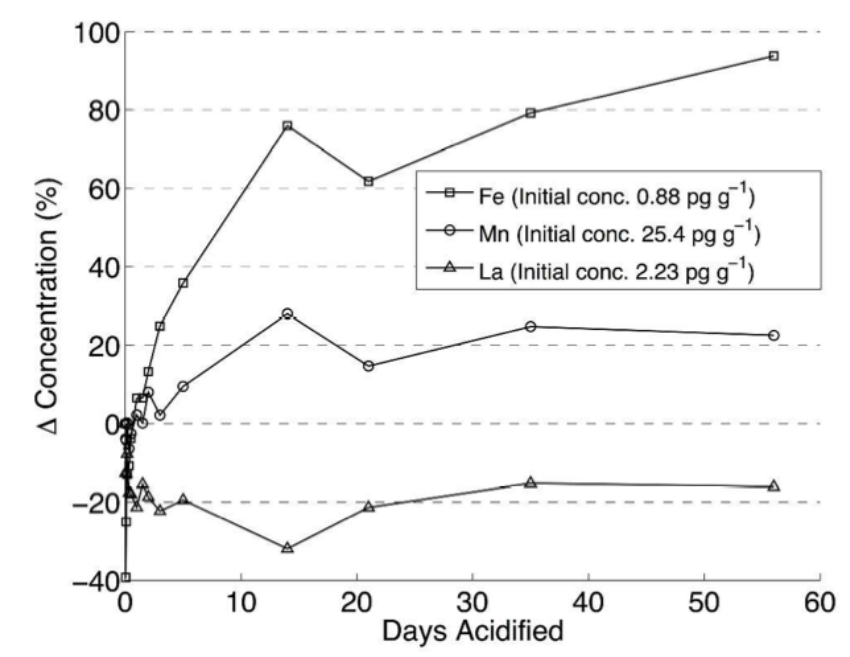

Figure 3.1. Percent change in RICE snow sample concentration after acidification with $1 \%$ $\mathrm{HNO}_{3}$; elements shown are $\mathrm{Fe}^{56}, \mathrm{Mn}^{55}$, and $\mathrm{La}^{139}$.

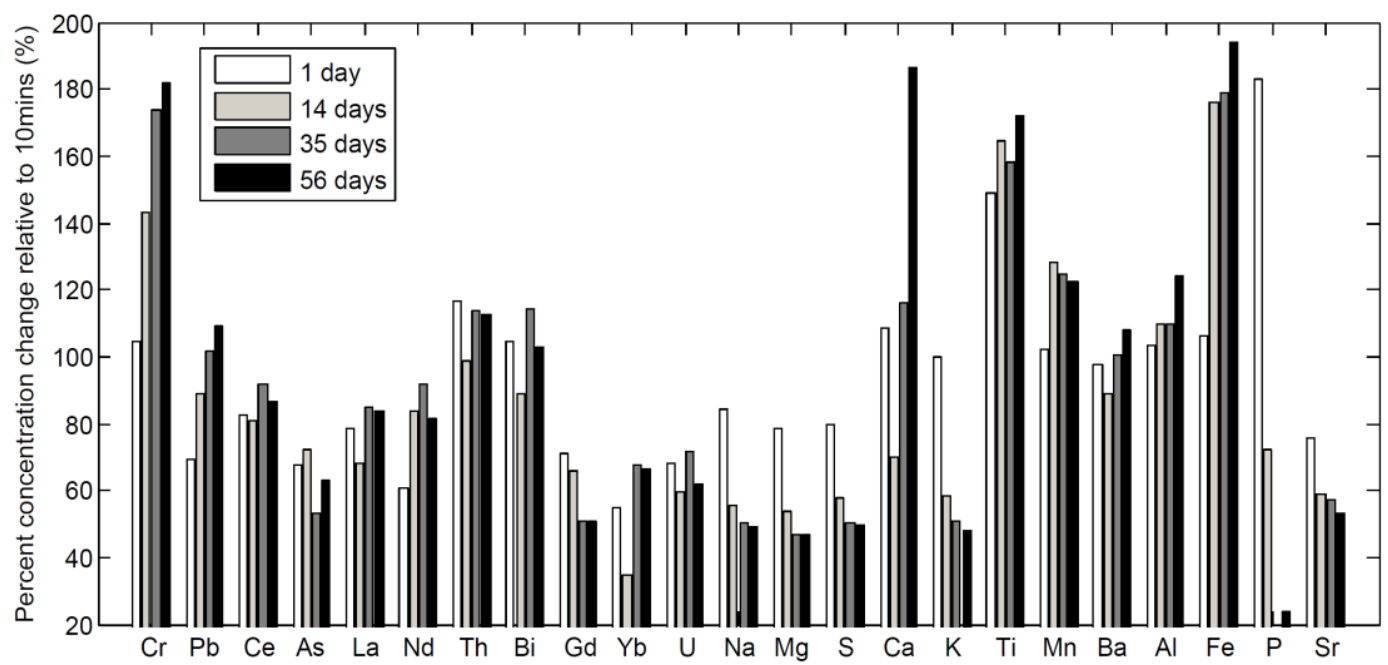

Figure 3.2. Percent concentration change in the acidified $\left(1 \% \mathrm{HNO}_{3}\right) \mathrm{RICE}$ Antarctic snow sample after 1 day, 14 days, 35 days and 56 days (plotted as in Koffman et al., 2014).

\subsection{ICPMS set up and sample analysis}

RICE samples (comprising samples from precipitation collection, a $3 \mathrm{~m}$ snow pit, a $20 \mathrm{~m}$ firn core, and the top $320 \mathrm{~m}$ of the RICE ice core) were acidified in mid-late 2013, however, several earthquakes and power failures caused multiple failures in the Element 2, leading to long delays in planned analyses. With delays reaching four months, the decision was made to analyse all RICE samples at Curtin University, Perth, Australia. These analyses took place in March 2014 over a period of four weeks - limiting the number of samples to just over 2000. 
The John de Laeter Centre Trace Research Advanced Clean Environment (TRACE) laboratory (Curtin University) is a unique, purpose-built, clean air environment designed for measuring extremely low concentrations of chemical species. The laboratory houses a Thermo Scientific Element XR in a large class 1000 exclusion space, and also contains smaller class 10 ultra-trace metal clean modules for sample preparation work. The Element XR was atypical in that it was fitted with a "Jet" interface pump. The Jet pump is a highcapacity interface pump, which allows interface cones with larger orifices to be used. These cones increase the ion transfer from the ICP into the mass analyser resulting in lower detection limits. The TRACE Element XR was fitted with nickel skimmer (X-cone, ESI) and Jet-Sampler cones (ESI), and was coupled to an ESI seaFAST S2 syringe-pump autosampler and an ESI APEX-Q desolvation nebuliser, with a nitrogen additional gas. Aerosol desolvation is a requirement of the larger orifice Jet-Sampler cones. The autosampler was set with a $2 \mathrm{~mL}$ sample loop to give $\sim 7$ minutes analytical time per sample. The APEX-Q desolvates aerosol by spraying solution from a PFA micro-flow nebulizer (ST, ESI) into a heated cyclonic spray chamber $\left(140^{\circ} \mathrm{C}\right)$. After the heated chamber, evaporated particles and water vapour pass through a Peltier-cooled $\left(3^{\circ} \mathrm{C}\right)$ condenser loop, condensing the water. Prior to entering the ICP torch injector the aerosol is passed through a PFA aerosol-focusing component that supplies the APEX-Q and requires an additional argon gas input. The ICP torch Ar gas flow rates were: cool gas $=16 \mathrm{~L} \mathrm{~min}^{-1}$; auxiliary gas $0.7 \mathrm{~L} \mathrm{~min}^{-1}$, and sample gas flow $\sim 0.8 \mathrm{~L} \mathrm{~min}^{-1}$ (tuned after every run). Instrument forward power was set $1248 \mathrm{~W}$.

The dry aerosol requires a small bleed of nitrogen gas into the APEX to optimise the ionisation in the ICP. The amount of $\mathrm{N}_{2}$ was optimised for highest sensitivity using a needle valve on the front of the APEX-Q. The syringe-pump autosampler is required for pumping the APEX-Q since pulsations from a peristaltic pump are amplified by a mass expansion in the APEX-Q's heated chamber. Self-aspiration can be used, but requires an internal standard to be added to the samples directly with high-reproducibility. The syringe pumps thus allow for a higher level of automation and the internal standard to be added inline. A $1.5 \mathrm{ppb}$ indium (In) internal standard acidified to $3 \%$ with $\mathrm{HNO}_{3}(\mathrm{v} / \mathrm{v} \%)$ was prepared from a commercial indium standard (ESI) and mixed with a sample at a ratio of 1.3 inside a tee junction before nebulisation. Sub-boiled double-distilled TRACE-2D $1 \% \mathrm{HNO}_{3}$ was used as the carrier, and for preparing standards, instrumental blanks and QC samples. In between samples, the sample probe was rinsed with ultrapure $1 \% \mathrm{HNO} 3 \mathrm{v} / \mathrm{v}$. The total flow rate into the APEX-Q was $300 \mu \mathrm{L} \mathrm{min}^{-1}$, resulting in a diluted internal standard concentration of 0.5 ng $\mathrm{g}^{-1}{ }^{115} \mathrm{In}$ which gave a response of $\sim 7 \times 10^{6}$ counts per second (equivalent to $14 \times 10^{6}$ 
counts per second for $1 \mathrm{ng} \mathrm{g}^{-1}{ }^{115} \mathrm{In}$ ) at low mass resolution. This high sensitivity was maintained throughout the analysis period. Samples were analysed for concentrations of 37 different elements (Table 3.2).

External calibration standards were prepared from certified single- and multi-element stock solutions (ESI). A suite of 10 standards (including a blank) were run at the start, middle and end of each analytical run (Table 3.2). A typical analytical run consisted of 269 analytes with 210 samples, usually taking about 32 hours per run. Quality assurance during the runs consisted of a QC standard (Table 3.3), an instrumental blank and a duplicate after every 10 samples. 


\begin{tabular}{|c|c|c|c|c|c|c|c|c|c|c|}
\hline Isotope & Std 10 & Std 9 & Std 8 & Std 7 & Std 6 & Std 5 & Std 4 & Std 3 & Std 2 & Std 1 \\
\hline $\mathrm{Na23(LR)}$ & 800000 & 533333 & 355556 & 237037 & 158025 & 105350 & 70233 & 46822 & 31215 & 20810 \\
\hline Rb85(LR) & 4000 & 2667 & 1778 & 1185 & 790.1 & 526.7 & 351.2 & 234.1 & 156.1 & 104.1 \\
\hline Sr88(LR) & 800.0 & 533.3 & 355.6 & 237.0 & 158.0 & 105.4 & 70.23 & 46.82 & 31.21 & 20.81 \\
\hline Y89(LR) & 4.00 & 2.7 & 1.78 & 1.19 & 0.79 & 0.53 & 0.35 & 0.23 & 0.16 & 0.10 \\
\hline In115(LR) & \multicolumn{10}{|c|}{ Internal Standard, 500ppt } \\
\hline Cs133(LR) & 1.50 & 1.00 & 0.67 & 0.44 & 0.30 & 0.20 & 0.13 & 0.09 & 0.06 & 0.04 \\
\hline Ba137(LR) & 200.0 & 133.3 & 88.89 & 59.26 & 39.51 & 26.34 & 17.56 & 11.71 & 7.80 & 5.20 \\
\hline La139(LR) & 4.00 & 2.67 & 1.78 & 1.19 & 0.79 & 0.53 & 0.35 & 0.23 & 0.16 & 0.10 \\
\hline Ce140(LR) & 8.00 & 5.33 & 3.56 & 2.37 & 1.58 & 1.05 & 0.70 & 0.47 & 0.31 & 0.21 \\
\hline $\operatorname{Pr} 141(L R)$ & 0.80 & 0.53 & 0.36 & 0.24 & 0.16 & 0.11 & 0.07 & 0.05 & 0.03 & 0.02 \\
\hline Nd146(LR) & 4.00 & 2.67 & 1.78 & 1.19 & 0.79 & 0.53 & 0.35 & 0.23 & 0.16 & 0.10 \\
\hline Sm147(LR) & 0.80 & 0.53 & 0.36 & 0.24 & 0.16 & 0.11 & 0.07 & 0.05 & 0.03 & 0.02 \\
\hline Eu153(LR) & 0.16 & 0.11 & 0.07 & 0.05 & 0.03 & 0.02 & 0.01 & 0.01 & 0.01 & 0.00 \\
\hline Gd157(LR) & 0.40 & 0.27 & 0.18 & 0.12 & 0.08 & 0.05 & 0.04 & 0.02 & 0.02 & 0.01 \\
\hline Tb159(LR) & 0.08 & 0.05 & 0.04 & 0.02 & 0.02 & 0.01 & 0.01 & 0.00 & 0.00 & 0.00 \\
\hline Dy163(LR) & 0.40 & 0.27 & 0.18 & 0.12 & 0.08 & 0.05 & 0.04 & 0.02 & 0.02 & 0.01 \\
\hline Ho165(LR) & 0.08 & 0.05 & 0.04 & 0.02 & 0.02 & 0.01 & 0.01 & 0.00 & 0.00 & 0.00 \\
\hline $\operatorname{Er166(LR)~}$ & 0.16 & 0.11 & 0.07 & 0.05 & 0.03 & 0.02 & 0.01 & 0.01 & 0.01 & 0.00 \\
\hline $\operatorname{Tm} 169(\mathrm{LR})$ & 0.04 & 0.03 & 0.02 & 0.01 & 0.01 & 0.01 & 0.00 & 0.00 & 0.00 & 0.00 \\
\hline Yb172(LR) & 0.16 & 0.11 & 0.07 & 0.05 & 0.03 & 0.02 & 0.01 & 0.01 & 0.01 & 0.00 \\
\hline Lu175(LR) & 0.04 & 0.03 & 0.02 & 0.01 & 0.01 & 0.01 & 0.00 & 0.00 & 0.00 & 0.00 \\
\hline T1205(LR) & 5.00 & 3.33 & 2.22 & 1.48 & 0.99 & 0.66 & 0.44 & 0.29 & 0.20 & 0.13 \\
\hline Pb208(LR) & 20.0 & 13.33 & 8.89 & 5.93 & 3.95 & 2.63 & 1.76 & 1.17 & 0.78 & 0.52 \\
\hline Bi209(LR) & 1.80 & 1.20 & 0.80 & 0.53 & 0.36 & 0.24 & 0.16 & 0.11 & 0.07 & 0.05 \\
\hline Th232(LR) & 5.00 & 3.33 & 2.22 & 1.48 & 0.99 & 0.66 & 0.44 & 0.29 & 0.20 & 0.13 \\
\hline U238(LR) & 0.15 & 0.10 & 0.07 & 0.04 & 0.03 & 0.02 & 0.01 & 0.01 & 0.01 & 0.00 \\
\hline Pu239(LR) & \multicolumn{10}{|c|}{ Not calibrated } \\
\hline Pu242(LR) & \multicolumn{10}{|c|}{ Not calibrated } \\
\hline Pu244(LR) & \multicolumn{10}{|c|}{ Not calibrated } \\
\hline Sn118(LR) & \multicolumn{10}{|c|}{ Correction for In 115} \\
\hline $\mathrm{U}^{238} \mathrm{O}^{16}(\mathrm{LR})$ & \multicolumn{10}{|c|}{ Oxide monitorring } \\
\hline $\mathrm{Ce}^{140} \mathrm{O}^{16}(\mathrm{LR})$ & \multicolumn{10}{|c|}{ Oxide monitorring } \\
\hline $\mathrm{Ce}^{140} \mathrm{O}^{16} / \mathrm{Ce}^{140}$ & \multicolumn{10}{|c|}{ Oxide monitorring } \\
\hline $\begin{array}{l}\mathbf{U}^{238} \mathbf{O}^{16} / \mathbf{U}^{238} \\
\text { LR }\end{array}$ & \multicolumn{10}{|c|}{ Oxide monitorring } \\
\hline Mg24(MR) & 120000 & 80000 & 53333 & 355556 & 23704 & 15802 & 10535 & 7023 & 4682 & 3121 \\
\hline Al27(MR) & 4000 & 2667 & 1778 & 1185 & 790.1 & 526.7 & 351.2 & 234.1 & 156.1 & 104.1 \\
\hline P31(MR) & 1750 & 1167 & 777.8 & 518.5 & 345.7 & 230.4 & 153.6 & 102.4 & 68.28 & 45.52 \\
\hline S32(MR) & 200000 & 133333 & 88889 & 59259 & 39506 & 26337 & 17558 & 11706 & 7804 & 5203 \\
\hline Cr52(MR) & 25.0 & 16.67 & 11.11 & 7.41 & 4.94 & 3.29 & 2.19 & 1.46 & 0.98 & 0.65 \\
\hline Mn55(MR) & 75.0 & 50.00 & 33.33 & 22.22 & 14.81 & 9.88 & 6.58 & 4.39 & 2.93 & 1.95 \\
\hline Fe56(MR) & 4000 & 2667 & 1778 & 1185 & 790.1 & 526.7 & 351.2 & 234.1 & 156.1 & 104.1 \\
\hline Co59(MR) & 8.0 & 5.33 & 3.56 & 2.37 & 1.58 & 1.05 & 0.70 & 0.47 & 0.31 & 0.21 \\
\hline Cu63(MR) & 500.0 & 333.3 & 222.2 & 148.2 & 98.77 & 65.84 & 43.90 & 29.26 & 19.51 & 13.01 \\
\hline In115(MR) & \multicolumn{10}{|c|}{ Internal Standard, 500ppt } \\
\hline Sn118(MR) & \multicolumn{10}{|c|}{ Correction for In 115} \\
\hline K39(HR) & 35000 & 23333 & 15556 & 10370 & 6914 & 4609 & 3073 & 2048 & 1366 & 910.4 \\
\hline Ca44(HR) & 45000 & 30000 & 20000 & 13333 & 8889 & 5926 & 3951 & 2634 & 1756 & 1171 \\
\hline As75(HR) & 12.5 & 8.33 & 5.56 & 3.70 & 2.47 & 1.65 & 1.10 & 0.73 & 0.49 & 0.33 \\
\hline In115(HR) & \multicolumn{10}{|c|}{ Internal Standard, 500ppt } \\
\hline Sn118(HR) & \multicolumn{10}{|c|}{ Correction for In 115} \\
\hline
\end{tabular}

Table 3.2. Full list of isotopes analysed by ICPMS at Curtin University, and the standard concentrations (all in parts per trillion, ppt) used to calibrate the ICPMS counts. 


\begin{tabular}{|c|c|c|c|}
\hline Isotope (resolution) & $\begin{array}{l}\text { QC Concentration } \\
\left(\operatorname{pg~g~}^{-1}\right)\end{array}$ & $\begin{array}{l}\text { Mean of } 96 \text { QC } \\
\text { measurements, }(\% \text { of } \\
\text { known conc.) }\end{array}$ & $\begin{array}{l}\text { RSD of } 96 \text { QC } \\
\text { measurements, }(\%)\end{array}$ \\
\hline Rb 85 (LR) & 526.7 & 99 & 2 \\
\hline Sr 88 (LR) & 105.3 & 99 & 2 \\
\hline Cs 133 (LR) & 0.198 & 99 & 2 \\
\hline Ba 137 (LR) & 26.3 & 95 & 9 \\
\hline La 139 (LR) & 0.527 & 100 & 3 \\
\hline Ce $140(L R)$ & 1.053 & 100 & 4 \\
\hline Pr 141 (LR) & 0.105 & 101 & 3 \\
\hline Nd 146 (LR) & 0.527 & 101 & 3 \\
\hline Sm 147 (LR) & 0.105 & 101 & 7 \\
\hline Eu 153 (LR) & 0.021 & 96 & 8 \\
\hline Gd 157 (LR) & 0.053 & 93 & 10 \\
\hline Tb 159 (LR) & 0.011 & 93 & 13 \\
\hline Dy 163 (LR) & 0.053 & 98 & 7 \\
\hline Ho 165 (LR) & 0.011 & 94 & 8 \\
\hline Er $166(L R)$ & 0.021 & 98 & 7 \\
\hline Tm 169 (LR) & 0.005 & 90 & 13 \\
\hline Yb 172 (LR) & 0.021 & 101 & 6 \\
\hline Lu 175 (LR) & 0.005 & 84 & 29 \\
\hline Tl 205 (LR) & 0.658 & 99 & 2 \\
\hline Pb 208 (LR) & 2.634 & 102 & 5 \\
\hline Bi 209 (LR) & 0.237 & 97 & 6 \\
\hline Th 232 (LR) & 0.658 & 100 & 3 \\
\hline U 238 (LR) & 0.020 & 101 & 10 \\
\hline Al 27 (MR) & 526.7 & 98 & 4 \\
\hline Cr 52 (MR) & 3.292 & 80 & 10 \\
\hline Mn 55 (MR) & 9.877 & 98 & 2 \\
\hline Fe 56 (MR) & 526.7 & 98 & 2 \\
\hline Co 59 (MR) & 1.053 & 96 & 5 \\
\hline Cu 63 (MR) & 65.8 & 99 & 2 \\
\hline As 75 (HR) & 1.646 & 89 & 10 \\
\hline
\end{tabular}

Table 3.3. QC known concentration, mean of 96 QC measurements and standard deviation of 96 QC measurements.

\subsubsection{Quality of ICPMS Measurements}

Elemental recoveries and instrument stability were assessed using the QC standards (run after every 10 samples). Statistics for the QCs determined over four individual $\sim 32$ hour run periods are shown in Table 3.3. Recoveries are between $95 \%$ and $100 \%$ for most elements analyzed. QC stability for selected elements is presented in Figure 3.3 for a 60 -hour period of near-continuous analysis. QC stability and replication is excellent across this time period, with no evidence for significant memory effects, suggesting autosampler washout procedures are effective. Accuracy is $>95 \%$ for all transition- and post-transition metals, and 
measurements are precise to within $5 \%$ (Table 3.3). Additionally, measurements of actinides are excellent with a mean concentration of $100 \%$ for ${ }^{232} \mathrm{Th}$, precise to within $4 \%$, and a mean concentration of ${ }^{238} \mathrm{U}$ only $1 \%$ greater than the known QC concentration suggesting only limited ${ }^{238} \mathrm{U}^{16} \mathrm{O}$ formation - and this at a very low concentration of $0.02 \mathrm{pg} \mathrm{g}^{-1} \cdot{ }^{52} \mathrm{Cr}$ and ${ }^{75}$ As show $80 \%$ and $98 \%$ recovery of expected QC concentration, with $10 \%$ standard deviation at concentrations less than $5 \mathrm{pg} \mathrm{g}^{-1}$.

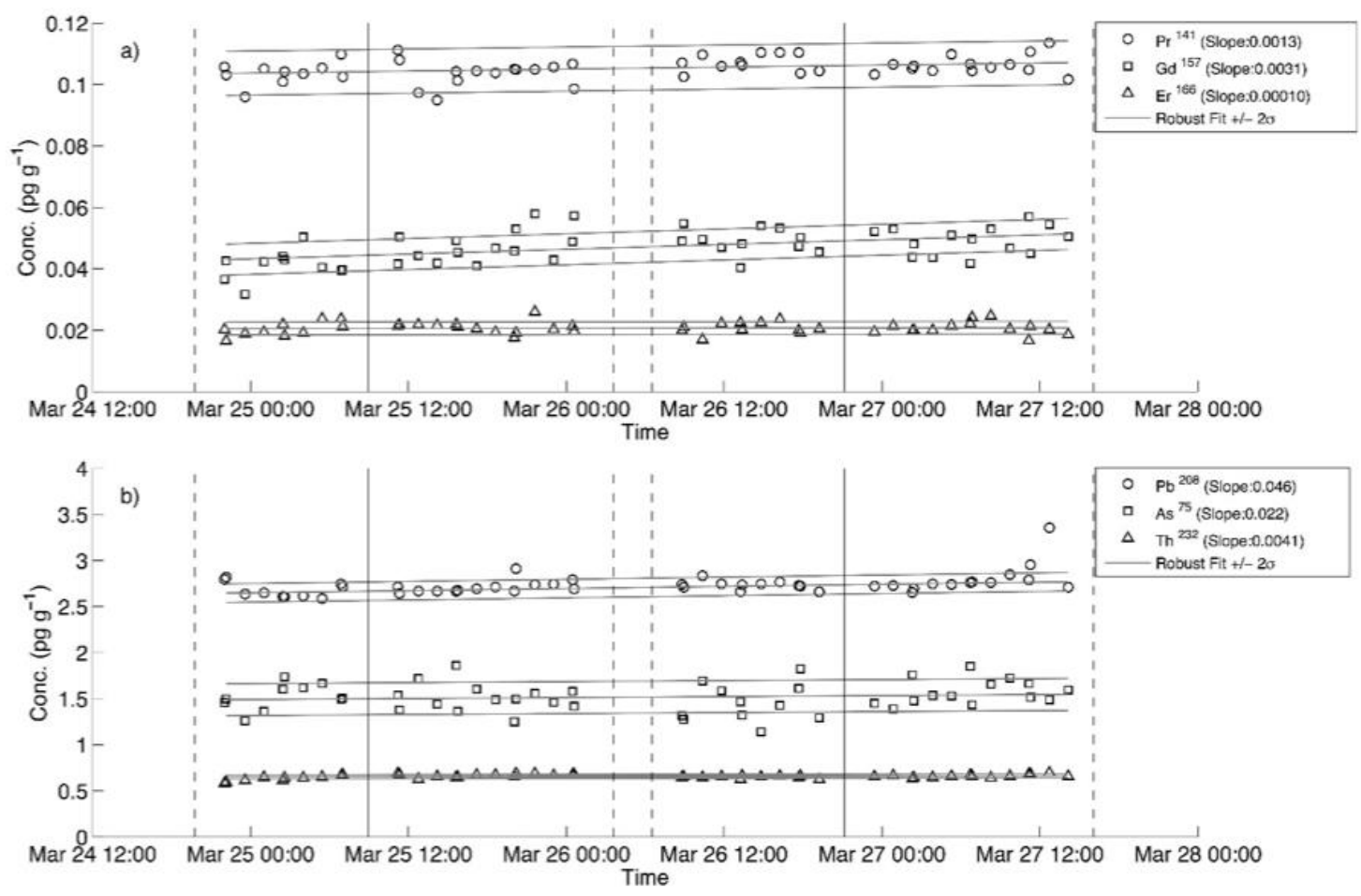

Figure 3.3. Low-concentration QC stability through a $\sim 60$-hour analysis period for a) REE (Pr, Gd, Er) and b) Pb, As and Th. Robust linear fits (grey line) are plotted through QCs, with $\pm 2 \sigma$ (dashed). Solid vertical lines mark standard calibrations used in final concentration calculations, dashed vertical lines mark additional calibrations.

The instrument was set each run to minimize oxide formation, tuned for ${ }^{238} \mathrm{U}^{16} \mathrm{O}$ production $<$ $5 \%$ and including standard REE oxide corrections. None of the REE exhibits appreciable additional recovery beyond the expected concentration of the QCs. As an additional test, REE-specific standards were prepared and measured in isolation, to observe whether oxide formation in mixed-element standards and QCs (which included $\mathrm{Ba}^{137}$ ) increased recovery of REE. No significant difference was observed. 


\subsubsection{Limits of Quantification and Concentration in Antarctic Ice Samples}

Many ice core trace element studies report estimates of instrumental limits of detection as three times the standard deviation of limited measurements of an ultrapure acid solution (Gabrielli et al., 2006; Koffman et al., 2014). While this is a critical measure, we provide a broader assessment to include all effects during analysis. Procedural and analytical background concentrations have the potential to limit quantification. Limits of detection for sector-field ICPMS instruments are expected in most cases to be well below blank concentrations due to background contamination during sampling procedures and laboratory analysis (Rodushkin et al., 2010). Means of analytical "run" blanks $(n=86)$ and procedural blanks $(n=13)$ are plotted in Figure 3.4a, as well as mean RICE Antarctic ice core sample concentration $(n=784)$ for comparison. Values are detailed in Table 3.4, including $3 \sigma$ limits of detection. These values represent the long-term backgrounds associated with this analytical campaign. Within individual runs samples were corrected for the analytical blank of that run - that is, the mean value of 10 measured run blanks (excluding $3 \sigma$ outliers). Mean sample relative standard deviation (RSD, sample standard deviation divided by mean concentration) for all isotopes is presented in Figure $3.4 \mathrm{~b}$ as a measure of signal stability during analysis. RSD should not be confused with standard deviation of sample concentrations displayed in Table 3.4, which are included to demonstrate natural variability of concentrations in Antarctic ice samples. 


\begin{tabular}{|c|c|c|c|c|c|}
\hline $\begin{array}{l}\text { Isotope } \\
\text { (Resolution) }\end{array}$ & $\begin{array}{l}\text { Sample mean, } \\
\text { blank subtracted } \\
(\mathrm{n}=784)\end{array}$ & $\begin{array}{l}\text { Sample SD } \\
(\mathrm{n}=784)\end{array}$ & $\begin{array}{l}\text { Analytical } \\
\text { Blank mean } \\
(\mathrm{n}=86) \\
\end{array}$ & $\begin{array}{l}\text { Procedural } \\
\text { Blank mean } \\
(\mathrm{n}=13)\end{array}$ & $\begin{array}{l}\text { LOD } \quad(3 * \mathrm{SD} \\
\text { Analytical } \\
\text { Blank) } \\
\end{array}$ \\
\hline Rb 85 (LR) & 4.864 & 3.031 & 0.259 & 0.354 & 0.239 \\
\hline Sr 88 (LR) & 232 & 150 & 0.191 & 2.000 & 0.244 \\
\hline Cs 133 (LR) & 0.111 & 0.115 & 0.002 & 0.011 & 0.002 \\
\hline Ba 137 (LR) & 5.314 & 5.356 & 16.630 & 18.275 & 7.286 \\
\hline La 139 (LR) & 0.324 & 0.385 & 0.004 & 0.009 & 0.004 \\
\hline Ce 140 (LR) & 1.313 & 3.148 & 0.010 & 0.012 & 0.036 \\
\hline $\operatorname{Pr} 141(L R)$ & 0.074 & 0.090 & 0.001 & 0.004 & 0.001 \\
\hline Nd $146(L R)$ & 0.289 & 0.354 & 0.003 & 0.007 & 0.006 \\
\hline Sm 147 (LR) & 0.055 & 0.066 & 0.005 & 0.007 & 0.007 \\
\hline Eu $153(L R)$ & 0.009 & 0.011 & 0.003 & 0.005 & 0.003 \\
\hline Gd 157 (LR) & 0.041 & 0.050 & 0.008 & 0.008 & 0.012 \\
\hline Tb 159 (LR) & 0.005 & 0.006 & 0.002 & 0.002 & 0.003 \\
\hline Dy 163 (LR) & 0.034 & 0.034 & 0.001 & 0.003 & 0.003 \\
\hline Ho 165 (LR) & 0.006 & 0.006 & 0.001 & 0.004 & 0.001 \\
\hline Er $166(L R)$ & 0.017 & 0.016 & $<0.001$ & $<0.001$ & 0.001 \\
\hline $\operatorname{Tm} 169$ (LR) & 0.002 & 0.002 & 0.001 & 0.002 & 0.002 \\
\hline Yb 172 (LR) & 0.004 & 0.003 & $<0.001$ & 0.001 & $<0.001$ \\
\hline Lu 175 (LR) & 0.002 & 0.006 & $<0.001$ & 0.001 & 0.001 \\
\hline Tl 205 (LR) & 0.051 & 0.047 & 0.015 & 0.034 & 0.007 \\
\hline Pb 208 (LR) & 5.297 & 5.647 & 0.333 & 0.227 & 1.670 \\
\hline Bi 209 (LR) & 0.057 & 0.093 & 0.028 & 0.062 & 0.051 \\
\hline Th 232 (LR) & 0.103 & 0.192 & 0.002 & 0.001 & 0.008 \\
\hline U 238 (LR) & 0.147 & 0.067 & 0.001 & 0.017 & 0.003 \\
\hline Al 27 (MR) & 573 & 804 & 28.26 & 112 & 37.21 \\
\hline Cr 52 (MR) & 1.147 & 3.8 & 3.652 & 9.654 & 2.157 \\
\hline Mn 55 (MR) & 12.37 & 15.36 & 0.388 & 4.196 & 0.354 \\
\hline Fe 56 (MR) & 472 & 1022 & 12.102 & 16.547 & 7.679 \\
\hline Co 59 (MR) & 0.367 & 1.26 & 0.268 & 0.274 & 0.102 \\
\hline Cu 63 (MR) & 58.23 & 92.87 & 1.084 & 1.436 & 0.959 \\
\hline As 75 (HR) & 1.975 & 1.230 & 0.282 & 0.725 & 0.252 \\
\hline
\end{tabular}

Table 3.4. Sample, analytical and procedural blanks ( $\left.\mathrm{pg} \mathrm{g}^{-1}\right)$. 


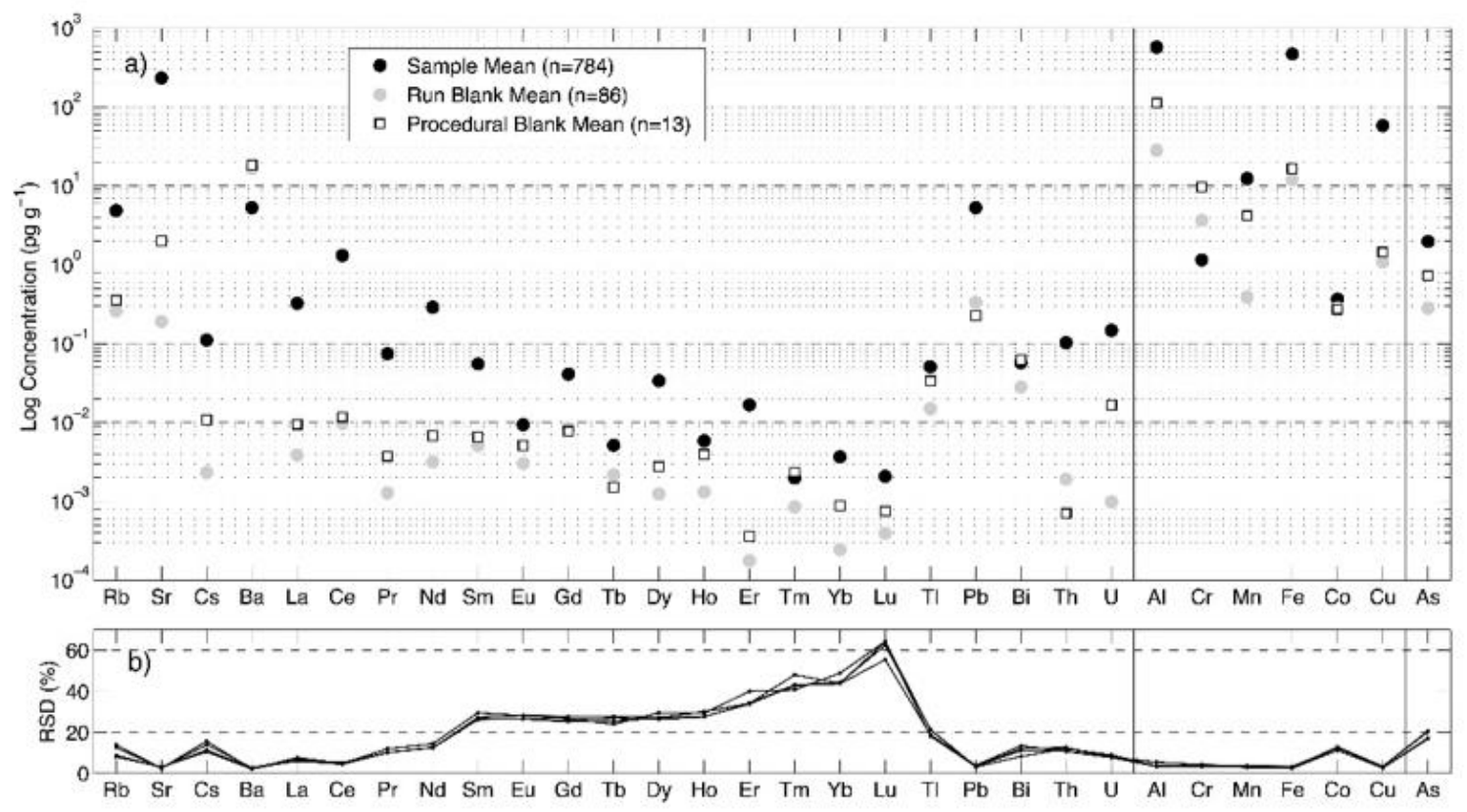

Figure 4.3. (a) Sample (black circle), run blank (grey circle) and procedural blank (white square) mean concentrations (logarithmic scale) for all isotopes. Vertical lines separate isotopes analyzed at low, medium and high instrument resolution from left to right. (b) Sample relative standard deviation (RSD, \%) for all isotopes, as an average of individual analytical runs; each run plotted as a black line.

Actinides ${ }^{232} \mathrm{Th}$ and ${ }^{238} \mathrm{U}$ have very low background contamination, ${ }^{232} \mathrm{Th}$ at the single $f g \mathrm{~g}^{-1}$ level and ${ }^{238} \mathrm{U}$ at tens of $\mathrm{fg}^{-1}$. Mean ice core sample values are well above blank levels for these analytes (Table 3.4). Analytical blank concentrations for light REE (La, Ce, Pr, Nd) are less than $2 \%$ of mean concentrations found in ice core samples, with procedural blanks concentrations less than $8 \%$ of the sample mean. Sample RSD for light REE are 5-13\% (Figure 3.4b). Medium and heavy REE show significantly higher blank concentrations relative to single digit part per quadrillion concentrations in ice core samples, especially the alternating abundance of medium REE ( $\mathrm{Sm}, \mathrm{Eu}, \mathrm{Gd}, \mathrm{Tb}, \mathrm{Dy})$ and heavy REE (Ho, Er, Tm, $\mathrm{Yb}, \mathrm{Lu}$ ). At such low concentrations (single $\mathrm{fg}^{-1}$ ), sample RSD are relatively high, approximately $25 \%$ across the medium REE and rising in a linear fashion across the heavy REE to a maximum RSD of $\sim 60 \%$ (Figure $4.3 \mathrm{~b}$ ). Tm is the only REE that shows a higher mean concentration in procedural blanks (Figure 3.4a), suggesting that laboratory contamination may render this element of limited use.

As discussed in the Foreword, this thesis focuses on the heavy metal elements while the rare earth elements were the focus of a separate thesis by Peter Neff. 
The full suite of transition metal and metalloid elements analysed includes $\mathrm{Cr}, \mathrm{Mn}, \mathrm{Fe}, \mathrm{Co}$, $\mathrm{Cu}, \mathrm{Al}, \mathrm{Tl}, \mathrm{Pb}, \mathrm{Bi}$, and As. However, some of these elements could not be distinguished from the blanks, or had persistent contamination issues. Of these elements, sample concentrations of $\mathrm{Bi}, \mathrm{Cr}$, and $\mathrm{Co}$ were not distinguishable from procedural blank concentrations (Figure 3.4a), so they have not been considered further in this thesis. Although sample concentrations of $\mathrm{Cu}$ are significantly above both procedural and analytical run blank concentrations, there is persistent contamination that occurs whenever there was a break in the melting process (i.e. every time a new stack of cores were added, or melting was paused and a core stick was lifted to trouble shoot problems). These persistent peaks of $\mathrm{Cu}$ are likely due to contamination from the melt-head itself which was gold-plated copper, combined with the switch between melted ice core water and MQ water. Although these parts of the time-series could have been cut out, the remaining $\mathrm{Cu}$ record would be extremely low resolution. Hence, only those heavy metals that are significantly above the procedural blanks and show no persistent contamination issues are considered in this thesis: $\mathrm{Mn}, \mathrm{Fe}, \mathrm{Al}, \mathrm{Pb}, \mathrm{Tl}$, and $\mathrm{As}$.

\subsection{Analysis of Plutonium Isotopes}

In addition to the 37 elements analysed for concentrations in the RICE samples, we also included three isotopes of Plutonium $(\mathrm{Pu})$ to discover if we could record any ICPMS counts per second for this element. We chose $\mathrm{Pu}^{239}, \mathrm{Pu}^{242}$, and $\mathrm{Pu}^{244}$ as these isotopes of $\mathrm{Pu}$ are commonly associated with $\mathrm{Pu}$ used in bombs (Gabrieli et al., 2011). Although we did not expect to measure any signal on these isotopes, we recorded counts per second (cps) of 0-6 cps on $\mathrm{Pu}^{239}, 0-3.3 \mathrm{cps}$ on $\mathrm{Pu}^{242}$, and 0-5.3 cps on $\mathrm{Pu}^{244}$. Only the time-series of $\mathrm{Pu}^{239}$ showed any features (Figure 3.3). We observe two broad peaks where counts per second were elevated more than $2 \sigma$ above the background. These peaks occur in samples dated between 1950 and 1958, and 1960 and 1966, which broadly coincide with the time periods of atmospheric atomic bomb tests (Heikkila et al., 2009). Although these counts per second cannot be converted to concentrations, the comparison to ICPMS counts for $\operatorname{In}^{115}(\sim 7$ million cps at $500 \mathrm{ppt}$ ) indicates that $\mathrm{Pu}$ concentrations in Antarctica are extremely low. Hence, there is a distinct possibility that these counts are influenced by background levels of $\mathrm{Pu}$ in the laboratory environment, however, these results also suggest it might be possible to successfully measure $\mathrm{Pu}$ bomb spikes in Antarctic snow and ice if method modifications are made to focus specifically on these isotopes. 


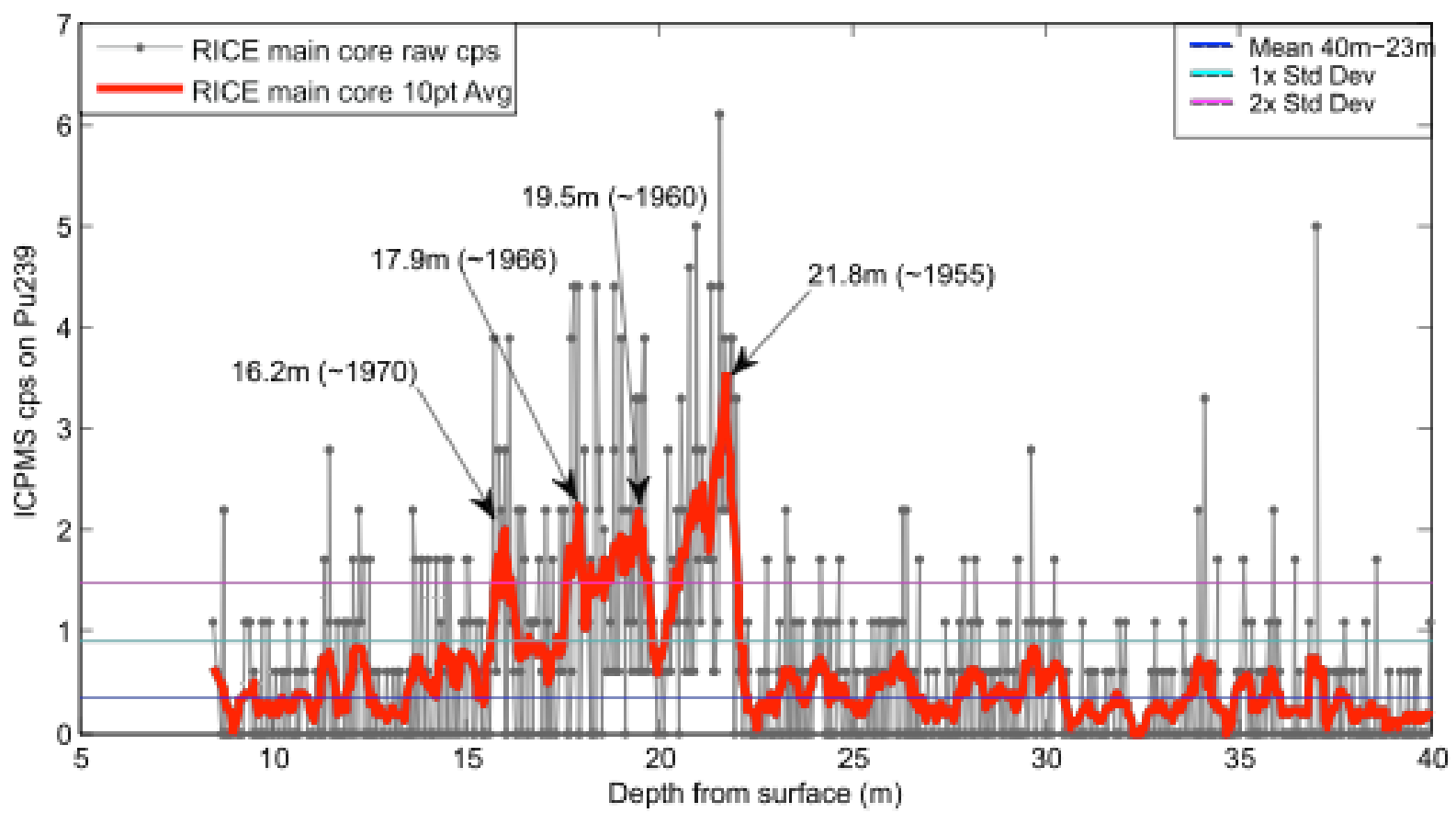

Figure 3.3. Element XR SF-ICPMS counts on isotope mass 239 (plutonium) in low resolution in RICE ice core samples from the top $40 \mathrm{~m}(\mathrm{n}=784)$. Dating is based on the RICE $2 \mathrm{ka} 1.0$ age scale.

\subsection{Data Processing}

All data processing was conducted in MATLAB, and the scripts written for this are included in Appendix A.

All samples were normalised to the internal standard and blank corrected. Internal standard normalisation calculations were performed against the $\operatorname{In}^{115}$ ion intensity using Equation 1.

Equation 1. $I=I_{\text {meas }} *\left(c_{I S} / I_{I S}\right)$

Where: $I_{\text {meas }}$ is the measured intensity of the desired isotope, $c_{I S}$ is the concentration of the internal standard (500 ppt $\mathrm{In}^{115}$ ), and $I_{I S}$ is the measured intensity of the internal standard. Normalised sample intensities were quantified using external calibration. A typical calibration consisted of 10 serial-standards made from certified single- and multi-element standards. Calibration curves were estimated using robust linear regression with bi-square weighting (Huber, 1981), which weights data points depending on deviation from the linear fit (i.e. points near the line get full weight), minimising the effect of outliers. Outliers $(>3 \sigma)$ were manually removed from standard calibrations and a new regression was calculated to convert ICPMS counts to concentrations. Finally, analytical background concentrations, the average of $\sim 10$ run blanks (excluding outliers, $>3 \sigma$ ) per $\sim 32$ hour run, were subtracted from all samples in that analytical session. 


\section{Chapter 4 - Transport and Deposition of Heavy Metals in the Ross Sea Region, Antarctica}

Andrea Tuohy ${ }^{1,2}$, Nancy Bertler ${ }^{1,2}$, Peter Neff ${ }^{1,2}$, Ross Edwards ${ }^{3}$, Daniel Emanuelsson ${ }^{1,2}$, Thomas Beers ${ }^{4}$, Paul Mayewski ${ }^{4}$.

1,2 - Andrea Tuohy, Nancy Bertler, Peter Neff, and Daniel Emanuelsson, Antarctic Research Centre, Victoria University of Wellington, New Zealand and GNS Science, Wellington, New Zealand.

3 - Ross Edwards, Department of Imaging and Applied Physics, Curtin University, Perth, Australia. 4 - Thomas Beers and Paul Mayewski, Climate Change Institute, University of Maine, Maine, USA.

Corresponding Author: A. J. Tuohy, Antarctic Research Centre, Victoria University of Wellington, PO Box 600, Wellington 6140, New Zealand. (andrea.tuohy@vuw.ac.nz)

\section{Key Points:}

- Rime ice and fog contribute to heavy metal concentrations at coastal sites

- Long-distance oceanic pathways deliver heavy metals to the Ross Sea Region

\subsection{Foreword}

This chapter constitutes a paper currently in review by the Journal of Geophysical Research: Atmospheres. In this paper we seek to determine the representativeness of heavy metal concentrations in snow and ice at Roosevelt Island, to inform interpretation of the time-series preserved in the RICE ice core. To achieve this we explore the changes in heavy metal concentration with different types of precipitation and air mass trajectories using measured concentrations of heavy metals in snow precipitation samples and air mass modelling using the European Centre for Medium-range Weather Forecasting (ECMWF) available ERA-Interim reanalysis data in the National Oceanic and Atmospheric Administration (NOAA) HySPLIT program. Furthermore we characterize the seasonality of heavy metal concentrations in a highresolution $3 \mathrm{~m}$ deep snow pit, and discuss the local deposition mechanisms affecting preservation of atmospheric signals in the surface snow layers.

I led the production of this manuscript, with written contributions from Nancy Bertler, Peter Neff, Ross Edwards, Daniel Emanuelsson, and Paul Mayewski. Thomas Beers contributed to field sampling in the 2011-2012 field season. 


\subsection{Abstract}

Emissions and long-range transport of toxic metals and metalloids pose a global threat to ecosystems and human health. Global industrialization occurring from the late $19^{\text {th }}$ Century releases large quantities of pollutants into the earth's atmosphere. Despite international efforts to mitigate emissions, accumulation of metals is still observed in the most remote regions of the planet. New baseline studies are needed to determine i) natural background concentration of pollutants, ii) contributions of anthropogenic emissions, iii) potential remobilization of previously deposited metals. Constructing such records requires distinguishing source strength from transport efficiency to the recording site, and accounting for local depositional effects. Here we investigate the sensitivity and representation of Southern Hemisphere atmospheric concentrations of heavy metals (Fe, Al, Mn, Pb, Tl, As) in the Roosevelt Island Climate Evolution (RICE) ice core, a new coastal Antarctic ice core site. Concentration variability with precipitation is explored in daily surface snow samples collected over 70 days, while seasonal deposition is investigated through snow pit sampling. We find that snow sample concentrations increase with particular snow precipitation types (rime, fog) and enhanced meridional atmospheric transport to the site. Snow pit heavy metals peak in summer and also show variable intra-annual peaks. Seasonal airmass modeling based on ERA Interim reanalysis data indicate a synoptic shift during the spring and summer months. We conclude that modern heavy metal concentrations are influenced by transport efficiency and scavenging behavior and thus time-series records from RICE have the potential to provide representative data of regional changes in heavy metals.

\section{Index Terms:}

0792, 0736, 0724, 3349

\section{Keywords:}

Anthropogenic pollution, heavy metals, transport, deposition mechanisms, Antarctica

\subsection{Introduction:}

Since the industrial revolution, concentrations of heavy metals in the environment have increased [Candelone et al., 1995; Järup, 2003; McConnell et al., 2014; Ngriagu, 1990]. Observational monitoring programs are too short to capture this increase, and thus natural baselines and variation of heavy metal concentration are poorly constrained, particularly in the Southern Hemisphere where fewer records are available [Fowler, 1990; Martin and Richardson, 1991]. Moreover, heavy metals have long residence times in the environment [Fowler, 1990; Jia and Jia, 2014; Martin and Richardson, 1991], so proxy records from high-resolution, annually-resolved sources spanning longer periods of time, such as ice cores, can provide important perspectives [Gabrielli et al., 2005; 
Hur et al., 2013; McConnell et al., 2007; Planchon et al., 2003]. In order to interpret new ice core time series, the proposed proxy records must be linked to environmental parameters in the modern environment, and an assessment of local depositional effects must be made.

The term 'heavy metals' is only loosely defined and generally groups metalloids, transition metals, basic metals, lanthanides and actinides [Duffus, 2002]. In the public domain heavy metals are associated with toxic metals and those commonly used in industry. For this reason we define heavy metals as the period 4 transition metals of the periodic table $(\mathrm{Mn}, \mathrm{Fe})$, in addition to a subset of basic metals and semi metals ( $\mathrm{Al}, \mathrm{Tl}, \mathrm{Pb}$, and $\mathrm{As})$. Advances in the measurement of ultra-low concentrations of pollutants by Inductively Coupled Plasma Mass Spectrometry (ICPMS) now permit the analysis of large sample numbers and low sample volume [Krachler et al., 2005; Osterberg et al., 2006]. This provides new opportunities to use Antarctic snow and ice as a sensitive recorder of modern and past pollutant concentrations with the aim to quantify Southern Hemisphere pre-industrial concentrations, establish natural variability, and to quantify and date anthropogenic contributions. To interpret Antarctic records, it is necessary to distinguish between the source strength, the transport efficiency, and scavenging effectiveness. Primary sources for pollutants recorded in Antarctica are thought to be predominantly from Southern Hemisphere emissions facilitated by meridional atmospheric transport, as indicated by metal isotopic fingerprinting [Vallelonga et al., 2010; Wolff and Suttie, 1994]. Atmospheric circulation is highly variable both spatially and through time, thus the transport efficiency of particulates to Antarctica is also highly variable and is a consequence of changing patterns of wind strength, temperature, and storm tracks [King and Turner, 1997]. Climate indices such as the El Niño Southern Oscillation (ENSO) and the Southern Annular Mode (SAM) describe major patterns in Pacific and high-latitude circulation, and understanding changes in these through time assists in the interpretation of atmospheric transport efficiency to regions such as the Ross Sea [Bertler et al., 2004; Bertler et al., 2006], and thus the transport efficiency of particulates to Antarctica [Duce et al., 1991; Li et al., 2008; Turner et al., 2013]. In order to utilize heavy metal concentrations in an ice core as recorders of environmental changes through time, the influence of transport and local depositional effects must first be characterized in the modern environment.

This paper explores the transport and deposition of the heavy metals $\mathrm{Pb}, \mathrm{Tl}, \mathrm{Al}, \mathrm{Mn}, \mathrm{As}, \mathrm{Fe}$ in surface snow from Roosevelt Island. Comparisons are drawn with selected elements known to represent crustal dust (La, Ce), and sea salt aerosols (Na, Sr) [Gabrielli et al., 2010; Grotti et al., 2011]. We focus on the influence of surface conditions, atmospheric circulation, and snow precipitation affecting heavy metal concentrations at Roosevelt Island to develop a model for 
interpreting time series of heavy metals from the RICE ice core. Daily surface snow samples and snow pit samples collected during the 2011-2012 austral summer season from Roosevelt Island $\left(79.36^{\circ} \mathrm{S}, 16170^{\circ} \mathrm{W}, 550 \mathrm{~m}\right)$, a grounded ice rise at the north-eastern edge of the Ross Ice Shelf (Figure 4.1). The samples were obtained as part of the Roosevelt Island Climate Evolution (RICE) project. In addition to a $763 \mathrm{~m}$ deep ice core drilled to bedrock, several shallow firn cores, snow pits and surface snow samples were collected over the two drilling seasons in 2011-2012 and 20122013. Roosevelt Island intercepts cyclonic air flow from the Ross Sea region of the Southern Ocean [Sinclair et al., 2010], and as such is an ideal site to monitor backgrounds of heavy metal concentrations in the South Pacific region, particularly in the Pacific and Indian sectors. Modeled air mass trajectories are linked to the concentrations of daily surface snow samples and highlight the major transport paths determined for the 2011-2012 summer.

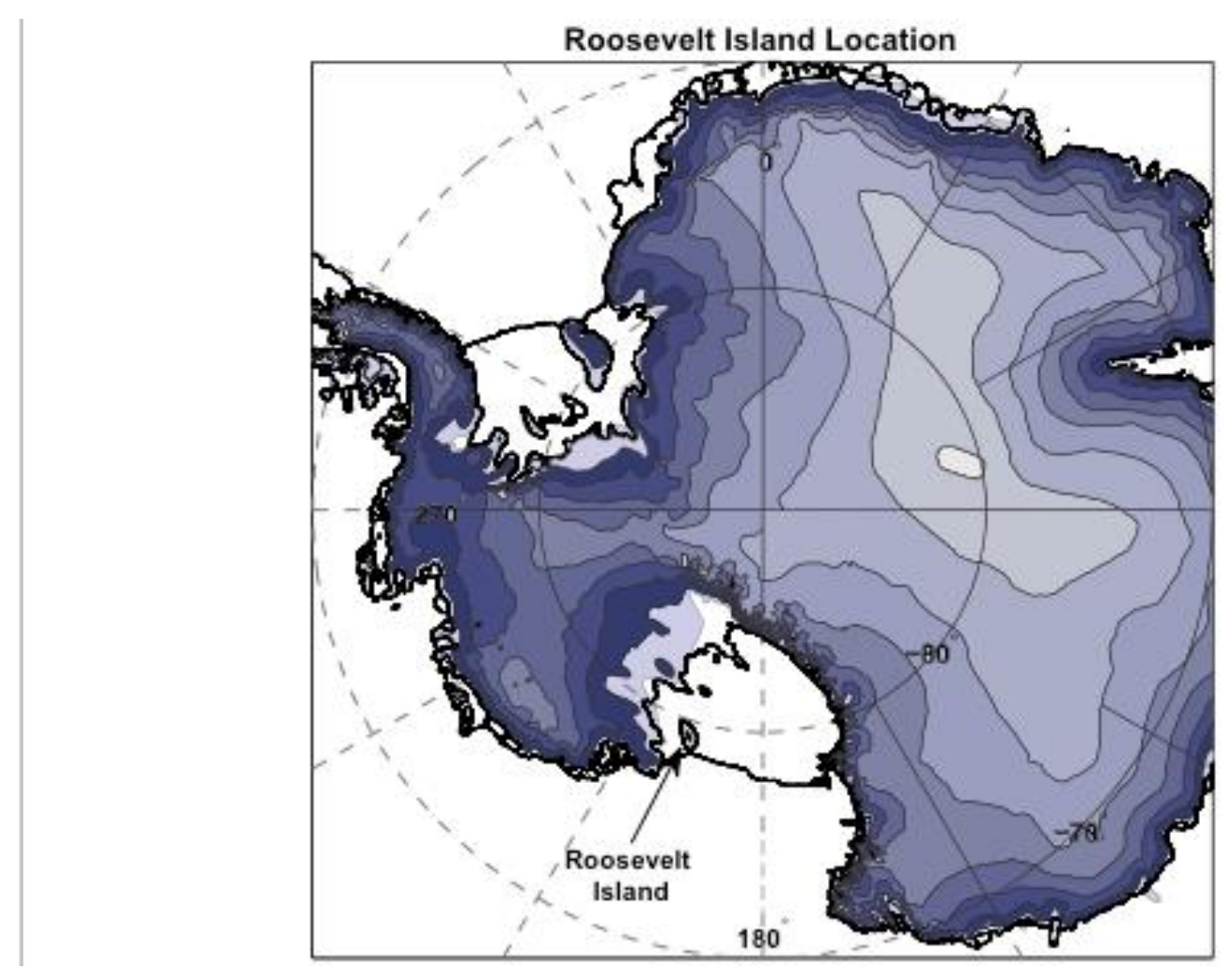

Figure 4.1. Location map of Roosevelt Island, Antarctica, produced using topographic data from Timmerman et al. (2010).

\subsection{Methods}

\subsubsection{Snow Precipitation Sampling}

Over an eight-week period during the 2011-2012 austral summer field season, daily samples of precipitation were collected on snow sampling trays positioned $350 \mathrm{~m}$ north of the RICE camp $\left(76.366^{\circ} \mathrm{S} 161.694^{\circ} \mathrm{W}, 560 \mathrm{~m}\right)$ (Figure 4.1). The site was chosen to minimize potential contamination from the RICE drill site and ski-way, while still being accessible multiple times a day by foot and 
during adverse weather conditions. In the previous season, the least frequent wind flow was observed from the south. For this reason, the sampling site was positioned to the north of the camp, and located $3.5 \mathrm{~km}$ away from the ski-way. The sample site was surrounded by a vehicle exclusion zone and no samples were collected during the days when aircraft landed at Roosevelt Island. All sampling tools were cleaned following similar procedures to those reported in Dixon et al. [2013]. Six white, high-density, polyethylene trays were pre-cleaned first with Citranox, then by three iterations of soaking and rinsing in ultra-pure water ( $>18 \Omega \mathrm{MQ})$ in a class 1000 clean lab, and then dried and sealed in plastic for transportation to the field. The trays were staked out $3 \mathrm{~m}$ apart in a hexagonal pattern to reduce possible drift effects. The trays were set up on the $6^{\text {th }}$ November 2011, however, no snow accumulated on the trays until the $21^{\text {st }}$ November. The total observational period was 70 days with the final day of sampling on the $14^{\text {th }}$ January 2012. Up to six samples were taken daily when there was enough precipitation to sample (a total of 257 samples over 41 days). The sampling occurred daily or more often during snow precipitation events, if the accessibility of the site was not restricted during storms. Weather observations (temperature, wind speed, wind direction, cloud cover) and basic physical snow properties (crystal shape, occurrence of rime, $20 \mathrm{~cm}$ snow temperature) were recorded at the time of sampling (see Table 4.ST1). Daily accumulation measurements were also made at a grid of 25 snow stakes covering $25 \mathrm{~m}^{2}$, that was located $\sim 100 \mathrm{~m}$ away from the snow sampling site. Tyvek clean suits and ultra-clean medical gloves were worn for sampling, and a pre-cleaned polyethylene spatula was used to transfer the contents of the trays into individual Whirl-Pac bags. The bags were then sealed, labeled and stored frozen for transport. The trays were shaken clean of all snow following sampling and placed back on the surface of the snow. A total of 160 samples (four per day) were analyzed by ICPMS for concentrations of heavy metals.

\subsubsection{Snow Pit Sampling Methods}

In addition to daily snow samples, a three-meter deep snow pit was excavated using electric chainsaws at the end of December $2011200 \mathrm{~m}$ west of the RICE camp. The sampling wall was smoothed back first with pre-cleaned shovels, then scraped back a further $20 \mathrm{~cm}$ with pre-cleaned (Citranox, then rinsed and soaked in $>18 \Omega \mathrm{MQ}$ water) ceramic knives. A new pre-cleaned ceramic knife was then used to scrape samples into a pre-cleaned sampling tray. The sampling was conducted while wearing Tyvek clean suits and ultra clean medical gloves. Due to compaction of the surface snow around the snow pit, a separate small pit was dug and cleaned $\sim 20 \mathrm{~m}$ from the main snow pit in undisturbed snow, and the top $10 \mathrm{~cm}$ was sampled, ensuring a $5 \mathrm{~cm}$ overlap with the main snow pit. Samples were stored frozen for transport. The snow pit was sampled at $1 \mathrm{~cm}$ resolution using acid-washed low-density polyethylene (LDPE) bottles, and aliquots were later taken from half of the samples in the lab for heavy metal analysis, giving a $2 \mathrm{~cm}$ resolution for 
heavy metal data (150 samples). Density measurements were taken in the field using a tool with a $100 \mathrm{~cm}^{3}$ volume, allowing one measurement to be made every $3 \mathrm{~cm}$ in the snow pit. Two to three samples were taken across the same layers, and the weights were averaged together. The density measurements were interpolated to match the $2 \mathrm{~cm}$ resolution of the ICPMS samples.

\subsubsection{ICPMS Analysis of Snow Precipitation and Snow Pit Samples}

All samples for ICPMS analysis were transported frozen from Roosevelt Island to the National Ice Core Research Laboratory at GNS Science in New Zealand. The samples were thawed and aliquoted into $10 \mathrm{~mL}$ vials. These vials were cleaned prior to use following a rigorous acid rinsing procedure, where batches of $\sim 25$ vials were rinsed three times in $>18 \mathrm{M} \Omega \mathrm{MQ}$ ultra-pure water and soaked for five days in $5 \%$ reagent grade $\mathrm{HNO}_{3}$. Following this, they were rinsed three times in ultra-pure water, then soaked overnight in ultra-pure water. After three additional rinses in ultrapure water vials were then capped and stored frozen until a few hours prior to use. Vial blanks were prepared at the same time snow samples were aliquoted into vials, and concentrations are similar to instrument blanks (Table 4.1).

A total of 310 samples (160 snow precipitation and 150 snow pit samples) were acidified to $1 \%$ with ultra-pure Seastar $\mathrm{HNO}_{3}$ six months prior to ICPMS analysis. All sample preparations were conducted in a class-100 clean room. The long acidification time was employed to maximize leaching from particulates and to ensure stable dissolved concentrations [Koffman et al., 2014; Rhodes et al., 2011]. In addition, we performed leaching tests on powdered rock standards and RICE snow samples following the method in Rhodes et al. (2011), and we found that concentrations stabilized within three months for all elements in the snow samples, with similar trends in concentration change to those reported by Koffman et al. (2014). The snow pit and snow precipitation samples were analyzed for concentrations of 37 elements in the Trace Research Advanced Clean Environment (TRACE) laboratory (Curtin University, Perth, Australia) using a Thermo Scientific Element XR sector field ICPMS. The samples were transported frozen to Australia to reduce the possibility of contamination and excessive shaking, and were thawed on arrival. Custom modifications were made to the sample introduction configuration to maximize instrument sensitivity. A jet vacuum pump was used, along with jet-compatible nickel X-skimmer and sample cones. A new quartz torch and injector were pre-conditioned with $1 \%$ ultra-pure nitric acid. A syringe pump Element Scientific Inc. (ESI) seaFAST autosampler (with an acrylic sample enclosure) controlled sample/standard delivery to an APEX-Q desolvation system $\left(100^{\circ} \mathrm{C} \pm 2^{\circ} \mathrm{C}\right)$ fitted with a PFA-ST nebulizer. Total flow rate into the APEX-Q was $300 \mu \mathrm{L} \mathrm{min}{ }^{-1}$, with online mixing of Indium $\left({ }^{115} \mathrm{In}\right)$ resulting in a diluted internal standard concentration of 500 parts per 
trillion (ppt). An additional gas (high purity nitrogen) was introduced to the APEX and adjusted for optimal signal response. The desolvation system was coupled to the ICPMS torch using a PFA aerosol focusing connector with an additional argon gas (Ar) of $0.350 \mathrm{~L}$ min-1. The gas flow rates were: cool gas $=16 \mathrm{~L}$ min-1; auxiliary gas $0.7 \mathrm{~L}$ min-1, and sample gas flow $\sim 0.8 \mathrm{~L}$ min-1 (tuned after every run $\sim 32$ hours). Instrument forward power was set $1248 \mathrm{~W}$. Operating parameters were tuned to maximize sensitivity ( $\sim 7 \times 10^{6}$ counts per second $)$ at low mass resolution) and minimize oxide production $\left({ }^{238} \mathrm{U}^{16} \mathrm{O}<5 \%\right)$ at the start of each run. A set of ten in-house standard solutions were analyzed for calibration of sample concentrations, and the middle standard plus a blank bracketed every 10 samples for quality control. The focus of this paper is on the concentrations of six transition metal/metalloid elements ( $\mathrm{Tl}, \mathrm{Pb}, \mathrm{Al}, \mathrm{Fe}, \mathrm{Mn}, \mathrm{As})$, for which average sample concentrations were at least three times higher than instrument blank concentrations (Table 4.1).

The raw ICPMS values were first corrected for drift by adjusting for changes in the internal standard (In), then re-calibrated using a robust linear fit, based on a bisquare method of weighting the residuals to ensure that calibration curves were statistically evaluating outliers [Huber, 1981]. A run blank (average of $>10$ run blanks from each run) was subtracted from the re-calibrated sample concentrations to correct for machine background. The quantification limits were determined as three times the standard deviation of the average run blank, and the elements that are the focus of this paper are all above this limit. The concentration of each element in each individual sample was compared to the element standard deviation over the whole run. Sample element concentrations more than five times the run standard deviation were labeled as outliers and not considered in the results. Individual elements outliers were removed from 4 or fewer samples out of $160(2.5 \%)$ in the snow tray dataset, and from 5 or fewer samples out of $150(3.3 \%)$ in the snow pit dataset. Finally, the average of the individual snow precipitation samples (up to four samples from each day) was calculated to produce average daily concentrations. 


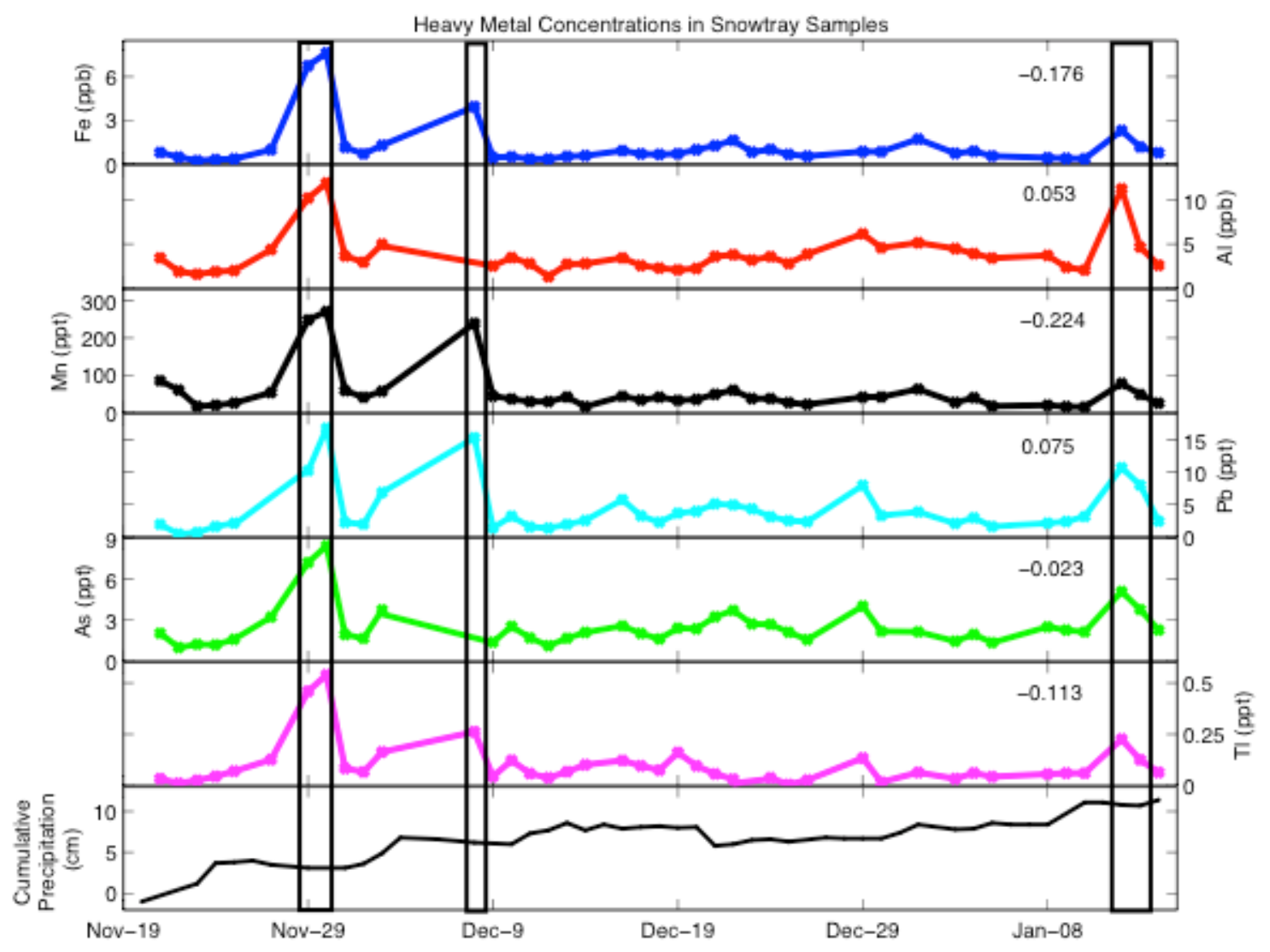

Figure 4.2. Concentrations of heavy metals from collection of daily snow precipitation during austral summer 2011-2012. Boxes indicate days when fog persisted all day accompanied by extensive rime ice growth.

\subsubsection{Snow Precipitation at Roosevelt Island}

Over the daily sampling period at Roosevelt Island, wind speeds ranged from $1 \mathrm{~m} / \mathrm{s}$ to $9 \mathrm{~m} / \mathrm{s}$, and temperatures ranged from $-2^{\circ} \mathrm{C}$ to $-14^{\circ} \mathrm{C}$. Out of the total observational period of 70 days, no snow accumulated on the trays during 28 days (40\%) - mainly occurring over a two-week period of clear weather from $6^{\text {th }}$ to $21^{\text {st }}$ November 2011. During 16 (23\%) recorded days drifting or blowing snow was observed, which generally occurred soon after a snow precipitation event when there was uncompacted snow and an average wind speed $>5 \mathrm{~m} / \mathrm{s}$. For 20 days (28\%) fresh snowfall was observed during the 24-hour sampling period. On 20 days (28\%) fog occurred for at least three hours, and rime ice usually developed during these conditions. See Supplementary Table 4.ST1 for daily observations. Observations of the rime ice coating undisturbed winterized equipment at Roosevelt Island revealed growth of $>0.5 \mathrm{~m}$ thickness, suggesting rime ice growth likely occurs throughout the year. Further evidence for extensive rime ice growth comes from the RICE Automatic Weather Station (AWS). During the winter months, the RICE AWS records warmer 
temperatures than expected from the nearby Margaret AWS. A recent study shows that coastal ice rises in Dronning Maud Land experience higher winter temperatures than the surrounding ice shelves as they are elevated above the cold inversion layer over the surrounding ice shelves, and that orographic uplift of moist air contributes to variable surface mass balance across the ice rise [Lenaerts et al., 2014]. These processes might also be important at Roosevelt Island, and may contribute to the formation of rime ice in the winter and to observed variable annual layer thicknesses.

Metal concentrations from daily precipitation are shown in Figure 2 for $\mathrm{Fe}, \mathrm{Mn}, \mathrm{Al}, \mathrm{As}, \mathrm{Tl}$, and $\mathrm{Pb}$. There are three major peaks in the snow precipitation concentrations, occurring from $29-30^{\text {th }}$ November 2011, 8-9 $9^{\text {th }}$ December 2011, and 13 $3^{\text {th }}$ January 2012 (Figure 4.2). These three events all occurred on days when fog persisted for the entire day, and wind speeds were at least $3 \mathrm{~m} / \mathrm{s}$. Extensive rime ice growth was observed throughout the camp during each of these three events, particularly for the event 29-30 November, and contributed significantly to the snow precipitation samples collected. Both fog and rime ice growth are known to be very effective contributors of aerosol impurities [Blas et al., 2010; Wolff et al., 1998]. Although fog and increased wind speeds occurred on other days throughout the snow sampling period, these conditions did not persist for more than a few hours. While rime was observed in the snow samples on other foggy days, it made only a minor contribution to the samples. We evaluate contamination of the snow precipitation samples as unlikely, as each daily sample represents an average of two to four individual samples, from which outliers have been removed.

In addition to snow precipitation sampling, daily accumulation measurements were made at a grid of 25 snow stakes covering $25 \mathrm{~m}^{2}$ that was located $\sim 100 \mathrm{~m}$ away from the snow sampling site. The amount of snowfall during an event can influence the concentrations of elements that are deposited with precipitation [Alley et al., 1995; Kreutz et al., 2000; Wolff et al., 1998]. We calculated the correlation between daily accumulation and daily concentration for each metal discussed here, and the r-values are indicated in Figure 4.2. None of the heavy metal elements have a significant correlation with daily accumulation, implying that there is no dilution effect. Moreover, the three peaks in concentration occur on days with minimal accumulation.

To test for a link between heavy metal concentrations and rime ice, we calculated the linear correlation between daily precipitation samples and wind speed from weather observations (Table 4.2). While the r-values are not high, concentrations of metals Fe, Mn, As, and Tl show positive correlations with wind speed at the $95 \%$ significance level, while $\mathrm{Al}$ and $\mathrm{Pb}$ show no statistically 
significant relationships. Other crustal elements ( $\mathrm{La}$ and $\mathrm{Ce}$ ) (Table 4.2) also show positive correlations, significant at the $95 \%$ level. The variability in concentrations explained by the wind speed is low, indicating that other environmental factors also affect heavy metal concentrations in snow at Roosevelt Island. However, modeling studies have shown that light to moderate wind speeds promote the growth of rime ice, through the impaction of water droplets [Makkonen, 2000]. Hence, the presence of statistically significant correlations supports a link between rime (type of snow precipitation) and heavy metal concentration.

Table 4.1. Heavy metal data statistics

\begin{tabular}{|l|c|c|c|c|c|c|}
\hline & $\begin{array}{c}\text { Snow } \\
\text { Precipitation } \\
\text { Average } \\
(\mathrm{ppt})\end{array}$ & $\sigma$ & $\begin{array}{c}\text { Snow Pit } \\
\text { Average } \\
(\mathrm{ppt})\end{array}$ & $\sigma$ & $\begin{array}{c}\text { Instrument } \\
\text { Blank } \\
\text { Average (ppt) } \\
(\mathrm{n}=18)\end{array}$ & $\begin{array}{c}\text { Vial Blank } \\
\text { Average } \\
(\mathrm{ppt})(\mathrm{n}=5)\end{array}$ \\
\hline${ }^{23} \mathrm{Na}$ & 3047340 & 349014 & 236547 & 241020 & 747.7 & 263.0 \\
\hline${ }^{88} \mathrm{Sr}$ & 261.2 & 273.6 & 205.3 & 180.9 & 0.270 & 2.49 \\
\hline${ }^{139} \mathrm{La}$ & 1.22 & 1.90 & 0.225 & 0.186 & 0.012 & 0.004 \\
\hline${ }^{140} \mathrm{Ce}$ & 2.386 & 3.938 & 0.479 & 0.397 & 0.025 & 0.005 \\
\hline${ }^{205} \mathrm{Tl}$ & 0.099 & 0.108 & 0.045 & 0.029 & 0.077 & 0.001 \\
\hline${ }^{208} \mathrm{~Pb}$ & 4.084 & 3.659 & 2.406 & 1.523 & 0.386 & 0.001 \\
\hline${ }^{27} \mathrm{Al}$ & 3821 & 2380 & 498.2 & 242.1 & 58.2 & 115.2 \\
\hline${ }^{55} \mathrm{Mn}$ & 54.3 & 59.0 & 23.5 & 20.4 & 2.01 & 2.81 \\
\hline${ }^{56} \mathrm{Fe}$ & 1154 & 1532 & 485.3 & 257.4 & 36.6 & 33.6 \\
\hline${ }^{75} \mathrm{As}$ & 2.56 & 1.52 & 1.17 & 0.532 & 0.366 & 0.346 \\
\hline \multicolumn{7}{|c|}{$\mathrm{Note}:{ }^{23} \mathrm{Na},{ }^{88} \mathrm{Sr},{ }^{139} \mathrm{La},{ }^{140} \mathrm{Ce},{ }^{205} \mathrm{Tl}$, and ${ }^{208} \mathrm{~Pb}$ were analysed in low resolution. ${ }^{27} \mathrm{Al},{ }^{55} \mathrm{Mn},{ }^{56} \mathrm{Fe}$} \\
\\
were analysed in medium resolution. ${ }^{75}$ As was analysed in high resolution. \\
\hline
\end{tabular}

\subsubsection{Scavenging efficiency of different snow precipitation}

Clear sky precipitation (diamond dust) dominates in the interior of Antarctica [Bromwich, 1988], whereas it is only a minor contributor along coastal regions, where snowfall is the dominant form of deposition [Sinclair et al., 2010]. West Antarctica, and particularly the Ross Sea region are heavily influenced by cyclonic activity that intrudes into West Antarctica, delivering heat and moisture [Dixon et al., 2012; Nicolas and Bromwich, 2011]. Variation in moisture delivery and snow accumulation in West Antarctica is tied to the coupling between the SAM and ENSO [Cohen et al., 2013; Sasgen et al., 2010]. In general, cyclonic systems near the Antarctic coast travel from lower latitudes, although some regions, such as the Ross Sea, are particularly known for mesoscale cyclogenesis [Hoskins and Hodges, 2005]. This is closely related to the track of synoptic-scale cyclone systems which vary seasonally, and interaction with katabatic air flow from major outlet glaciers [Bromwich, 1991; Carraso et al., 2003]. 
Previous research on trace element concentrations in snow has indicated that forms of wet deposition (deposition associated with snow) are the dominant source of impurities (particularly crustal elements) in coastal polar snow [Davidson et al., 1981]. However, dry deposition, involving the incorporation of aerosols and particulates into the snow pack without precipitation can contribute between $10 \%$ and $25 \%$ of chemical impurities in snow, and these mechanisms increase in relative importance with decreasing annual accumulation [Davidson et al., 1981; Gabrielli et al., 2006; Wolff et al., 1998]. In high-accumulation sites studies that examine the deposition types have shown that fresh snowfall is generally related to the highest trace element concentrations [Kreutz et al., 2000; Wolff et al., 1998]. However, at sites where rime ice growth is prevalent, it can be a major contributor to trace element concentration due to its high scavenging efficiency [Duncan, 1992; Schwikowski et al., 2004]. Rime forms in clouds as droplets of super-cooled water that impact snowflakes and can increase the specific surface area of the snowflake by $20 \%$ or more [Fassnacht et al., 1999; Makkonen, 2000; Rango et al., 2003], increasing the potential for particulate scavenging. Rime also forms at the snow surface where super-cooled cloud droplets impact the surface topography and the accumulation of droplets can lead to needle or plate-like growth with low densities and high specific surface areas [Berg et al., 1991; Fassnacht et al., 1999; Macklin, 1962]. Extensively rimed snow crystals have been found to be more acidic than un-rimed crystals and have higher ion concentrations [Puxbaum and Tscherwenka, 1998]. Fog has also been recorded as having higher trace chemical concentrations than other precipitation [Wolff et al., 1998]. Although the contribution of fog in many areas in Antarctica is generally low, at Roosevelt Island fog with rime formation occurred on $28 \%$ of the recorded days over the 2011-2012 summer, suggesting that fog and riming may contribute more strongly to the heavy metal concentrations in the permanent snowpack. The site at Roosevelt Island was occupied during summer from 20102015. Fog was frequently observed during each field season and was the most prominent cause of flight delays to the site [Bertler, personal communication]. The high number of fog days at Roosevelt Island may be due to the proximity of the Ross Shelf polynya (RSP), which is an open water source to Roosevelt Island for most of the year [Comiso et al., 2011]. The combination of cold conditions and water vapor availability from a seasonally open ocean during summer and autumn, and the polynya throughout most of the year, create ideal conditions for rime development [Comiso et al., 2011; Hong et al., 1994]. Though the location and size of the RSP cannot be assumed to be stationary through time, this study demonstrates a link between heavy metal concentrations in new precipitation and the frequency of rime and fog. This implies that, in coastal Antarctic locations, heavy metal time series may be influenced by changes in the frequency of rime or fog in addition to atmospheric transport and emission source changes. 


\subsubsection{Back Trajectory Modeling}

Modeling the pathway of air masses delivering precipitation to Roosevelt Island is useful for inferring possible source regions and for understanding the relative importance of atmospheric systems (e.g. katabatic air flow vs oceanic cyclonic). The Hybrid Single Particle Lagrangian Integrated Trajectory (HySPLIT) software is a National Oceanic and Atmospheric Administration (NOAA) product that computes air-parcel trajectories. For modeling daily back trajectories from Roosevelt Island, the European Centre for Medium-Range Weather Forecasting (ECMWF) ERA Interim data are used, as recent studies have shown that this reanalysis dataset is the most accurate for the Antarctic [Bracegirdle and Marshall, 2012; Bromwich et al., 2007]. Back-trajectories were initiated at $0000 \mathrm{hrs}, 0600 \mathrm{hrs}$ and $0900 \mathrm{hrs}$ for each day that samples were collected (41 days, 123 total trajectories), at $1000 \mathrm{~m}$ above ground level (AGL), and they were run for the previous 5 days (120 hours). Three trajectories per day ensured that the air masses associated with each $24 \mathrm{hr}$ precipitation sample were captured. The initiation height of back-trajectories has been shown to influence the vertical path of modeled air masses: initiation heights of 500m AGL are affected by surface topography, while initiation heights of $1500 \mathrm{~m}$ are above the katabatic layer and are more representative of regional/synoptic scale air masses [Markle et al., 2012; Sinclair et al., 2010]. We have tested the effect of initiation heights at $500 \mathrm{~m}, 1000 \mathrm{~m}$, and $1500 \mathrm{~m}$ on our trajectories and confirmed they are spatially consistent. Because our focus is on air masses responsible for precipitation at Roosevelt Island, we have chosen $1000 \mathrm{~m}$ as the initiation height for our backtrajectories to retain some links with the surface, but to avoid the influence of surface topography which is only imperfectly represented in the reanalysis data [Dee et al., 2011].

The HySLPIT software uses a k-means clustering algorithm to group trajectories [Draxler and Hess, 1997; 1998]. The clustering process calculates the spatial variance between trajectories grouped within each cluster, then for each iteration of clusters, the total spatial variance (TSV) sums the cluster spatial variance across all the clusters [Baker, 2010]. As each iteration progresses, clusters are combined in an order that results in the lowest increase in TSV. Towards the end of the iterations there is a large increase in the TSV, indicating that the clusters being combined are not very similar [Baker, 2010]. The optimum number of clusters is the iteration just prior to the increase in TSV [Baker, 2010].

For the trajectories initiated here, we have determined that three clusters are sufficient to capture the 2012 summer trajectory variability (Figure 4.3). These clusters incorporate a local component comprising $54 \%$ of summer trajectories, a long-range oceanic component comprising $17 \%$ of trajectories, and a cluster of $28 \%$ of trajectories from the West Antarctic/Amundsen-Bellingshausen 
Sea region (Figure 4.3). When these trajectories are extended from five days to ten days we observe that the West Antarctic pathway comprises air masses located within the South Pacific sector, while the long-range oceanic pathway comprises fast moving systems that have travelled long distances over the Southern Ocean before moving into the Ross Sea region (Figure 4.3). The summer trajectory clusters compare well to previously published data on the synoptic systems and back trajectory pathways in the Ross Sea region [Markle et al., 2012; Sinclair et al., 2013]. Both Markle et al. (2012) and Sinclair et al. (2013) investigated back-trajectory pathways from ice core sites in Victoria Land. Their results indicated that air masses were sourced from regions over both East and West Antarctica, as well as the Southern Ocean. As Roosevelt Island is located further east (towards West Antarctica) than the sites discussed in Markle et al. (2012) and Sinclair et al. (2013), we expect air flow will more commonly come from the Southern Ocean and West Antarctica [Carraso et al., 2003; Nicolas and Bromwich, 2011]. The results from our clustered summer trajectories support this, indicating that summer moisture delivery to Roosevelt Island is commonly derived from local and long-distance oceanic pathways, and very few pathways pass over East Antarctica.
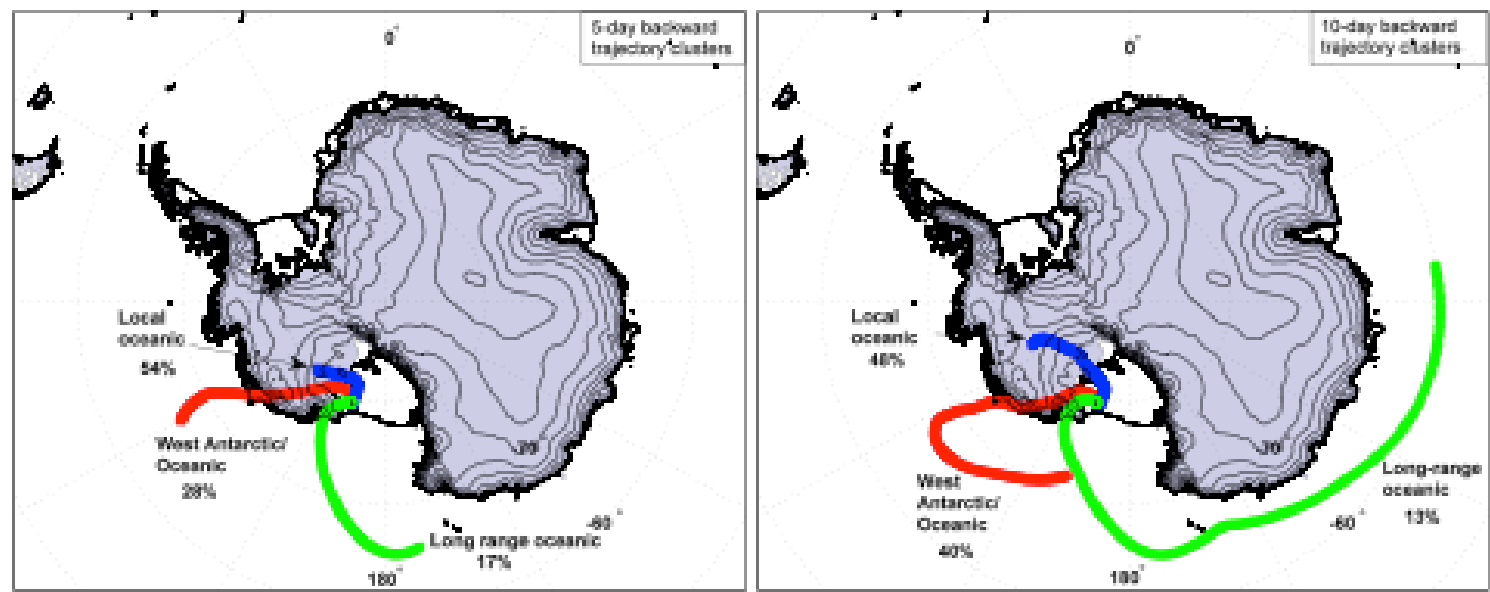

Figure 4.3. HySPLIT clustered air mass pathways calculated from 123 back-trajectories from summer 2011-2012. Topographic data from Timmerman et al. (2010).

All the back-trajectories were generated on the days that surface snow samples were collected, linking the daily snow concentrations to airmass trajectories. Each trajectory cluster can then be compared to the corresponding average surface snow concentration, to determine if different mean trajectories influence the delivery of impurities to Roosevelt Island. Figure 4.4 displays the normalized mean concentrations of the heavy metal elements per cluster, as well as selected sea-salt and crustal associated elements. The highest concentrations of heavy metals in our summer precipitation samples are associated with air masses clustered within the West Antarctic / Oceanic trajectory (Figure 4.4). Figure 4.3 indicates that these air masses transport aerosols from the SouthPacific sector of the Southern Ocean through the Amundsen / Bellingshausen Sea area and West 
Antarctica. These air masses thus have the potential to capture mineral particulates transported into the South Pacific from mid-latitude continental regions such as South America or Australia. Conversely, sea-salt-associated elements such as $\mathrm{Na}, \mathrm{S}$, and $\mathrm{Sr}$ show the highest concentrations with the Long-Range Oceanic pathway (Figure 4.4). This suggests that the faster moving oceanic trajectories are more highly salt-laden compared to the other pathways, though these pathways may also deliver particulates from the South Indian sector. Coastal sea salt aerosols consist of large particles, which contribute to deposition in high concentrations near the coast and lower concentrations with increasing distance from the source [Kerminen et al., 2000]. This relationship has previously been described across the Antarctic continent as sea salt concentrations were found to show a negative correlation with elevation and distance from the coast [Bertler et al., 2006; Dixon et al., 2013].

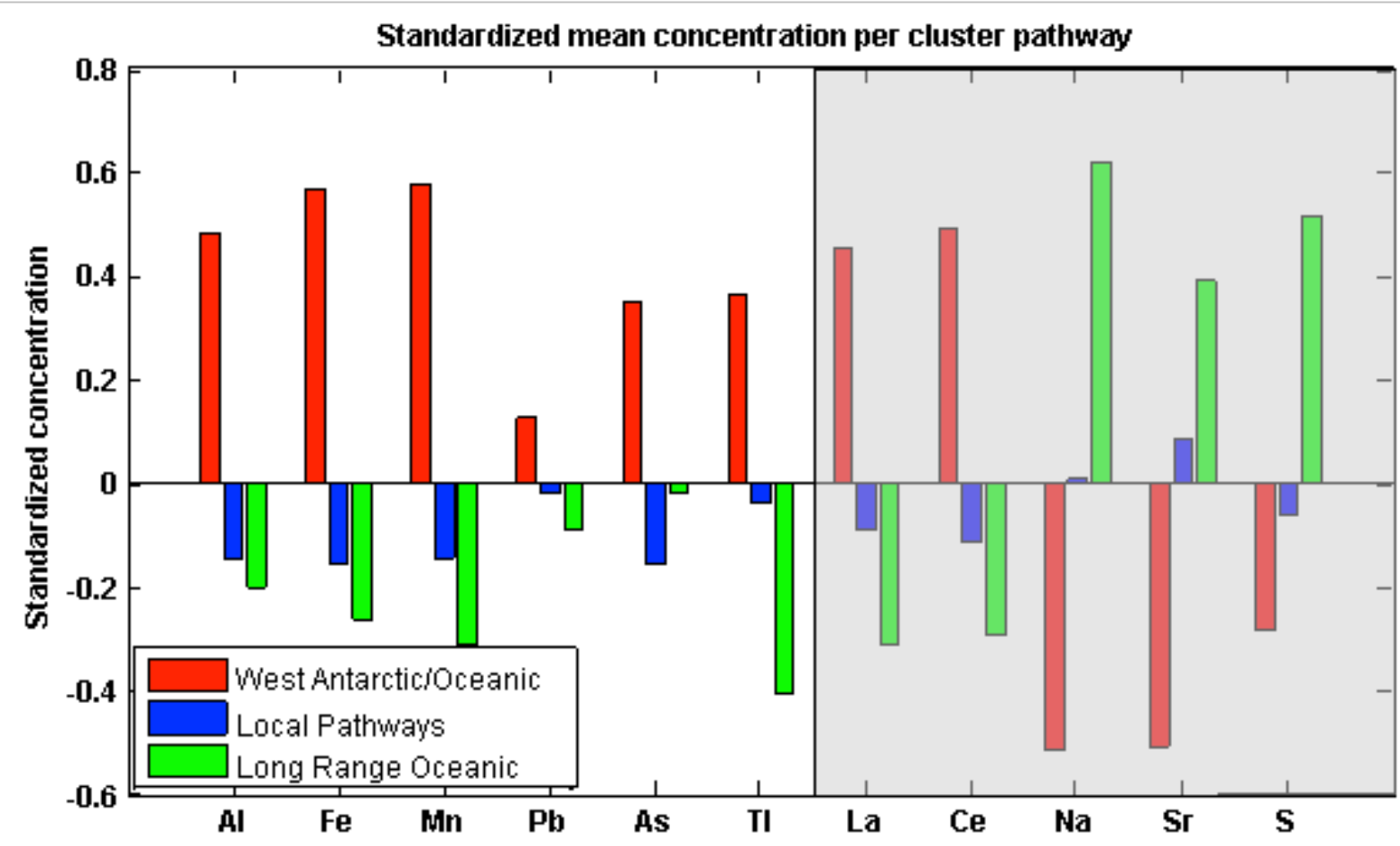

Figure 4.4. Bar graph comparing the normalized average concentrations of heavy metal elements per air mass pathway. Grey bar highlights selected crustal and marine associated elements for comparison.

The association of higher heavy metal concentrations with West Antarctic - South Pacific oceanic air masses suggests the Roosevelt Island heavy metal record is representative of the regional background concentrations of these elements, although this does not rule out the potential for some contribution from local/or West Antarctic dust sources. The link between higher concentrations of heavy metals and air masses from the South Pacific suggests that an ice core time-series of heavy metals from Roosevelt Island will be sensitive to changes in the strength and position of the Amundsen Sea Low (ASL), and other atmospheric circulation features such as the Southern 
Annular Mode and the El Nino Southern Oscillation [Fogt et al., 2009; Hosking et al., 2013; Turner, 2004].

The relationship between heavy metal concentrations and West Antarctic airmass pathways can be tested by comparing snow pit concentrations of heavy metals with daily trajectories covering the time period captured in the snow pit. Using HySPLIT, daily trajectories from September 2006 to January 2012 were plotted and then clustered over spring (September-November), summer (December-January), autumn (March-May) and winter (June-August) throughout this time period (Figure 4.5). There is some spatial difference between the 2012 summer pathways and the average summer pathways between 2006 and 2012, although the directional components are the same (Figures 4.3, 4.5). The seasonal clusters show that summer and spring each have three components - local, long-range oceanic and West Antarctic. Spring has more clusters based on the increase in TSV (Supplementary Figure 4.S2), however, the overall characteristics are the same as the summer clusters. Winter and autumn pathways also have the same three components, as well as a fourth component delivering southerly air from the Antarctic interior. This component most likely represents katabatic air flow to Roosevelt Island.

By investigating the main clusters of air mass trajectories for each season between 2006 and 2012 we have created an air mass transport framework that we can use to interpret the changes in heavy metal concentrations in snow pit samples. 


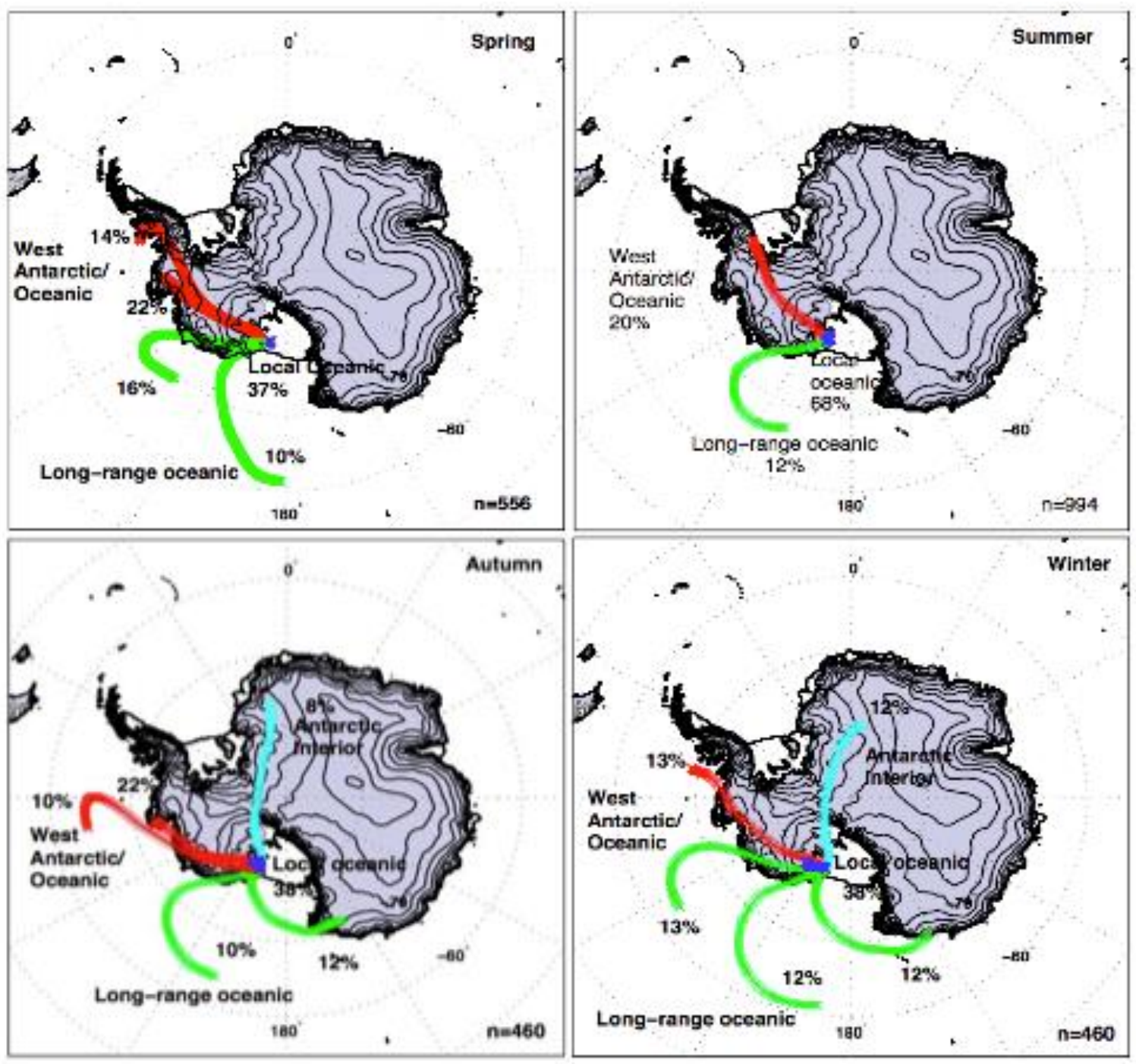

Figure 4.5. HySPLIT seasonal clusters of daily 5-day back-trajectories from 2006 to 2012. Percentage of daily trajectories included in each cluster is indicated, number of daily trajectories for each season is indicated at bottom right of each panel. Topographic data from Timmerman et al. (2010).

\subsection{Snowpack Dating}

The dating of the snow pit was based on multiple parameters including stable isotope $\delta^{18} \mathrm{O}$ measurements and concentrations of sulfur, uranium, strontium. Highest weighting was given to sulfur, which shows sharp, well-defined summer peaks (Figure 4.6). Annual snow-stake measurements began in November 2010, and for the 2010-2011 year recorded $82 \mathrm{~cm}$ of accumulation (H. Conway, personal communication 2015). Years determined as $1^{\text {st }}$ January were positioned where sulfur peaks aligned with peaks or shoulders of peaks in the $\delta^{18} \mathrm{O}$ record. Winters were determined as $1^{\text {st }}$ July where a sulfur trough aligned with a $\delta^{18} \mathrm{O}$ trough. Years were assigned full certainty where all dating parameters agreed. We have classified one year as uncertain (summer 2010 , at $110 \mathrm{~cm}$ depth from surface). This year is included after comparison to other shallow firn cores spanning the same snow depths from the RICE site, for which $\mathrm{SO}_{4}$ measurements are 
available. The data from these other cores suggests that the peak at $110 \mathrm{~cm}$ in the snow pit should be counted as a summer layer, and we thus assign an age uncertainty of \pm 0.5 year to the age model. Hence, the age scale indicates that the snow pit covers just over six years from late 2005 to January 2012, and a linear interpolation was used to assign a calendar age to each heavy metal sample.

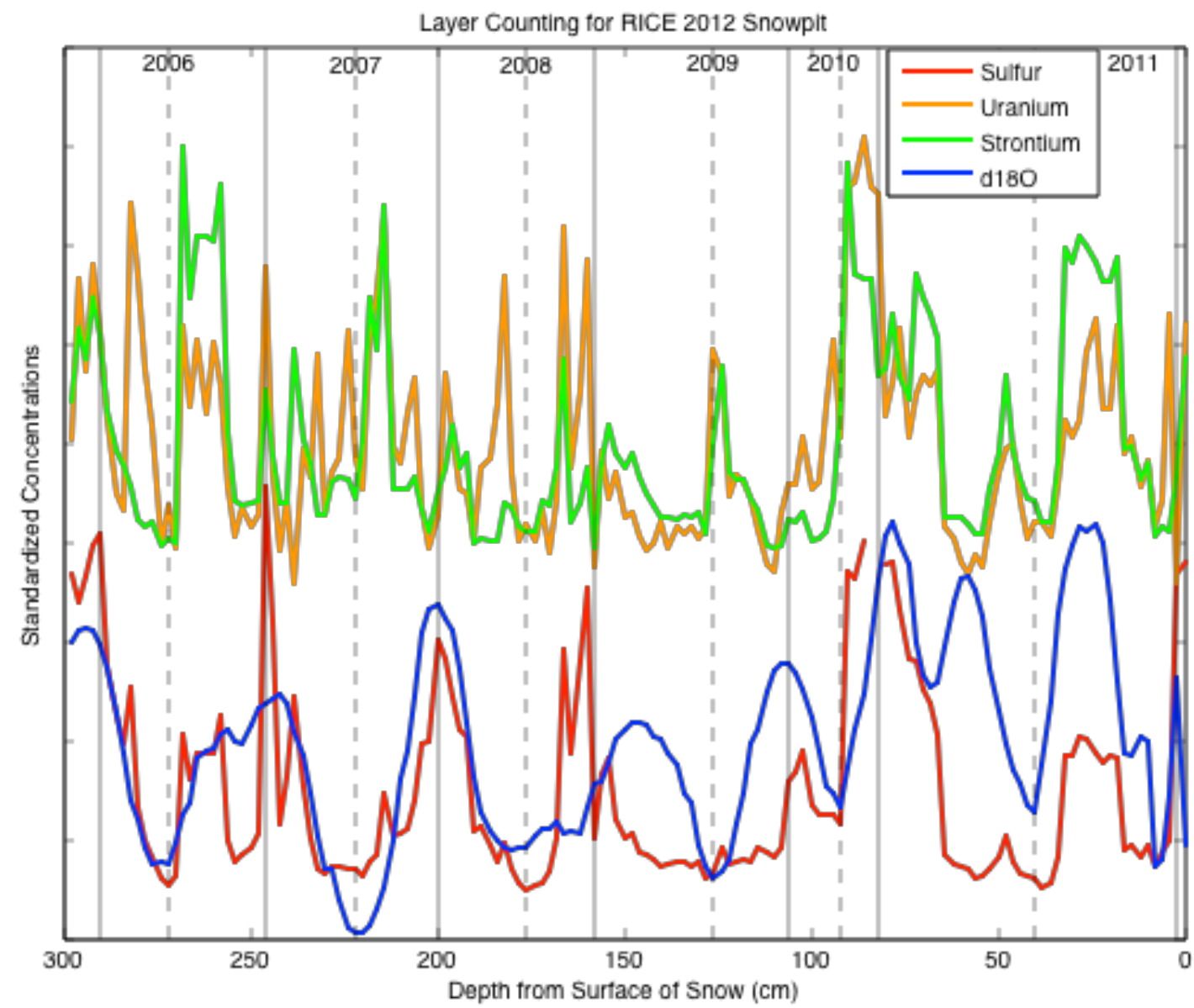

Figure 4.6. Chemistry data contributing to snow pit age model. Solid vertical lines indicate January (summer), dashed vertical lines indicate July (winter).

\subsection{Snowpack Concentration and Flux}

The variability and average concentration of the heavy metals are lower in the snow pit samples than the daily precipitation samples (Figure 4.7). As discussed above, the highest concentrations in the daily samples are sensitive to the type of precipitation in addition to atmospheric concentrations. However, the lack of equally high concentrations in the snow pit suggests that post-depositional processes also influence the heavy metals in the snow pack. Wind-driven blowing and drifting snow re-distribute fresh precipitation over wide areas; and when coupled with ablation, can remove significant amounts of snow at storm event scales [Pomeroy and Jones, 1996]. At Roosevelt Island, drifting and blowing snow was observed on 16 out of $70(23 \%)$ days when samples were taken. In some instances, these events led to the removal of all recently precipitated snow, in particular lowdensity material, such as rimed surfaces. Local snow accumulation was measured over a $5 \mathrm{~m}$ by $5 \mathrm{~m}$ grid of stakes at the same time as daily surface snow sampling, and over the eight-week period total 
snow accumulation was $20.5 \mathrm{~cm}$, and snow loss was $8.2 \mathrm{~cm}$, with a net snow accumulation of $12.3 \mathrm{~cm}$ (Figure 4.2 ). This suggests that up to $40 \%$ of the snowfall may be lost to redistribution and ablation, with the effect of smoothing the average heavy metal concentration signal in the snow pit. Estimates of Antarctic snow accumulation lost to redistribution and ablation vary greatly (20\% to 60\%) depending on local conditions [Frezzotti et al., 2004; Visbeck and Hall, 2004]. Given the relatively low wind speeds recorded during summer at Roosevelt Island, this basic calculation of snow loss does not seem unreasonable, though further monitoring would allow a better estimate of snow accumulation and loss over longer temporal scales. Melting does not appear to be a common occurrence at Roosevelt Island, and no melt layers were observed in the $3 \mathrm{~m}$ snow pit.

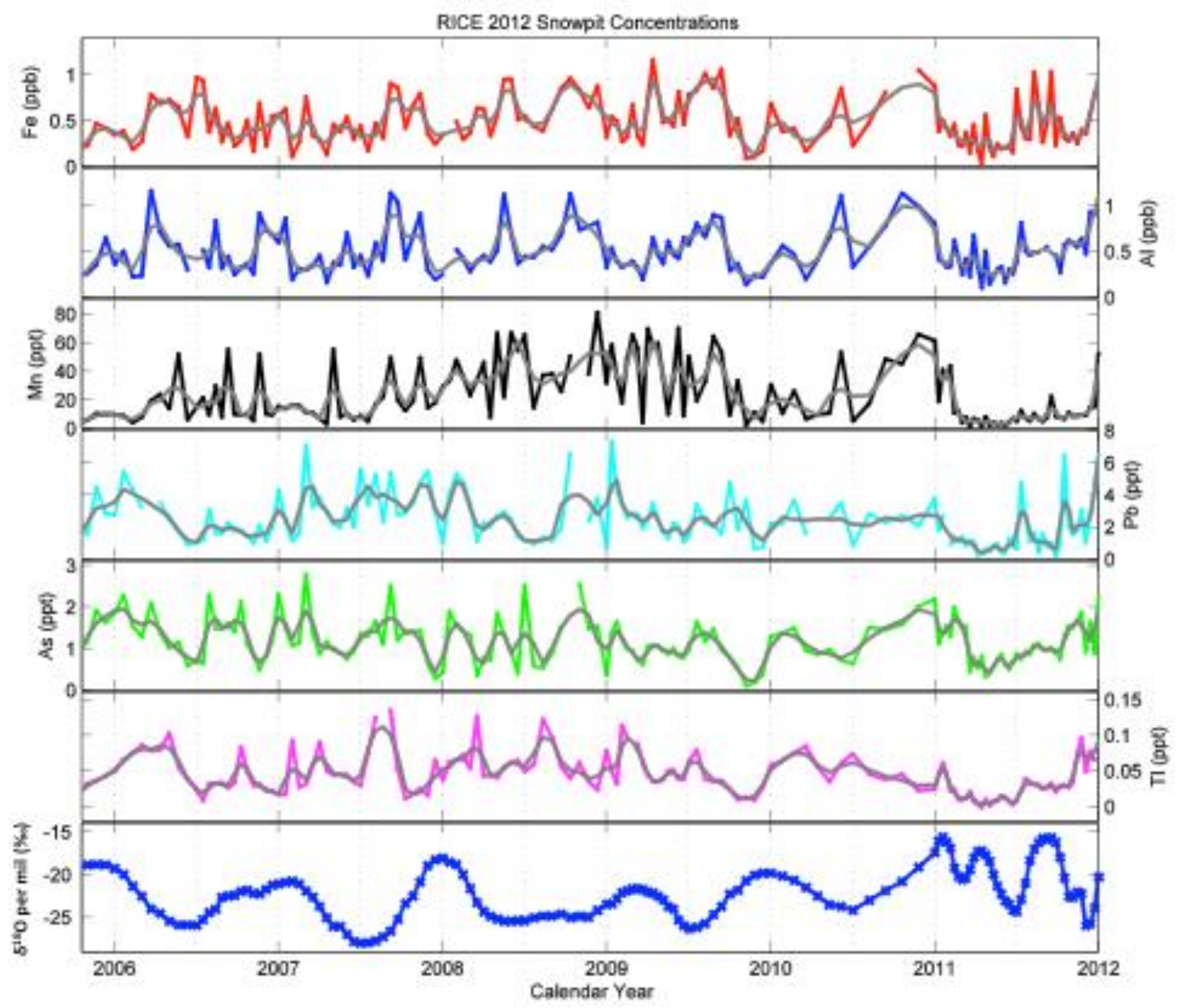

Figure 4.7. RICE snow pit concentrations of heavy metals, $n=150$. Colored lines indicate raw values, grey line indicates 5-point smoothed values.

For the permanent snowpack (and therefore ice cores) to reliably record the seasonal heavy metal concentrations there must be adequate preservation of monthly to annual precipitation. Although there are many processes involved in the metamorphism of surface snow in Antarctica, in general, layers with lower density are associated with rime and sub-surface hoar [Alley, 1988; Colbeck, 1982; Dadic et al., 2008; Hanot and Domine, 1999]. In particular, the formation of sub-surface hoar 
can alter trace element chemistry in the snow [Alley et al., 1990]. The snow pit at Roosevelt Island consists of alternating layers of higher density wind compacted snow and lower density layers (Figure 4.8). Post-depositional metamorphism of snow into hoar is characterized by cup-shaped crystals or chains [Domine et al., 2003]. We do not observe cup-shaped crystals in the snow, arguing that the lower density layers do not represent sub-surface hoar and are simply low-density precipitation. This suggests that a range of snow precipitation is preserved in the snow pack, and that the lower density layers likely include some rime. Preservation of rime may occur during large precipitation events that rapidly bury lower density snow before wind redistribution can remove all new snow. Although the links between changes in snow chemistry and snow metamorphism remain poorly understood, higher concentrations of impurities have been associated with low-density layers at other sites [Alley et al., 1990; Domine et al., 2009; Hörhold et al., 2011]. We observe negative correlations (significant at 95\%) between crustal associated elements (Al, Fe, Mn, La, and Ce) and snow density (Table 4.2). These correlations suggest that the low-density (higher concentration) layers are formed through large precipitation storm events, and we expect these elements to be strongly associated with snowfall and wet deposition.

Snow Density and Accumulation

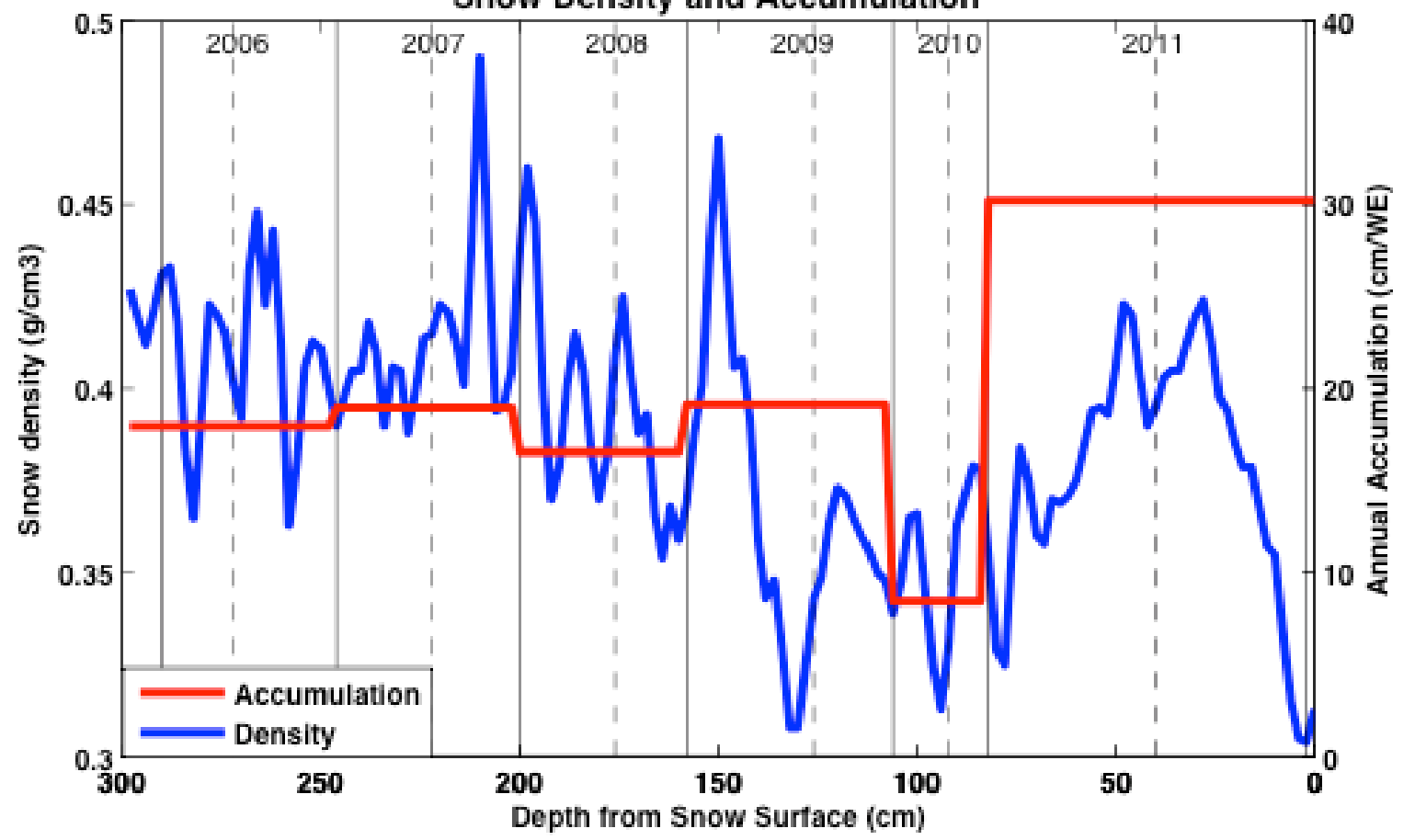

Figure 4.8. Measured snow pit density and calculated annual accumulation in water equivalent. Solid vertical lines indicate January (summer), dashed vertical lines indicate July (winter).

We can infer that trace elements are primarily deposited through wet deposition if there is a positive correlation between the annual flux rate of the element and the annual accumulation [Alley et al., 1995; Kreutz and Mayewski, 1999; Witherow et al., 2006]. The annual trace element flux is defined as the average concentration per year, multiplied by the accumulation in water equivalent for that 
year [Witherow et al., 2006]. For wet-deposited trace elements the flux will be higher for years when there is high accumulation (Supplementary Figure 4.S1). Element flux rates that do not correlate with accumulation are affected more by dry deposition mechanisms. The heavy metals Al, $\mathrm{Fe}$, and As all show strong positive correlations between annual flux and accumulation, as do La and Ce (Table 4.2). This indicates that the concentrations of these elements are strongly linked to the amount of snowfall per year at Roosevelt Island. Elements $\mathrm{Mn}, \mathrm{Pb}$, and $\mathrm{Tl}$ also show positive correlations, though these are not as strong, suggesting that dry deposition may contribute more to the concentrations of these elements at RICE [Cunningham and Waddington, 1993]. The phases in which an element is present will affect the primary mechanism of deposition. Heavy metals can be present in snow either bound to particulates, or with some proportion present in dissolved aerosols [Grotti et al., 2011]. Grotti et al. [2011] suggest that about 90\% of $\mathrm{Al}$ and $\mathrm{Fe}$ is present as particulates, whereas $\sim 50 \%$ of $\mathrm{Mn}$ and $\mathrm{Pb}$ are present in both dissolved and particulate phases.

The complexity of the heavy metal annual signal in the snow pit may be related to the variability of annual precipitation, atmospheric transport, and trace element sources (Figure 4.7). The heavy metals (except $\mathrm{Tl}$ ) tend to have a consistent late-spring to early summer peak in concentrations (Figure 4.7). In addition to this early summer peak are intra-annual peaks occurring at variable times. Crustal dust related elements $\mathrm{Fe}$, and Al have one to two intra-annual peaks occurring in early to late winter and the timing of these peaks is consistent between these two elements. Mn is also known to derive from crustal dust, and the general timing of early summer peaks is similar to $\mathrm{Fe}$ and Al [Velasco, 1995]. However, Mn displays higher variability in concentration, and the timing of intra-annual peaks is not always consistent with $\mathrm{Fe}$ and $\mathrm{Al}$. $\mathrm{Pb}$, and $\mathrm{As}$ concentrations also show an early summer peak and two to three intra-annual peaks which do not coincide with Al and Fe. Tl peaks tend to occur in autumn rather than summer, with a second peak occurring in spring. The differences in the timing of seasonal concentration peaks between the heavy metals suggests that different sources may be contributing to the different metals. 
Table 4.2. Pearson's linear correlation coefficients between snow precipitation and wind speed, snow pit concentration/flux and accumulation, and average concentrations of snow pit peaks and troughs. Significant $r$-values at $95 \%$ level are indicated by bold text.

\begin{tabular}{|l|c|c|c|c|c|c|c|c|}
\hline & $\begin{array}{c}\text { Snow Precip } \\
\text { Concentration } \\
\text { and Wind } \\
\text { Speed }\end{array}$ & $\begin{array}{c}\text { Snowpit Flux } \\
\text { and } \\
\text { Accumulation }\end{array}$ & $\begin{array}{c}\text { Snowpit } \\
\text { Concentration } \\
\text { and Density }\end{array}$ & $\begin{array}{c}\text { Snowpit } \\
\text { Avg } \\
\text { Enrichment } \\
\text { Factor (/La) }\end{array}$ & \multicolumn{3}{|c|}{ Snctry } \\
\hline & r-value & r-value & r-value & Crustal EFc & Peaks & Lows & Difference & Std Dev \\
\hline $\mathrm{Fe}$ & $\mathbf{0 . 3 6}$ & $\mathbf{0 . 8 9}$ & $\mathbf{- 0 . 3 7}$ & 3.27 & 805.0 & 317.3 & 487.8 & 242.1 \\
\hline $\mathrm{Al}$ & 0.23 & $\mathbf{0 . 9 8}$ & $\mathbf{- 0 . 3 2}$ & 1.38 & 774.4 & 345.9 & 428.5 & 257.4 \\
\hline $\mathrm{Mn}$ & $\mathbf{0 . 3 2}$ & 0.14 & $\mathbf{- 0 . 2 8}$ & 9.66 & 44.1 & 14.2 & 29.9 & 20.4 \\
\hline $\mathrm{Pb}$ & 0.17 & 0.67 & -0.01 & 32.24 & 5.63 & 1.08 & 4.55 & 1.52 \\
\hline $\mathrm{As}$ & $\mathbf{0 . 3 2}$ & $\mathbf{0 . 9 3}$ & -0.01 & 146 & 1.74 & 0.63 & 1.12 & 0.53 \\
\hline $\mathrm{Tl}$ & $\mathbf{0 . 3 2}$ & 0.52 & -0.04 & 14.5 & 0.10 & 0.02 & 0.08 & 0.03 \\
\hline $\mathrm{La}$ & $\mathbf{0 . 3 2}$ & $\mathbf{0 . 7 4}$ & $\mathbf{- 0 . 3 2}$ & - & 0.48 & 0.08 & 0.40 & 0.19 \\
\hline $\mathrm{Ce}$ & $\mathbf{0 . 3 4}$ & $\mathbf{0 . 7 8}$ & $\mathbf{- 0 . 3 2}$ & 1.05 & 0.93 & 0.16 & 0.77 & 0.40 \\
\hline
\end{tabular}

The contribution from crustal dust to the heavy metal concentrations found in the snow pit can be evaluated by calculating enrichment factors $(\mathrm{EFc})$ that have been normalized to average upper crust concentrations [Gabrielli et al., 2005; Wedepohl, 1995]. We use La as a conservative tracer of crustal dust, and EFc values that are close to unity (less than 5) indicate that the primary source is crustal dust (Table 4.2) [Gabrielli et al., 2005]. We find that $\mathrm{Al}$ and $\mathrm{Fe}$ are primarily derived from crustal dust. Although $\mathrm{Mn}$ is generally reported to be derived solely from crustal dust, we find EFc values greater than 5 for $\mathrm{Mn}$ as well as for $\mathrm{Pb}$ and $\mathrm{Tl}$. This suggests that there are sources other than crustal dust particulates contributing to the concentrations of these elements in the RICE snowpack. A proportion of $\mathrm{Mn}$ and $\mathrm{Pb}$ are found in dissolved phases in Antarctic snow, and that the more volatile form leads to higher EFc values [Grotti et al., 2011; Reimann and De Caritat, 2000]. As has a very high EFc value indicating that very little As in RICE snow is derived from crustal dust. Previous literature has suggested that, in addition to emissions from volcanoes and marine aerosols, industrial anthropogenic emissions contribute to modern concentrations of $\mathrm{Pb}, \mathrm{As}$, and $\mathrm{Tl}$ in Antarctica [Hong et al., 2013; Hur et al., 2007; Hur et al., 2013; McConnell et al., 2014]. The variety of heavy metal sources will contribute to the complexity of the annual peaks in heavy metal concentrations, as emissions from multiple sources may peak at different times of the year.

The pattern of multiple annual peaks has been observed in the Lambert Glacier Basin area, and was linked to variable atmospheric transport and aerosol loading [Hur et al., 2007]. We suggest a similar mechanism occurs at Roosevelt Island. Summer peaks in concentration are related to higher aerosol loading, and intra-annual/winter peaks are associated with large precipitation events. Despite the change in atmospheric transport pathways between winter and summer at Roosevelt Island (Figure 4.5), there is not a significant change in the percentage of air masses following the West 
Antarctic/Oceanic pathway. However, this transport shift may contribute to variability in precipitation events and to seasonal wind speeds. Large precipitation events tend to occur more often during winter, and would lead to increased concentrations of Fe and Al in snow. Furthermore, winter and autumn generally experience higher wind speeds, which may increase the dry deposition proportion of $\mathrm{Tl}, \mathrm{Pb}$, and $\mathrm{Mn}$. Emissions of dust and heavy metal bearing particulates from Southern Hemisphere continental sources tend to peak in spring or summer [ $L i$ et al., 2008; Prospero et al., 2002; Werner et al., 2002]. Furthermore, summer peaks in dust-related trace elements have been found through aerosol monitoring at Neumayer station in East Antarctica [Weller et al., 2008]. The summer increase in dust emissions coupled with the change in atmospheric transport paths would increase the availability of aerosol particulates at Roosevelt Island, and could explain the higher summer concentrations.

In summary, the majority of heavy metal elements at Roosevelt Island are associated with wet deposition, although seasonal changes in concentration are not straightforward to interpret. Changes in aerosol loading and atmospheric transport paths, as well as the occurrence of large precipitation events contribute to generally higher metals concentrations in summer and winter. Though the annual patterns observed in the modern snow at RICE does not imply that these relationships have remained the same in the past, these data indicate that heavy metal concentrations are sensitive to changes in atmospheric transport and source. Hence time series of heavy metals can be used in conjunction with other ice core proxies to investigate changes in these environmental parameters in the Ross Sea Region in the past.

\subsection{Conclusions}

In addition to establishing the average modern concentrations of a range of transition metal/metalloid elements, the data from event-scale precipitation samples and the modern snow pack have enabled the determination of primary deposition mechanisms and transport pathways for heavy metals to Roosevelt Island. Daily snow precipitation samples show the highest concentrations of heavy metal elements with air mass pathways from the West Antarctic/South Pacific region, implying that concentrations at Roosevelt Island are representative of regional to hemispheric scale changes in background heavy metals. Heavy metal concentrations do not show a straightforward annual cycle, but approximately two main peaks per year, generally occurring in summer and in winter. The high inter- and intra- annual variability is linked to atmospheric transport changes and to variable accumulation. The heavy metals Al, Fe, and As, are strongly linked to wet deposition, while $\mathrm{Mn}, \mathrm{Pb}$, and $\mathrm{Tl}$, are likely influenced by dry deposition in addition to wet deposition. The higher summer concentrations appear to be related to the absence of katabatic air flow (present in 
winter trajectories) combined with increased summer dust loading in the atmosphere, while winter peaks are most likely related to higher accumulation. Our results suggest that heavy metal concentrations at RICE are sensitive to a range of atmospheric circulation changes and local depositional effects, in addition to source emission changes.

\section{Acknowledgements:}

This work is a contribution to the Roosevelt Island Climate Evolution (RICE) Program, funded by national contributions from New Zealand, Australia, Denmark, Germany, Italy, the People's Republic of China, Sweden, United Kingdom, and the United States of America. The main logistic support was provided by Antarctica New Zealand (K049) and the US Antarctic Program. This work has been funded by the New Zealand Ministry of Business, Innovation, and Employment Grants (RDF-VUW-1103, 540GCT32), Victoria University and GNS Science. The US portion of this research was supported by NSF grant ANT-1042883. We also acknowledge the ECMWF for providing access to the ERA Interim reanalysis data and NOAA/ARL for converting the ERA Interim meteorological data to a HySPLIT compatible format. All data presented in this paper will be uploaded at publication to the NOAA National Climatic Data Centre http://www.ncdc.noaa.gov/data-access/paleoclimatology-data/. Prior to this any requests for access can be directed to the lead author at andrea.tuohy@vuw.ac.nz.

\subsection{References:}

Alley, R. B. (1988), Concerning the deposition and diagenesis of strata in polar firn, Journal of Glaciology, 34, 283-290.

Alley, R. B., R. C. Finkel, K. Nishizumi, A. Anandakrishnan, C. A. Shuman, G. Mershon, G. A. Zielinski, and P. A. Mayewski (1995), Changes in continental and sea-salt atmospheric loadings in central Greenland during the most recent deglaciation: Model-based estimates, Journal of Glaciology, 41(139), 503-514.

Alley, R. B., E. S. Saltzman, K. M. Cuffey, and J. J. Fitzpatrick (1990), Summertime formation of depth hoar in Central Greenland, Geophysical Research Letters, 17(12), 2393-2396.

Baker, J. (2010), A cluster analysis of long range air transport pathways and associated pollutant concentrations within the UK, Atmospheric Environment, 44(4), 563-571.

Berg, N., P. Dunn, and M. Fenn (1991), Spatial and temporal variability of rime ice and snow chemistry at five sites in California, Atmospheric Environment, 25A(5/6), 915-926.

Bertler, N. A. N., P. J. Barrett, P. A. Mayewski, R. L. Fogt, K. J. Kreutz, and J. Shulmeister (2004), El Nino suppresses Antarctic warming, Geophysical Research Letters, 31(L15207), 1-4.

Bertler, N. A. N., T. R. Naish, H. Oerter, S. Kipfstuhl, P. J. Barrett, P. A. Mayewski, and K. Kreutz (2006), The effects of joint ENSO-Antarctic Oscillation forcing on the McMurdo Dry Valleys, Antarctica, Antarctic Science, 18(4), 507-514.

Blas, M., K. Cichala-Kamrowska, M. Sobik, Z. Polkowska, and J. Namiesnik (2010), Conditions controlling atmospheric pollutant deposition via snowpacl, Environmental Reviews, 18, 87114.

Bracegirdle, T. J., and G. J. Marshall (2012), The reliability of Antarctic tropospheric pressure and 
temperature in the latest global reanalyses, Journal of Climate, 25, 7138-7146.

Bromwich, D. H. (1988), Snowfall in High Southern Latitudes, Reviews of Geophysics, 26(1), 149168.

Bromwich, D. H. (1991), Mesoscale cyclogenesis over the Southwestern Ross Sea linked to strong katabatic winds, Monthly weather review, 119(7), 1736-1753.

Bromwich, D. H., R. L. Fogt, K. I. Hodges, and J. E. Walsh (2007), A tropospheric assessment of the ERA-40, NCEP, and JRA-25 global reanalyses in the polar regions, Journal of Geophysical Research, 112(D10111), 1-21.

Candelone, J.-P., S. Hong, C. Pellone, and C. Boutron (1995), Post-industrial revolution changes in large-scale atmospheric pollution of the northern hemisphere by heavy metals as documented in central Greenland snow and ice, Journal of Geophysical Research: Atmospheres, 100(D8), 16605-16616.

Carraso, J. F., D. H. Bromwich, and A. J. Monaghan (2003), Distribution and characteristics of the mesoscale cyclones in the Antarctic: Ross Sea eastward to the Weddell Sea, Monthly Weather Review, 131, 289-301.

Cohen, L., S. Dean, and J. Renwick (2013), Synoptic weather types for the Ross Sea Region, Antarctica, Journal of Climate, 26, 636-649.

Colbeck, S. C. (1982), An overview of seasonal snow metamorphism, Reviews of Geophysics, 20(1), 45-61.

Comiso, J. C., R. Kwok, S. Martin, and A. L. Gordon (2011), Variability and trends in sea ice extent and ice production in the Ross Sea, Journal of Geophysical Research, 116(C04021), $1-19$.

Cunningham, J., and E. D. Waddington (1993), Air flow and dry deposition of non-sea salt sulfate in polar firn: Paleoclimatic implications, Atmospheric Environment, 27A(17/18), 2943-2956.

Dadic, R., M. Schneebeli, M. Lehning, M. A. Hutterli, and A. Ohmura (2008), Impact of the microstructure of snow on its temperature: A model validation with measurements from Summit, Greenland, Journal of Geophysical Research, 113(D14303), 1-11.

Davidson, C. I., L. Chu, T. C. Grimm, M. A. Nasta, and M. P. Qamoos (1981), Wet and dry deposition of trace elements onto the Greenland ice sheet, Atmospheric Environment (1967), 15(8), 1429-1437.

Dee, D. P., et al. (2011), The ERA-Interim reanalysis: configuration and performance of the data assimilation system, Quarterly Journal of the Royal Meteorological Society, 137, 553-597.

Dixon, D., P. A. Mayewski, I. D. Goodwin, G. J. Marshall, and R. Freeman (2012), An ice-core proxy for northerly air mass incursions into West Antarctica, International Journal of Climatology, 32(10), 1455-1465.

Dixon, D., P. A. Mayewski, E. Korotkikh, S. B. Sneed, M. J. Handley, D. S. Introne, and T. A. Scambos (2013), Variations in snow and firn chemistry along US ITASE traverses and the effect of surface glazing, The Cryosphere, 7(2), 515-535.

Domine, F., T. Lauzier, A. Cabanes, L. Legagneux, W. Kuhs, K. Techmer, and T. Heinrichs (2003), Snow metamorphism as revealed by scanning electron microscopy, Microscopy Research and Technique, 62, 33-48.

Domine, F., A.-S. Taillandier, A. Cabanes, T. A. Douglas, and M. Sturm (2009), Three examples where the specific surface area of snow increased over time, The Cryosphere, 3, 31-39.

Draxler, R. R., and G. D. Hess (1997), Description of the HYSPLIT-4 modelling system, NOAA Technical Memo. ERL ARL-224, 24pp.

Draxler, R. R., and G. D. Hess (1998), An overview of the HYSPLIT-4 modelling system for trajectories, dispersion, and deposition, Australian Meteorological Magazine, 47, 295-308.

Duce, R. A., et al. (1991), The atmospheric input of trace species to the world ocean, Global Biogeochemical Cycles, 5(3), 193-259.

Duffus, J. H. (2002), "Heavy metals" a meaningless term? (IUPAC Technical Report), Pure and Applied Chemistry, 74(5), 793-807.

Duncan, L. C. (1992), Chemistry of rime and snow collected at a site in the central Washington 
Cascades, Environmental Science \& Technology, 26(1), 61-66.

Fassnacht, S. R., J. Innes, N. Kouwen, and E. D. Soulis (1999), The specific surface area of fresh dendritic snow crystals, Hydrological Processes, 13, 2945-2962.

Fogt, R. L., J. Perlwitz, A. J. Monaghan, D. H. Bromwich, J. M. Jones, and G. J. Marshall (2009), Historical SAM variability. Part II:Twentieth-century variability and trends from reconstructions, observations and the IPCC AR4 models, Journal of Climate, 22, 53465365.

Fowler, S. W. (1990), Critical review of selected heavy metal and chlorinated hydrocarbon concentrations in the marine environment, Marine Environmental Research, 29, 1-64.

Frezzotti, M., et al. (2004), New estimations of precipitation and surface sublimation in East Antarctica from snow accumulation measurements, Climate Dynamics, 23, 803-813.

Gabrielli, P., C. Barbante, C. Boutron, G. Cozzi, V. Gaspari, F. Planchon, C. Ferrari, C. Turetta, S. Hong, and P. Cescon (2005), Variations in atmospheric trace elements in Dome C (East Antarctica) ice over the last two climatic cycles, Atmospheric Environment, 39, 6420-6429.

Gabrielli, P., G. Cozzi, S. Torcini, P. Cescon, and C. Barbante (2006), Source and origin of atmospheric trace elements entrapped in winter snow of the Italian Eastern Alps, Atmospheric Chemsitry and Physics Discussions, 6, 8781-8815.

Gabrielli, P., A. Wegner, J. R. Petit, B. Delmonte, P. De Deckker, V. Gaspari, H. Fischer, U. Ruth, M. Kriews, and C. Boutron (2010), A major glacial-interglacial change in aeolian dust composition inferred from Rare Earth Elements in Antarctic ice, Quaternary Science Reviews, 29(1), 265-273.

Grotti, M., F. Soggia, F. Ardini, and E. Magi (2011), Major and trace element partitioning between dissolved and particulate phases in Antarctic surface snow, Journal of Environmental Monitoring, 13(2511-2520).

Hanot, L., and F. Domine (1999), Evolution of the surface area of a snow layer, Environmental Science \& Technology, 33, 4250-4255.

Hong, S., J.-P. Candelone, C. C. Patterson, and C. F. Boutron (1994), Greenland ice evidence of hemispheric lead pollution two millenia ago by Greek and Roman civilisations, Science, 265, 1841-1843.

Hong, S., C. H. Han, H. J. Hwang, T.-O. Soyol-Erdene, J. H. Kang, S. D. Hur, L. J. Burn-Nunes, P. Gabrielli, C. Barbante, and C. F. Boutron (2013), Trace elements and Pb isotope record in Dome C (East Antarctica) ice over the past 800,000 years, E3S Web of Conferences, 1(23001), 1-4.

Hörhold, M., S. Kipfstuhl, F. Wilhelms, J. Freitag, and A. Frenzel (2011), The densification of layered polar firn, Journal of Geophysical Research: Earth Surface (2003-2012), 116(F1).

Hosking, J. S., A. Orr, G. J. Marshall, J. Turner, and T. Phillips (2013), The influence of the Amundsen-Bellingshausen Seas Low on the climate of West Antarctica and its representation in coupled climate model simulations, Journal of Climate(2013).

Hoskins, B. J., and K. I. Hodges (2005), A new perspective on Southern Hemisphere storm tracks, Journal of Climate, 18(20), 4108-4129.

Huber, P. J. (1981), Robust statistics, John Wiley \& Sons, Inc, Hoboken, NJ, USA.

Hur, S. D., X. Cunde, S. Hong, C. Barbante, P. Gabrielli, K. Lee, C. F. Boutron, and Y. Ming (2007), Seasonal patterns of heavy metal deposition to the snow on the Lambert Glacier basin, East Antarctica, Atmospheric Environment, 41, 8567-8578.

Hur, S. D., T.-O. Soyol-Erdene, H. J. Hwang, C. Han, P. Glabrielli, C. Barbante, C. Boutron, and S. Hong (2013), Climate-related variations in $\mathrm{Sb}$ and $\mathrm{Tl}$ in the EPICA Dome $\mathrm{C}$ ice (East Antarctica) during the past 800,000 years, Global Biogeochemical Cycles, 27, 1-11.

Järup, L. (2003), Hazards of heavy metal contamination, British Medical Bulletin, 68, 167-182.

Jia, G., and J. Jia (2014), Atmospheric residence times of the fine-aerosol in the region of South Italy estimated from the activity concentration ratios of $210 \mathrm{Po} / 210 \mathrm{~Pb}$ in air particulates, Analytical and Bioanalytical Techniques, 5(5/1000216), 1-9.

Kerminen, V.-M., K. Teinila, and R. Hillamo (2000), Chemistry of sea-salt particles in the summer 
Antarctic atmosphere, Atmospheric Environment, 34, 2817-2825.

King, J. C., and J. Turner (1997), Antarctic meteorology and climatology, 425 pp., Cambridge University Press, Cambridge, UK.

Koffman, B. G., M. J. Handley, E. C. Osterberg, M. L. Wells, and K. J. Kreutz (2014), Dependence of ice-core relative trace-element concentration on acidification, Journal of Glaciology, 60(219), 103-112.

Krachler, M., J. Zheng, D. Fisher, and W. Shotyk (2005), Analytical procedures for improved trace element detection limits in polar ice from Arctic Canada using ICP-SMS, Analytica Chimica Acta, 530, 291-298.

Kreutz, K. J., and P. A. Mayewski (1999), Spatial variability of Antarctic surface snow glaciochemistry: implications for palaeoatmospheric circulation reconstructions, Antarctic Science, 11(1), 105-118.

Kreutz, K. J., P. A. Mayewski, L. D. Meeker, M. S. Twickler, and S. I. Whitlow (2000), The effect of spatial and temporal accumulation rate variability in West Antarctica on soluble ion deposition, Geophysical Research Letters, 27(16), 2517-2520.

Lenaerts, J. T. M., et al. (2014), High variability of climate and surface mass balance induced by Antarctic ice rises, Journal of Glaciology, 60(224), 1-10.

Li, F., P. Ginoux, and V. Ramaswamy (2008), Distribution, transport, and deposition of mineral dust in the Southern Ocean and Antarctica: Contribution of major sources, Journal of Geophysical Research: Atmospheres (1984-2012), 113(D10).

Macklin, W. C. (1962), The density and structure of ice formed by accretion, Quarterly Journal of the Royal Meteorological Society, 88(375), 30-50.

Makkonen, L. (2000), Models for the growth of rime, glaze, icicles and wet snow on structures, Philosophical Transactions: Mathematical, Physical and Engineering Sciences, 358(1776), 2913-2939.

Markle, B. R., N. A. N. Bertler, K. E. Sinclair, and S. B. Sneed (2012), Synoptic variability in the Ross Sea region, Antarctica, as seen from back-trajectory modeling and ice core analysis, Journal of Geophysical Research, 117 (D02113)(D02113), 1-17.

Martin, M., and B. J. Richardson (1991), Long term contaminant biomonitoring: Views from Southern and Northern Hemisphere perspectives, Marine Pollution Bulletin, 22(11), 533 537.

McConnell, J., A. J. Aristarain, J. R. Banta, R. Edwards, and J. C. Simoes (2007), 20th-Century doubling in dust archinved in an Antarctic Peninsula ice core parallels climate change and desertification in South America, PNAS, 104(14), 5743-5748.

McConnell, J., et al. (2014), Antarctic-wide array of high-resolution ice core records reveals pervasice lead pollution began in 1889 and persists today, Nature: Scientific Reports, 4(5848), 1:5.

Ngriagu, J. O. (1990), Global metal pollutions: Poisoning the biosphere?, Environment: science and policy for sustainable development, 32(7), 7-33.

Nicolas, J. P., and D. H. Bromwich (2011), Climate of West Antarctica and influence of marine air intrusions, Journal of Climate, 24, 49-67.

Osterberg, E. C., M. J. Handley, S. B. Sneed, P. A. Mayewski, and K. J. Kreutz (2006), Continuous ice core melter system with discrete sampling for major ion, trace element, and stable isotope analyses, Environmental Science Technology, 40(10), 3355-3361.

Planchon, F. A. M., K. Van De Velde, K. J. R. Rosman, E. W. Wolff, C. P. Ferrari, and C. F. Boutron (2003), One hundred fifty-year record of lead isotopes in Antarctic snow from Coats Land, Geochimica et Cosmochimica Acta, 67(4), 693-708.

Pomeroy, J. W., and H. G. Jones (1996), Wind-blown snow: Sublimation, transport and changes to polar snow, in Chemical exchange between the atmosphere and polar snow, edited by $\mathrm{E} . \mathrm{W}$. Wolff and R. C. Bales, Springer-Verlag.

Prospero, J. M., P. Ginoux, O. Torres, S. E. Nicholson, and T. E. Gill (2002), Environmental 
characterization of global sources of atmospheric soil dust identified with the Nimbus 7 total ozone mapping spectrometer (TOMS) absorbing aerosol product, Reviews of Geophysics, 40(1), 1-31.

Puxbaum, H., and W. Tscherwenka (1998), Relationships of major ions in snow fall and rime at Sonnblick Observatory (SBO, 3106m) and implications for scavenging processes in mixed clouds, Atmospheric Environment, 32(23), 4011-4020.

Rango, A., J. Foster, E. G. Josberger, E. F. Erbe, C. Pooley, and W. P. Wergin (2003), Rime and graupel: description and characterization as revealed by low-temperature scanning electron microscopy, Scanning, 25, 121-131.

Reimann, C., and P. De Caritat (2000), Intrinsic flaws of element enrichment factors (EFs) in environmental geochemistry, Environmental Science \& Technology, 34, 5084-5091.

Rhodes, R. H., J. A. Baker, M.-A. Millet, and N. A. N. Bertler (2011), Experimental investigation of the effects of mineral dust on the reproducibility and accuracy of ice core trace element analyses, Chemical Geology, 286, 207-221.

Sasgen, I., H. Dobslaw, Z. Martinec, and M. Thomas (2010), Satellite gravimetry observation of Antarctic snow accumulation related to ENSO, Earth and Planetary Science Letters, 299, 352-358.

Schwikowski, M., et al. (2004), Post-17th-century changes of European lead emissions recorded in high-altitude alpine snow and ice, Environmental Science \& Technology, 38(4), 957-964.

Sinclair, K. E., N. A. N. Bertler, and W. J. Trompetter (2010), Synoptic controls on precipitation pathways and snow delivery to high-accumulation ice core sites in the Ross Sea region, Antarctica, Journal of Geophysical Research: Atmospheres (1984-2012), 115(D22).

Sinclair, K. E., N. A. N. Bertler, W. J. Trompetter, and W. T. Baisden (2013), Seasonality of airmass pathways to coastal Antarctica: Ramifications for interpreting high-resolution ice core records, Journal of Climate, 26(6), 2065-2076.

Turner, J. (2004), Review: The El Nino-Southern oscillation and Antarctica, International journal of Climatology, 24, 1-31.

Turner, J., T. Phillips, J. S. Hosking, G. J. Marshall, and A. Orr (2013), The Amundsen Sea Low, International Journal of Climatology, 33, 1818-1829.

Vallelonga, P., et al. (2010), Lead isotopic compositions in the EPICA Dome C ice core and Southern Hemisphere Potential Source Areas, Quaternary Science Reviews, 29, 247-255.

Velasco, P. (1995), The Mineral Industry of Chile, edited, USGS.

Visbeck, M., and A. Hall (2004), Reply, Journal of Climate, 17(2255-2258).

Wedepohl, K. H. (1995), The composition of the continental crust, Geochimica et Cosmochimica Acta, 59(7), 1217-1232.

Weller, R., J. Wöltjen, C. Piel, R. Resenberg, D. Wagenbach, G. König-Langlo, and M. Kriews (2008), Seasonal variability of crustal and marine trace elements in the aerosol at Neumayer station, Antarctica, Tellus, 60(5), 742-752.

Werner, M., I. Tegen, S. P. Harrison, K. E. Kohfeld, I. C. Prentice, Y. Balkanski, H. Rodhe, and C. Roelandt (2002), Seasonal and interannual variability of the mineral dust cycle under present and glacial climate conditions, Journal of Geophysical Research, 107(D24/4744), 119.

Witherow, R. A., W. B. Lyons, N. A. N. Bertler, K. A. Welch, P. A. Mayewski, S. B. Sneed, T. Nylen, M. J. Handley, and A. Fountain (2006), The aeolian flux of calcium, chloride and nitrate to the McMurdo Dry Valleys landscape: evidence from snow pit analysis, Antarctic Science, 18(4), 497-505.

Wolff, E. W., J. S. Hall, R. Mulvaney, E. C. Pasteur, D. Wagenbach, and M. Legrand (1998), Relationship between chemistry of air, fresh snow and firn cores for aerosol species in coastal Antarctica, Journal of Geophysical Research, 103(D9), 11,057-011,070.

Wolff, E. W., and E. D. Suttie (1994), Antarctic snow record of southern hemisphere lead pollution, Geophysical Research Letters, 21(9), 781-784. 


\subsection{Supplementary Information}

Here we provide an additional figure and table to support the data and results discussed in our manuscript. Figure 4.S1 presents the calculated flux values (annual average concentration multiplied by annual accumulation in cm water equivalent) for the heavy metal elements analyzed in the $3 \mathrm{~m}$ deep snow pit from Roosevelt Island, in support of the correlations presented in Table 4.2. Table 4.ST1 presents the average daily concentrations of the heavy metals analyzed in the snow precipitation sampled at Roosevelt Island between November 2011 and January 2012, and a summary of the daily field observations made at the same time as sampling. This supports the classification of snow type, and frequency and extent of fog and rime ice growth discussed in the text and displayed in Figure 4.2.

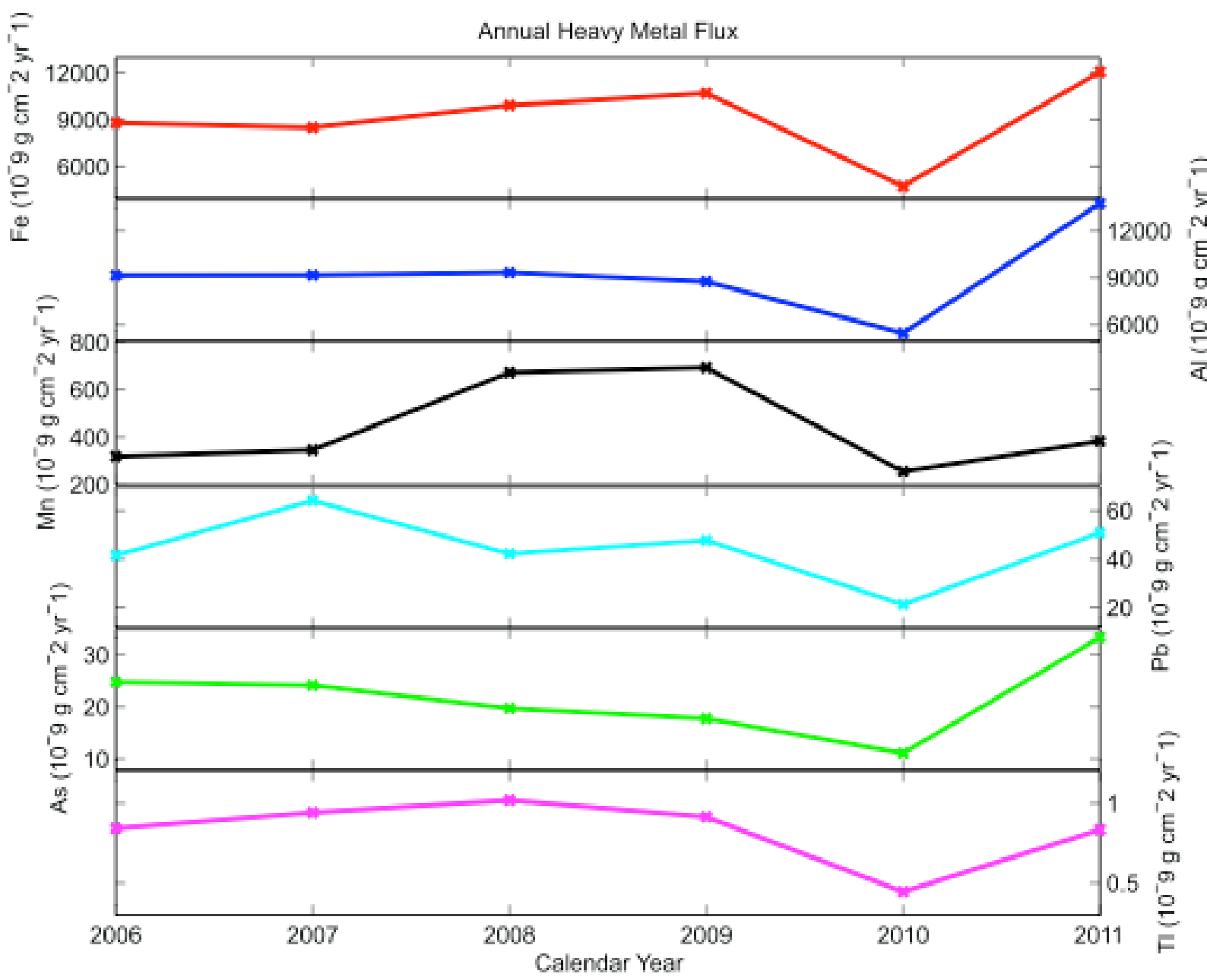

Figure 4.S1. Annual average flux values for heavy metals in RICE snow between 2006 and 2012. 


\begin{tabular}{|c|c|c|c|c|c|c|c|c|}
\hline Date & La139(LR) & Tl205(LR) & Pb208(LR) & Al27(MR) & S32(MR) & Mn55(MR) & Fe56(MR) & As75(HR) \\
\hline $21 / 11 / 2011$ & 0.414 & 0.033 & 1.912 & 3448.3 & 27142.8 & 85.269 & 774.037 & 2.046 \\
\hline $22 / 11 / 2011$ & 0.168 & 0.011 & 0.433 & 1893.6 & 3084.3 & 60.668 & 447.181 & 0.999 \\
\hline $23 / 11 / 2011$ & 0.137 & 0.025 & 0.680 & 1587.5 & 10010.1 & 17.094 & 204.387 & 1.231 \\
\hline $24 / 11 / 2011$ & 0.161 & 0.045 & 1.593 & 1877.7 & 12686.8 & 19.878 & 279.986 & 1.199 \\
\hline $25 / 11 / 2011$ & 0.180 & 0.070 & 2.107 & 1993.8 & 19311.1 & 25.579 & 331.215 & 1.598 \\
\hline $27 / 11 / 2011$ & 0.533 & 0.127 & $\mathrm{NaN}$ & 4395.2 & 217895.5 & 53.764 & 951.509 & 3.232 \\
\hline $29 / 11 / 2011$ & 7.782 & 0.459 & 10.209 & 10249.1 & 149358.2 & 248.440 & 6750.889 & 7.212 \\
\hline $30 / 11 / 2011$ & 8.890 & 0.539 & 16.793 & 11987.7 & 246814.8 & 270.904 & 7639.646 & 8.447 \\
\hline $1 / 12 / 2011$ & 0.973 & 0.084 & 2.211 & 3659.2 & 31613.7 & 59.219 & 1128.843 & 1.952 \\
\hline $2 / 12 / 2011$ & 0.540 & 0.066 & 1.934 & 2946.7 & 19869.3 & 41.002 & 667.493 & 1.669 \\
\hline $3 / 12 / 2011$ & 1.539 & 0.164 & 6.855 & 5009.3 & 269268.8 & 57.231 & 1266.828 & 3.755 \\
\hline $8 / 12 / 2011$ & 4.642 & 0.262 & 15.319 & $\mathrm{NaN}$ & $\mathrm{NaN}$ & 239.284 & 3935.289 & $\mathrm{NaN}$ \\
\hline $9 / 12 / 2011$ & 0.282 & 0.044 & 1.379 & 2532.7 & 84018.5 & 44.386 & 422.009 & 1.394 \\
\hline $10 / 12 / 2011$ & 0.332 & 0.123 & 3.175 & 3478.0 & 82530.3 & 36.544 & 475.470 & 2.550 \\
\hline $11 / 12 / 2011$ & 0.330 & 0.059 & 1.541 & 2784.6 & 82461.6 & 29.513 & 320.409 & 1.708 \\
\hline $12 / 12 / 2011$ & 0.232 & 0.038 & 1.340 & 1310.6 & 65908.4 & 29.359 & 328.974 & 1.134 \\
\hline $13 / 12 / 2011$ & 0.288 & 0.067 & 1.910 & 2739.6 & 133674.7 & 41.835 & 494.515 & 1.678 \\
\hline $14 / 12 / 2011$ & 0.274 & 0.101 & 2.532 & 2793.5 & 207991.3 & 15.874 & 554.173 & 2.110 \\
\hline $16 / 12 / 2011$ & 0.833 & 0.122 & 5.742 & 3453.1 & 136060.7 & 43.611 & 891.428 & 2.582 \\
\hline $17 / 12 / 2011$ & 0.597 & 0.096 & 3.233 & 2572.8 & 160930.8 & 33.789 & 671.643 & 2.025 \\
\hline $18 / 12 / 2011$ & 0.514 & 0.075 & 2.256 & 2294.6 & 111743.9 & 41.533 & 637.234 & 1.626 \\
\hline $19 / 12 / 2011$ & 0.540 & 0.162 & 3.662 & 2089.9 & 177106.6 & 32.768 & 684.588 & 2.422 \\
\hline $20 / 12 / 2011$ & 0.810 & 0.096 & 3.926 & 2255.1 & 166995.1 & 35.087 & 954.156 & 2.365 \\
\hline $21 / 12 / 2011$ & 1.161 & 0.057 & 5.094 & 3613.6 & 295618.2 & 49.065 & 1237.707 & 3.249 \\
\hline $22 / 12 / 2011$ & 1.262 & 0.031 & 4.915 & 3810.1 & 418760.3 & 59.822 & 1605.198 & 3.717 \\
\hline $23 / 12 / 2011$ & 0.586 & $\mathrm{NaN}$ & 4.307 & 3196.5 & 404722.0 & 37.731 & 795.259 & 2.721 \\
\hline $24 / 12 / 2011$ & 0.846 & 0.038 & 3.108 & 3590.5 & 243326.8 & 37.449 & 979.227 & 2.700 \\
\hline $25 / 12 / 2011$ & 0.583 & 0.004 & 2.503 & 2799.4 & 213363.5 & 26.366 & 635.755 & 2.120 \\
\hline $26 / 12 / 2011$ & 0.366 & 0.027 & 2.343 & 3870.9 & 195428.5 & 21.944 & 515.362 & 1.576 \\
\hline $29 / 12 / 2011$ & 0.946 & 0.134 & 7.961 & 6196.2 & 571222.4 & 41.164 & 827.201 & 4.034 \\
\hline $30 / 12 / 2011$ & 0.575 & 0.017 & 3.272 & 4609.7 & 234295.6 & 41.852 & 823.504 & 2.190 \\
\hline $1 / 01 / 2012$ & 4.418 & 0.064 & 3.858 & 5163.1 & 175053.1 & 63.102 & 1691.452 & 2.152 \\
\hline $3 / 01 / 2012$ & 0.680 & 0.033 & 2.041 & 4498.1 & 243926.2 & 26.943 & 705.248 & 1.462 \\
\hline $4 / 01 / 2012$ & 0.643 & 0.061 & 2.936 & 3929.2 & 278202.8 & 39.909 & 860.088 & 1.969 \\
\hline $5 / 01 / 2012$ & 0.473 & 0.043 & 1.595 & 3413.8 & 179678.0 & 17.421 & 529.567 & 1.349 \\
\hline $8 / 01 / 2012$ & 0.540 & 0.056 & 2.112 & 3722.2 & 285244.8 & 19.837 & 399.514 & 2.516 \\
\hline $9 / 01 / 2012$ & 0.311 & 0.061 & 2.348 & 2387.2 & 217183.2 & 16.172 & 365.620 & 2.282 \\
\hline $10 / 01 / 2012$ & 0.373 & 0.061 & 3.122 & 2061.6 & 249539.5 & 15.062 & 341.223 & 2.148 \\
\hline $12 / 01 / 2012$ & 2.615 & 0.227 & 10.678 & 11307.2 & $\mathrm{NaN}$ & 78.263 & 2287.057 & 5.102 \\
\hline $13 / 01 / 2012$ & 1.842 & 0.126 & 7.995 & 4686.5 & 731064.3 & 48.387 & 1155.893 & 3.781 \\
\hline $14 / 01 / 2012$ & 0.735 & 0.064 & 2.420 & 2617.9 & 341943.5 & 24.933 & 745.545 & 2.276 \\
\hline
\end{tabular}

Table 4.ST1. Daily snow precipitation heavy metal concentrations and field observations. 


\begin{tabular}{|c|c|c|c|c|c|c|c|}
\hline Date & $\begin{array}{l}\text { wind } \\
\text { speed } \\
\text { knots }\end{array}$ & $\begin{array}{l}\text { Direction } \\
\text { Grid }\end{array}$ & Pressure & $\begin{array}{l}\text { Air } \\
\text { Temp } \\
{ }^{\circ} \mathbf{C} \\
\end{array}$ & $\begin{array}{l}\text { Dew } \\
\text { point } \\
{ }^{\mathbf{o}} \mathbf{C} \\
\end{array}$ & $\begin{array}{l}\text { Snow } \\
\text { Temp } \\
{ }^{\circ} \mathrm{C} \\
\end{array}$ & Field Observations \\
\hline $21 / 11 / 2011$ & 9.0 & 090 & 2909 & -10.7 & -13.3 & -14.3 & New snowfall, star-shaped flakes, whole \\
\hline $22 / 11 / 2011$ & 8.0 & 060 & 2829 & -13.4 & $\mathrm{NaN}$ & -14.4 & New snowfall, star-shaped flakes, whole \\
\hline $23 / 11 / 2011$ & 12.0 & 270 & 2903 & -11.7 & $\mathrm{NaN}$ & -13.8 & New snowfall, some snow drifts forming \\
\hline $24 / 11 / 2011$ & 9.7 & 270 & 2909 & -6.9 & -7.7 & -13.2 & New snowfall, star-shaped flakes, whole \\
\hline $25 / 11 / 2011$ & 6.4 & 300 & 2914 & -6.6 & -9.9 & -11.3 & Wind blown snow, quite conpacted, broken flakes \\
\hline $27 / 11 / 2011$ & 6.0 & 330 & 2902 & -6 & -10 & $\mathrm{NaN}$ & Wind blown snow, quite conpacted, broken flakes \\
\hline 29/11/2011 & 12.2 & 090 & 2871 & -9.8 & -10.9 & -11.3 & Fog, extensive rime ice in samples \\
\hline $30 / 11 / 2011$ & 19.0 & 100 & 2877 & -8.7 & -9.7 & -10.9 & Fog, extensive rime ice in samples \\
\hline $1 / 12 / 2011$ & 16.7 & 090 & 2869 & -9.7 & -10.2 & -11.1 & Fog, new snow on trays \\
\hline $2 / 12 / 2011$ & 6.0 & 100 & 2871 & -9.9 & -11.4 & -10.8 & Fog, lots of new snow \\
\hline $3 / 12 / 2011$ & 3.3 & 280 & 2899 & -5.4 & -9.4 & -10.4 & Calm weather, old snow from previous day \\
\hline $8 / 12 / 2011$ & 5.6 & 270 & 2903 & -7.4 & -8.4 & -9.8 & Fog, and rime ice forming \\
\hline $9 / 12 / 2011$ & 2.9 & 220 & 2893 & -7.6 & -9.6 & -8.9 & New snowfall, star-shaped flakes, whole \\
\hline $10 / 12 / 2011$ & 8.2 & 240 & 2895 & -7.6 & -9.2 & -8.2 & New snowfall, star-shaped flakes, whole \\
\hline $11 / 12 / 2011$ & 4.5 & 320 & 2908 & -9.5 & -11.2 & -8.3 & $\begin{array}{l}\text { New snow, drifting snow (rounded flakes) blowing } \\
\text { onto trays }\end{array}$ \\
\hline $12 / 12 / 2011$ & 8.2 & 130 & 2930 & -9 & -11 & -9.2 & $\begin{array}{l}\text { New snow (whole flakes), and wind compacted } \\
\text { snow (broken flakes) }\end{array}$ \\
\hline $13 / 12 / 2011$ & 11.3 & 290 & 2903 & -9.6 & -12.4 & -8.4 & Overcast, some new snow \\
\hline $14 / 12 / 2011$ & 7.0 & 060 & 2907 & -10 & -15 & -9.4 & Drifting snow, rounded flakes blowing onto trays \\
\hline $16 / 12 / 2011$ & 6.0 & 110 & 2931 & -11 & -14 & -10.9 & Calm weather, old snow from previous days \\
\hline $17 / 12 / 2011$ & 2.5 & 225 & 2951 & -9.5 & -15.4 & -10.9 & Small amount new snow \\
\hline $18 / 12 / 2011$ & 11.3 & 350 & 2935 & -12.6 & -15.5 & -11.8 & Small amount new snow \\
\hline $19 / 12 / 2011$ & 11.0 & 020 & 2883 & -13 & -15 & -10.7 & New snow, some rime crystals growing on trays \\
\hline 20/12/2011 & 2.0 & 070 & 2888 & -7 & -15 & -11.6 & Drifting snow (rounded flakes) \\
\hline $21 / 12 / 2011$ & 7.0 & 300 & 2926 & -5 & -7 & -9.6 & Wind blown snow, broken flakes \\
\hline $22 / 12 / 2011$ & 6.0 & 190 & 2896 & -6 & -11 & -8.8 & Drifting snow, some rime ice and fog \\
\hline 23/12/2011 & 0.4 & 080 & 2907 & -6 & -8.5 & -7.9 & Wind blown snow, broken flakes, compacted, fog \\
\hline $24 / 12 / 2011$ & 15.9 & 070 & 2911 & -5 & -5.3 & -7.4 & New snow on top of wind blown compacted snow \\
\hline 25/12/2011 & 10.0 & 140 & 2918 & -5 & -7 & $\mathrm{NaN}$ & $\begin{array}{l}\text { Wind blown snow (broken and compacted), some } \\
\text { fog and rime ice }\end{array}$ \\
\hline 26/12/2011 & 3.0 & 090 & 2931 & -3 & -7 & -8.4 & New snowfall, fresh new star-shaped flakes \\
\hline $29 / 12 / 2011$ & 5.0 & 090 & 2898 & -5 & -13 & -7.2 & Some fog and rime ice, some new snowfall \\
\hline $30 / 12 / 2011$ & 9.5 & 090 & 2885 & -8 & -9 & -6.9 & Some fog and new snowfall \\
\hline $1 / 01 / 2012$ & 4.0 & 300 & 2912 & -7 & -10 & -7.2 & Fog and some new snowfall \\
\hline $3 / 01 / 2012$ & 6.2 & 300 & 2914 & -6.4 & -7.8 & -6.9 & New snow and drifting snow (rounded flakes) \\
\hline $4 / 01 / 2012$ & 6.6 & 000 & 2895 & -8 & -14.6 & $\mathrm{NaN}$ & Wind blown snow (broken and compacted) \\
\hline $5 / 01 / 2012$ & 4.1 & 230 & 2873 & -7.5 & -14 & -8.4 & Some fog and rime ice, drifting snow \\
\hline $8 / 01 / 2012$ & 9.5 & 225 & 2919 & -6.6 & -7.8 & -6.9 & New snowfall \\
\hline $9 / 01 / 2012$ & 12.0 & 020 & 2920 & -8 & -10 & -7.4 & Wind blown snow, some fog \\
\hline $10 / 01 / 2012$ & 6.0 & 200 & 2950 & -6 & -9 & -7.6 & Drifting snow, some fog \\
\hline $12 / 01 / 2012$ & 5.0 & 260 & 2921 & -8 & -10 & -7.5 & Extensive fog, and some rime ice \\
\hline $13 / 01 / 2012$ & 12.8 & 010 & 2912 & -9.6 & -11.7 & -8.4 & Extensive fog and some rime ice \\
\hline $14 / 01 / 2012$ & 5.0 & 070 & 2931 & -13.3 & -16.2 & -10.2 & New snowfall and drifting snow \\
\hline
\end{tabular}

Table 4.ST1-continued. Daily snow precipitation heavy metal concentrations and field observations. 


\title{
Chapter 5-20 ${ }^{\text {th }}$ Century Arsenic Pollution: A record of anthropogenic emissions and recent decreases
}

\author{
A.J. Tuohy, N.A.N. Bertler, R. Edwards, P.D. Neff, T.J. Fudge, A. Kurbatov, E. Brooks, J. \\ Lee, T. Blunier, P. Mayewski, (final author list to be confirmed).
}

\subsection{Foreword}

This chapter consists of a manuscript that is in preparation for submission to Nature or to Nature Climate Change. Here we present the first high resolution, 2,000-year record of arsenic concentrations from a new Antarctic ice core. We discuss atmospheric arsenic (As) concentration, trends and variability over the $20^{\text {th }}$ Century in the context of natural variability over the past 2,000 years. Since $1880 \mathrm{AD}$, anthropogenic arsenic emissions increased atmospheric concentrations by $400 \%$ above the natural pre-industrial variability. A decrease in concentrations from the late 1990s to within pre-industrial levels in recent snow can be linked to increased public awareness of As toxicity and national regulation and mitigation policies in Southern Hemisphere countries regarding the industrial use and emissions of arsenic. The potential effects of changes in atmospheric transport on the arsenic record as well as the pre-industrial sources are quantified. We link the natural variability of atmospheric arsenic over the past 2,000 years in Antarctica to volcanic emissions and organoarsenic compounds (MA/DMA) from biogenic emissions in the Ross Sea region.

As this manuscript is yet to be finalised, the acknowledgements section has not been included. As it stands, I have led the preparation of this manuscript, with contributions from N. Bertler, R. Edwards, and P. Neff. The current list of authors include key contributors to ice core sampling, and development of the preliminary RICE 2 ka age scale.

\subsection{Introduction}

Heavy metal pollution from anthropogenic emissions has become an increasing health and environmental risk ${ }^{1}$. Monitoring pollution levels has been implemented in many regions but postdates natural baselines and the onset of significant anthropogenic emission increases ${ }^{2}$. This poses a difficult challenge for the implementation of meaningful emission limits and ecosystem impact and exposure assessments. Here we present an exceptionally high-resolution arsenic record from a new Antarctic ice core to evaluate $20^{\text {th }}$ Century concentrations in the context of natural climate variability over 
the last 2,000 years. The Roosevelt Island Climate Evolution (RICE) ice core reveals a large increase in arsenic concentration during the $20^{\text {th }}$ Century, and links peak concentrations up to $400 \%$ higher than the pre-industrial average during the 1970 s and 1980s to anthropogenic emissions. Moreover, the RICE ice core record shows a remarkable decrease in concentrations from the late 1990s and a corresponding decrease in crustal enrichment factor values. We link this to a reduction in industrial arsenic emissions following national-level legislative reforms in industry emissions and environmental policy in Southern Hemisphere countries ${ }^{3-5}$. Natural variability prior to anthropogenic emissions is low and we find a significant correlation between arsenic and non-sea salt, marine sulfur compounds that suggests emissions from Antarctic $\operatorname{algae}^{6}$ may be an important source of natural arsenic in coastal Antarctica.

Arsenic (As) has been used extensively in several industry areas (wood preservation, pesticides, non-ferrous metal production, and coal combustion) over the $20^{\text {th }}$ century ${ }^{7-9}$. Arsenic is classified as a heavy metal pollutant and even in small concentrations is highly toxic ${ }^{1}$. Monitoring stations recording atmospheric concentrations have existed since the $1980 \mathrm{~s}^{2}$. However, these records are too recent to date or pre-date the onset of anthropogenic emissions and thus are insufficient to quantify anthropogenic contributions or to determine natural baselines. Furthermore, most monitoring sites are restricted to local continental sites, monitoring specific pollution sources rather than large-scale impacts. To develop effective policies and regulations it is important to determine natural background levels (nonavoidable), which serve as an important reference to reduce anthropogenic emissions (avoidable). Pollutants released to the atmosphere have the potential to be transported long distances over short timescales of days to weeks due to the rapid mixing induced by vigorous atmospheric circulation ${ }^{10,11}$. Although gases and particulates in the atmosphere are well mixed, different trace species remain in the atmosphere for different periods of time. Elements commonly bound to dust particulates, such as iron (Fe) aluminium (Al) and lead $(\mathrm{Pb})$, are precipitated in a matter of days to weeks ${ }^{12,13}$. Anthropogenic emissions of heavy metals including arsenic are usually present in the fine particulate dust fraction ${ }^{14}$. Analysing the concentrations of trace element pollutants in remote locations, such as Antarctica, allows monitoring of current and past pollutants emissions, transport pathways, and long and short term ecosystem exposure.

Ice cores provide a useful recording mechanism as they are generally well dated, capture atmospheric conditions, show limited post-depositional effects, and thus can be used to 
constrain the timing of major global changes in pollutant concentrations ${ }^{15}$. Records from coastal sites where snow accumulation is high can capture changes at a high temporal resolution, monitoring trends in atmospheric pollutant concentrations.

Moisture and pollutants are delivered to Antarctica from air masses that have travelled along meridional gradients across the Southern Ocean ${ }^{10,16}$. The air over the Southern Ocean is well mixed due to vigorous transport, and hence contains concentrations of trace elements that are representative of Hemisphere-wide concentrations ${ }^{17}$. Snow and other forms of annual precipitation in Antarctica include concentrations of trace elements through scavenging hence concentrations in ice cores can be used to reconstruct the concentration of trace elements in air masses that have travelled from mid-latitudes ${ }^{18-20}$. Over two austral summer field seasons (2011-2012, 2012-2013) a $763 \mathrm{~m}$ ice core was drilled to bedrock at Roosevelt Island, a coastal ice dome, as part of the Roosevelt Island Climate Evolution (RICE) project. Roosevelt Island is located in the north-eastern Ross Ice Shelf, and is exposed to direct airmass transport from the South Pacific. As such, the RICE ice core record delivers a timeseries of trace element concentration changes that is representative of the Southern Hemisphere (Tuohy et al., JGR in review).

Here we present the first, high-resolution, continuous record of As concentration as recorded in the RICE ice core, focusing on the last 2,000 years. We investigate natural sources and variability of As during the pre-industrial period of the last 2,000 years and evaluate $20^{\text {th }}$ Century concentration changes in the context of this record.

\subsection{Results and Discussion}

The high-resolution As record for the past 2,000 years is shown in Figure 5.1. The time resolution of the samples changes with depth (see methods). While the first 150 years are resolved sub-annually (average of 7.4 samples per year), the deeper record is smoothed to 3year averages. Lower resolution sampling induces an apparent reduction in the observed variability in comparison to higher resolution records. To compare trends across the entire record we calculated 3-year averages over the last 150 years. Over most of the past two millennia As concentrations in the RICE record remain relatively stable at 0.7 parts per trillion (ppt) with only minor ( $\pm 0.3 \mathrm{ppt}$ ) variations (Table 6.1). At 1880 AD concentrations significantly increase by almost $200 \%$ to about 2 ppt and remain at this level until 1970 when concentrations abruptly increase to about $4 \mathrm{ppt}( \pm 1.5 \mathrm{ppt})$ (Figure 6.1), which represents a $400 \%$ increase compared to natural variability. Since the late 1990s arsenic 
concentrations show a remarkable decrease, returning to natural background levels of $\sim 1 \mathrm{ppt}$ during the last decade.

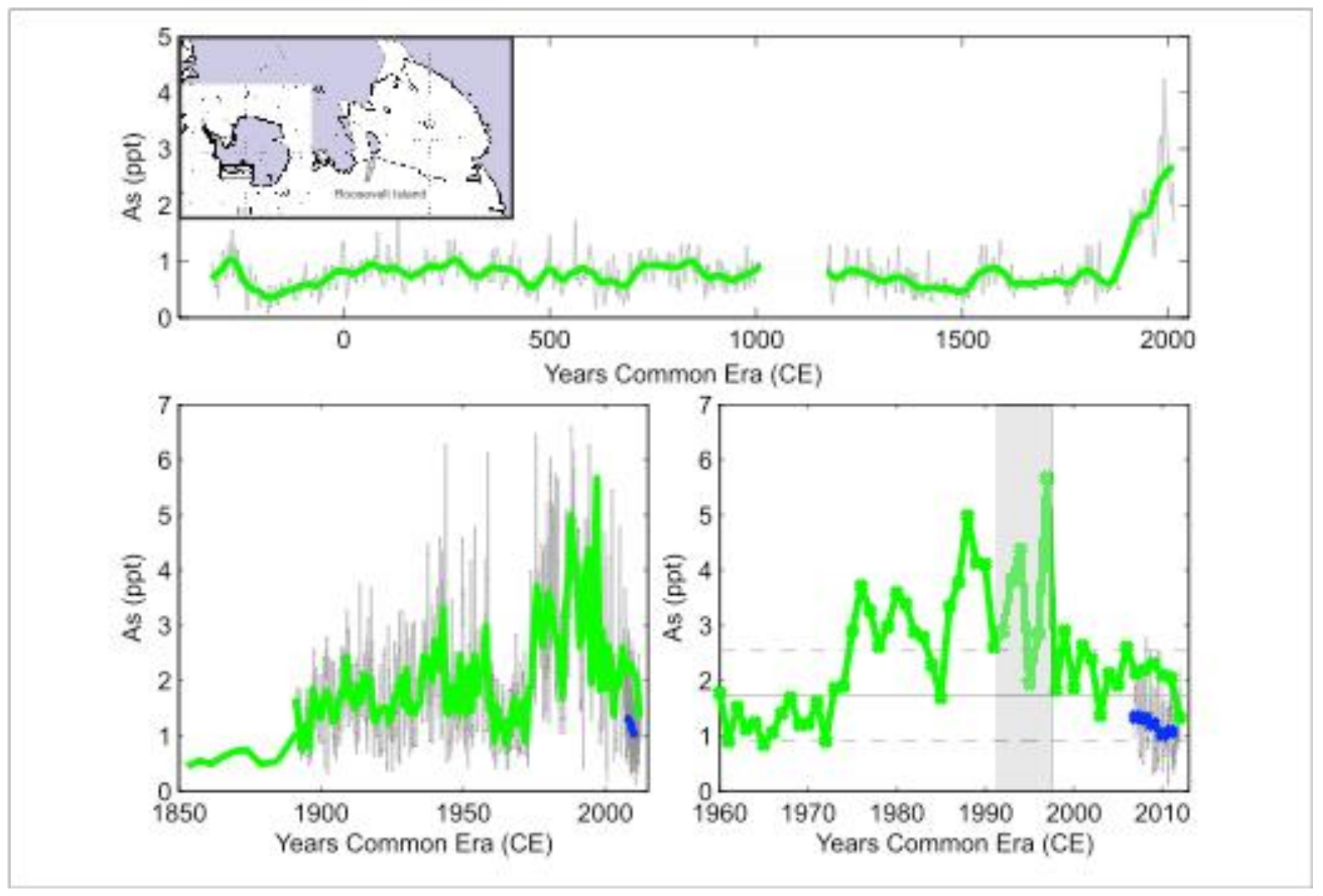

Figure 5.1. RICE arsenic record. Top: As concentration over the last 2,000 years, all data points in grey ( $\sim 3 \mathrm{yr}$ resolution), 20 -point moving average in green. Inset - location map, plotted using data from Timmerman et al. (2010). Lower Left: As concentrations over the last 150 years from the RICE ice core and the snow pit, all raw samples in grey, annual average concentrations in green. Lower Right: Annual average concentrations from 1960 to 2012 (green), with snow pit raw (grey) and annual average (blue) values from 2006-2012. Grey vertical bar indicates period of national environmental laws reforms in Southern Hemisphere countries. 


\begin{tabular}{|l|l|l|l|}
\hline \multicolumn{4}{|l|}{ Overall Characteristics of As - Table 5.1 } \\
\hline Time Period & $\begin{array}{l}\text { Average Concentration } \\
\text { (As) (ppt) }\end{array}$ & $\begin{array}{l}\text { Standard } \\
\text { Deviation }\end{array}$ & $\begin{array}{l}\text { Average Crustal } \\
\text { EF value }\end{array}$ \\
\hline $\begin{array}{l}\text { Early 20th Century Average (1885- } \\
1960)\end{array}$ & 1.73 & 0.82 & 98.56 \\
\hline 1970 to 2000 & 2.90 & 1.47 & 194.34 \\
\hline Snowpit (2006-2012) & 1.17 & 0.53 & 118.90 \\
\hline $\begin{array}{l}\text { Pre-Industrial Average (13- } \\
1800 A D)\end{array}$ & 0.73 & 0.27 & 114.01 \\
\hline MWP (800-1200AD) & 0.81 & 0.25 & 130.37 \\
\hline LIA (1300-1800 AD) & 0.64 & 0.22 & 119.23 \\
\hline
\end{tabular}

Table 5.1. Average concentrations and crustal enrichment values (using La as a conservative element) for As over different time periods in the RICE ice core.

\subsubsection{Sources of Pre-Industrial Arsenic}

We find that average concentrations of As changed by only $0.17 \mathrm{ppt}$ between $13 \mathrm{CE}$ and 1800 CE. While we find no apparent trends or significant peaks, statistically higher concentrations occurred during the Medieval Warm Period (MWP-800 CE to $1200 \mathrm{CE}$ ) compared to the Little Ice Age (LIA-1300 CE to $1800 \mathrm{CE}$ ) (Figure 5.1, Table 5.1). Though the MWP/LIA events were primarily northern hemisphere climate perturbations, concurrent changes in temperature, wind strength, sea ice extent, and marine primary productivity have been observed in Antarctic and high latitude records ${ }^{21,22}$. While the extent of climatic changes in Antarctic is uncertain during the MWP, several records have shown that during the LIA time period conditions in Antarctica were cooler with a higher frequency of storms ${ }^{22-24}$.

The few existing records of As in Antarctica have been used to suggest that the main natural source is volcanic emissions ${ }^{25-27}$. However, the absence of significant peaks in the RICE record at times of major known volcanic eruptions ${ }^{28}$, suggests either a strong local volcanic source (i.e. Mt Erebus), or alternative sources which mask volcanic contributions. We calculated crustal enrichment factors $(\mathrm{EFc})$ using Lanthanum $(\mathrm{La})$ as a conservative crustal element, by dividing the sample As/La ratio by the ratio of As/La in the upper crust (Table 5.1) ${ }^{29,30}$. As expected, the EFc values indicate that only insignificant contributions of As are derived from crustal dust sources. Calculated correlation coefficients with other trace elements analysed in the RICE ice core (Table 5.2) confirm that As does not correlate with crustal-associated or sea salt-associated elements, suggesting that these are not major natural sources (Table 5.2). Instead we find statistically significant correlation coefficients $(p \leq 0.01)$ 
with Sulfur (S), non-sea salt Sulfur (nssS), and Thallium (Tl). Spectral analyses indicate that $\mathrm{S}$ has very strong annual and six-monthly peaks, while As also has a strong annual peak along with other peaks at 8,6, and 5 month periods (Supplementary Figure 5.S1). Despite the variability in seasonal peaks in the As record, major As maxima coincide with $\mathrm{S}$ peaks (Figure 5.2). Volcanic emissions are important natural sources for both $\mathrm{Tl}$ and $\mathrm{S}$, however, we do not observe volcanic markers in the S record either. In coastal Antarctica, sea-salt S and other $\mathrm{S}$ sources can mask volcanic signatures ${ }^{22}$. In contrast, biogenic algae emissions have been identified as a significant source for S precipitation in coastal Antarctic snow ${ }^{31}$.

\begin{tabular}{|l|l|l|}
\hline Element & Pre-Industrial As & $20^{\text {th }}$ Century As \\
\hline $\mathrm{Al}$ & 0.142 & $\mathbf{0 . 3 3 7}$ \\
\hline $\mathrm{Fe}$ & 0.050 & $\mathbf{0 . 3 3 2}$ \\
\hline $\mathrm{La}$ & 0.053 & 0.127 \\
\hline $\mathrm{Mn}$ & 0.064 & $\mathbf{0 . 3 6 8}$ \\
\hline $\mathrm{Na}$ & -0.012 & -0.029 \\
\hline $\mathrm{Pb}$ & 0.029 & $\mathbf{0 . 4 2 2}$ \\
\hline $\mathrm{S}$ & $\mathbf{0 . 2 1 3}$ & 0.112 \\
\hline $\mathrm{nssS}$ & $\mathbf{0 . 2 1 6}$ & 0.146 \\
\hline $\mathrm{Sr}$ & -0.013 & -0.12 \\
\hline $\mathrm{Tl}$ & $\mathbf{0 . 3 2 4}$ & -0.01 \\
\hline
\end{tabular}

Table 5.2. Pearson's Linear Correlation coefficients between As and other elements from the RICE ice core. Bold numbers indicate R-values that are significant at $99 \%$. nssS is calculated using RICE concentrations of $\mathrm{Na}$, and the $\mathrm{S} / \mathrm{Na}$ ratio in sea-water ${ }^{32,33}$.

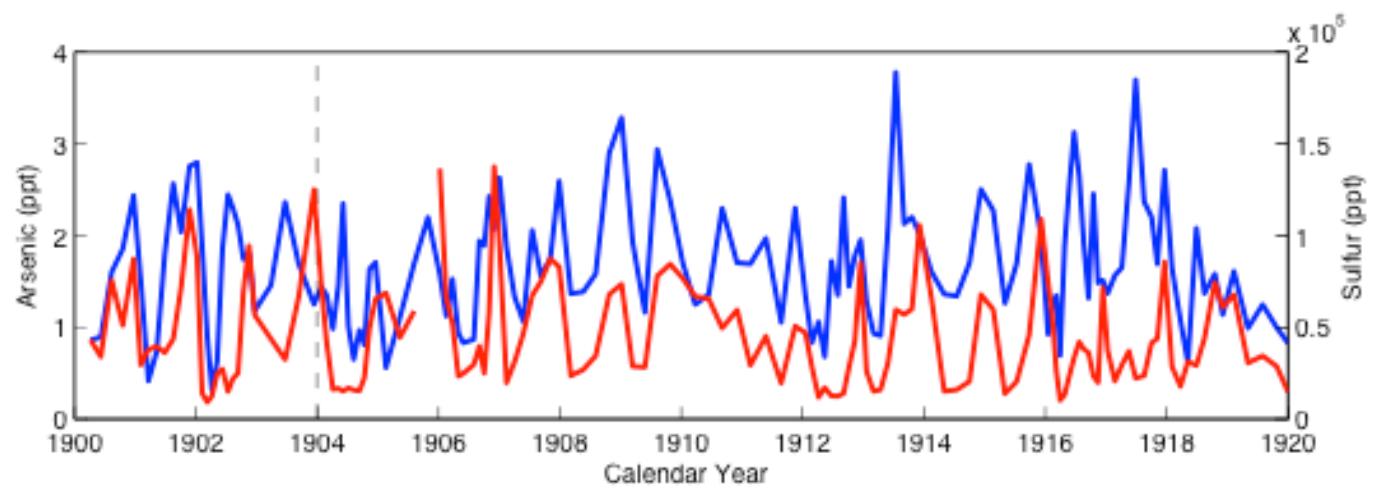

Figure 5.2. Concentrations of $\mathrm{S}$ (red) and As (blue) $(\mathrm{n}=121)$ showing co-occurrence of peaks. Dashed vertical line indicates 1904 Guatemala volcanic event recorded in WAIS Divide ice core $^{28}$, that occurs with low As concentrations in the RICE ice core. 
During summer months, the Ross Sea region exhibits a brief but high-vitality primary marine productivity with extensive algal blooms developing during late December-early January ${ }^{34-}$ ${ }^{36}$. These seasonal algal blooms emit dimethylsulfoniopropionate (DMSP) which produces as a metabolic by-product dimethylsulfide (DMS) ${ }^{37}$. Once emitted to the atmosphere DMS oxidizes to methanesulfonate (MS) and sulfate $\left(\mathrm{SO}_{4}\right)$. While the relative oxidation ratio of DMS into MS and $\mathrm{SO}_{4}$ is not known ${ }^{37}$, MS (measured as methanesulfonic acid - MSA) has successfully been used in the Ross Sea to quantify primary productivity ${ }^{31,38}$. Several studies have shown that As readily bio-accumulates in Antarctic algae through reduction and methylation and, among various organoarsenical compounds, also forms both dimethylarsinate (DMA) which oxidizes to methlyarsonate (MA) ${ }^{6,39,40}$. Our data show modest but significant correlations between RICE ice core MSA and As of $r=0.38(p<$ $0.01)$ and $\mathrm{S}$ and As of $\mathrm{r}=0.2(\mathrm{p}<0.01)$. We propose that this relationship suggests that organoarsenical compounds may be contributing to the natural As concentration variations in the Ross Sea region and perhaps the Southern Ocean.

\subsubsection{Arsenic over the 20 ${ }^{\text {th }}$ Century}

$20^{\text {th }}$ Century concentrations of As in snow and ice at Roosevelt Island are more than four times the average concentrations over the last 2000 years. In addition to variability in atmospheric concentration, transport efficiency to the ice core site could lead to variable concentrations recorded in the ice core. To evaluate the potential effect of transport on our data, we take advantage of the well-established atmospheric lead $(\mathrm{Pb})$ concentration record ${ }^{15}$. We propose that if more efficient/vigorous transport caused the substantial $20^{\text {th }}$ Century increase in the RICE As data, the RICE $\mathrm{Pb}$ record should exceed $\mathrm{Pb}$ concentrations from other Antarctic ice core records. Comparing our $\mathrm{Pb}$ record to the recently published stacked Antarctic $\mathrm{Pb}$ record ${ }^{15}$, we find that the RICE data capture well the character and total concentration levels of atmospheric $\mathrm{Pb}$ concentration (Supplementary Figure 5.S2). We therefore conclude that changes in transport efficiency, while significant, are unable to explain the entire variability in RICE $\mathrm{Pb}$ and As over the $20^{\text {th }}$ Century.

Average As concentrations increase from $0.7 \mathrm{ppt}$ over the past two millennia to $1.7 \mathrm{ppt}$ from 1880 AD (Table 5.2), however, the largest increase in concentrations occurs from the mid1970s. The highest concentrations in this record occur during the 1980s, with As concentrations exceeding pre-industrial concentrations by $400 \%$, reaching peak annual averages of 4.3 ppt (Figure 5.1, Table 5.1). Large increases in EFc values (peak value of 675, average 194) suggest this concentration increase is due to a new source that is most likely 
anthropogenic emissions (Table 5.1). Decoupling of As from S concentrations is indicated by a change to non-significant correlations over the $20^{\text {th }}$ Century (Table 5.2). This relationship change suggests a source of As that does not affect $\mathrm{S}$ concentrations. In contrast, As develops significant correlations with other heavy metal elements ( $\mathrm{Pb}, \mathrm{Fe}, \mathrm{Mn}, \mathrm{Al})$ known to exhibit large concentration increases due to anthropogenic emissions ${ }^{15,41,42}$.

Worldwide industrial production of As was estimated at 18,820 tonnes per year in 1983, but dropped to 5,011 tonnes per year by $1995^{43,44}$. From 1995 data, three South American countries are among the 10 largest emitters of As to the atmosphere from non-ferrous metal production, and globally, South America and Australasia together contributed $20 \%$ of the 1995 worldwide total As emissions ${ }^{44}$. The retention time for As in the atmosphere is between 7 and 10 days, and anthropogenically induced emissions of As are generally transported as particulates ${ }^{45}$. While the retention time is sufficient for anthropogenic emissions of As to reach Antarctica ${ }^{46}$, the short residence time suggests concentrations in snow should adjust rapidly to changes in anthropogenic emissions.

Public awareness of the toxicity of many pollutants grew during the 1990s, and several studies particularly focused on the health risks posed by As ${ }^{47,48}$. Recognition of the health effects posed by As lead to development of cross-industry regulation and health and safety procedures from the 1990s onwards, including a range of clean-air policies and a voluntary ban in As use for wood preservation in some countries ${ }^{49-51}$. Among the many environmental reforms of the early 1990s, South American countries (Chile, Argentina) introduced for the first time environmental constitutional amendments and national environmental laws, along with government bodies to oversee environmental management ${ }^{3-5}$. Similarly, in Australia and New Zealand a variety of amendments to existing environmental and health and safety policies, along with new laws were passed to tighten regulations of pollutant emissions and resource use during the early $1990 \mathrm{~s}^{52,53}$.

Our data suggest that the introduced policies along with public awareness successfully achieved a remarkable reduction in atmospheric As. The reduction in anthropogenic As emissions reaching Antarctica is discernible in the RICE ice core as a decrease in both As concentrations and EFc values from 1996 (Figure 5.1). Average concentrations in the surface snow (2006-2012) return to within the variability of early $20^{\text {th }}$ Century concentrations (Table 5.2), which are above natural variability but remain well below the peak emissions of the 1970s-1996 values. Curiously, EFc values decrease further to within pre-industrial variability 
of the natural baseline. On the basis of our results, we hypothesize that, in addition to industrial emissions, increased dust emissions from land-use changes over the $20^{\text {th }}$ Century such as open cast mining and deforestation, perhaps contributed to As emissions along with other pollutants (i.e. $\mathrm{Pb}$ ) and crustal elements (i.e. $\mathrm{Fe}, \mathrm{Al}$ ) that occur naturally in dust (thus reduced $\mathrm{EFc}$ ). However, the remarkable decrease in total concentration and the sharp drop in enrichment factors suggests that policy measure and public awareness have been highly successful in empowering industry to reduce As emissions.

\subsection{Methods}

A $763 \mathrm{~m}$ deep ice core was collected from Roosevelt Island and processed using a continuous melting procedure at the National Ice Core Research Facility, GNS Science, in New Zealand 54-56. In addition to the ice core, 150 samples were collected using clean-sampling techniques from a $3 \mathrm{~m}$ deep snow pit. A gold-plated copper melt-head, with a double ring configuration was used to separate clean inner ice core water from the contaminated outer part of prepared ice core rods. The water from the inner section was collected for discrete analysis by inductively coupled plasma mass spectrometer (ICPMS) using fraction collectors located inside HEPA-filtered hoods and ultra-clean (acid washed) vials.

Over 2000 ICPMS samples were analysed for concentrations of 37 different trace elements. All samples ( $4 \mathrm{~mL}$ ice core water) were acidified with $1 \%$ ultra-pure $\mathrm{HNO}_{3}$ three months prior to analysis. Trace element analyses took place in Perth, Australia, in the TRACE laboratory at Curtin University, using a Thermo Scientific Element XR ICPMS. Modifications were made to the sample introduction system to increase the sensitivity of the mass spectrometer, improving the precision and accuracy of measurements at very low concentrations (Neff et al., ES\&T submitted). Just over 784 samples were analysed from the top $40 \mathrm{~m}$ of the ice core as well as all 150 ICPMS samples from the snow pit, giving subannual resolution. 621 averaged samples ( $\sim 3$ year resolution) were prepared by combining $>10,000$ samples between $40 \mathrm{~m}$ to $320 \mathrm{~m}$ of the ice core. The combining was carried out in a class 1000 laboratory, with class 100 laminar flow hoods. Pipette tips underwent the same acid washing procedure as the vials, and furthermore were triple rinsed in ultra-pure $10 \%$ nitric acid, then in ultra-pure MQ water prior to being inserted into individual samples. Pipette tips were then discarded after every combined sample had been prepared. Procedural blanks were taken at every step (Supplementary Table 5.ST1). During the shipping process 40 samples spanning $20 \mathrm{~m}$ between $177.5 \mathrm{~m}$ and $198 \mathrm{~m}$ of the ice core were misplaced. We do 
not expect any departure outside the natural standard deviation from the mean to occur in any of these samples (Figure 5.1).

ICPMS counts were corrected for drift using the online internal standard (Indium, In). Concentrations were calculated from calibration curves based on robust linear regression with bi-square weighting of outliers, from 10 in-house standards made from certified single- and multi-element standards. Machine run blanks were subtracted from the concentrations. The quantification limit was calculated for each element as three times the standard deviation of the average run blank for each run. RICE sample As concentrations are between 2 and 3 times the procedural blank (Table 5.ST1).

Samples are assigned an age from the RICE 1.0 age scale which was accepted by the RICE community in 2014. This age scale is formed from annual layer counts based on chemistry measurements (primarily $\delta^{18} \mathrm{O}$ values, sulfur, sulfate, and iodine concentrations) from the top $40 \mathrm{~m}$ of the RICE ice core. This results in annual year counts back to $1890 \mathrm{CE}(38 \mathrm{~m})$ with an age uncertainty of \pm 1 year. A tephra layer at $165 \mathrm{~m}$ is identified as the $1257 \mathrm{CE}$ Unknown event. Continuous flow methane measurements and a one dimensional ice flow model were used to provide an approximate age model for ice depths below $40 \mathrm{~m}$. The calculated age below $1890 \mathrm{CE}$ has been evaluated using snow accumulation changes, which show a smooth transition. The delta gas/ice age has been calculated at the close off depth of $54 \mathrm{~m}$ at 120 years. The estimated age uncertainty below $1890 \mathrm{CE}$ increases to \pm 20 years. The snow pit age was also based on summer/winter layer counting of $\delta^{18} \mathrm{O}$ values and total sulfur concentrations, and was matched to the RICE 1.0 age scale, with samples spanning late 2006 to Jan 2012 with age uncertainty of \pm 0.5 year. 


\subsection{References}

1 Hughes, M. F. Arsenic toxicity and potential mechanisms of action. Toxicology Letters 133, 1-16 (2002).

2 Torseth, K. et al. Introduction to the European Monitoring and Evaluation Program (EMEP) and observed atmospheric composition change during 1972-2009. Atmospheric Chemsitry and Physics 12, 5447-5481 (2012).

3 Carruthers, D. Environmental policies in Chile: Legacies of dictatorship and democracy. Third World Quarterly 22, 343-358 (2001).

4 Hochstetler, K. After the boomerang: Environmental movements and politics in the La Plata River Basin. Global Environmental Politics 2, 35-57 (2002).

5 Nonna, S. C. in Sixth International Conference on Environmental Compliance and Enforcement.

6 Farias, S. et al. Total and inorganic arsenic in Antarctic macroalgae. Chemosphere 69, 1017-1024 (2007).

7 Barnes, H. M., Freeman, M. H., Shupe, T. F. \& Vlosky, R. P. Past, present, and future of the wood preservation industry: wood is a renewable natural resource that typically is preservative treated to ensure structural integrity in many exterior applications. Forest Products Journal 53, 8-15 (2003).

8 Bissen, M. \& Frimmel, F. H. Arsenic - a review. Part 1: Occurrence, toxicity, speciation, mobility. Acta Hydrochimica et Hydrobiologica 31, 9-18 (2003).

9 Mandal, B. K. \& Suzuki, K. T. Arsenic round the world: a review. Talanta 58, 201235 (2002).

10 Dixon, D., Mayewski, P. A., Goodwin, I. D., Marshall, G. J. \& Freeman, R. An icecore proxy for northerly air mass incursions into West Antarctica. International Journal of Climatology 32, 1455-1465 (2012).

11 Li, F., Ginoux, P. \& Ramaswamy, V. Transport of Patagonian dust to Antarctica. Journal of Geophysical Research 115, 1-9 (2010).

12 Mahowald, N. M. et al. Atmospheric global dust cycle and iron inputs to the ocean. Global Biogeochemical Cycles 19, 1-15 (2005).

13 Sigman, D. M. \& Boyle, E. A. Glacial/interglacial variations in atmospheric carbon dioxide. Nature 407, 859-869 (2000).

14 Perry, K. D., Cahill, T. A., Schnell, R. C. \& Harris, J. M. Long-range transport of anthropogenic aerosols to the National Oceanic and Atmospheric Administation baseline station at Mauna Loa Observatory, Hawaii. Journal of Geophysical Research 104, 18521-18533 (1999).

15 McConnell, J. et al. Antarctic-wide array of high-resolution ice core records reveals pervasice lead pollution began in 1889 and persists today. Nature: Scientific Reports 4, 1:5 (2014).

16 Nicolas, J. P. \& Bromwich, D. H. Climate of West Antarctica and influence of marine air intrusions. Journal of Climate 24, 49-67 (2011).

17 Cassar, N. et al. The Southern Ocean biological response to aeolian iron deposition. Science 317 (2007).

18 Bertler, N. A. N. et al. Snow chemistry across Antarctica. Annals of Glaciology 41, 167-179 (2005).

19 Legrand, M. \& Mayewski, P. A. Glaciochemistry of polar ice cores: A review. Reviews of Geophysics 53, 219-243 (1997).

20 Wolff, E. W. et al. Relationship between chemistry of air, fresh snow and firn cores for aerosol species in coastal Antarctica. Journal of Geophysical Research 103, 11,057-011,070 (1998).

21 Mayewski, P. A. et al. Holocene climate variability. Quaternary Research 62, 243 255 (2004). 
22 Bertler, N. A. N., Mayewski, P. A. \& Carter, L. Cold conditions in Antarctica during the Little Ice Age - Implications for abrupt climate change mechanisms. Earth and Planetary Science Letters 308, 41-51 (2011).

23 Benoist, J. P., Jouzel, J., Lorius, C., Merlivat, L. \& Pourchet, M. Isotope climatic record over the last $2.5 \mathrm{ka}$ from Dome C, Antarctica, ice cores. Annals of Glaciology 3, 17-22 (1982).

24 Kreutz, K. J. et al. Bipolar changes in atmospheric circulation during the Little Ice Age. Science 277, 1294-1296 (1997).

25 Gabrielli, P. et al. Trace elements in Vostok Antarctic ice during the last four climatic cycles. Earth and Planetary Science Letters 234, 249-259 (2005).

26 Hur, S. D. et al. Climate-related variations in Sb and Tl in the EPICA Dome C ice (East Antarctica) during the past 800,000 years. Global Biogeochemical Cycles 27, 111 (2013).

27 Hong, S. et al. Evidence of global-scale As, Mo, Sb, and $\mathrm{Tl}$ atmospheric pollution in the Antarctic snow. Environmental Science \& Technology 46, 11550-11557 (2012).

28 Sigl, M. et al. A new bipolar ice core record of volcanism from WAIS Divide and NEEM and implications for climate forcing of the last 2000 years. Journal of Geophysical Research: Atmospheres (2013).

29 Gabrielli, P. et al. Variations in atmospheric trace elements in Dome C (East Antarctica) ice over the last two climatic cycles. Atmospheric Environment 39, 64206429 (2005).

30 Wedepohl, K. H. The composition of the continental crust. Geochimica et Cosmochimica Acta 59, 1217-1232 (1995).

31 Rhodes, R. H. et al. Sea ice variability and primary productivity in the Ross Sea, Antarctica, from methylsulphonate snow record. Geophysical Research Letters 36 (L107041), 1-5 (2009).

32 Goldberg, E. D. in Chemical Oceanography (eds J P Riley \& G Skirrow) Ch. 5, 163196 (Academic Press, 1965).

33 Wolff, E. W. et al. Changes in environment over the last 800,000 years from chemical analysis of the EPICA Dome C ice core. Quaternary Science Reviews 29, 285-295 (2010).

34 Arrigo, K. R. \& van Dijken, G. L. Annual changes in sea-ice, chlorophyll a, and primary production in the Ross Sea, Antarctica. Deep-Sea Research II 51, 117-138 (2004).

35 Ducklow, H. W. et al. Water-column processes in the West Antarctic Peninsula and the Ross Sea: Interannual variations and foodweb structure. Deep-Sea Research II 53, 834-852 (2006).

36 Winton, V. H. L. et al. The contribution of aeolian sand and dust to iron fertilization of phytoplankton blooms in southwestern Ross Sea, Antarctica. Global Biogeochemical Cycles 28, 423-436 (2014).

37 Saltzman, E. S., Dioumaeva, I. \& Finley, B. D. Glacial/interglacial variations in methanesulfonate (MSA) in the Siple Dome ice core, West Antarctica. Geophysical Research Letters 33, 1-4 (2006).

38 DiTullio, G. C., Jones, D. R. \& Geesey, M. E. in Biogeochemistry of the Ross Sea, Antarct.Res. Ser. Vol. 78 Antarctic Research Series (eds G C DiTullio \& R B Dunbar) 279-294 (AGU, Washington, D.C., 2003).

39 Grotti, M., Lagomarsino, C., Goessler, W. \& Francesconi, K. A. Arsenic speciation in marine organisms from Antarctic coastal environments. Environmental Chemistry 7, 207-214 (2010).

40 Wuilloud, R. G., Altamirani, J. C., Smichowski, P. N. \& Heitkemper, D. T. Investigation of arsenic speciation in algae of the Antarctic region by HPLC-ICP-MS 
and HPLC-ESI-Ion Trap MS. Journal of Analytical Atomic Spectrometry 21, 12141223 (2006).

41 Boutron, C. F. \& Patterson, C. C. Relative levels of natural and anthropogenic lead in recent Antarctic snow. Journal of Geophysical Research 92, 8454-8464 (1987).

42 Vallelonga, P. et al. The lead pollution history of Law Dome, Antarctica, from isotopic measurements on ice cores: 1500 AD to 1989 AD. Earth and Planetary Science Letters 204, 291-306 (2002).

43 Nriagu, J. O. \& Pacyna, J. M. Quantitative assessment of worldwide contamination of air, water and soils by trace metals. Nature 333, 134-139 (1988).

44 Pacyna, J. M. \& Pacyna, E. G. An assessment of global and regional emissions of trace metals to the atmosphere from anthropogenic sources worldwide. Environmental Reviews 9, 269-298 (2001).

45 Matschullat, J. Arsenic in the geosphere - a review. The Science of the Total Environment 249, 297-312 (2000).

46 Li, F., Ginoux, P. \& Ramaswamy, V. Distribution, transport, and deposition of mineral dust in the Southern Ocean and Antarctica: Contribution of major sources. Journal of Geophysical Research: Atmospheres (1984-2012) 113 (2008).

47 Khan, B. I., Solo-Gabriele, H. M., Townsend, T. G. \& Cai, Y. Release of arsenic to the environment from CCA-treated wood. 1. Leaching and speciation during service. Environmental Science \& Technology 40, 988-993 (2006).

48 Hughes, M. F., Beck, B. D., Chen, Y., Lewis, A. S. \& Thomas, D. J. Arsenic exposure and toxicology: A historical perspective. Toxicological Sciences 123, 305-332 (2011).

49 Hsueh, L. Beyond regulations: Industry voluntary ban in arsenic use. Journal of Environmental Management 131, 435-446 (2013).

50 OECD/ECLAC. OECD Environmental Performace Reviews: Chile 2005. (OECD Publishing, 2005).

51 OECD. OECD Environmental Performance Reviews: Australia 2007. (OECD Publishing, 2008).

52 McLaughlin, M. J., Hamon, R. E., McLaren, R. G., Speir, T. W. \& Rogers, S. L. Review: A bioavailability-based rationale for controlling metal and metalloid contamination of agricultural land in Australia and New Zealand. Australian Journal of Soil Research 38, 1037-1086 (2000).

53 Memon, P. A. \& Gleeson, B. J. Towards a new planning paradigm? Reflections on New Zealand's resource management act. Environment and Planning B: Planning and Design 22, 109-124 (1995).

54 Bigler, M. et al. Optimization of high-resolution continuous flow analysis for transient climate signals in ice cores. Environmental Science \& Technology 45, 44834489 (2011).

55 Kaufmann, P. R. et al. An improved continuous flow analysis system for highresolution field measurements on ice cores. Environmental Science \& Technology 42, 8044-8050 (2008).

56 Osterberg, E. C., Handley, M. J., Sneed, S. B., Mayewski, P. A. \& Kreutz, K. J. Continuous ice core melter system with discrete sampling for major ion, trace element, and stable isotope analyses. Environmental Science Technology 40, 33553361 (2006).

57 Schulz, M. \& Mudelsee, M. REDFIT: estimating red-noise spectra directly from unevenly spaced paleoclimatic time series. Computers and Geosciences 28, 421-426 (2002).

58 Schulz, M. \& Stattegger, K. Spectrum: spectral analysis of unevenly spaced paleoclimatic time series. Computers and Geosciences 23, 929-945 (1997). 


\subsection{Supplementary Figures and Tables}
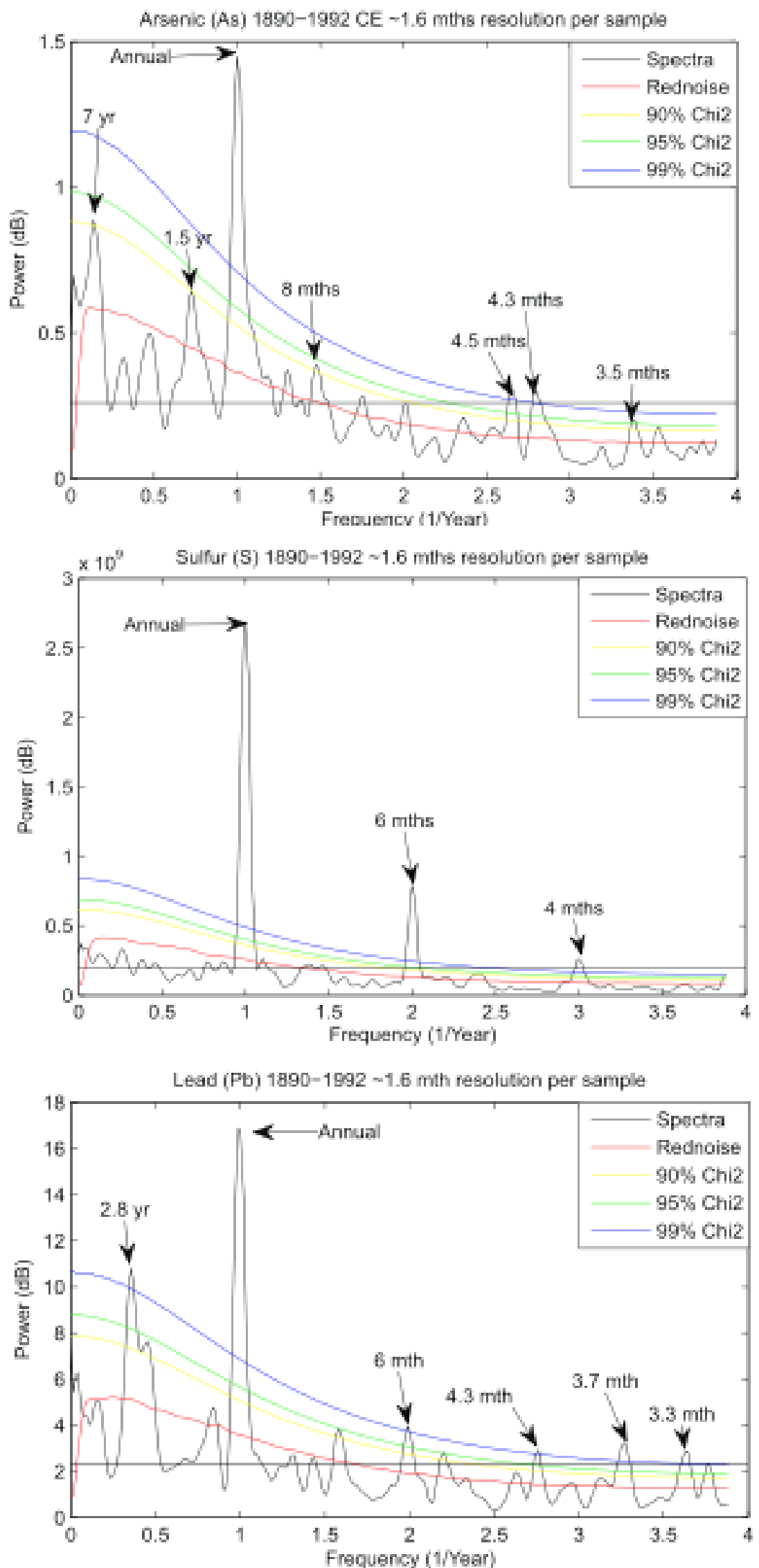

Figure 5.S1. Spectral analysis of arsenic (top), sulfur (middle), and lead (bottom) using Spectrum ${ }^{57,58}$. 


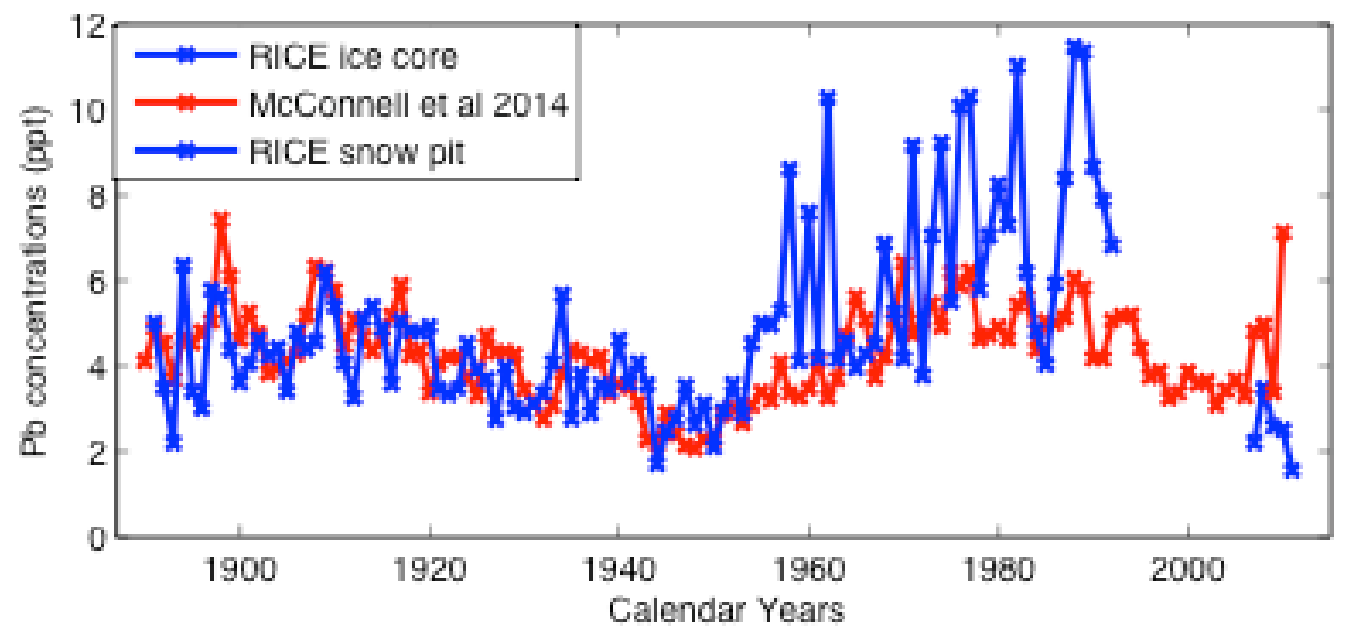

Figure 5.S2. Comparison of annual average lead $(\mathrm{Pb})$ concentrations in the RICE ice core and snow pit, and the stacked concentrations reported in McConnell et al. (2014) from 1880 AD to $2012 \mathrm{AD}$.

\begin{tabular}{|l|l|l|l|l|l|}
\hline $\begin{array}{l}\text { Isotope } \\
\text { (Resolution) }\end{array}$ & $\begin{array}{l}\text { Sample mean, } \\
\text { blank subtracted } \\
(\mathrm{n}=1405)\end{array}$ & $\begin{array}{l}\text { Sample } \\
\text { SD } \\
(\mathrm{n}=1405)\end{array}$ & $\begin{array}{l}\text { Analytical blank } \\
\text { mean }(\mathrm{n}=108)\end{array}$ & $\begin{array}{l}\text { Procedural blank } \\
\text { mean }(\mathrm{n}=27)\end{array}$ & $\begin{array}{l}\text { LOD } \\
(3 * \text { analytical } \\
\text { blank })\end{array}$ \\
\hline As 75 (HR) & 1.426 & 1.060 & 0.274 & 0.700 & 0.822 \\
\hline
\end{tabular}

Table 5.ST1. Mean sample and blank concentrations, limits of detection. Concentrations are in parts per trillion (ppt). 


\title{
Chapter 6 - Heavy Metal Pollutants over the last 2,000 years at Roosevelt Island, Antarctica
}

\author{
A.J. Tuohy ${ }^{1,2}$, N.A.N. Bertler ${ }^{1,2}$, R. Edwards ${ }^{3}$, P. Neff ${ }^{1,2}$, D. Sinclair ${ }^{2}$ \\ 1 - Antarctic Research Centre, Victoria University of Wellington, New Zealand \\ 2 - GNS Science, Wellington, New Zealand \\ 3 - Department of Imaging and Applied Physics, Curtin University, Perth, Australia
}

Corresponding Author: A.J. Tuohy, Antarctic Research Centre, Victoria University of Wellington, PO Box 600, Wellington 6140, New Zealand. (andrea.tuohy@vuw.ac.nz)

\subsection{Foreword}

This chapter contains a draft manuscript in preparation for submission to the journal Climate of the Past - Discussions. I have led the preparation of this manuscript, with written contributions from all co-authors. In this paper we present changes in the Roosevelt Island ice core concentrations of iron, aluminium, manganese, lead, and thallium over the last 2,300 years. We compare $20^{\text {th }}$ Century increases with natural pre-industrial variability, and discuss the possible effect of changes in atmospheric transport on concentrations in addition to source emission changes.

\subsection{Abstract}

Over the last 150 years, we observe large increases in concentrations of a variety of heavy metals in Antarctic snow and ice; however, with the exception of $\mathrm{Pb}$, these appear to relate to increasing dust rather than to anthropogenic industrial emissions. We compare the $20^{\text {th }}$ Century concentration changes in iron $(\mathrm{Fe})$, aluminium $(\mathrm{Al})$, manganese $(\mathrm{Mn})$, lead $(\mathrm{Pb})$, and thallium (Tl) with natural concentrations and variability over the last $\sim 2,000$ years in a new, high-resolution ice core record from the Ross Sea region. We also evaluate changes in atmospheric transport and source emissions, and show that heavy metal elements in coastal Antarctic snow and ice derive from several different sources. $\mathrm{Pb}$ is the only heavy metal that shows a pattern of $20^{\text {th }}$ Century concentration change characteristic of anthropogenic emissions. We find that enhanced atmospheric transport and increases in crustal dust account for up to a five-fold increase in $\mathrm{Fe}, \mathrm{Al}$, and Mn concentrations over pre-industrial levels. 


\subsection{Introduction}

Heavy metals are a key resource underpinning global industrialisation, however, in the environment they are also biological toxins (Hughes, 2002). Metal emissions are well known to contaminate local soil and water in industrial areas, and small-size particulates $\left(\mathrm{PM}_{10}\right.$, $\mathrm{PM}_{2.5}$ ) bearing heavy metals have the potential to be transported long-distances in the atmosphere (Allen et al., 2001). Observational records of heavy metal concentrations are sparsely located and cover short timescales (Fowler, 1990; Martin and Richardson, 1991). Generally such records monitor point source emissions such as metal smelters or coal-fired energy plants (Pilgrim and Hughes, 1994). Hence, the hemispheric and global pattern of background contamination is relatively unknown for many pollutants.

Heavy metal concentrations from ice and snow in Antarctica can provide records that are representative of hemispheric-wide changes in heavy metals through long-periods of time (Gabrielli et al., 2005b). Antarctica is isolated from all major anthropogenic sources of heavy metals, thus ice core records can be used to distinguish background concentration and pollutant transport changes (Marteel et al., 2008). Moreover, ice cores from coastal regions with high annual snow accumulation can provide high-resolution records, allowing the timing of significant changes in source and concentration to be accurately dated.

Here we present a 2,300-year record of five heavy metal elements ( $\mathrm{Fe}, \mathrm{Al}, \mathrm{Mn}, \mathrm{Pb}$, and $\mathrm{Tl}$ ) from a new ice core from the Ross Sea region. Roosevelt Island is a small (550 $\mathrm{m}$ above sea level) ice dome, located at the north-eastern edge of the Ross Ice Shelf. We focus on highresolution data from a $3 \mathrm{~m}$ deep snow pit, and from the top $320 \mathrm{~m}$ of a $760 \mathrm{~m}$ deep ice core, drilled to bedrock during two austral summer field seasons in 2011/2012 and 2012/2013. These samples were collected as part of the Roosevelt Island Climate Evolution (RICE) project.

We also consider the role of atmospheric transport in affecting heavy metal concentrations, and use spectral analysis to investigate annual to decadal oscillations in heavy metals. Over the last $\sim 2,000$ years global climate records suggest there have been several climate perturbations (Mann, 2003). Prior to the $20^{\text {th }}$ Century, the warmest period globally was between $800 \mathrm{CE}$ and $1100 \mathrm{CE}$ and is known as the Medieval Warm Period (MWP), while the coldest period globally occurred between $1400 \mathrm{CE}$ and $1800 \mathrm{CE}$ and is known as the Little Ice Age (LIA) (MacFarling Meure et al., 2006; Mann, 2003; Mann et al., 2008). Records show climatic changes were strongest in the Northern Hemisphere, though changes in 
temperature and wind strength also occurred in the Southern Hemisphere, including in Antarctica (Bertler et al., 2011; MacFarling Meure et al., 2006). If we compare $20^{\text {th }}$ Century concentrations of heavy metal pollutants to concentrations and natural variability during these climate shifts we can place anthropogenic contributions into the context of natural environmental processes.

Over the $20^{\text {th }}$ Century an increase in the strength of poleward atmospheric transport has been observed (Fogt et al., 2009; Marshall, 2003). This atmospheric change could cause increases in concentrations of heavy metals in Antarctic snow and ice even if pollutant emissions were constant. The Southern Annular Mode (SAM) describes zonally symmetric daily pressure fluctuations around the southern high latitudes, with a characteristic wavenumber-3 signature (Arblaster and Meehl, 2006). The SAM index describes positive and negative departures from the mean on monthly and annual time scales (Gong and Wang, 1999). Since the 1970s the SAM index has shown an increasing trend to positive index values, and this is associated with increased wind speeds and lower sea surface pressure around Antarctica (Fogt et al., 2009; Marshall, 2003). The SAM has also been linked to the surface pressure and temperature in the Pacific and El Niño Southern Oscillation (ENSO), suggesting that there is variability in the Pacific-region teleconnection between low and high southern latitudes (Fogt et al., 2011; Turner, 2004). Because atmospheric transport affects the delivery of particulates and heavy metals to Antarctica, it has been suggested that increased transport efficiency could lead to an increase in heavy metals deposited in Antarctic snow and ice (Laluraj et al., 2014; McConnel et al., 2007). Here, we compare the variability between the pre-industrial and the $20^{\text {th }}$ century to evaluate the impact of changes in atmospheric transport on heavy metal concentrations in the Ross Sea region.

\subsection{Methods}

We present data spanning the last 2,300 years collected from Roosevelt Island. A $3 \mathrm{~m}$ deep snow pit was sampled for Inductively Coupled Plasma Mass Spectrometric (ICPMS) analysis using extensive clean-handling procedures at $2 \mathrm{~cm}$ resolution (150 samples). A $20 \mathrm{~m}$ shallow firn core was collected in addition to the main RICE ice core, drilled from $8 \mathrm{~m}$ to bedrock at $763 \mathrm{~m}$. All ice cores and snow pit samples were transported frozen to New Zealand, and were processed at the GNS Science Ice Core Facility in Wellington. The snow pit samples were transferred to pre-cleaned (acid washed) vials, and stored frozen until acidification and analysis. 
A pre-cleaned, inner $34 \times 34 \mathrm{~mm}$ section of each meter of the core was sampled using a continuous melter system (Kaufmann et al., 2008; Osterberg et al., 2006). A heated goldplated copper melt head with a double ring configuration was used to separate the melt water of the inner, pristine part of the core section from the outer part. The inner fraction of ice core melt-water was pumped to discrete fraction collectors located inside HEPA-filtered hoods, and $10 \mathrm{~mL}$ pre-cleaned (acid washed) vials were filled with $\sim 4 \mathrm{~mL}$ of water.

All samples, (150 - snow pit, 212 - $20 \mathrm{~m}$ firn core, 786 - top $40 \mathrm{~m}$ ice core) were acidified to $1 \%$ with ultra-pure grade nitric acid three months prior to analysis. Samples below $40 \mathrm{~m}$ (1890 common era (CE)) were combined to make four-year averaged samples. This involved preparing 621 samples from $>10,000$ discrete vials. In order to obtain a sample resolution of $\sim$ four years we used the modelled age of the ice to determine the number of discrete vials required per combined sample (Fudge, personal communication, 2015). This resulted in combining progressively fewer discrete samples with depth due to the modelled densification and thinning of the ice.

All sample preparation was carried out in the Victoria University of Wellington (VUW) Geochemical facilities in a class 100 clean laboratory, equiped with class 10 laminar flow hoods. Pipette tips underwent the same acid washing procedure as the vials, and furthermore were conditioned in two separate vials of ultra-pure trace element grade $10 \%$ nitric acid, then in ultra-pure Milli-Q (MQ, >18.2 M $)$ water prior to use. Pipette tips were discarded after every combined sample had been prepared and blanks were taken to monitor contamination from pipettes, vials, room conditions and acid.

More than 2,000 samples were analysed for concentrations of 37 different trace elements at the Trace Research Advanced Clean Environment (TRACE) laboratory, Curtin University, Perth, Australia. A Thermo Scientific Element XR SF-ICPMS was used, with modifications to the sample introduction system to improve sensitivity in order to successfully analyse very low concentrations of transition metal elements and rare earth elements ( 7 million cps, 0.5 ppb Indium) (Neff et al. ES\&T in review). ICPMS counts were corrected for drift using the online internal standard (Indium, In, at $0.5 \mathrm{ppb}$ ). Element concentrations were calculated from calibration curves utilising a robust-fit and bi-square weighting of outliers, which used 10 points based on known concentrations of a serially-diluted in-house standard (prepared from NIST traceable single element solutions). Calibration standards were analysed at the beginning, middle and end of each run, to further assist any drift corrections. An analytical 
run consisted of 200 RICE samples, and every 10 samples were bracketed by instrument blacks of double distilled $1 \% \mathrm{HNO}_{3}$, and quality control samples. Average instrument blanks $(\mathrm{n}=>10)$ were subtracted from the element concentrations from each analytical run. The detection limit for each element was calculated as three times the standard deviation of the overall average run blank.

Following analysis it appeared that the $20 \mathrm{~m}$-firn core was contaminated for some heavy metal elements $(\mathrm{Fe}, \mathrm{Al}, \mathrm{Mn}, \mathrm{Pb})$, particularly in the topmost four metres, which are the most porous surface layers, and which showed greatly elevated concentrations compared to the snow pit samples. Hence, this dataset has been removed and there is a gap in the heavy metal time-series between the end of the snow pit $(3 \mathrm{~m}, \sim 2006)$ and the start of the main RICE ice core $(8.4 \mathrm{~m}, \sim 1992)$. In addition to this, one analytical run comprising 200 combined samples between $40 \mathrm{~m}$ and $177 \mathrm{~m}$ of the RICE ice core were contaminated for Pb concentrations. These have been removed from the $\mathrm{Pb}$ time-series. The remaining heavy metal elements in this analysis were not affected.

Crustal enrichment factors $(\mathrm{EFc})$ have been calculated here using Lanthanum (La) as the conservative element. EFc values are calculated by dividing the Element-La ratio in the ice core samples with the Element-La ratio in the upper crust $\left(\mathrm{E} / \mathrm{La}_{\text {sample }} / \mathrm{E} / \mathrm{La}_{\text {crust }}\right)(\mathrm{Gabrielli}$ et al., 2005a), using upper crustal average concentrations of trace elements as reported in Wedepohl et al. (1995). When calculating crustal enrichment factors it is important to use a conservative element that is known to derive predominantly from crustal rock dust (Gabrielli et al., 2005a). Lanthanides are ubiquitous trace elements in the upper continental crust, thus the predominant source of La in Antarctic snow and ice is crustal dust particulates (Nriagu, 1989). This means that La can be used successfully as a conservative element to calculate enrichment ratio values of other elements over crustal dust. Furthermore, the other usual crustal tracers (Al, Fe, Mn) are elements of interest in this study (Gabrielli et al., 2005a; McConnell et al., 2002).

\subsubsection{RICE Age Scale}

Samples are assigned an age from the RICE 2 ka 1.0 age scale which was accepted by the RICE community in 2014, and modified in 2015. This age scale is formed from annual layer counts based on chemistry measurements (primarily $\delta^{18} \mathrm{O}$ values, sulfur, sulfate, and iodine concentrations) from the top $40 \mathrm{~m}$ of the RICE ice core. This results in annual year counts back to $1890 \mathrm{CE}(38 \mathrm{~m})$ with an age uncertainty of $+/$ - one year. The age scale between $40 \mathrm{~m}$ 
and $320 \mathrm{~m}$ is based on six methane ages that have been tied to the well-dated WAIS Divide ice core (Members, 2013), and a tephra layer at $165 \mathrm{~m}$ that is identified as the $1252 \mathrm{CE}$ unknown volcanic event (Kurbatov, Lee, personal communication, 2015). The age scale has been interpolated between these age-tie points using a Nye-interpolation, and has been adjusted for accumulation changes (Fudge, Lee, personal communication, 2015). The snow pit age was based on summer/winter layer counting of $\delta^{18} \mathrm{O}$ values and total sulfur concentrations, and was matched to the RICE 1.0 age scale, resulting in very high-resolution samples from late 2006 to Jan 2012 with an age uncertainty of one year.

\subsection{Results and Discussion}
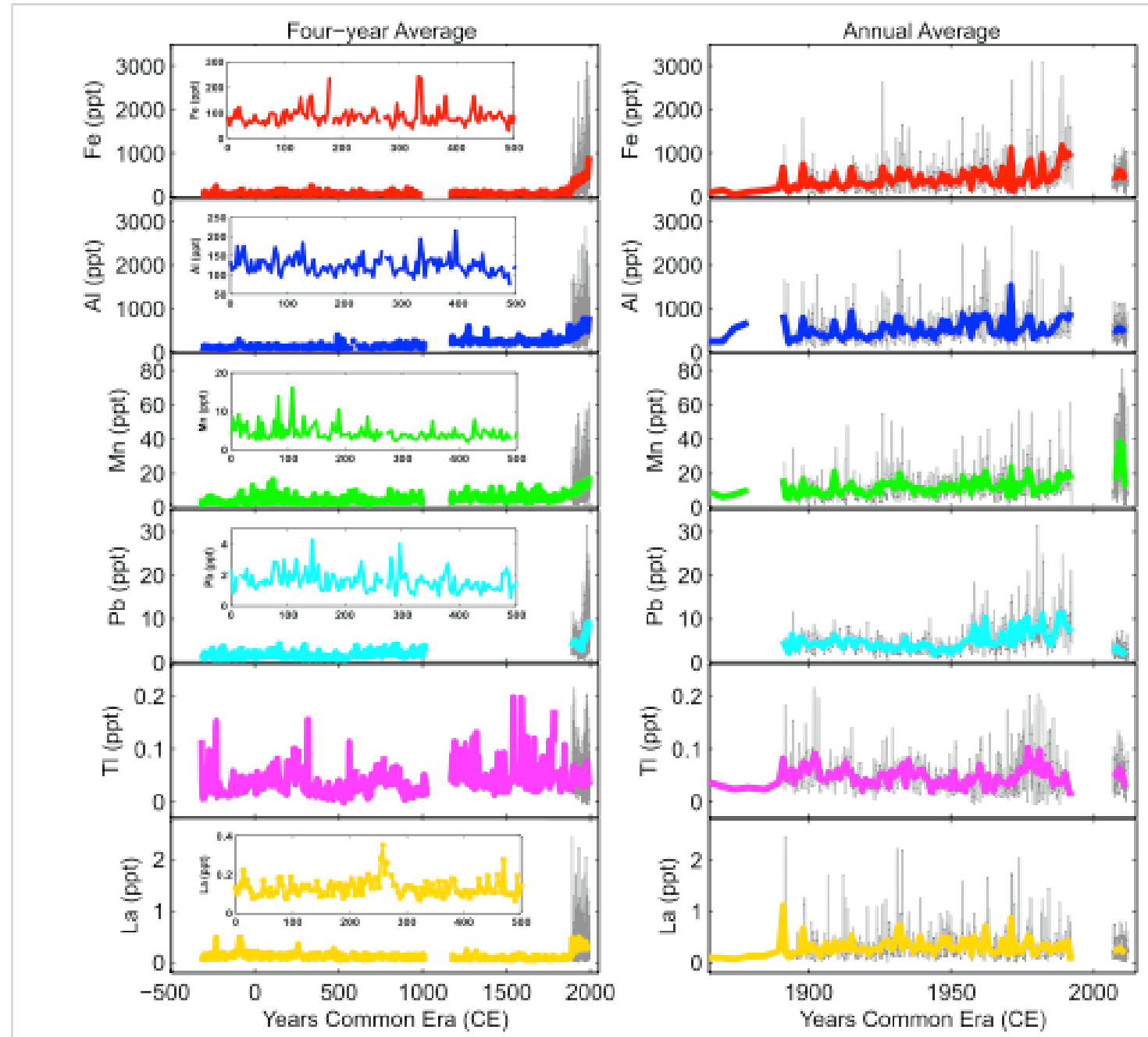

Figure 6.1. Heavy metal concentrations over the last 2,300 years. Inset figures show heavy metal concentrations and variability between $0 \mathrm{CE}$ and $500 \mathrm{CE}$. On plots to the left, coloured points indicate four-year average values, grey points indicate raw values. On plots to the right, coloured points indicate annual averages, grey points indicate raw values. RICE snow pit data cover years $2006 \mathrm{CE}$ to $2012 \mathrm{CE}$. 


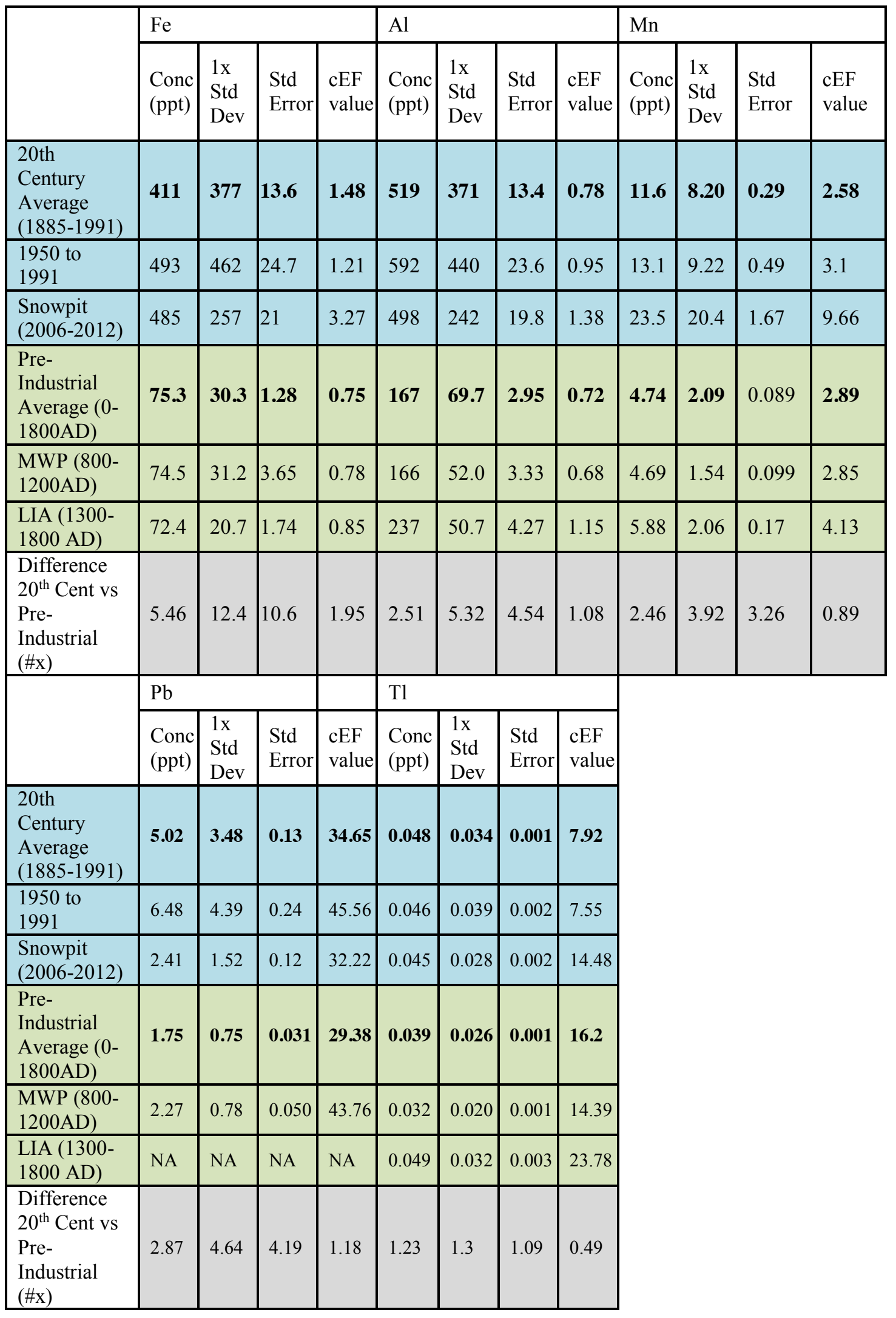

Table 6.1 - Concentrations in parts per trillion (ppt), and crustal Enrichment Factor (cEF) values for pre-industrial and industrial time periods. 


\subsubsection{Metal concentrations and variability}

Prior to the $20^{\text {th }}$ Century the concentrations of heavy metals recorded in the RICE ice core do not change significantly (Figure 6.1). The average concentrations of the five heavy metals considered here remain within natural variability during both the MWP and the LIA (Table 6.1). This suggests that there have been no changes in either the sources for these metals or the atmospheric transport efficiency large enough to significantly change the concentrations recorded at Roosevelt Island. In contrast to the pre-industrial period, there are large increases in heavy metal concentrations from the end of the $19^{\text {th }}$ Century. Average $20^{\text {th }}$ Century Fe concentrations are five times higher than the pre-industrial average, while $\mathrm{Al}, \mathrm{Mn}$, and $\mathrm{Pb}$ are 2, 2.4, and 2.9 times higher respectively. These concentrations are well outside the variability observed during the last 2,300 years, and suggest significant changes in the source emissions and atmospheric transport of heavy metals has occurred.

While there are few records of heavy metal concentrations beyond some observational data, there has been an emerging array of records for $\mathrm{Pb}$ concentrations from Antarctica (Barbante et al., 1997; Planchon et al., 2003; Vallelonga et al., 2002; Wolff and Suttie, 1994). For this reason we compare the $\mathrm{RICE} \mathrm{Pb}$ data with the Antarctic $\mathrm{Pb}$ array to evaluate potential influences of changes in transport efficiency on the RICE heavy metal concentrations. A recent paper summarises the $20^{\text {th }}$ Century changes in atmospheric $\mathrm{Pb}$ concentration through a stacked record of 11 ice cores (McConnell et al., 2014). This record highlights the large increase in $\mathrm{Pb}$ concentrations at the end of the $19^{\text {th }}$ Century, and shows a double peak in $\mathrm{Pb}$ concentrations through the $20^{\text {th }}$ Century in the early 1900s and in the 1980s (McConnell et al., 2014). Our $\mathrm{Pb}$ record is similar to the stacked record both in trends and in total concentration (Figure 6.2). We observe an initial peak in 1905, followed by a decrease in both concentrations and EFc values during the 1920s-1940s, and an increase to the highest average concentrations during the 1980s. Furthermore, our $\mathrm{Pb}$ record agrees with the decreasing trend in concentrations from the mid-1990s, though our record shows this continues to the present, in contrast to the data array published by McConnell et al. (2014). In our record $\mathrm{Pb}$ concentration in the surface snow pit (2006 to 2012) decreases to an average of $2.4 \mathrm{ppt}$, which is within the pre-industrial natural variability. This may suggest that nationallevel policies to reduce $\mathrm{Pb}$ emissions, particularly the removal of $\mathrm{Pb}$ from petrol, has been effective in reducing the atmospheric concentrations of $\mathrm{Pb}$. 


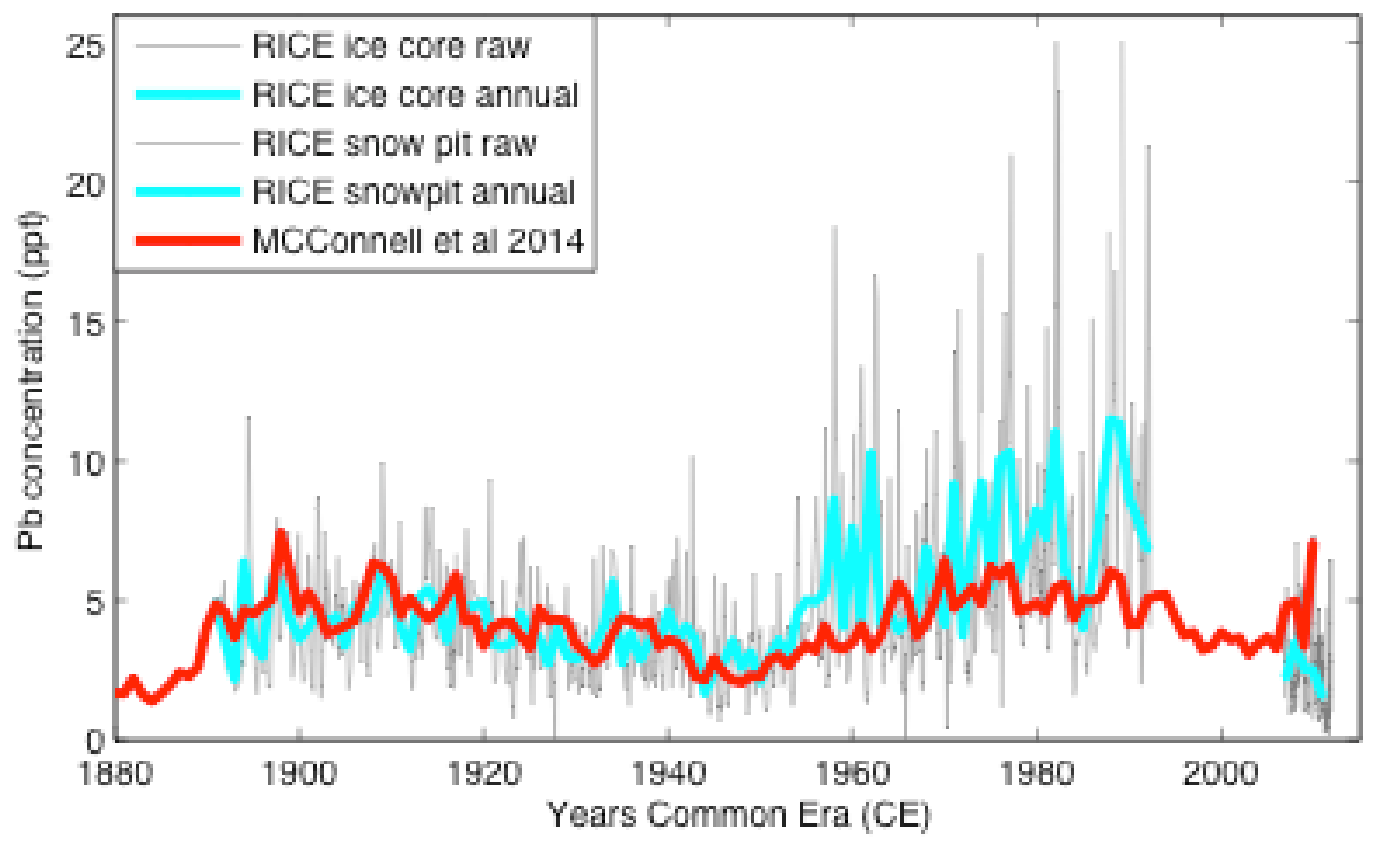

Figure 6.2. Pb concentration values from 1885 to the present, from the RICE top $40 \mathrm{~m}$ and the RICE snow pit in comparison to the stacked annual average concentrations from McConnell et al. (2014).

\subsubsection{Heavy Metal Sources}

We applied analytical techniques that measure total leachable concentrations. It is prudent to consider the partitioning of these elements between particulate-bound and dissolved phases present in aerosols, though the partitioning may vary from site to site (Ugletti et al., 2014). On average, $70 \%$ to $100 \%$ of $\mathrm{Fe}, \mathrm{Al}$, and $\mathrm{Mn}$ are derived from crustal particulates (Grotti et al., 2011). In contrast to Fe, Mn, and Al, Grotti et al., (2011) showed that at coastal sites $\mathrm{Pb}$ was partitioned between particulate and dissolved phases, with $\sim 50 \%$ derived from particulates. Thus crustal dust is not the only source of $\mathrm{Pb}$ to Antarctic snow, and sources such as volcanic degassing may also contribute to the $\mathrm{Pb}$ concentrations (Matsumoto and Hinkley, 2001).

The pre-industrial EFc value can also be used to indicate the presence of sources other than crustal dust. Values close to unity (e.g. less than 5) indicate that crustal dust is the dominant source of the element (Table 6.1) (Gabrielli et al., 2005a). A change in the EFc value of an element can show if concentration changes are due to the introduction of new sources that do not affect the conservative crustal element. We observe no significant change in enrichment ratio values for $\mathrm{Fe}, \mathrm{Al}$, and $\mathrm{Mn}$ over the $20^{\text {th }}$ Century (Table 6.1). This is most likely due to an increase in La concentrations of 2.6 times the pre-industrial average, which is a proportional increase with the other heavy metals. This suggests that there is no new source 
of $\mathrm{Fe}, \mathrm{Al}$, and $\mathrm{Mn}$ during the $20^{\text {th }}$ Century and the increase in concentrations is due to an increase in crustal dust reaching Roosevelt Island. An increasing trend in dust flux to Antarctica has been reported in several other studies (Li et al., 2008; Mahowald et al., 2010; McConnell et al., 2007).

Correlations between different elements can be used to investigate the influence of additional sources through time. Correlation coefficients between pre-industrial element and industrial element concentrations are shown in Table 6.2. The data show that during the pre-industrial time period $\mathrm{Pb}$ correlates significantly $(<0.01)$ with $\mathrm{Fe}$, and very strongly with $\mathrm{Na}$ and $\mathrm{Sr}$ (Table 6.2). This suggests that while $\mathrm{Pb}$ is sourced from crustal particulate, the timing of deposition at RICE may coincide with peaks in sea salt aerosols (as represented by marine elements $\mathrm{Na}$ and $\mathrm{Sr}$ ). The elements expected to derive predominantly from crustal dust (La, $\mathrm{Al}, \mathrm{Fe}$, and $\mathrm{Mn}$ ) all show significant correlations with each other during the pre-industrial period.

\begin{tabular}{|c|c|c|c|c|c|c|c|c|c|c|c|c|}
\hline & \multicolumn{11}{|c|}{ Industrial } \\
\hline & & Al & As & $\mathbf{F e}$ & $\mathbf{L a}$ & Mn & $\mathbf{N a}$ & $\mathbf{P b}$ & $\mathbf{S}$ & nssS & $\mathrm{Sr}$ & Tl \\
\hline \multirow{11}{*}{ 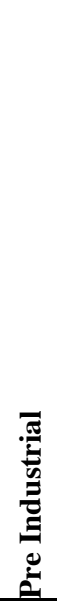 } & Al & & 0.337 & 0.894 & 0.517 & 0.890 & 0.075 & 0.791 & 0.156 & 0.125 & -0.03 & 0.015 \\
\hline & As & 0.142 & & 0.332 & 0.127 & 0.368 & -0.029 & 0.422 & 0.112 & 0.146 & -0.12 & -0.028 \\
\hline & $\mathbf{F e}$ & 0.277 & 0.050 & & 0.498 & 0.887 & 0.116 & 0.845 & 0.238 & 0.189 & 0.04 & 0.065 \\
\hline & $\mathbf{L a}$ & 0.321 & 0.053 & 0.457 & & 0.597 & -0.045 & 0.537 & 0.120 & 0.166 & 0.01 & 0.163 \\
\hline & Mn & 0.319 & 0.064 & 0.305 & 0.081 & & 0.063 & 0.789 & 0.161 & 0.138 & 0.00 & 0.050 \\
\hline & $\mathbf{N a}$ & 0.092 & -0.012 & 0.074 & -0.052 & 0.197 & & 0.004 & 0.478 & -0.142 & 0.82 & 0.085 \\
\hline & $\mathbf{P b}$ & 0.068 & 0.029 & 0.219 & -0.160 & 0.316 & 0.636 & & 0.236 & 0.265 & -0.06 & 0.157 \\
\hline & $\mathbf{S}$ & 0.222 & 0.213 & 0.078 & 0.253 & -0.063 & 0.277 & 0.030 & & 0.802 & 0.47 & 0.031 \\
\hline & nssS & 0.180 & 0.216 & 0.035 & 0.276 & -0.166 & -0.249 & -0.321 & 0.862 & & -0.03 & -0.023 \\
\hline & $\mathrm{Sr}$ & 0.064 & -0.013 & 0.053 & -0.053 & 0.197 & 0.952 & 0.645 & 0.186 & -0.312 & & 0.207 \\
\hline & Tl & -0.002 & 0.324 & 0.142 & 0.242 & 0.105 & -0.037 & 0.057 & -0.002 & 0.017 & -0.028 & \\
\hline
\end{tabular}

Table 6.2. Linear correlation coefficients (r-values) between different elements during preindustrial and industrial time periods. Bold values indicate significant $r$-values at $99 \%$, grey shaded boxes indicate very strong correlations.

There are few records of thallium ( $\mathrm{Tl}$ ) measurements in Antarctic snow or ice, and those that exist suggest the dominant source of $\mathrm{Tl}$ is volcanic emissions (Hong et al., 2012; Hur et al., 2013). For example, $\mathrm{Tl}$ has successfully been used as a tracer for volcanic eruptions in an ice core record from Bolivia (Kellerhals et al., 2010). The relatively low EFc value suggests that some proportion of $\mathrm{Tl}$ may derive from crustal dust, and this is supported by significant correlations with $\mathrm{La}$ and $\mathrm{Fe}$ (Table 6.2). The strongest correlation for $\mathrm{Tl}$ during the preindustrial is with As (Table 6.2), which also likely has a volcanic source (see Chapter 5). If 
volcanic emissions are a strong source of $\mathrm{Tl}$ to Roosevelt Island we would also expect significant correlations with sulfur (S) and non-sea-salt S. However, a large proportion of S appears to derive from sea salts, and this signal is likely to obscure the volcanic contribution at coastal sites in Antarctica (Bertler et al., 2011; Rhodes et al., 2009), explaining the lack of a relationship between $\mathrm{Tl}$ and $\mathrm{S}$.

\subsection{3 $20^{\text {th }}$ Century Source Changes}

The EFc values do not significantly change for Fe, Al, and $\mathrm{Mn}$. This suggests that there is no new source for these elements, and that the large concentration change is due to increased dust flux to coastal Antarctica. Tl EFc values decrease by $50 \%$, which may indicate that volcanic emissions of $\mathrm{Tl}$ have remained constant and an increase in dust deposition contributes a higher proportion over the $20^{\text {th }}$ Century. $\mathrm{Tl}$ is the only heavy metal element from the Roosevelt Island ice core that does not increase in concentration over the $20^{\text {th }}$ Century. In contrast, $\mathrm{EFc}$ values of $\mathrm{Pb}$ increase by a factor of 1.5, and the pattern of $\mathrm{EFc}$ increase matches the concentration increase. This suggests that a new source - anthropogenic industrial emissions - is contributing to the changes in $\mathrm{Pb}$ concentration.

We consider three possibilities that could lead to an increase in concentrations of $\mathrm{Fe}, \mathrm{Al}$, and Mn without changing the EFc ratio to La:

1- there is increased transport efficiency of dust to Roosevelt Island

2- there is increased dust loading in aerosols transported to Roosevelt Island

3- there is increased dust contribution from local large-particulate Antarctic sources

Air mass trajectory modelling for the time period covered in the RICE snow pit suggests current air mass pathways are primarily West-Antarctic/marine, and that recent heavy metal concentrations are linked to pole-ward moving air masses sourced from the South Pacific (Tuohy et al. JGR in review). The current major trajectory pathways have the potential to transport dust from local Antarctic source areas such as the McMurdo Dry Valleys and areas along the West Antarctic coast-line towards Roosevelt Island (Bromwich, 1991; Markle et al., 2012). Synoptic scale and mesoscale activity in the Ross Sea region may have been enhanced over the $20^{\text {th }}$ Century as the shift in the SAM to a more positive mode is related to strengthening of the Southern Ocean westerly winds and strength of cyclonic systems (Nriagu, 1989). This may be a possible source for the increase in crustal-associated heavy metals at Roosevelt Island, though it is clear from the RICE Pb record that long-distance 
transport of industrial pollutants also contributes to concentrations in snow and ice, and are representative of hemispheric trends.

We performed spectral analyses on the heavy metal time series in the RICE ice core to explore whether inter-annual transport variability in atmospheric circulation patterns such as the El Nino Southern Oscillation (ENSO) influences the concentrations at Roosevelt Island. The ENSO oscillation occurs on time scales of two to seven years, and has been suggested to affect transport efficiency and thus heavy metal concentration variability in Antarctica (Kestin et al., 1998; Wolter and Timlin, 2011).

Spectral frequencies present in the RICE heavy metal concentrations have been calculated using Spectrum and Redfit (https://www.marum.de/en/Michael_Schulz_Software.html, Schulz, 2013), programs designed to work with unevenly sampled data (Schulz and Mudelsee, 2002; Schulz and Stattegger, 1997). Frequencies have been calculated for two different time periods (Figure 6.3). First, frequencies were calculated for the pre-industrial time series, which have on average four-year resolution per sample. Second, frequencies were calculated for between the years of 1890 and 1992 using the high-resolution data from the top $40 \mathrm{~m}$ of the RICE ice core, with an average resolution of 1.6 months per sample, and which coincides with the anthropogenic era.

\begin{tabular}{|c|c|c|c|c|c|c|c|c|}
\hline & \multicolumn{8}{|c|}{ Significant Frequencies Present } \\
\hline & \multicolumn{3}{|c|}{ Pre-Industrial } & \multicolumn{5}{|c|}{ Industrial } \\
\hline & $90 y r s+$ & 20-30yrs & 10-12yrs & $5-7 \mathrm{yrs}$ & 2-3yrs & $1 \mathrm{yr}$ & 5-6mths & 3-4mths \\
\hline Al & 106 & & $11 / 13$ & 6 & $2 / 3$ & 1 & & \\
\hline $\mathbf{F e}$ & 133 & & $10 / 11$ & 6 & $2 / 3$ & 1 & 6 & 4 \\
\hline Mn & 120 & 17 & $8 / 10$ & & $2 / 3$ & 1 & 6 & \\
\hline $\mathbf{P b}$ & $90 / 50$ & $18 / 15$ & $9 / 11$ & & 2.8 & 1 & 6 & $3 / 4$ \\
\hline Tl & & $17 / 16$ & 10 & & & 1 & 9 & 3.5 \\
\hline $\mathbf{S}$ & & & & & & & 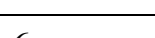 & 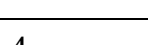 \\
\hline 3 & & $20 / 16$ & $8 / 11$ & & & 1 & 6 & 4 \\
\hline $\mathrm{Sr}$ & 105 & $15 / 20 / 33$ & $9 / 11$ & 8 & & 1 & 6 & \\
\hline $\mathbf{N a}$ & 105 & $15 / 20 / 34$ & $10 / 11$ & 8 & & 1 & 6 & 4 \\
\hline $\mathbf{L a}$ & 145 & & $11 / 13$ & 8 & $2 / 3$ & 1 & 9 & \\
\hline
\end{tabular}

Table 6.3. Frequency interval of significant spectral peaks in heavy metals and selected crustal and sea-salt associated elements. Blank spaces indicate no significant peak is present. Some elements have two significant peaks within the same period bracket, i.e. '2/3'. 

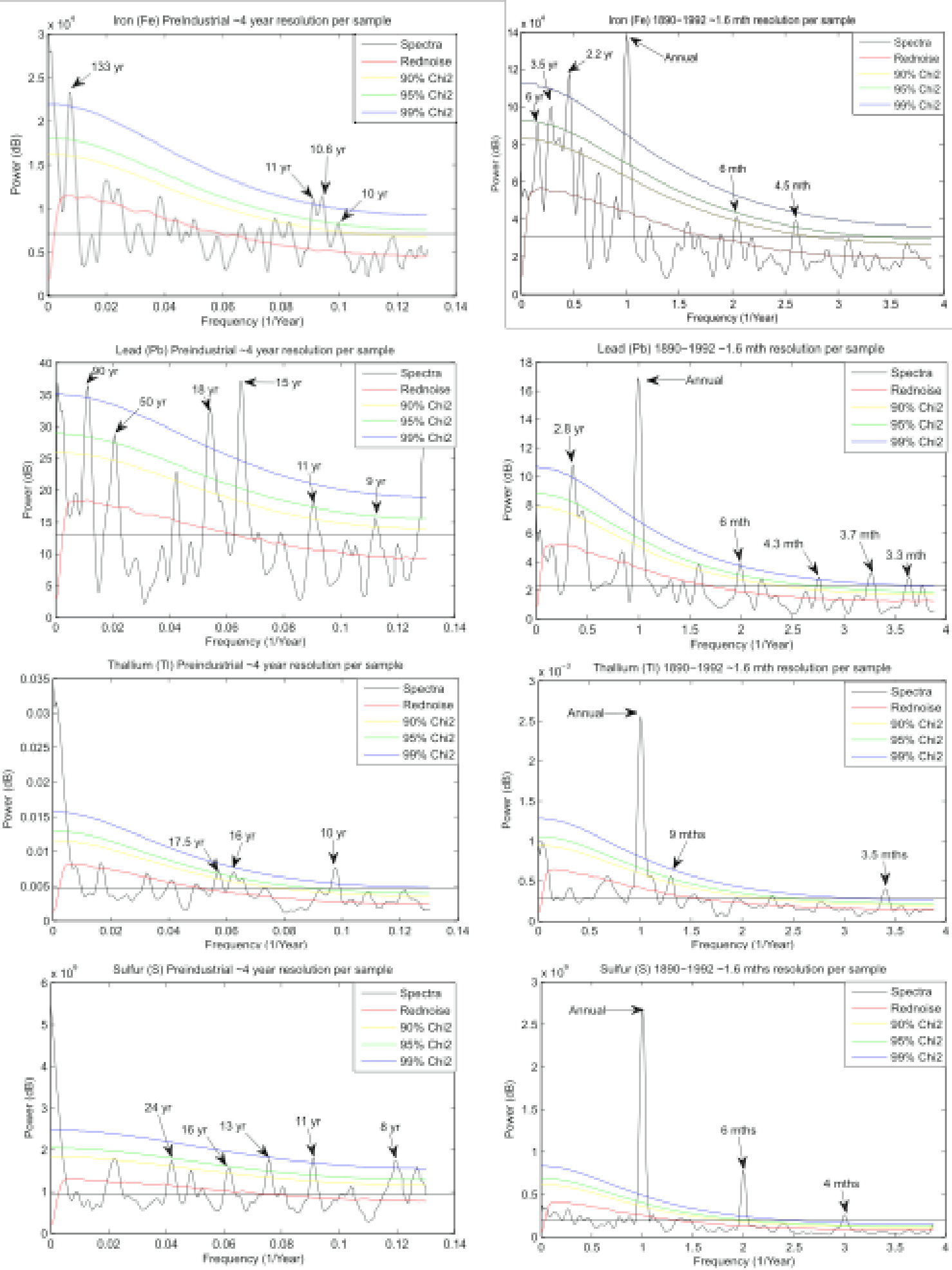

Figure 6.3. Spectral frequency plots for $\mathrm{Fe}, \mathrm{Pb}, \mathrm{Tl}$, and $\mathrm{S}$. Spectral frequencies calculated using pre-industrial (prior to $1800 \mathrm{CE}$ ) are on the left, spectral frequencies using $20^{\text {th }}$ century (1890 CE to $1992 \mathrm{CE}$ ) are on the right. Significant frequencies are labelled with the periodicity. 
The spectral frequencies in the heavy metal time series over the $20^{\text {th }}$ Century predominantly reflect the annual and six-monthly (seasonal) variations in concentration (Figure 6.3, Table 6.3). The complex seasonality present in heavy metal concentrations appears to be related to changes in atmospheric transport and accumulation events, along with increased particulate loading in summers (Tuohy et al. JGR in review). In addition we observe two- and three-year frequency peaks, which are particularly well developed in crustal dust associated elements ( $\mathrm{Al}, \mathrm{Fe}, \mathrm{Mn}, \mathrm{Pb}$, and La). Moreover, $\mathrm{La}, \mathrm{Fe}$, and $\mathrm{Al}$ show significant peaks at five- to sevenyear frequency. The co-variation of these elements suggests that these elements have the same transport mechanisms, and are influenced by ENSO cyclicity (Kestin et al., 1998). ENSO variability has also been reported for heavy metal time series from other Antarctic ice cores (McConnell et al., 2014). These frequencies are notably absent from $\mathrm{Tl}$ and S, which supports the assumption that they are linked to local Antarctic sources and are not affected by changes in long-distance transport.

We also observe significant frequencies at 10-12 years, 20-30 years, and 90-100 years. All the examined trace elements exhibit a periodicity of 10-12 years. While we are not able to show a physical mechanism that would create a decadal frequency, two suggestions have been made in the literature. Fogt and Bromwich (2006) linked the decadal frequency with changes in the SAM index and teleconnections in the Pacific region. In addition, the 11-year cycle is a well-established frequency of solar activity which has been shown to influence local atmospheric circulation (Bertler et al., 2005), and more generally on polar climate and atmospheric circulation (Rind, 2002).

The elements $\mathrm{S}, \mathrm{Tl}, \mathrm{Pb}, \mathrm{Mn}, \mathrm{Na}$, and $\mathrm{Sr}$ all show a spectral peak around 20-30 years. Both the Southern Annualar Mode (SAM) and the Pacific Decadal Oscillation (PDO) are known to oscillate on multi-decadal timescales, with the effect of modifying wind strength in the Southern Ocean (Marshall, 2003; Wolter and Timlin, 2011). This would primarily influence the atmospheric transport of sea-salt related elements around Antarctica. Although the instrumental record is generally too short to show multi-decadal periodicities of 20 to 30 years, spectral frequencies in this range have been observed in several other ice core records (Goodwin et al., 2004; Kreutz et al., 2000).

Finally there is another strong periodicity in the RICE heavy metal time-series (except for Tl and S) at 90-100 years. A range of climate proxy records, such as pollen records, lake sediments and ice cores (Mayr et al., 2007; Nielsen et al., 2004), have previously reported 
centennial-scale periodicities (Shulmeister et al., 2004). It has been hypothesised that there are oscillations in solar activity and atmospheric and oceanic transport patterns that occur on 100-year timescales (Nielsen et al., 2004; Stocker and Mysak, 1992).

While there have been new sources contributing to $\mathrm{Pb}$, and an increase in the dust flux to Antarctica over the $20^{\text {th }}$ Century, there have also been trends in atmospheric transport mechanisms that have increased the efficiency of particulate transport to Antarctica. These mechanisms are particularly important in the Pacific region, and hence have a high likelihood of affecting heavy metal concentrations in the RICE ice core. We observe significant increases of between $20 \%$ and $50 \%$ in heavy metal variability over the $20^{\text {th }}$ Century (Table 6.4). Similar increases in variability are present in sea-salt related $\mathrm{Na}$ and $\mathrm{S}$, in addition to crustal-related elements. This suggests that changes in atmospheric transport are contributing to increased trace element variability over the $20^{\text {th }}$ Century, as well as source changes.

\begin{tabular}{|l|l|l|l|l|l|l|l|l|l|l|}
\hline$\%$ & $\mathrm{Al}$ & $\mathrm{Fe}$ & $\mathrm{Mn}$ & $\mathrm{As}$ & $\mathrm{Pb}$ & $\mathrm{Tl}$ & $\mathrm{La}$ & $\mathrm{Na}$ & $\mathrm{Sr}$ & $\mathrm{S}$ \\
\hline $\begin{array}{l}\text { Pre Industrial (-320- } \\
\text { 1800 AD) }\end{array}$ & 41.8 & 40.2 & 44.2 & 36.7 & 42.6 & 67.4 & 46.6 & 39.0 & 70.5 & 27.7 \\
\hline $\begin{array}{l}\text { 20th Century (1950- } \\
\text { 1991) }\end{array}$ & 74.3 & 93.7 & 70.3 & 61.9 & 67.8 & 85.2 & 97.7 & 74.9 & 61.7 & 65.3 \\
\hline Difference (\%) & $\mathbf{3 2 . 5}$ & $\mathbf{5 3 . 5}$ & $\mathbf{2 6 . 1}$ & $\mathbf{2 5 . 1}$ & $\mathbf{2 5 . 2}$ & $\mathbf{1 7 . 8}$ & $\mathbf{5 1 . 0}$ & $\mathbf{3 6 . 0}$ & $\mathbf{- 8 . 8}$ & $\mathbf{3 7 . 6}$ \\
\hline
\end{tabular}

Table 6.4. Comparison of variability ( $1 \sigma$ as a percent of the mean) between the pre-industrial period and $20^{\text {th }}$ century.

\subsection{Conclusions}

Transport is an important contributor of natural variability affecting concentrations of heavy metals on inter-annual to decadal timescales, and occurs in conjunction with source emission changes over the $20^{\text {th }}$ Century. Over the last 150 years, we observe large increases in the concentrations of a variety of heavy metals; however, with the exception of $\mathrm{Pb}$ these appear to relate to increases in dust reaching Roosevelt Island, rather than to anthropogenic industrial emissions. As these concentration changes are much larger than those changes observed over natural climate events during the last 2,000 years, it seems likely that human produced changes in land-use have increased the amount of dust being entrained into the atmosphere, in conjunction with increased local Antarctic dust. Finally, although heavy metals are often grouped together in ice core proxy records, they derive from a range of sources and are affected by different transport and depositional mechanisms. These must be taken into account when interpreting heavy metal time series proxy records. 


\subsection{References}

Allen, A.G., Nemitz, E., Shi, H., R M, Greenwood, J.C., 2001. Size distributions of trace metals in atmospheric aerosols in the United Kingdom. Atmospheric Environment 35, 4581-4591.

Arblaster, J.M., Meehl, G.A., 2006. Contributions of external forcings to Southern Annular Mode trends. Journal of Climate 19, 2896-2905.

Barbante, C., Turetta, C., Capodaglio, G., Scarponi, G., 1997. Recent decrease in the lead concentration of Antarctic snow. International Journal of Environmental Analytical Chemistry 68, 457-477.

Bertler, N.A.N., Mayewski, P.A., Aristarain, A., Barrett, P., Becagli, S., Bernardo, R., Bo, S., Xiao, C., Curran, M., Qin, D., Dixon, D., Ferron, F., Fischer, H., Frey, M., Frezzotti, M., Fundel, F., Genthon, C., Gragnani, R., Hamilton, G., Handley, M., Hong, S., Isaksson, E., Kang, J., Ren, J., Kamiyama, K., Kanamori, S., Karkas, E., Karlof, L., Kaspari, S., Kreutz, K., Kurbatov, A., Meyerson, E., Ming, Y., Zhang, M., Motoyama, H., Mulvaney, R., Oeter, H., Osterberg, E., Proposito, M., Pyne, A., Ruth, U., Simoes, J., Smith, B., Sneed, S., Teinila, K., Traufetter, F., Udisti, R., Virkkula, A., Watanabe, O., Williamson, B., Winther, J.-G., Li, Y., Wolff, E., Li, Z., Zielinski, A., 2005. Snow chemistry across Antarctica. Annals of Glaciology 41, 167-179.

Bertler, N.A.N., Mayewski, P.A., Carter, L., 2011. Cold conditions in Antarctica during the Little Ice Age - Implications for abrupt climate change mechanisms. Earth and Planetary Science Letters 308, 41-51.

Bromwich, D.H., 1991. Mesoscale cyclogenesis over the Southwestern Ross Sea linked to strong katabatic winds. Monthly weather review 119, 1736-1753.

Fogt, R.L., Bromwich, D.H., Hines, K.M., 2011. Understanding the SAM influence on the South Pacific ENSO teleconnection. Climate Dynamics 36, 1555-1576.

Fogt, R.L., Perlwitz, J., Monaghan, A.J., Bromwich, D.H., Jones, J.M., Marshall, G.J., 2009. Historical SAM variability. Part II:Twentieth-century variability and trends from reconstructions, observations and the IPCC AR4 models. Journal of Climate 22, 5346-5365.

Fowler, S.W., 1990. Critical review of selected heavy metal and chlorinated hydrocarbon concentrations in the marine environment. Marine Environmental Research 29, 1-64.

Gabrielli, P., Barbante, C., Boutron, C., Cozzi, G., Gaspari, V., Planchon, F., Ferrari, C., Turetta, C., Hong, S., Cescon, P., 2005a. Variations in atmospheric trace elements in Dome C (East Antarctica) ice over the last two climatic cycles. Atmospheric Environment 39, 6420-6429.

Gabrielli, P., Planchon, F.A.M., Hong, S., Lee, K.H., Hur, S.D., Barbante, C., Ferrari, C.P., Petit, J.R., Lipenkov, V.Y., Cescon, P., 2005b. Trace elements in Vostok Antarctic ice during the last four climatic cycles. Earth and Planetary Science Letters 234, 249-259.

Gong, D., Wang, S., 1999. Definition of Antarctic oscillation index. Geophysical Research Letters 26, 459-462.

Goodwin, I.D., van Ommen, T.D., Curran, M.A.J., Mayewski, P.A., 2004. Mid latitude winter climate variability in the South Indian and southwest Pacific regions since 1300 AD. Climate Dynamics 22, 783-794.

Grotti, M., Soggia, F., Ardini, F., Magi, E., 2011. Major and trace element partitioning between dissolved and particulate phases in Antarctic surface snow. Journal of Environmental Monitoring 13.

Hong, S., Soyol-Erdene, T.-O., Hwang, H.J., Hong, S.B., Hur, S.D., Motoyama, H., 2012. Evidence of global-scale As, Mo, Sb, and $\mathrm{Tl}$ atmospheric pollution in the Antarctic snow. Environmental Science \& Technology 46, 11550-11557.

Hughes, M.F., 2002. Arsenic toxicity and potential mechanisms of action. Toxicology Letters $133,1-16$. 
Hur, S.D., Soyol-Erdene, T.-O., Hwang, H.J., Han, C., Glabrielli, P., Barbante, C., Boutron, C., Hong, S., 2013. Climate-related variations in $\mathrm{Sb}$ and $\mathrm{Tl}$ in the EPICA Dome $\mathrm{C}$ ice (East Antarctica) during the past 800,000 years. Global Biogeochemical Cycles 27, 111.

Kaufmann, P.R., Federer, U., Hutterli, M.A., Bigler, M., Schupbach, S., Ruth, U., Schmitt, J., Stocker, T.F., 2008. An improved continuous flow analysis system for high-resolution field measurements on ice cores. Environmental Science \& Technology 42, 80448050.

Kellerhals, T., Tobler, L., Brutsch, S., Sigl, M., Wacker, L., Gaggeler, H.W., Schwikowski, M., 2010. Thallium as a tracer for preindustrial volcanic eruptions in an ice core record from Illimani, Bolivia. Environmental Science \& Technology 44, 888-893.

Kestin, T.S., Karoly, D.J., Yano, J.-I., 1998. Time-frequency variability of ENSO and stochastic simulations. Journal of Climate 11, 2258-2272.

Kreutz, K.J., Mayewski, P.A., Pittalwala, I.I., Meeker, L.D., Twickler, M.S., Whitlow, S.I., 2000. Sea level pressure in the Amundsen Sea region inferred from a West Antarctic glaciochemical record. Journal of Geophysical Research 105, 4047-4059.

Laluraj, C.M., Thamban, M., Satheesan, K., 2014. Dust and associated geochemical fluxes in a firn core from coastal East Antarctica and its linkages with Southern Hemisphere climate variability over the last 50 years. Atmospheric Environment 90, 23-32.

Li, F., Ginoux, P., Ramaswamy, V., 2008. Distribution, transport, and deposition of mineral dust in the Southern Ocean and Antarctica: Contribution of major sources. Journal of Geophysical Research: Atmospheres (1984-2012) 113.

MacFarling Meure, C., Etheridge, D., Trudinger, C., Steele, P., Langenfelds, R., Van Ommen, T., Smith, A., Elkins, J., 2006. Law Dome CO2, CH4 and N2O ice core records extended to 2000 years BP. Geophysical Research Letters 33.

Mahowald, N., Kloster, S., Engelstaedter, S., Moore, J.K., Mukhopadhyay, S., McConnell, J.R., Albani, S., Doney, S.C., Bhattacharya, A., Curran, M.A.J., Flanner, M.G., Hoffman, F.M., Lawrence, D.M., Lindsay, K., Mayewski, P.A., Neff, J., Rothenberg, D., Thomas, E., Thornton, P.E., Zender, C.S., 2010. Observed 20th Century desert dust variability: impact on climate and biogeochemistry. Atmospheric Chemsitry and Physics 10, 10875-10893.

Mann, M.E., 2003. Global surface temperatures over the past two millenia. Geophysical Research Letters 30, 1-5.

Mann, M.E., Zhang, Z., Hughes, M.K., Bradley, R.S., Miller, S.K., Rutherfors, S., Ni, F., 2008. Proxy-based reconstructions of hemispheric and global surface temperature variations over the last two millenia. Proceedings of the National Academy of Sciences of the United States of America 105, 13252-13257.

Markle, B.R., Bertler, N.A.N., Sinclair, K.E., Sneed, S.B., 2012. Synoptic variability in the Ross Sea region, Antarctica, as seen from back-trajectory modeling and ice core analysis. Journal of Geophysical Research 117 (D02113), 1-17.

Marshall, G.J., 2003. Trends in the Southern Annular Mode from observations and reanalyses. Journal of Climate 16, 4134-4143.

Marteel, A., Boutron, C., Barbante, C., Gabrielli, P., Cozzi, G., Gaspari, V., Cescon, P., Ferrari, C.P., Dommergue, A., Rosman, K., Hong, S., Hur, S.D., 2008. Changes in atmospheric heavy metals and metalloids in Dome C (East Antarctica) ice back to 672.0 kyr BP (Marine Isotopic Stages 16.2). Earth and Planetary Science Letters 272, 579-590.

Martin, M., Richardson, B.J., 1991. Long term contaminant biomonitoring: Views from Southern and Northern Hemisphere perspectives. Marine Pollution Bulletin 22, 533537.

Matsumoto, A., Hinkley, T., 2001. Trace metal suites in Antarctic pre-industrial ice are 
consistent with emissions from quiescent degassing of volcanoes worldwide. Earth and Planetary Science Letters 186, 33-43.

Mayr, C., Wille, M., Haberzettl, T., Fey, M., Janssen, S., Lucke, A., Ohlendorf, C., Oliva, G., Schabitz, F., Schleser, G.H., Zolitschka, B., 2007. Holocene variability of the Southern Hemisphere westerlies in Argentinean Patagonia (52oS). Quaternary Science Reviews 26, 579-584.

McConnell, J., Maselli, O.J., Sigl, M., Vallelonga, P., Neumann, T., Anschutz, H., Bales, R.C., Curran, M.A.J., Das, S.B., Edwards, R., Kipfstuhl, S., Layman, L., Thomas, E.R., 2014. Antarctic-wide array of high-resolution ice core records reveals pervasice lead pollution began in 1889 and persists today. Nature: Scientific Reports 4, 1:5.

McConnell, J.R., Aristarain, A.J., Banta, J.R., Edwards, R., Simoes, J.C., 2007. 20th-Century doubling in dust archinved in an Antarctic Peninsula ice core parallels climate change and desertification in South America. PNAS 104, 5743-5748.

McConnell, J.R., Lamorey, G.W., Hutterli, M.A., 2002. A 250-year high-resolution record of $\mathrm{Pb}$ flux and crustal enrichment in central Greenland. Geophysical Research Letters 29, 1-4.

Members, W.D.P., 2013. Onset of deglacial warming in West Antarctica driven by local orbital forcing. Nature 500, 440-444.

Nielsen, S.H.H., Koc, N., Crosta, X., 2004. Holocene climate in the Atlantic sector of the Southern Ocean: Controlled by insolation or oceanic circulation? Geology 32, $317-$ 320.

Nriagu, J.O., 1989. A global assessment of natural sources of atmospheric trace metals. Nature 338, 47-49.

Osterberg, E.C., Handley, M.J., Sneed, S.B., Mayewski, P.A., Kreutz, K.J., 2006. Continuous ice core melter system with discrete sampling for major ion, trace element, and stable isotope analyses. Environmental Science Technology 40, 3355-3361.

Pilgrim, W., Hughes, R.N., 1994. Lead, cadmium, arsenic and zinc in the ecosystem surrounding a lead smelter. Environmental Monitoring and Assessment 32, 1-20.

Planchon, F.A.M., Van De Velde, K., Rosman, K.J.R., Wolff, E.W., Ferrari, C.P., Boutron, C.F., 2003. One hundred fifty-year record of lead isotopes in Antarctic snow from Coats Land. Geochimica et Cosmochimica Acta 67, 693-708.

Rhodes, R.H., Bertler, N.A.N., Baker, J.A., Sneed, S.B., Oerter, H., Arrigo, K.R., 2009. Sea ice variability and primary productivity in the Ross Sea, Antarctica, from methylsulphonate snow record. Geophysical Research Letters 36 (L107041), 1-5.

Rind, D., 2002. The sun's role in climate variations. Science 296, 673-677.

Schulz, M., Mudelsee, M., 2002. REDFIT: estimating red-noise spectra directly from unevenly spaced paleoclimatic time series. Computers and Geosciences 28, 421-426.

Schulz, M., Stattegger, K., 1997. Spectrum: spectral analysis of unevenly spaced paleoclimatic time series. Computers and Geosciences 23, 929-945.

Shulmeister, J., Goodwin, I., Renwick, J., Harle, K., Armand, L., McGlone, M.S., Cook, E., Dodson, J., Hesse, P.P., Mayewski, P.A., Curran, M., 2004. The Southern Hemisphere westerlies in the Australasian sector over the last glacial cycle: a synthesis. Quaternary International 118-119, 23-53.

Stocker, T.F., Mysak, L.A., 1992. Climatic fluctuation on the century time scale: A review of high-resolution proxy data and possible mechanisms. Climatic Change 20, 227-250.

Turner, J., 2004. Review: The El Nino-Southern oscillation and Antarctica. International journal of Climatology 24, 1-31.

Ugletti, C., Gabrielli, P., Olesik, J.W., Lutton, A., Thompson, L.G., 2014. Large variability of trace element mass fractions determined by ICP-SFMS in ice core samples from worldwide high altitude glaciers. Applied Geochemistry.

Vallelonga, P., Van De Velde, K., Candelone, J.-P., Morgan, V.I., Boutron, C.F., Rosman, 
K.J.R., 2002. The lead pollution history of Law Dome, Antarctica, from isotopic measurements on ice cores: 1500 AD to 1989 AD. Earth and Planetary Science Letters 204, 291-306.

Wolff, E.W., Suttie, E.D., 1994. Antarctic snow record of southern hemisphere lead pollution. Geophysical Research Letters 21, 781-784.

Wolter, K., Timlin, M.S., 2011. El Nono/Southern Oscillation behaviour since 1871 as diagnosed in an extended multivariate ENSO index (MEI.ext). International journal of Climatology 31, 1074-1087. 


\section{Chapter 7 - Summary and Conclusions}

This thesis compiles research investigating Southern Hemisphere changes in heavy metal pollutant concentrations over the $20^{\text {th }}$ Century. Many of the heavy metals released to the environment through industrial processes are recognised as environmental contaminants in elevated quantities. As such, the majority of monitoring programmes have focused on point sources of emissions such as metal smelters and coal-fired energy generation plants. However, many heavy metal pollutants are transported long-distances as particulates in the atmosphere, hence it is necessary to monitor the concentrations of these elements in remote locations to assess industrial impacts on wider regional, hemispheric, and global scales.

This task requires knowledge of natural sources and variability of heavy metals from time periods prior to human industrialisation. Without long-term records that capture pre-industrial levels, the modern observations of these elements contain both human induced and natural changes. Polar ice cores can provide high-resolution measurements of heavy metal concentrations over thousands of years, and can be used to de-convolve natural variability from anthropogenic inputs. Furthermore, the modern trends present in ice core records can be used to inform future policy decisions regarding regulation of pollutant emissions.

This thesis presents new time series records of heavy metal concentrations from a new ice core from Roosevelt Island, in the Ross Sea region of Antarctica. In order to evaluate whether heavy metal concentrations at Roosevelt Island are representative of background atmospheric concentrations in the wider South Pacific region, the local deposition and transport of heavy metal elements to the site must be characterised. This is addressed by the first research question:

What are the modern concentrations and seasonal variability of heavy metals at Roosevelt Island, and what are the major atmospheric transport paths of these elements? Is the RICE ice core likely to contain a record of heavy metal concentrations that is representative of the wider South Pacific region?

Chapter 4 discusses this question by using surface snow samples from a $3 \mathrm{~m}$ deep snow pit and snow precipitation samples collected over the 2011-2012 field season to characterise the modern transport and deposition processes of heavy metals. We investigate the major transport pathways delivering heavy metal elements to Roosevelt Island by modelling the back-trajectory pathways of air masses associated with each snow precipitation sample. The 
highest heavy metal concentrations are associated with air masses that travel from the South Pacific through the Amundsen Sea region and over West Antarctica. This suggests that heavy metals deposited in snow at Roosevelt Island are transported through south-ward airflow from lower latitudes in the South Pacific - suggesting that South America and Australasia may be important sources for these elements.

We also find that certain types of precipitation are associated with higher concentrations of heavy metals. The highest concentrations were measured in samples containing extensive rime ice growth. Growth of rime ice occurred when Roosevelt Island was affected by longperiods ( $>4$ hours) of fog. The scavenging potential of both fog and rime ice is known to be greater than that of snow, however, for these forms of precipitation to have a significant effect on trace element concentrations in surface snow these conditions must occur often. It seems likely that other coastal locations in Antarctica that also experience extensive fog may also show relatively enriched concentrations of trace elements.

The high-resolution samples $(2 \mathrm{~cm})$ in the $3 \mathrm{~m}$ deep snow pit allows the seasonality of heavy metals at Roosevelt Island to be examined. Dating of the snow pit indicates that the data-set spans almost five years from late 2006 to January 2012. The seasonality of the heavy metals over this period is complex. Most elements show concentration maxima in summer, and a second peak in concentration in the middle of the year. The second peak has variable year-toyear timing, and could be related to variability in large precipitation events during the winter. The majority of heavy metals investigated in the snow pit are deposited with snowfall (or other forms of water), as opposed to dry deposition (without water), hence the amount of precipitation at Roosevelt Island can affect the concentrations recorded in the surface snow layers.

The results of this study suggest that concentrations of heavy metals at Roosevelt Island are representative of South Pacific atmospheric backgrounds, but that large precipitation events may influence the timing of seasonal peaks.

The time series of heavy metal concentrations in the RICE ice core span the last 2,300 years. These data can thus contribute to other 2,000-year array records to investigate global climate over the recent past. Several abrupt climate events occurred during the last 2,000 years and understanding the processes and environmental changes associated with these provide muchneeded context for observed changes both now and in the future. While there are some 
Antarctic records that span the last 1,000 years, they mainly focus on changes in $\mathrm{Pb}$ only, or are from ice core sites in East Antarctica, which are less likely to capture airborne particulates from the South Pacific. This led to the final two research questions:

How have arsenic concentrations changed in Antarctic snow and ice over the last 2,000 years, what are the major sources, when did anthropogenic emissions become significant, and can anthropogenically-derived arsenic increases and policy-related reduction be quantified?

How do $20^{\text {th }}$ century concentrations of heavy metals at Roosevelt Island compare to concentrations and variability during natural climate events over the last 2,000 years, and how significant are changes in atmospheric transport compared to source changes?

The RICE record of arsenic (As) is the first 2,000-year time series for the element measured in an Antarctic ice core. In Chapter 5 we are able to show that As concentrations remained very low until the beginning of the $20^{\text {th }}$ century. We suggest that, in addition to volcanic emissions, biogenic emissions of organo-arsenical compounds may contribute to natural As concentrations in Antarctic snow and ice. It has no crustal dust source, and thus is expected to behave differently to the other crustal-associated heavy metals such as Fe and Al.

The RICE ice core reveals a significant peak in As concentrations in the 1970s and 1980s, with average annual concentrations up to a factor of four times higher than average preindustrial concentrations. This increase is interpreted to reflect anthropogenic emissions of As, as the enrichment factor increases and the concentrations of As decouple from sulfur concentrations - indicating a new source is contributing to As and not to sulfur. Following this large peak in As concentrations in Antarctica, concentrations begin to decrease from 1997. This trend continues into the present surface snow layers in the $3 \mathrm{~m}$ deep snow pit, with both concentrations and enrichment values returning to within pre-industrial variability. The timing of this decline coincides with increasing public awareness of the health effects caused by As, and with the introduction of constitutional changes to national law in many Southern Hemisphere countries to control pollutant emissions and air quality. It seems apparent that these policy changes have led to a reduction in airborne-particulates containing industrially produced As, thus reducing the concentrations transported to Antarctica.

In Chapter 6 we discuss the changes in five other heavy metal elements ( $\mathrm{Fe}, \mathrm{Al}, \mathrm{Pb}, \mathrm{Mn}$, and $\mathrm{Tl}$ ) over the last 2,300 years. Over the pre-industrial period (prior to $1800 \mathrm{CE}$ ) concentrations of heavy metals in the RICE ice core are low, with standard deviations between $18 \%$ and 43 
$\%$ of the mean. We observe no significant changes in mean concentrations between the Medieval Warm Period and the Little Ice Age, though there is some change in variability (particularly in $\mathrm{Fe}$ ). In contrast to the pre-industrial period we observe large increases in heavy metal concentrations over the $20^{\text {th }}$ century. All heavy metals considered here (except $\mathrm{Tl}$ ) increase between two and five times the pre-industrial average. $\mathrm{Tl}$ is the only heavy metal element analysed in the RICE ice core that does not increase over the $20^{\text {th }}$ century. This may be because there are few industrial sources of $\mathrm{Tl}$, and the primary natural source appears to be volcanism.

The increases in $\mathrm{Fe}, \mathrm{Mn}$, and $\mathrm{Al}$ are not accompanied by a change in crustal enrichment value - due to the proportional increase in La concentrations (used as a conservative tracer for crustal dust) over the $20^{\text {th }}$ century. Hence, there does not appear to be a significant change in the source of these elements, but rather an increase in the amount of crustal dust particulates reaching Roosevelt Island. This could be due to increased efficiency of atmospheric transport, an increase in dust emissions to the atmosphere in Southern Hemisphere landmasses, or to increased local Antarctic dust contributions. There have been significant changes in land-use in the Southern Hemisphere continents, particularly in South America and Australia, with extensive areas of land converted from natural vegetation to crop and pasture land. These kind of large-scale changes in vegetation increase the availability of dust to the atmosphere and large increases in dust reaching Antarctica have also been reported from other Antarctic ice core records (McConnell et al., 2014).

$20^{\text {th }}$ century increases in RICE $\mathrm{Pb}$ concentrations show an anthropogenic influence. The changes in concentration are matched by changes in the enrichment factor, indicating that a new source is contributing to the increased concentrations. We compare the RICE Pb time series over the $20^{\text {th }}$ century to the recently published stacked record from 11 Antarctic ice cores (McConnell et al., 2014), and we find a very good match, both in absolute concentrations and in the timing of concentration peaks. This reinforces the suggestion that the RICE ice core is a faithful recorder of Southern Hemisphere atmospheric concentrations of heavy metals. We observe low concentrations of $\mathrm{Pb}$ in the surface snow layers, indicating that the decreasing trend of $\mathrm{Pb}$ concentrations from the mid-1990s continues to the present.

Spectral frequency analysis of the heavy metal time series indicates there are frequency peaks significant at $99 \%$ that coincide with ENSO (2-7 years) and multi-decadal frequencies. The elements that show strong peaks in the 5-7 year frequencies are those that are transported 
from lower latitudes $(\mathrm{Fe}, \mathrm{Al}, \mathrm{Mn}, \mathrm{La}, \mathrm{Pb})$. Interestingly the sea salt related elements do not show these lower frequency peaks, however, this may because they show very strong annual and bi-annual peaks which may overprint any inter-year variability.

\subsection{Future Directions}

In addition to achieving the research aims of this thesis, several areas are identified as opportunities for future work.

Chapter 4 discussed chemistry changes in Antarctic surface snow layers and the preservation of precipitation and atmospheric concentrations of heavy metals. Although we had measurements of density changes in the top $3 \mathrm{~m}$ of the snow, our data did not support further exploration of the physical changes in snow over these layers. There is scope for specific field studies to investigate the changes in snow trace element chemistry during physical snow metamorphism. There are many physical changes that occur both in the top layers of snow and as the snow densifies into firn and ice, which could affect the concentrations of trace elements. Detailed, high-resolution field sampling of snow and firn in coastal locations could add considerably to our understanding of the interaction between physical snow changes and snow chemistry.

In Chapter 3 the first attempts at measurements of bomb-related $\mathrm{Pu}$ isotopes in Antarctic snow and ice are presented. Although our measurements are preliminary, we observe peaks in ICPMS counts of more than $2 \sigma$ above the background during the 1950s and 1960s. This suggests that a dedicated attempt to quantify these isotopes could result in successful analysis, and could potentially be used as a new dating tool.

When investigating the spectral frequencies present in the pre-industrial time series of the heavy metals presented in this thesis, significant peaks indicating the presence of centennial scale oscillations were observed. At present there are few indices of atmospheric variability that span long enough periods to quantify centennial-scale variability; however, they appear to be a fairly common characteristic of high-resolution Holocene proxy records. There is scope to compare the different proxy records to further investigate the common characteristics of centennial variability and explore the physical processes responsible.

In Chapter 5 we present the first 2,000-year record of As from an Antarctic ice core and discuss possible natural sources. It remains difficult to determine specific sources due to the 
lack of As measurements in older ice around Antarctica. It seems likely that volcanic emissions are a significant source, but further work could investigate whether this is due to degassing or to emissions of volcanic particulates. In addition, the possibility of biogenic emissions of As to Antarctic snow could be tested by trial measurements for organo-arsenical compounds in pre-concentrated ice core samples.

Finally, the work presented in this thesis focusses on only a small sub-set of the trace element data generated. While the heavy metal and rare earth elements have been explored, there is extensive scope for further analysis of the other trace elements measured in the RICE ice core. 


\section{Thesis References}

Andersen, K.K., Azuma, N., Barnola, J.-M., Bigler, M., Biscaye, P., Caillon, N., Chappellaz, J., Clausen, H.B., Dahl-Jensen, D., Fischer, H., 2004. High-resolution record of Northern Hemisphere climate extending into the last interglacial period. Nature 431, 147-151.

Anderson, J.B., Shipp, S.S., Lowe, A.L., Wellner, J.S., Mosola, A.B., 2002. The Antarctic ice sheet during the Last Glacial Maximum and its subsequent retreat history: a review. Quaternary Science Reviews 21, 49-70.

Arblaster, J.M., Meehl, G.A., 2006. Contributions of external forcings to Southern Annular Mode trends. Journal of Climate 19, 2896-2905.

Barbante, C., Turetta, C., Capodaglio, G., Scarponi, G., 1997. Recent decrease in the lead concentration of Antarctic snow. International Journal of Environmental Analytical Chemistry 68, 457-477.

Barker, S., Diz, P., Vautravers, J., Pike, J., Knorr, G., Hall, I.R., Broecker, W.S., 2009. Interhemispheric Atlantic seesaw response during the last deglaciation. Nature 457, 1097-1103.

Basile, I., Petit, J.R., Touron, S., Grousset, F.E., Barkov, N., 2001. Volcanic layers in Antarctic (Vostok) ice cores: Source identification and atmospheric implications. Journal of Geophysical Research 106, 31,915-931,931.

Bertler, N.A.N., Barrett, P.J., Mayewski, P.A., Fogt, R.L., Kreutz, K.J., Shulmeister, J., 2004a. El Nino suppresses Antarctic warming. Geophysical Research Letters 31, 1-4.

Bertler, N.A.N., Mayewski, P.A., Aristarain, A., Barrett, P., Becagli, S., Bernardo, R., Bo, S., Xiao, C., Curran, M., Qin, D., Dixon, D., Ferron, F., Fischer, H., Frey, M., Frezzotti, M., Fundel, F., Genthon, C., Gragnani, R., Hamilton, G., Handley, M., Hong, S., Isaksson, E., Kang, J., Ren, J., Kamiyama, K., Kanamori, S., Karkas, E., Karlof, L., Kaspari, S., Kreutz, K., Kurbatov, A., Meyerson, E., Ming, Y., Zhang, M., Motoyama, H., Mulvaney, R., Oeter, H., Osterberg, E., Proposito, M., Pyne, A., Ruth, U., Simoes, J., Smith, B., Sneed, S., Teinila, K., Traufetter, F., Udisti, R., Virkkula, A., Watanabe, O., Williamson, B., Winther, J.-G., Li, Y., Wolff, E., Li, Z., Zielinski, A., 2005. Snow chemistry across Antarctica. Annals of Glaciology 41, 167-179.

Bertler, N.A.N., Mayewski, P.A., Barrett, P.J., Sneed, S.B., Handley, M.J., 2004b. Monsoonal circulation of the McMurdo Dry Valleys, Ross Sea Region, Antarctica: Signal from the snow chemistry. Annals of Glaciology 39, 139-145.

Bertler, N.A.N., Mayewski, P.A., Carter, L., 2011. Cold conditions in Antarctica during the Little Ice Age - Implications for abrupt climate change mechanisms. Earth and Planetary Science Letters 308, 41-51.

Bertler, N.A.N., Naish, T.R., Oerter, H., Kipfstuhl, S., Barrett, P.J., Mayewski, P.A., Kreutz, K., 2006. The effects of joint ENSO-Antarctic Oscillation forcing on the McMurdo Dry Valleys, Antarctica. Antarctic Science 18, 507-514.

Blas, M., Cichala-Kamrowska, K., Sobik, M., Polkowska, Z., Namiesnik, J., 2010. Conditions controlling atmospheric pollutant deposition via snowpacl. Environmental Reviews 18, 87-114.

Blunier, T., Brook, E.J., 2001. Timing of Millenial-Scale climate change in Antarctica and Greenland during the last glacial period. Science 291, 109-112.

Boutron, C.F., Patterson, C.C., 1986. Lead concentration changes in Antarctic ice during the Wisconsin/Holocene transition. Nature 323, 222-225.

Brailsford, G.W., Stephens, B.B., Gomez, A.J., Riedel, K., Mikaloff Fletcher, S.E., Nichol, S.E., Manning, M.R., 2012. Long-term continuous atmospheric CO2 measurements at Baring Head, New Zealand. Atmospheric Measurements and Techniques 5, 31093117. 
Broecker, W.S., 1997. Thermohaline circulation, the achilles heel of our climate system: will man-made CO2 upset the current balance? Science 278, 1582-1588.

Bromwich, D.H., 1988. Snowfall in High Southern Latitudes. Reviews of Geophysics 26, 149-168.

Bromwich, D.H., 1991. Mesoscale cyclogenesis over the Southwestern Ross Sea linked to strong katabatic winds. Monthly weather review 119, 1736-1753.

Bromwich, D.H., Fogt, R.L., Hodges, K.I., Walsh, J.E., 2007. A tropospheric assessment of the ERA-40, NCEP, and JRA-25 global reanalyses in the polar regions. Journal of Geophysical Research 112, 1-21.

Bromwich, D.H., Nicholas, J.P., Monaghan, A.J., Lazzara, M.A., Keller, L.M., Weidner, G.A., Wilson, A.B., 2013. Central West Antarctica among the most rapidly warming regions on Earth. Nature Geoscience 6, 139-145.

Burn-Nunes, L.J., Vallelonga, P., Loss, R.D., Burton, G.R., Moy, A., Curran, M., Hong, S., Smith, A.M., Edwards, R., Morgan, V.I., 2011. Seasonal variability in the input of lead, barium and indium to Law Dome, Antarctica. Geochimica et Cosmochimica Acta 75, 1-20.

Byrne, R.H., Kump, L.R., Cantrell, K.J., 1988. The influence of temperature and pH on trace metal speciation in seawater. Marine Chemistry 25, 163-181.

Carraso, J.F., Bromwich, D.H., Monaghan, A.J., 2003. Distribution and characteristics of the mesoscale cyclones in the Antarctic: Ross Sea eastward to the Weddell Sea. Monthly Weather Review 131, 289-301.

Cunningham, J., Waddington, E.D., 1993. Air flow and dry deposition of non-sea salt sulfate in polar firn: Paleoclimatic implications. Atmospheric Environment 27A, 2943-2956.

Davidson, C.I., Chu, L., Grimm, T.C., Nasta, M.A., Qamoos, M.P., 1981. Wet and dry deposition of trace elements onto the Greenland ice sheet. Atmospheric Environment (1967) 15, 1429-1437.

De Deckker, P., Norman, M., Goodwin, I., Wain, A., Gingele, F., 2010. Lead isotopic evidence for an Australian source of aeolian dust to Antarctica at times over the last 170,000 years. Palaeogeography, Palaeoclimatology, Palaeoecology 285, 205-223.

Delmonte, B., Andersson, P.S., Hansson, M., Schoberg, H., Petit, J.R., Basile-Doelsch, I., Maggi, V., 2008. Aeolian dust in East Antarctica (EPICA-Dome C and Vostok): Provenance during glacial ages over the last 800 kyr. Geophysical Research Letters 35, 1-6.

Delmonte, B., Basile-Doelsch, I., Petit, J.-R., Maggi, V., Revel-Rolland, M., Michard, A., Jagoutz, E., Grousset, F., 2004. Comparing the Epica and Vostok dust records during the last 220,000 years: stratigraphical correlation and provenance in glacial periods. Earth-Science Reviews 66, 63-87.

Delmonte, B., Petit, J.R., Krinner, G., Maggi, V., Jouzel, J., Udisti, R., 2005. Ice core evidence for secular variability and 200-year dipolar oscillations in atmospheric circulation over East Antarctica during the Holocene. Climate Dynamics 24, 641-654.

Dixon, D., Mayewski, P.A., Goodwin, I.D., Marshall, G.J., Freeman, R., 2012. An ice-core proxy for northerly air mass incursions into West Antarctica. International Journal of Climatology 32, 1455-1465.

Dixon, D., Mayewski, P.A., Korotkikh, E., Sneed, S.B., Handley, M.J., Introne, D.S., Scambos, T.A., 2013. Variations in snow and firn chemistry along US ITASE traverses and the effect of surface glazing. The Cryosphere 7, 515-535.

Do Hur, S., Cunde, X., Hong, S., Barbante, C., Gabrielli, P., Lee, K., Boutron, C.F., Ming, Y., 2007. Seasonal patterns of heavy metal deposition to the snow on the Lambert Glacier basin, East Antarctica. Atmospheric Environment 41, 8567-8578.

Duncan, L.C., 1992. Chemistry of rime and snow collected at a site in the central Washington Cascades. Environmental Science \& Technology 26, 61-66.

Edwards, R., Sedwick, P., Morgan, V., Boutron, C., 2006. Iron in ice cores from Law Dome: 
A record of atmospheric iron deposition for maritime East Antarctica during the Holocene and Last Glacial Maximum. Geochemistry Geophysics Geosystems 7, 1-15. Emanuelsson, B.D., Baisden, W.T., Bertler, N.A.N., Keller, E.D., Gkinis, V., 2014. Highresolution continuous flow analysis setup for water isotopic measurement from ice cores using laser spectroscopy. Atmospheric Measurement Techniques Discussions 7, 12081-12124.

EPICA Community Members, 2004. Eight glacial cycles from an Antarctic ice core. Nature 429, 623-628.

Fogt, R.L., Bromwich, D.H., Hines, K.M., 2011. Understanding the SAM influence on the South Pacific ENSO teleconnection. Climate Dynamics 36, 1555-1576.

Fogt, R.L., Perlwitz, J., Monaghan, A.J., Bromwich, D.H., Jones, J.M., Marshall, G.J., 2009. Historical SAM variability. Part II:Twentieth-century variability and trends from reconstructions, observations and the IPCC AR4 models. Journal of Climate 22, 53465365.

Fogt, R.L., Wovrosh, A.J., Langen, R.A., Simmonds, I., 2012. The characteristic variability and connection to the underlying synoptic activity of the Amundsen-Bellingshausen Seas Low. Journal of Geophysical Research 117, 1-22.

Fretwell, P., Pritchard, H.D., Vaughan, D.G., Bamber, J., Barrand, N., Bell, R., Bianchi, C., Bingham, R., Blankenship, D., Casassa, G., Catania, G., Callens, D., Conway, H., Cook, A., 2013. Bedmap2: improved ice bed, surface and thickness datasets for Antarctica. The Cryosphere 7, 375-393.

Frezzotti, M., Pourchet, M., Flora, O., Gandolfi, S., Gay, M., Urbini, S., Vincent, C., Becagli, S., Gragnani, R., Proposito, M., Severi, M., Traversi, R., Udisti, R., Fily, M., 2005. Spatial and temporal variability of snow accumulation in East Antarctica from traverse data. Journal of Glaciology 51, 113-124.

Gabrieli, J., Cozzi, G., Vallelonga, P., Schwikowski, M., Sigl, M., Eickenberg, J., Wacker, L., Boutron, C., Gaggeler, H., Cescon, P., Barbante, C., 2011. Contamination of Alpine snow and ice at Colle Gnifetti, Swiss/Italian Alps, from nuclear weapons tests. Atmospheric Environment 45, 587-593.

Gabrielli, P., Barbante, C., Boutron, C., Cozzi, G., Gaspari, V., Planchon, F., Ferrari, C., Turetta, C., Hong, S., Cescon, P., 2005. Variations in atmospheric trace elements in Dome C (East Antarctica) ice over the last two climatic cycles. Atmospheric Environment 39, 6420-6429.

Gabrielli, P., Cozzi, G., Torcini, S., Cescon, P., Barbante, C., 2006. Source and origin of atmospheric trace elements entrapped in winter snow of the Italian Eastern Alps.

Gabrielli, P., Wegner, A., Petit, J.R., Delmonte, B., De Deckker, P., Gaspari, V., Fischer, H., Ruth, U., Kriews, M., Boutron, C., 2010. A major glacial-interglacial change in aeolian dust composition inferred from Rare Earth Elements in Antarctic ice. Quaternary Science Reviews 29, 265-273.

Golledge, N.R., Levy, R.H., McKay, R.M., Fogwill, C.J., White, D.A., Graham, A.G.G., Smith, J.A., Hillenbrand, C.-D., Licht, K., Denton, G.H., Ackert, R.P., Maas, S.M., Hall, B.L., 2013. Glaciology and geological signature of the Last Glacial Maximum Antarctic ice sheet. Quaternary Science Reviews 78, 225-247.

Goosse, H., Masson-Delmotte, V., Renssen, H., Delmotte, M., Fichefet, T., Morgan, V., van Ommen, T., Khim, B.K., Stenni, B., 2004. A late medieval warm period in the Southern Ocean as a delayed response to external forcing? Geophysical Research Letters 31, 1-5.

Gorodetskaya, I.V., Tsukernik, M., Claes, K., Ralph, M.F., Neff, W.D., Van Lipzig, N.P.M., 2014. The role of atmospheric rivers in anomalous snow accumulation in East Antarctica. Geophysical Research Letters 41, 6199-6206.

Gregory, S., Noone, D., 2008. Variability in the teleconnection between the El Nino-Southern 
Oscillation and West Antarctic climate deduced from West Antarctic ice core isotope records. Journal of Geophysical Research 113, 1-17.

Grotti, M., Soggia, F., Ardini, F., Magi, E., 2011. Major and trace element partitioning between dissolved and particulate phases in Antarctic surface snow. Journal of Environmental Monitoring 13.

Heikkila, U., Beer, J., Feichter, J., Alfimov, V., Synal, H.-A., Schotterer, U., Eichler, A., Schwikowski, M., Thompson, L., 2009. 36Cl bomb peak: comparison of modeled and measured data. Atmospheric Chemsitry and Physics 9, 4145-4156.

Hirasawa, N., Nakamura, H., Yamanouchi, T., 2000. Abrupt changes in meteorological conditions observed at an inland Antarctic station in association with wintertime blocking. Geophysical Research Letters 27, 1911-1914.

Holland, M.M., Bitz, C.M., 2003. Polar amplification of climate change in coupled models. Climate Dynamics 21, 221-232.

Holland, P.R., Kwok, R., 2012. Wind-driven trends in Antarctic sea-ice drift. Nature Geoscience 5, 872-875.

Hong, S., Candelone, J.-P., Patterson, C.C., Boutron, C.F., 1994. Greenland ice evidence of hemispheric lead pollution two millenia ago by Greek and Roman civilisations. Science 265, 1841-1843.

Hong, S., Han, C.H., Hwang, H.J., Soyol-Erdene, T.-O., Kang, J.H., Hur, S.D., Burn-Nunes, L.J., Gabrielli, P., Barbante, C., Boutron, C.F., 2013. Trace elements and Pb isotope record in Dome C (East Antarctica) ice over the past 800,000 years. E3S Web of Conferences 1, 1-4.

Hong, S., Soyol-Erdene, T.-O., Hwang, H.J., Hong, S.B., Hur, S.D., Motoyama, H., 2012. Evidence of global-scale As, Mo, Sb, and $\mathrm{Tl}$ atmospheric pollution in the Antarctic snow. Environmental Science \& Technology 46, 11550-11557.

Hoskins, B.J., Hodges, K.I., 2005. A new perspective on Southern Hemisphere storm tracks. Journal of Climate 18, 4108-4129.

Huber, P.J., 1981. Robust statistics. John Wiley \& Sons, Inc, Hoboken, NJ, USA.

Hughes, M.F., 2002. Arsenic toxicity and potential mechanisms of action. Toxicology Letters $133,1-16$.

Hur, S.D., Cunde, X., Hong, S., Barbante, C., Gabrielli, P., Lee, K., Boutron, C., Ming, Y., 2007. Seasonal patterns of heavy metal deposition to the snow on Lambert Glacier basin, East Antarctica. Atmospheric Environment 41, 8567-8578.

Hur, S.D., Soyol-Erdene, T.-O., Hwang, H.J., Han, C., Glabrielli, P., Barbante, C., Boutron, C., Hong, S., 2013. Climate-related variations in $\mathrm{Sb}$ and $\mathrm{Tl}$ in the EPICA Dome $\mathrm{C}$ ice (East Antarctica) during the past 800,000 years. Global Biogeochemical Cycles 27, 111.

Inatsu, M., Hoskins, B.J., 2004. The zonal assymetry of the Southern Hemisphere winter storm track. Journal of Climate 17, 4882-4892.

IPCC, 2013. Summary for policymakers, in: Stocker, T.-F., Qin, D., Plattner, G.-K., Tignor, M., Allen, S.K., Boschung, J., Nauels, A., Xia, Y., Bex, V., Midgley, P.M. (Eds.), Climate Change 2013: The physical science basis. Contribution of Working Group 1 to the fifth assessment report of the International Panel on Climate Change.

Cambridge University Press, Cambridge, UK, and New York, NY, USA.

Irving, D., Simmonds, I., Keay, K., 2010. Mesoscale cyclone activity over the ice-free Southern Ocean: 1999-2008. Journal of Climate 23, 5404-5420.

Jones, J.M., Fogt, R.L., Widmann, M., Marshall, G.J., Jones, P.D., Visbeck, M., 2009.

Historical SAM variability. Part I: Century-length seasonal reconstructions. Journal of Climate 22, 5319-5345.

Karl, T.R., Trenberth, K.E., 2003. Modern global climate change. Science 302, 1719-1723.

Knüsel, S., Piguet, D.E., Schwikowski, M., Gäggeler, H.W., 2003. Accuracy of 
continuous ice-core trace-element analysis by inductively coupled plasma sector field mass spectrometry. Environmental Science Technology 37, 2267-2273.

Koffman, B.G., Handley, M.J., Osterberg, E.C., Wells, M.L., Kreutz, K.J., 2014. Dependence of ice-core relative trace-element concentration on acidification. Journal of Glaciology 60, 103-112.

Kreutz, K.J., Mayewski, P.A., 1999. Spatial variability of Antarctic surface snow glaciochemistry: implications for palaeoatmospheric circulation reconstructions. Antarctic Science 11, 105-118.

Kreutz, K.J., Mayewski, P.A., Meeker, L.D., Twickler, M.S., Whitlow, S.I., 2000. The effect of spatial and temporal accumulation rate variability in West Antarctica on soluble ion deposition. Geophysical Research Letters 27, 2517-2520.

Krinner, G., Genthon, C., 2003. Tropospheric transport of continental tracers towards Antarctica under varying climatic conditions. Tellus 55B, 54-70.

Lambeck, K., Rouby, H., Purcelle, A., Sun, Y., Sambridge, M., 2014. Sea level and global ice volume from the Last Glacial Maximum to the Holocene. PNAS 111, 15296-15303.

Lambert, F., Delmonte, B., Petit, J.R., Bigler, M., Kaufamnn, P.R., Hutterli, M.A., Stocker, T.F., Ruth, U., Steffensen, J.P., Maggi, V., 2008. Dust-climate couplings over the past 800,000 years from the EPICA Dome C ice core. Nature 452, 616-619.

Lambert, F., Kug, J.-S., Park, R.J., Mahowald, N., Winckler, G., Abe-Ouchi, A., O'ishi, R., Takemura, T., Lee, J.-H., 2013. The role of mineral-dust aerosols in polar temperature amplification. Nature Climate Change 3, 487-491.

Legrand, M., Mayewski, P.A., 1997. Glaciochemistry of polar ice cores: A review. Reviews of Geophysics 53, 219-243.

Li, F., Ginoux, P., Ramaswamy, V., 2008. Distribution, transport, and deposition of mineral dust in the Southern Ocean and Antarctica: Contribution of major sources. Journal of Geophysical Research: Atmospheres (1984-2012) 113.

Lythe, M.B., Vaughan, D.G., BEDMAP Consortium, 2001. BEDMAP: A new ice thickness and subglacial topographic model of Antarctica. Journal of Geophysical Research 106, 11335-11351.

MacFarling Meure, C., Etheridge, D., Trudinger, C., Steele, P., Langenfelds, R., Van Ommen, T., Smith, A., Elkins, J., 2006. Law Dome CO2, CH4 and N2O ice core records extended to 2000 years BP. Geophysical Research Letters 33.

Mackintosh, A., Golledge, N., Domack, E., Dunbar, R., Leventer, A., White, D., Pollard, D., DeConto, R., Fink, D., Zwartz, D., Gore, D., Lavoie, C., 2011. Retreat of the East Antarctic ice sheet during the last glacial termination. Nature Geoscience 4, 195-202.

Mann, M.E., 2003. Global surface temperatures over the past two millenia. Geophysical Research Letters 30, 1-5.

Markle, B.R., Bertler, N.A.N., Sinclair, K.E., Sneed, S.B., 2012. Synoptic variability in the Ross Sea region, Antarctica, as seen from back-trajectory modeling and ice core analysis. Journal of Geophysical Research 117 (D02113), 1-17.

Marteel, A., Boutron, C., Barbante, C., Gabrielli, P., Cozzi, G., Gaspari, V., Cescon, P., Ferrari, C.P., Dommergue, A., Rosman, K., Hong, S., Hur, S.D., 2008. Changes in atmospheric heavy metals and metalloids in Dome C (East Antarctica) ice back to 672.0 kyr BP (Marine Isotopic Stages 16.2). Earth and Planetary Science Letters 272, 579-590.

Massom, R.A., Pook, M.J., Comiso, J.C., Adams, N., Turner, J., Lachlan-Cope, T., Gibson, T.T., 2004. Precipitation over the interior East Antarctic ice sheet related to midlatitude blocking-high activity. Journal of Climate 17, 1914-1928.

Masson, V., Vinmeux, F., Jouzel, J., Morgan, V., Delmotte, M., ciais, P., Hammer, C., Johnsen, S., Lipenkov, V.Y., Mosley-Thompson, E., Petit, J.R., Steig, E.J., Stievenard, M., Vaikmae, R., 2000. Holocene climate variability in Antarctica based on 11 ice-core isotopic records. Quaternary Research 54, 348-358. 
Masson-Delmotte, V., Kageyama, M., Braconnot, P., Charbit, S., Krinner, G., Ritz, C., Guilyardi, E., Jouzel, J., Abe-Ouchi, A., Crucifix, M., Gladstone, R.M., Hewitt, C.D., Kitoh, A., LeGrande, A.N., Marti, O., Merkel, U., Motoi, T., Ohgaito, R., OttoBliesner, B., Peltier, W.R., Ross, I., Valdes, P.J., Vettoretti, G., Weber, S.L., Wolk, F., Yu, Y., 2006. Past and future polar amplification of climate change: climate model intercomparisons and ice-core constraints. Climate Dynamics 26, 513-529.

Matsumoto, A., Hinkley, T., 2001. Trace metal suites in Antarctic pre-industrial ice are consistent with emissions from quiescent degassing of volcanoes worldwide. Earth and Planetary Science Letters 186, 33-43.

Mayewski, P.A., Frezzotti, M., Bertler, N., Van Ommen, T., Hamilton, G., Jacka, T.H., Welch, B., Frey, M., Qin, D., Ren, J., Simões, J., Fily, M., Oerter, H., Nishio, F., Isaksson, E., Mulvaney, R., Holmund, P., Lipenkov, V., Goodwin, I., 2005. The International Trans-Antarctic Scientific Expedition (ITASE): an overview. Annals of Glaciology 41, 180-185.

Mayewski, P.A., Meredith, M.P., Summerhayes, C.P., Turner, J., Worby, A., Barrett, P.J., Casassa, G., Bertler, N.A.N., Bracegirdle, T., Naveira Garabato, A.C., Bromwich, D.H., Campbell, H., Hamilton, G.S., Lyons, W.B., Maasch, K.A., Aoki, S., Xiao, C., van Ommen, T., 2009. State of the Antarctic and Southern Ocean climate system. Reviews of Geophysics 47, 1-38.

Mayewski, P.A., Rohling, E.E., Stager, J.C., Karlen, W., Maasch, K.A., Meeker, L.D., Meyerson, E.A., Gasse, F., van Kreveld, S., Holmgren, K., Lee-Thorp, J., Rosqvist, G., Rack, F., Staubwasser, M., Schneider, R.R., Steig, E.J., 2004. Holocene climate variability. Quaternary Research 62, 243-255.

McConnell, J., Maselli, O.J., Sigl, M., Vallelonga, P., Neumann, T., Anschutz, H., Bales, R.C., Curran, M.A.J., Das, S.B., Edwards, R., Kipfstuhl, S., Layman, L., Thomas, E.R., 2014. Antarctic-wide array of high-resolution ice core records reveals pervasice lead pollution began in 1889 and persists today. Nature: Scientific Reports 4, 1:5.

McConnell, J.R., Lamorey, G.W., Lambert, S.W., Taylor, K.C., 2002. Continuous ice-core chemical analyses using independently coupled plasma mass spectrometry. Environmental Science \& Technology 36, 7-11.

McKay, R.M., Dunbar, G.B., Naish, T.R., Barrett, P.J., Carter, L., Harper, M., 2008. Retreat history of the Ross Ice Sheet (Shelf) since the Last Glacial Maximum from deep-basin sediment cores around Ross Island. Palaeogeography, Palaeoclimatology, Palaeoecology 260, 245-261.

McPhaden, M.J., Zebiak, S.E., Glantz, M.H., 2006. ENSO as an integrating concept in earth science. Science 314, 1740-1745.

Members, W.D.P., 2013. Onset of deglacial warming in West Antarctica driven by local orbital forcing. Nature 500, 440-444.

Moreno, P.I., Kaplan, M.R., Francois, J.P., Villa-Martinez, R., Moy, C.M., Stern, C.R., Kubik, P.W., 2009. Renewed glacial activity during the Antarctic cold reversal and persistence of cold conditions until $11.5 \mathrm{ka}$ in southerwestern Patagonia. Geology 37, 375-378.

Naish, T., Powell, R., Levy, R., Wilson, G., Scherer, R., Talarico, F., Krissek, L., Niessen, F., Pompilio, M., Wilson, T., Carter, L., DeConto, R., Huybers, P., McKay, R., Pollard, D., Ross, J., Winter, D., Barrett, P., Browne, G., Cody, R., Cowan, E., Crampton, J., Dunbar, G., Dunbar, N., Florindo, F., Gebhardt, C., Graham, I., Hannah, M., Hansaraj, D., Harwood, D., Helling, D., Henrys, S., Hinnov, L., Kuhn, G., Kyle, P., Läufer, A., Maffioli, P., Magens, D., Mandernack, K., McIntosh, W., Millan, C., Morin, R., Ohneiser, C., Paulsen, T., Persico, D., Raine, I., Reed, J., Riesselman, C., Sagnotti, L., Schmitt, D., Sjunneskog, C., Strong, P., Taviani, M., Vogel, S., Wilch, T., Williams, T., 2009. Obliquity-paced Pliocene West Antarctic ice sheet oscillations. Nature 458, 322-329. 
Naithani, J., Gallee, H., Schayes, G., 2002. Marine air intrusion into Adelie Land sector of East Antarctica: A study using the regional climate model (MAR). Journal of Geophysical Research 107, 1-6.

$\mathrm{Ng}$, A., Patterson, C., 1981. Natural concentrations of lead in ancient Arctic and Antarctic ice. Geochimica et Cosmochimica Acta 45, 2109-2121.

Nicolas, J.P., Bromwich, D.H., 2011. Climate of West Antarctica and influence of marine air intrusions. Journal of Climate 24, 49-67.

Okumura, Y.M., Schneider, D., Deser, C., Wilson, R., 2012. Decadal-Interdecadal climate variability over Antarctica and linkages to the tropics: Analysis of ice core, instrumental and tropical proxy data. Journal of Climate 25, 7421-7441.

Oort, A.H., 1971. The observed annual cycle in the meridional transport of atmospheric energy. Journal of the Atmospheric Science 28, 325-339.

Orsi, A.J., Cornuelle, B.D., Severinghaus, J.P., 2012. Little Ice Age cold interval in West Antarctica: Evidence from borehole temperature at the West Antarctic Ice Sheet (WAIS) Divide. Geophysical Research Letters 39, 1-7.

Pacyna, J.M., Pacyna, E.G., 2001. An assessment of global and regional emissions of trace metals to the atmosphere from anthropogenic sources worldwide. Environmental Reviews 9, 269-298.

Pahnke, K., Zahn, R., 2005. Southern hemisphere water mass conversion linked with north Atlantic climate variability. Science 307, 1741-1746.

Patterson, C.C., Boutron, C., Flegal, R., 1985. Present status and future of lead studies in polar snow, in: Langway, C.C., Oeschger, H., Dansgaard, W. (Eds.), Greenland ice core: Geophysics, geochemistry, and the environment. Americal Geophysical Union, Washington, D.C.,.

Patterson, N.G., Bertler, N.A.N., Naish, T.R., Morgenstern, U., 2005. ENSO variability in the deuterium-excess record of a coastal Antarctic ice core from the McMurdo Dry Valleys, Victoria Land. Annals of Glaciology 41, 140-146.

Pedro, J.B., Rasmussen, S.O., van Ommen, T.D., Morgan, V.I., Chappellaz, J., Moy, A.D., Masson-Delmotte, V., Delmotte, M., 2011. The last deglaciation: timing the bipolar seesaw. Climate of the Past 7, 671-683.

Petit, J.R., Jouzel, J., Raynaud, D., Barkov, N.I., Barnola, J.-M., Basile, I., Bender, M., Chappellaz, J., Davis, M., Delaygue, G., Delmotte, M., Kotlyakov, V.M., Legrand, M., Lipenkov, V.Y., Lorius, C., Pepin, L., Ritz, C., Saltzman, E., Stievenard, M., 1999. Climate and atmospheric history of the past 420,000 years from the Vostok ice core, Antarctica. Nature 399, 429-436.

Pilgrim, W., Hughes, R.N., 1994. Lead, cadmium, arsenic and zinc in the ecosystem surrounding a lead smelter. Environmental Monitoring and Assessment 32, 1-20.

Planchon, F.A.M., Boutron, C.F., Barbante, C., Wolff, E.W., Cozzi, G., Gaspari, V., Ferrari, C.P., Cescon, P., 2001. Ultrasensitive determination of heavy metals at the subpicogram per gram level in ultraclean Antarctic snow samples by inductively coupled plasma sector field mass spectrometry. Analytica Chimica Acta 450, 193-205.

Planchon, F.A.M., Van De Velde, K., Rosman, K.J.R., Wolff, E.W., Ferrari, C.P., Boutron, C.F., 2003. One hundred fifty-year record of lead isotopes in Antarctic snow from Coats Land. Geochimica et Cosmochimica Acta 67, 693-708.

Putnam, A., Denton, G.H., Schaefer, J.M., Barrell, D.J.A., Andersen, B.G., Finkel, R.C., Schwartz, R., Doughty, A.M., Kaplan, M.R., Schlüchter, C., 2010. Glacier advance in southern middle-latitudes during the Antarctic Cold Reversal. Nature Geoscience 3, 700-704.

Rankin, A.M., Wolff, E.W., Martin, S., 2002. Frost flowers: Implication for tropospheric chemistry and ice core interpretation. Journal of Geophysical Research 107, 1-4.

Raphael, M.N., 2004. A zonal wave 3 index for the Southern Hemisphere. Geophysical Research Letters 31, 1-4. 
Rhodes, R.H., Baker, J.A., Millet, M.-A., Bertler, N.A.N., 2011. Experimental investigation of the effects of mineral dust on the reproducibility and accuracy of ice core trace element analyses. Chemical Geology 286, 207-221.

Rhodes, R.H., Bertler, N.A.N., Baker, J., Steen-Larsen, H.C., Sneed, S.B., Morgenstern, U., Johnsen, S.J., 2012. Little Ice Age climate and oceanic conditions of the Ross Sea, Antarctica from a coastal ice core record. Climate of the Past 8, 1223-1238.

Rhodes, R.H., Bertler, N.A.N., Baker, J.A., Sneed, S.B., Oerter, H., Arrigo, K.R., 2009. Sea ice variability and primary productivity in the Ross Sea, Antarctica, from methylsulphonate snow record. Geophysical Research Letters 36 (L107041), 1-5.

Rodushkin, I., Engström, E., Baxter, D.C., 2010. Sources of contamination and remedial strategies in the multi-elemental trace analysis laboratory. Analytical and Bioanalytical Chemistry 396, 365-377.

Rosman, K.J.R., Chisholm, W., Boutron, C.F., Candelone, J.-P., Patterson, C., 1994. Anthropogenic lead isotopes in Antarctica. Geophysical Research Letters 21, 26692672.

Ruth, U., Barbante, C., Bigler, M., Delmonte, B., Fischer, H., Gabrielli, P., Gaspari, V., Kaufmann, P., Lambert, F., Maggi, V., Marino, F., Petit, J.-R., Udisti, R., Wagenbach, D., Wegner, A., Wolff, E.W., 2008. Proxies and measurement techniques for mineral dust in Antarctic ice cores. Environmental Science Technology 42, 5675-5681.

Salinger, M.J., Renwick, J.A., Mullan, A.B., 2001. Interdecadal Pacific Oscillation and South Pacific climate. International Journal of Climatology 21, 1705-1721.

Severinghaus, J.P., 2009. Southern see-saw seen. Nature 457, 1093-1094.

Sigl, M., McConnell, J.R., Layman, L., Maselli, O., McGwire, K., Pasteris, D., Dahl-Jensen, D., Steffensen, J.P., Vinther, B., Edwards, R., 2013. A new bipolar ice core record of volcanism from WAIS Divide and NEEM and implications for climate forcing of the last 2000 years. Journal of Geophysical Research: Atmospheres.

Sigman, D.M., Hain, M.P., Haug, G.H., 2010. The polar ocean and glacial cycles in atmospheric CO2 concentration. Nature 466, 47-55.

Sinclair, K.E., Bertler, N.A.N., Trompetter, W.J., 2010. Synoptic controls on precipitation pathways and snow delivery to high-accumulation ice core sites in the Ross Sea region, Antarctica. Journal of Geophysical Research: Atmospheres (1984-2012) 115.

Sinclair, K.E., Bertler, N.A.N., Trompetter, W.J., Baisden, W.T., 2013. Seasonality of airmass pathways to coastal Antarctica: Ramifications for interpreting high-resolution ice core records. Journal of Climate 26, 2065-2076.

Solomon, S., Plattner, G.-K., Knutti, R., Friedlingstein, P., 2009. Irreversible climate change due to carbon dioxide emissions. PNAS 106, 1704-1709.

Stammerjohn, S.E., Martinson, D.G., Smith, R.C., Yuan, X., Rind, D., 2008. Trend in Antarctic annual sea ice retreat and advance and their relation to El Nino-Southern Oscillation and Southern Annular Mode variability. Journal of Geophysical Research $113,1-20$.

Stefels, J., Steinke, M., Turner, S., Malin, G., Belviso, S., 2007. Environmental constraints on the production and removal of the climatically active gas dimethylsulphide (DMS) and implications for ecosystem modelling. Biogeochemistry 83, 245-275.

Steig, E.J., Ding, Q., White, J.W.C., Kuttel, M., Rupper, S.B., Neumann, T.A., Neff, P.D., Gallant, A.J.E., Mayewski, P.A., Taylor, K.C., Hoffmann, G., Dixon, D.A., Schoenemann, S.W., Markle, B.R., Fudge, T.J., Schneider, D.P., Schauer, A.J., Teel, R.P., Vaughn, B.H., Burgener, L., Williams, J., Korotkikh, E., 2013. Recent climate and ice-sheet changes in West Antarctica compared with the past 2,000 years. Nature Geoscience 6, 372-375.

Steig, E.J., Schneider, D.P., Rutherford, S.D., Mann, M.E., Comiso, J.C., Shindell, D.T., 2009. Warming of the Antarctic ice-sheet surface since the 1957 International Geophysical Year. Nature 457, 459-463. 
Stenni, B., Buiron, D., Frezzotti, M., Albani, S., Barbante, C., Bard, E., Barnola, J.M., Baroni, M., Baumgartner, M., Bonazza, M., Capron, E., Castellano, E., Chappellaz, J., Delmonte, B., Falourd, S., Genoni, L., Iacumin, P., Jouzel, J., Kipstuhl, S., Landais, A., Lemieux-Dudon, B., Maggi, V., Masson-Delmotte, V., Mazzola, C., Minster, B., Montagnat, M., Mulvaney, R., Narcisi, B., Oerter, H., Parrenin, F., Petit, J.R., Ritz, C., Scarchilli, C., Schilt, A., Schupbach, S., Schwander, J., Selmo, E., Severi, M., Stocker, T.F., Udisti, R., 2010. Expression of the bipolar see-saw in Antarctic climate records during the last deglaciation. Nature Geoscience 4, 46-49.

Torseth, K., Aas, W., Breivik, K., Fjaeraa, A.M., Fiebig, M., Hjellbrekke, A.G., Lund Myhre, C., Solberg, S., Yttri, K.E., 2012. Introduction to the European Monitoring and Evaluation Program (EMEP) and observed atmospheric composition change during 1972-2009. Atmospheric Chemsitry and Physics 12, 5447-5481.

Turner, J., 2004. Review: The El Nino-Southern oscillation and Antarctica. International journal of Climatology 24, 1-31.

Turner, J., Colwell, S.R., Marshall, G.J., Lachlan-Cope, T.A., Carleton, A.M., Jones, P.D., Lagun, V., Reid, P.A., Iagovkina, S., 2005. Antarctic climate change during the last 50 years. International journal of Climatology 25, 279-294.

Turner, J., Lachlan-Cope, T.A., Colwell, S.R., Marshall, G.J., Connolley, W.M., 2006. Significant warming of the Antarctic winter troposphere. Science 311, 1914-1917.

Turner, J., Phillips, T., Hosking, J.S., Marshall, G.J., Orr, A., 2013. The Amundsen Sea Low. International Journal of Climatology 33, 1818-1829.

Vallelonga, P., Gabrielli, P., Balliana, E., Wegner, A., Delmonte, B., Turetta, C., Burton, G., Vanhaecke, F., Rosman, K.J.R., Hong, S., Boutron, C.F., Cescon, P., Barbante, C., 2010. Lead isotopic compositions in the EPICA Dome $C$ ice core and Southern Hemisphere Potential Source Areas. Quaternary Science Reviews 29, 247-255.

Vallelonga, P., Van De Velde, K., Candelone, J.-P., Morgan, V.I., Boutron, C.F., Rosman, K.J.R., 2002. The lead pollution history of Law Dome, Antarctica, from isotopic measurements on ice cores: 1500 AD to 1989 AD. Earth and Planetary Science Letters 204, 291-306.

van Sebille, E., Spence, P., Mazloff, M.R., England, M.H., Rintoul, S.R., Saenko, O.A., 2013. Abyssal connections of Antarctic bottom water in a Southern Ocean state estimate. Geophysical Research Letters 40, 2177-2182.

Vaughan, D.G., Marshall, G.J., Connolley, W.M., Parkinson, C., Mulvaney, R., Hodgson, D.A., King, J.C., Pudsey, C.J., Turner, J., 2003. Recent rapid regional climate warming on the Antarctic Peninsula. Climatic Change 60, 243-274.

von Deimling, T.S., Ganopolski, A., Held, H., Rahmstorf, S., 2006. How cold was the Last Glacial Maximum? Geophysical Research Letters 33, 1-5.

Wanner, H., Beer, J., Butikofer, J., Crowley, T.J., Cubasch, U., Fluckiger, J., Goosse, H., Grosjean, M., Joos, F., Kaplan, J.O., Kuttel, M., Muller, S.A., Prentice, I.C., Solomina, O., Stocker, T.F., Tarasov, P., Wagner, M., Widmann, M., 2008. Mid- to Late Holocene climate change: an overview. Quaternary Science Reviews 27, 17911828.

Wolff, E.W., Barbante, C., Becagli, S., Bigler, M., Boutron, C.F., Castellano, E., de Angelis, M., Federer, U., Fischer, H., Fundel, F., Hansson, M., Hutterli, M., Jonsell, U., Karlin, T., Kaufmann, P., Lambert, F., Littot, G.C., Mulvaney, R., Röthlisberger, R., Ruth, U., Severi, M., Siggaard-Andersen, M.L., Sime, L.C., Steffensen, J.P., Stocker, T.F., Traversi, R., Twarloh, B., Udisti, R., Wagenbach, D., Wegner, A., 2010. Changes in environment over the last 800,000 years from chemical analysis of the EPICA Dome C ice core. Quaternary Science Reviews 29, 285-295.

Wolff, E.W., Fischer, H., Fundel, F., Ruth, U., Twarloh, B., Littot, G.C., Mulvaney, R., Röthlisberger, R., de Angelis, M., Boutron, C.F., Hansson, M., Jonsell, U., Hutterli, M.A., Lambert, F., Kaufmann, P., Stauffer, B., Stocker, T.F., Steffensen, J.P., Bigler, 
M., Siggaard-Andersen, M.L., Udisti, R., Becagli, S., Castellano, E., Severi, M., Wagenbach, D., Barbante, C., Gabrielli, P., Gaspari, V., 2006. Southern Ocean sea-ice extent, productivity and iron flux over the past eight glacial cycles. Nature 440, 491496.

Wolff, E.W., Hall, J.S., Mulvaney, R., Pasteur, E.C., Wagenbach, D., Legrand, M., 1998. Relationship between chemistry of air, fresh snow and firn cores for aerosol species in coastal Antarctica. Journal of Geophysical Research 103, 11,057-011,070. 


\section{Appendix A}

This appendix contains the script files written for use in MATLAB to import and process the ICPMS data. The final corrected concentrations for all heavy metal data presented in this thesis (with outliers removed) are published in the electronic spreadsheets on the CD/USB accompanying this thesis.

Initially, the runs were reviewed to check for overall drift, comparing the raw ICPMS counts per second with the Internal Standard corrected values calculated within the Element Software at the end of each run. There are four steps used to process the data to obtain final concentrations for all elements. Each run was processed independently from the others.

Step 1 - Import all the raw data

Step 2 - Correct the zero calibration standard intensities in order to ensure that the zero standard used in the calibration contains the lowest intensities measured during the run.

Step 3 - Manually calculate Internal Standard corrected values for the Calibration Standards using the same equation that the Element Software uses. Then calculate new calibration curves through the standards using the 'robustfit' function. Then use the generated linear calibration equations to calibrate the Internal Standard Corrected values for Samples, Instrumental (Run) Blanks, Duplicates and QC samples.

Step 4 - Blank correction to remove the instrumental (run) background from the final Samples and Quality Control concentrations.

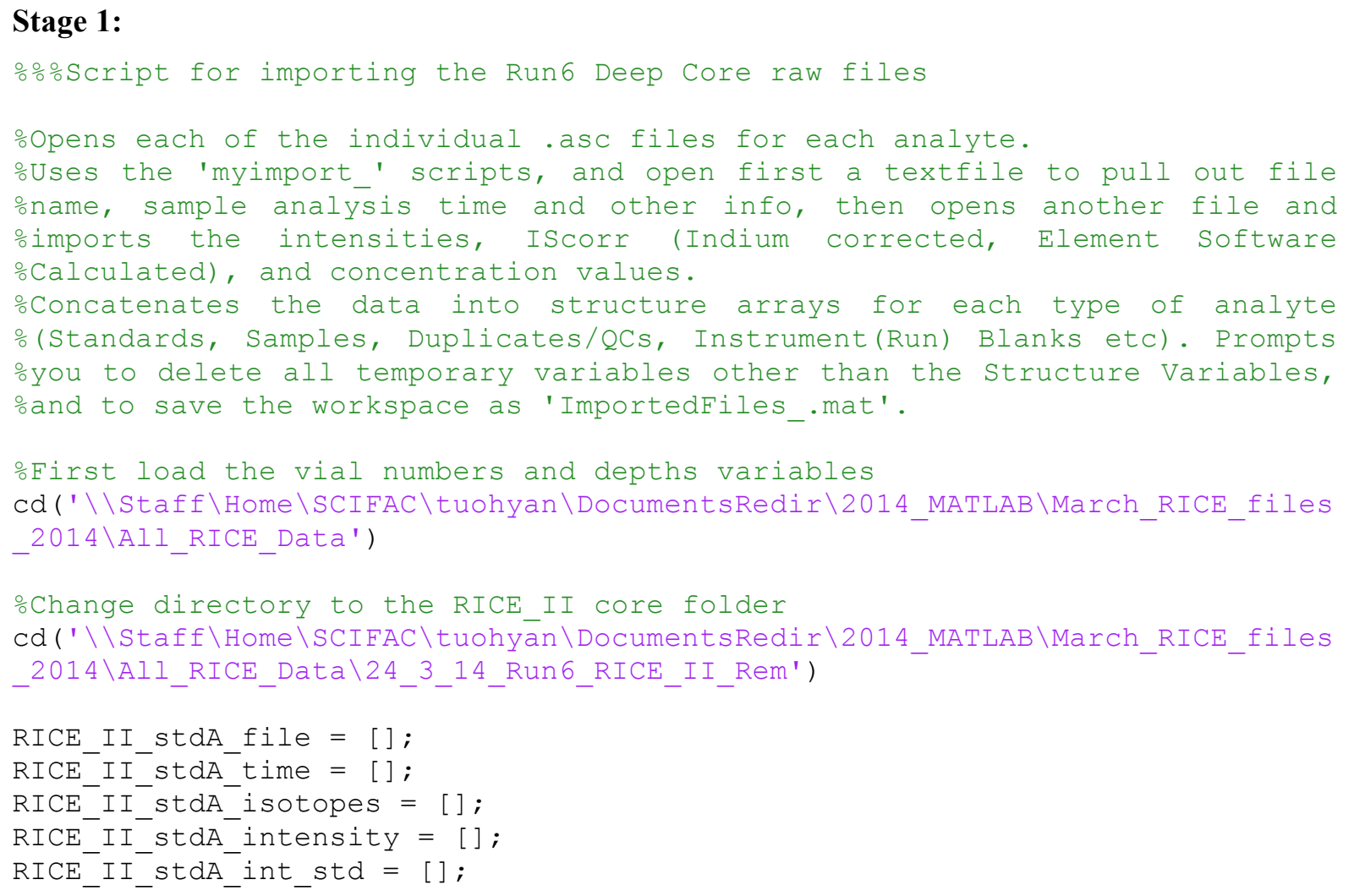




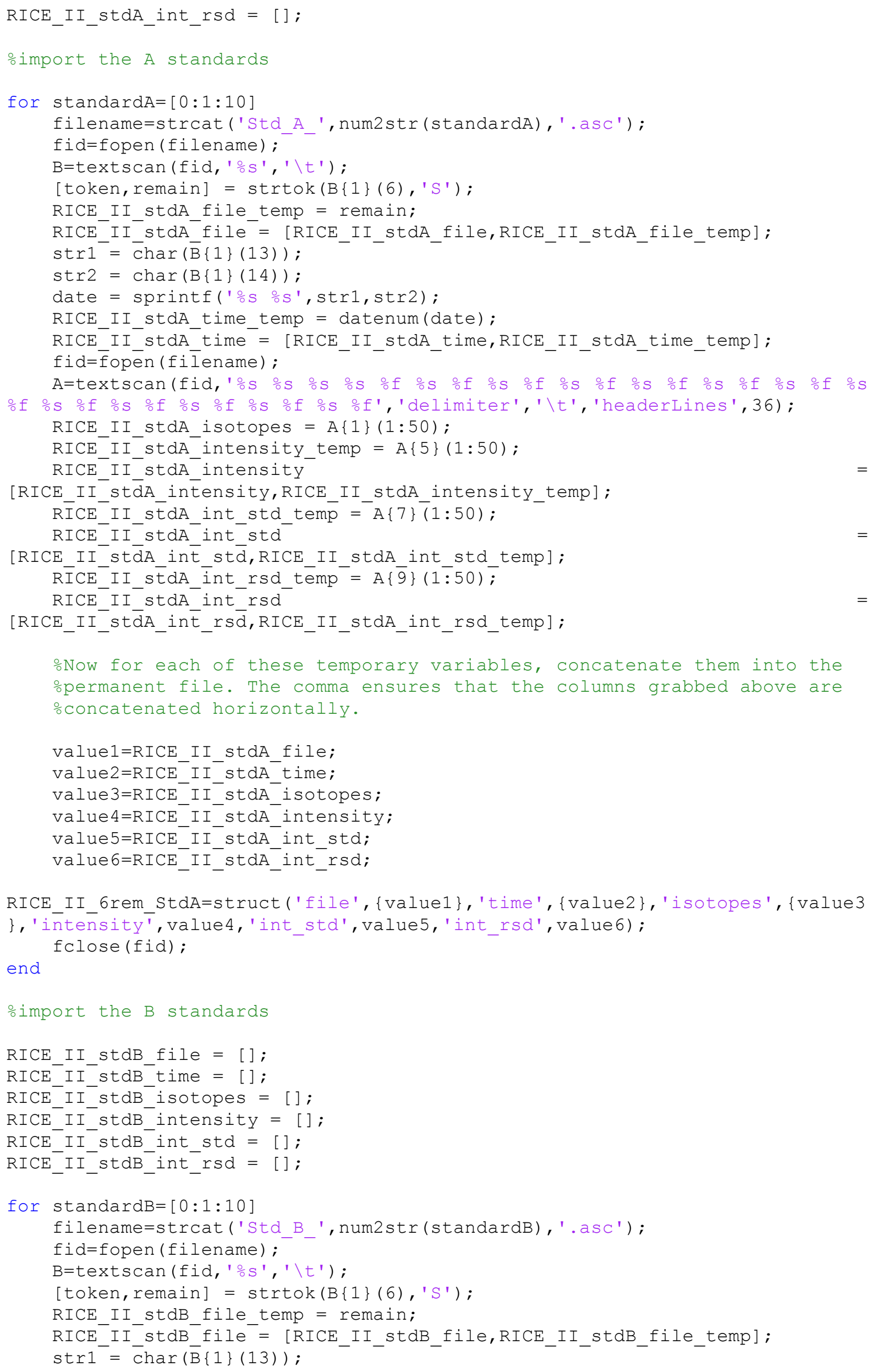




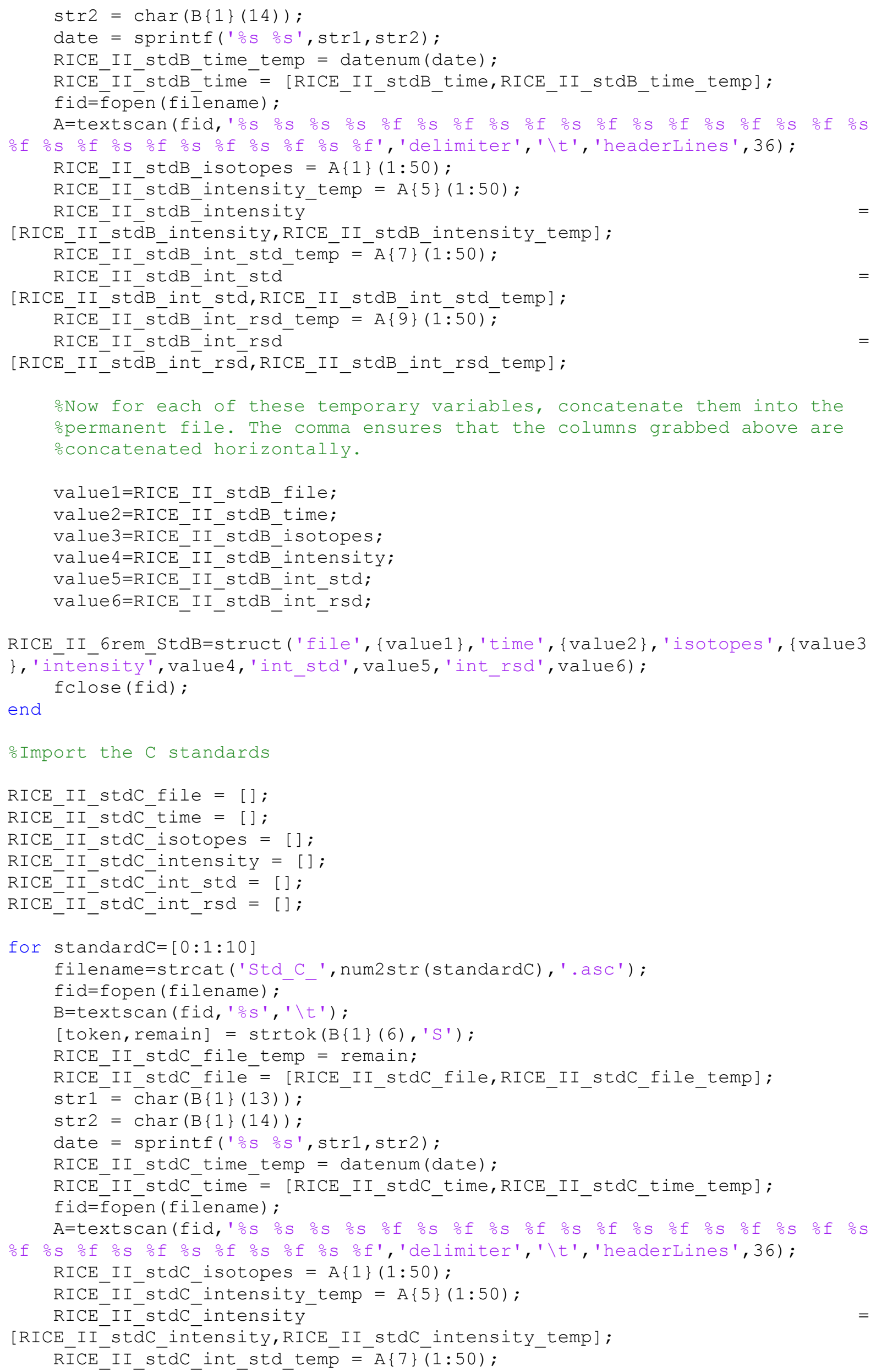


RICE II stdC int std

[RICE_II ${ }^{-}$st $\bar{d} C$ int $\bar{t}$ st $\bar{d}$, RICE_II_stdC int_std_temp];

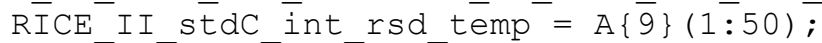

RICE_II_stdC_int_rsd

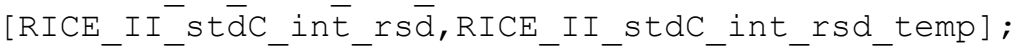

oNow for each of these temporary variables, concatenate them into the opermanent file. The comma ensures that the columns grabbed above are oconcatenated horizontally.

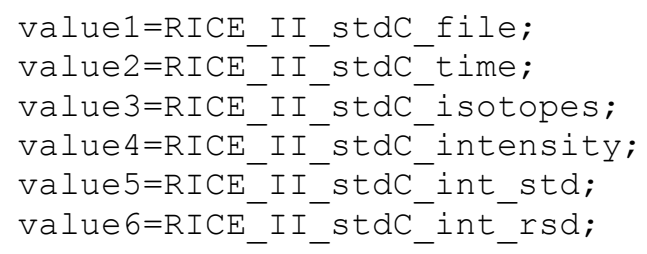

RICE_II_6rem_StdC=struct ('file', \{value1\},'time', \{value2\},'isotopes', \{value3 \}, 'intensity', value4, 'int_std', value5, 'int_rsd', value6);

fclose (fid);

end

display ('Remember to delete all workspace variables apart from RICE_II_run6... Structure files')

oplot Na intensities from Std A, B, C to check they have worked

figure (1);

plot(RICE_II_6rem_StdA.intensity ( (9), 1:end), 'b-x') ;

set (gca, 'X'Tick', 1:11);

set (gca,'XTickLabel', (RICE_II_6rem_StdA.file((1), 1:11)));

xticklabel_rotate;

set(gcf,'Name', 'stdA_Ce_Calibration') ;

figure (2);

plot (RICE_II_6rem_StdB.intensity ( (9), 1:end), 'b-x') ;

set (gca, 'XTick', 1: 11 );

set (gca, 'XTickLabel', (RICE_II_6rem_StdB.file((1), 1:11))) ;

xticklabel rotate;

set(gcf,'Nāme', 'stdB_Ce_Calibration') ;

figure (3);

plot(RICE_II_6rem_StdC.intensity ( (9), 1:end), 'b-x') ;

set (gca, 'XTick', 1:11);

set (gca, 'XTickLabel', (RICE_II_6rem_StdC.file((1), 1:11)));

xticklabel rotate;

set (gcf, 'Name', 'StdC_Ce_Calibration') ;

oimport the samples

RICE_II_samp_file $=$ [];

RICE_II_samp_time $=$ [];

RICE_II_samp_isotopes = [];

RICE_II_samp_intensity $=$ [ ] ;

RICE_II_samp_int_std $=$ [];

RICE II_samp_int_rsd $=[]$;

RICE_II_samp_IScorr $=$ [ ];

RICE II_samp_IScorr_std $=$ [ ];

RICE_II_samp_IScorr_rsd $=$ [ ] ;

RICE_II_samp_conc $=$ [];

RICE_II_samp_conc_std $=$ [ ];

RICE_II_samp_conc_rsd = [ ] ; 
$a=[254: 506] ;$

momod $(0:$ length $(a)-1,4)$;

for sample=a $(\mathrm{m}=2)$;

filename=strcat ('RICE_II_ICPMS_', num2str (sample), '.asc');

fid=fopen (filename);

$\mathrm{B}=$ textscan (fid, 'os', '\t');

[token, remain] = strtok $\left(B\{1\}(6),{ }^{\prime} P^{\prime}\right)$;

RICE_II_samp_file_temp = strcat('RICE_II_IC', remain);

RICE_II_samp_file ${ }^{-}=$[RICE_II_samp_file, RICE_II_samp_file_temp];

$\operatorname{str} 1=\overline{\operatorname{Char}}(\overline{\mathrm{B}}\{1\}(13))$;

str2 = $\operatorname{char}(B\{1\}(14))$;

date = sprintf('으의 ', str1, str2);

RICE_II_samp_time_temp = datenum (date);

RICE_II_samp_time ${ }^{-}=$[RICE_II_samp_time,RICE_II_samp_time_temp];

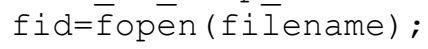

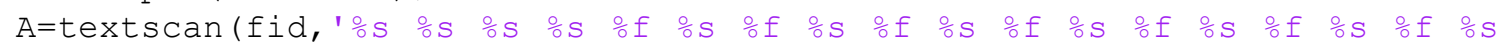

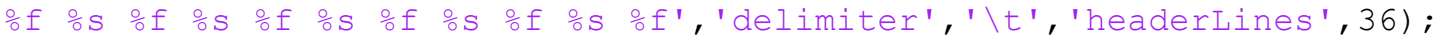

RICE_II_samp_isotopes $=A\{1\}(1: 50)$;

RICE_II_samp_intensity_temp $=A\{5\}(1: 50)$;

RICE ${ }^{-} I^{-}$samp_intensity

[RICE_II_samp_intensity,RICE_II_samp_intensity_temp] ;

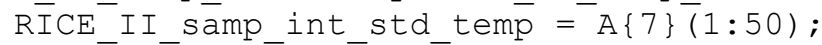

RICE II samp int std

[RICE II samp int st $\bar{d}$, RICE_II samp int std temp];

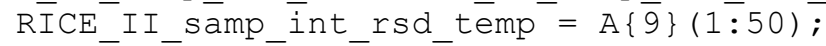

RICE II samp int rsd

[RICE II samp_int_rs $\bar{d}$, RICE_II_samp int_rsd_temp];

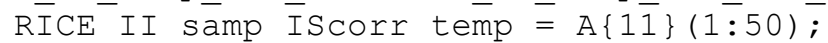

RICE_II_samp_IScorr ${ }^{-}=$[RICE_II_samp_IScorr,RICE_II_samp_IScorr_temp];

RICE II samp IScorr std temp $=\bar{A}\{13\}(1: 50)$;

RICE_II_samp_IScorr_std

[RICE_II_samp_IScorr_stē, RICE_II_samp_IScorr_std_temp];

RICE_II_samp_IScorr_rsd_temp $=A\{\overline{1} 5\}(1: 5 \overline{0})$;

RICE II samp IScorr ${ }^{-}$rsd

[RICE_II_samp_IScorr_rsd, RICE_II_samp_IScorr_rsd_temp];

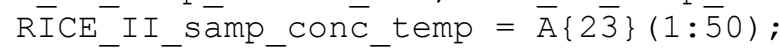

RICE_II_samp_conc ${ }^{-}=$[RICE_II_samp_conc,RICE_II_samp_conc_temp];

RICE II samp conc std temp $=\bar{A}\{25 \bar{\beta}(1: 50)$;

RICE II samp_conc_std

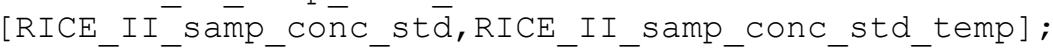

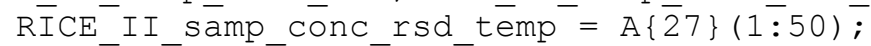

RICE_II_samp_conc_rsd

[RICE_II_samp_coñc_rs $\bar{d}, \mathrm{RICE}$ _II_samp_conc_rsd_temp] ;

$\mathrm{f} \overline{\mathrm{close}}(\mathrm{fi} \overline{\mathrm{d}})$;

valuel=RICE_II_samp_file;

value2=RICE_II_samp_time;

value3=RICE_II_samp_isotopes;

value4=RICE_II_samp_intensity;

value5=RICE_II_samp_int_std;

value6=RICE_II_samp_int_rsd;

value7=RICE II_samp_IScorr;

value8=RICE_II_samp_IScorr_std;

value9=RICE_II samp_IScorr_rsd;

value10=RICE I I

value11=RICE_II_samp_conc_std;

value12=RICE_II_samp_conc_rsd;

RICE_II_6rem_Sample=struct ('file', $\{$ value1\},'time', \{value2\},'isotopes', $\{$ valu e3\},'intensity', value4, 'int_std', value5, 'int_rsd', value6, 'Iscorr', value7, 'I Scorr_std', value8, 'IScorr_rsd', value9, 'conc', value10, 'conc_std', value11, 'co nc_rs $\overline{\mathrm{d}}$ ', value12);

En $\bar{d}$ 


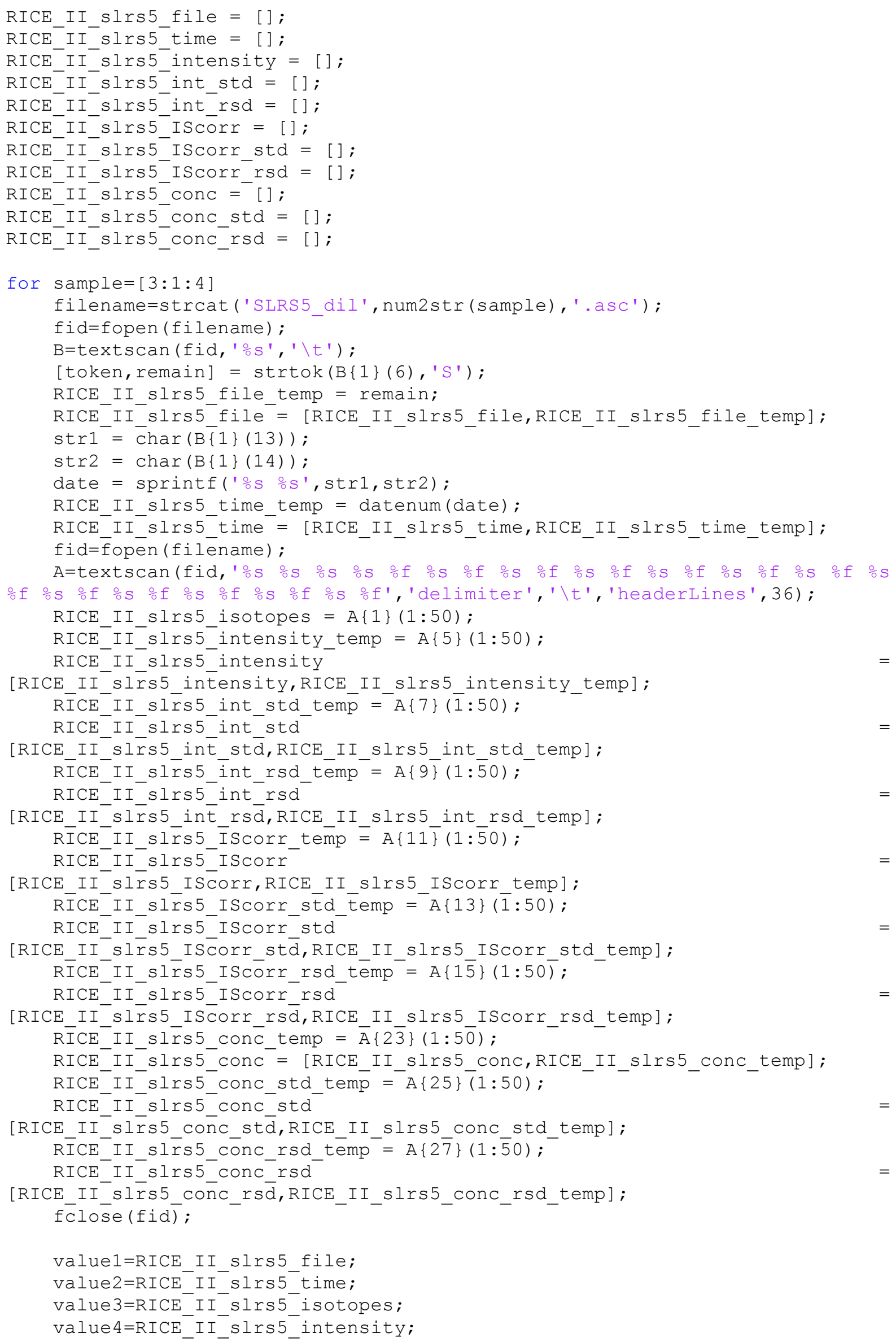




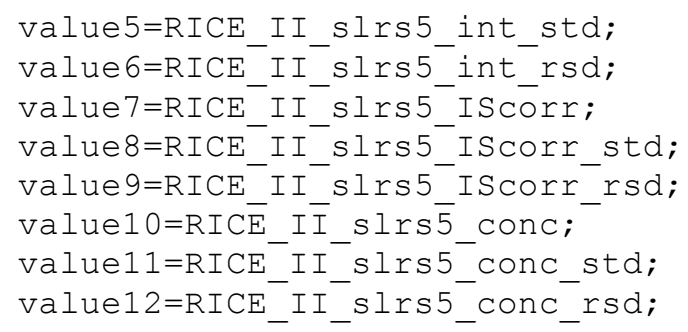

RICE_II_6rem_SLRS5=struct ('file', \{value1\},'time', \{value2\},'isotopes', \{value 3\},' 'intēnsitȳ', value4, 'int_std', value5, 'int_rsd', value6, 'IScorr', value7, 'IS corr std', value8, 'IScorr rśs', value9, 'conc', value10, 'conc std', value11, 'con c_rs' ', value12)

end

oImport the Run Blanks

RICE_II_rb_file $=$ [ ] ;

RICE II rb time $=[]$;

RICE II_rb_isotopes $=[]$;

RICE_II_rb_intensity $=$ [];

RICE_II_rb_int_std = [];

RICE II rb int rsd = [];

RICE II rb- ISCOrr $=[]$;

RICE_II_rb_IScorr_std = [];

$\mathrm{RICE}^{-} \mathrm{II}^{-} \mathrm{rb}{ }^{-} \mathrm{ISCOrr}{ }^{-} \mathrm{rsd}=[]$;

$\mathrm{RICE}^{-} \mathrm{II}^{-} \mathrm{rb}{ }^{-} \mathrm{COnC}={ }^{-}[]$;

$\mathrm{RICE}^{-} \mathrm{II}^{-} \mathrm{rb}$ - conc std $=[]$;

RICE_II_rb_conc_rsd = [ ] ;

for sample $=[21: 1: 41]$

filename=strcat ('Run_Blank_', num2str(sample), '.asc') ;

fid=fopen (filename);

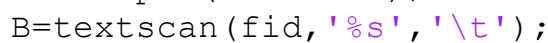

[token, remain] = strtok $\left(B\{1\}(6), \mathrm{k}^{\prime}\right)$;

RICE_II_rb_file_temp = strcat('Blan',remain);

RICE_II_rb_file ${ }^{-}=$[RICE_II_rb_file,RICE_II_rb_file_temp];

$\operatorname{str} \overline{1}^{-}=\overline{\operatorname{char}}(\mathrm{B}\{1\}(13)) ;$

str2 $=\operatorname{char}(B\{1\}(14)) ;$

date = sprintf ('\%s $\% S^{\prime}$, str1, str2);

RICE II rb time temp = datenum(date);

RICE_II_rb_time ${ }^{-}=$[RICE_II_rb_time,RICE_II_rb_time_temp];

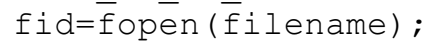

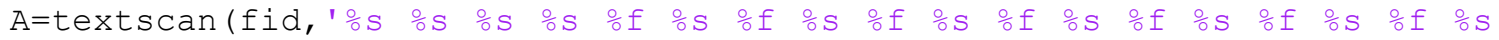

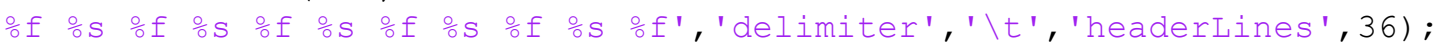

RICE_II_rb_isotopes $=A\{1\}(1: 50)$;

RICE_II_rb_intensity_temp $=A\{5\}(1: 50)$;

RICE II rb intensity

[RICE_II_rb_intensity,RICE_II_rb_intensity_temp];

RICE_II_rb_int_std_temp $=\overline{-} A\{\overline{7}\}(1: 50)$;

RICE_II_rb_int_std ${ }^{-}=$[RICE_II_rb_int_std,RICE_II_rb_int_std_temp];

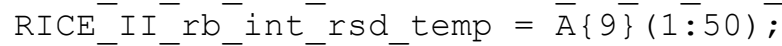

RICE II_rb_int_rsd ${ }^{-}=$[RICE_II_rb_int_rsd, RICE_II_rb_int_rsd_temp];

RICE_II_rb_IScorr_temp $=\bar{A} \overline{\{} 11 \overline{1}(1 \overline{1}: 50) \overline{\text {; }}$

$\mathrm{RICE}^{-} \mathrm{II}^{-}{ }_{\mathrm{rb}}^{-} \mathrm{ISCOrr}^{-}=$[RICE_II_rb_IScorr, RICE_II_rb_IScorr_temp];

RICE II rb_IScorr_std_temp $=\bar{A}\{\overline{1} 3\}(1: 50)$;

RICE II_rb_IScorr_std

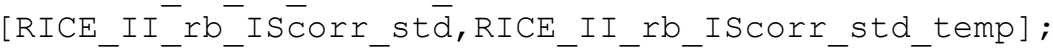

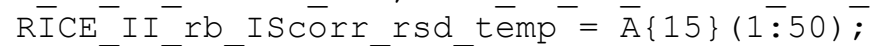

RICE-II_rb- IScorr_rsd

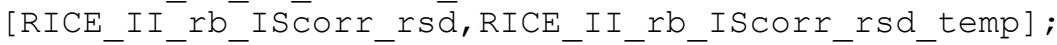

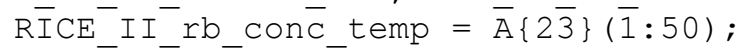

RICE_II_rb_conc ${ }^{-}=$[RICE_II_rb_conc, RICE_II_rb_conc_temp]; 


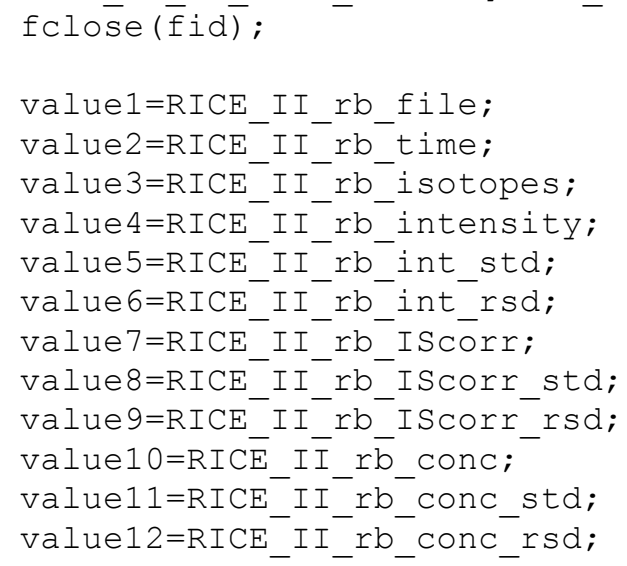

RICE II 6rem RunBlank=struct('file', \{value1\},'time', \{value2\},'isotopes', \{va lue3\}, 'intensity', value4, 'int_std', value5, 'int_rsd', value6, 'IScorr', value7, 'IScorr_std', value8, 'IScorr_rsd', value9, 'conc', value10, 'conc_std', value11,' conc_rs '́, value12);

end

OImport the Duplicates and QCS

RICE_II_dupqC_file $=[]$;

RICE_II_dupqc_time $=$ [];

$\mathrm{RICE}^{-}{ }^{-} \mathrm{I}^{-}$dupqC ${ }^{-}$isotopes $=[]$;

RICE_II_dupqC intensity $=$ [ ] ;

RICE_II_dupqC_int_std $=$ [ ] ;

RICE_II_dupqC_int_rsd $=[]$;

$\mathrm{RICE}^{-} \mathrm{II}{ }^{-}$dupqC ISCŌr $=[]$;

RICE_II_dupqC_IScorr_std = [ ] ;

RICE_II_dupqC_IScorr_rsd = [ ] ;

RICE_II_dupqc_conc $=[]$;

RICE II dupqC conc std $=[]$;

RICE_II_dupqc_conc_rsd $=$ [ ] ;

for sample $=[5: 1: 11]$

filename=strcat ('Duplicate_', num2str(sample), '.asc');

fid=fopen (filename);

$B=$ textscan (fid, 'os', '\t') ;

[token, remain] = strtok $\left(B\{1\}(6), ' p^{\prime}\right)$;

RICE_II_dupqc_file_temp $=\operatorname{strcat}\left({ }^{\prime} \mathrm{Du}\right.$ ', remain);

RICE_II_dupqC_file $=$ [RICE_II_dupqC_file,RICE_II_dupqC_file_temp];

$\operatorname{str} 1=\overline{\operatorname{Char}}(\mathrm{B}\{1\}(13))$;

str2 $=\operatorname{char}(B\{1\}(14))$;

date = sprintf(' $\%$ s $\% S^{\prime}$, str $\left.1, \operatorname{str} 2\right)$;

RICE_II_dupqc_time_temp = datenum(date);

RICE_II_dupqC_time ${ }^{-}=$[RICE_II_dupqC_time, RICE_II_dupqC_time_temp];

fid=fopen (filename);

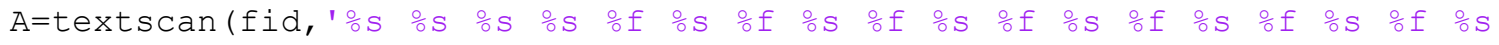

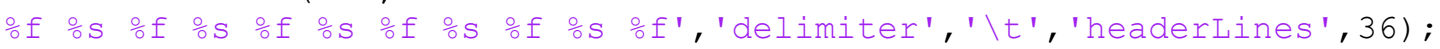

RICE II dupqC isotopes $=A\{1\}(1: 50)$;

RICE_II_dupqC_intensity_temp $=A\{5\}(1: 50)$;

RICE_II_dupqC_intensity

[RICE_II_dupqc_intensity,RICE_II_dupqc_intensity_temp] ;

RICE_II_dupqc_int_std_temp $=\bar{A} A\{7\}(\overline{1}: 50)$;

RICE_II_dupqC_int_std

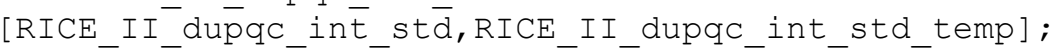

RICE_II_dupqc_int_rsd_temp $=A\{9\}(1: \overline{5} 0)$; 
RICE II dupqC int rsd

[RICE II dup $\bar{p} q c_{-} i n \bar{t} r s \bar{d}, R I C E$ II_dupqC_int_rsd_temp] ;

$\mathrm{RICE}{ }^{-} \mathrm{II}$ dupqC $\overline{\mathrm{ISCO}} \mathrm{T}$ temp $=\mathrm{A}\{11 \overline{1}\}(1: \overline{5} 0)$;

RICE_II_dupqC_IScorr

[RICE_II_dupqc_ISC̄orr,RICE_II_dupqC_IScorr_temp];

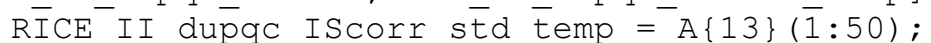

RICE_II_dupqC_IScorr_std

[RICE_II_dupqc_IS $\bar{c}$ orr_stē, RICE_II_dupqC_IScorr_std_temp];

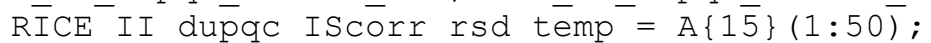

$\mathrm{RICE}^{-} \mathrm{II}^{-}$dupqC ${ }^{-} \mathrm{ISCOrr}{ }^{-} \mathrm{rsd}$

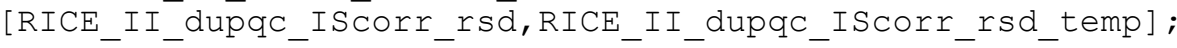

$\mathrm{RI} C \mathrm{E}^{-} \mathrm{II}$ dup $\mathrm{p} \mathrm{c}$ con $\overline{\mathrm{C}}$ temp $=\overline{\mathrm{A}}\{2 \overline{3}\}(1: 5 \overline{0})$;

RICE II_dupqC Conc $=$ [RICE II_dupqC_conc, RICEIIIdupqC_conc temp];

RICE_II_dupqC_conc_std_temp $=\bar{A}\{25\} \overline{(1: 50)}$;

RICE_II_dupqC_conc_std

[RICE_II_dup̄qc_coñc_st $\bar{d}$, RICE_II dupqc conc std temp];

RICE II_dupqc_conc_rsd_temp $=A\{2 \overline{7}\}(1: \overline{5} 0)$;

RICE ${ }^{-} I^{-}$dupqC_conc_rsd

[RICE_II_dupqc_coñc_rs $\bar{d}$, RICE_II_dupqc_conc_rsd_temp]; fōlose (fid);

end

for sample=[19:1:35]

filename=strcat ('QC_', num2str (sample), '.asc') ;

fid=fopen (filename);

$\mathrm{B}=$ textscan (fid, 'ㅇ' ', '\t') ;

[token, remain] = strtok $\left(B\{1\}(6), \mathrm{Q}^{\prime}\right)$;

RICE II_dupqC file temp = remain;

RICE_II_dupqC_file $=$ [RICE_II_dupqC_file,RICE_II_dupqC_file_temp];

str $1=\overline{C h a r}(B \overline{\{} 1\}(13))$;

str2 $=\operatorname{char}(B\{1\}(14))$;

date = sprintf('\%s $\% \mathrm{~s}^{\prime}$, str $\left.1, \operatorname{str} 2\right)$;

RICE_II_dupqc_time_temp = datenum(date);

RICE II dupqC time $=$ [RICE II dupqc time, RICE II dupqC time temp];

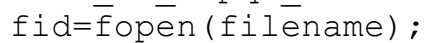

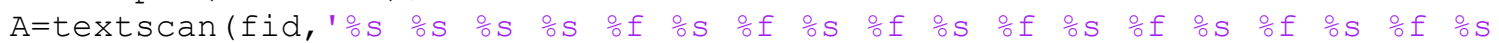

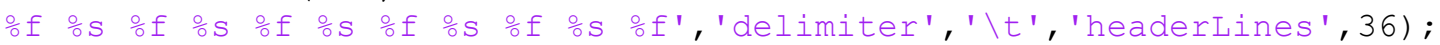

RICE II dupqC isotopes $=A\{1\}(1: 50)$;

$\mathrm{RICE}^{-} \mathrm{II}^{-}$dupqC intensity temp $=\mathrm{A}\{5\}(1: 50)$;

RICE_II_dupqC_intensity

[RICE_II_dupqc_intensity, RICE_II_dupqc intensity_temp] ;

$\mathrm{R} \overline{\mathrm{I} C E} \overline{I I}^{-}$dup $q \mathrm{C}$ int std temp $=\overline{\mathrm{A}}\{7\}(\overline{1}: 50)$;

RICE_II_dupqC_int_std

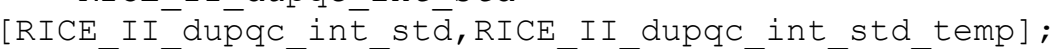

$\mathrm{R} \overline{\mathrm{I} C E}{ }^{-} \mathrm{II}$ dup $q \mathrm{C}$ int rsd temp $=\mathrm{A}\{9 \overline{\mathrm{e}}(1: \overline{5} 0)$;

RICE ${ }^{-} I^{-}$dupqC int ${ }^{-} \mathrm{sd}^{-}$

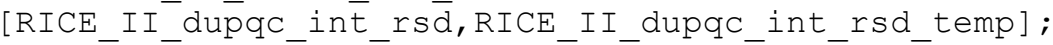

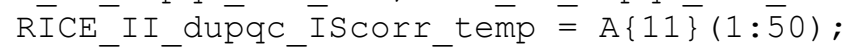

RICE II dupqC IScorr

[RICE_II_dupqc_ISC̄orr,RICE_II_dupqC_IScorr_temp];

RICE II_dupqc_IScorrstete temp $=\bar{A}\{13\}(\overline{1}: 50)$;

RICE ${ }^{-} I^{-}$dupqC ${ }^{-}$IScorr ${ }^{-}$std

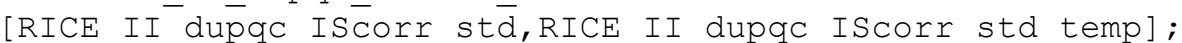

RICE_II_dup̃qC_IScorr_rsd_temp $=A\{1 \overline{5}\}(1: 50)$;

RICE II dupqC ISCOrr ${ }^{-}{ }^{-}{ }^{-} d^{-}$

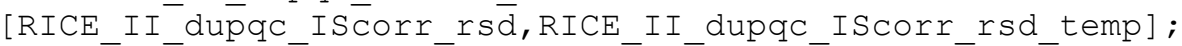

RICE_II_dupqc_conc_temp $=\overline{\mathrm{A}}\{2 \overline{3}\}(1: 5 \overline{0})$;

RICE_II_dupqC_conc ${ }^{-}=$[RICE_II_dupqC_conc,RICE_II_dupqC_conc_temp];

RICE_II_dupqc_conc_std_temp $=\bar{A}\{25\} \overline{(1: 50)}$;

RICE II dupqC conc std

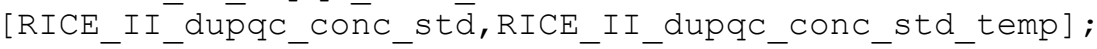

RICE_II_dupqc_conc_rsd_temp $=A\{2 \overline{7}\}(1: \overline{5} 0)$; 
RICE II dupqC conc rsd

[RICE_II ${ }^{-}$dup $\bar{p} q \mathrm{c}$ coñc_rs $\bar{d}, \mathrm{RICE} I I$ dupqc_conc_rsd_temp];

f́close (fid);

end

valuel=RICE_II_dupqc_file;

value2=RICE_II_dupqC_time;

value $3=$ RICE$^{-}$II_dupqC_isotopes;

value $4=$ RICE $^{-} I^{-}$dupqC ${ }^{-}$intensity;

value $5=\mathrm{RICE}^{-} \mathrm{II}^{-}$dupqC ${ }^{-}$int std;

value6=RICE_II_dupqC_int_rsd;

value $7=$ RICE $^{-} \mathrm{II}^{-}$dupqC ISCorr;

value 8=RICE II_dupqC_IScorr_std;

value $9=\mathrm{RICE}^{-} \mathrm{II}$ dupqC IScorr rsd;

value10=RICE_III_dupqC_conc;

value11=RICE II_dupqC_conc_std;

value12=RICE_II_dupqC_conc_rsd;

RICE_II_6rem_DuplQCs=struct('file', \{value1\},'time', \{value2\},'isotopes', \{val ue3\},' 'iñtensíty', value4, 'int std', value5, 'int rsd', value6, 'IScorr', value7,' IScorrstd', value8, 'IScorr_ssd', value9, 'conc', value10, 'conc_std', value11, 'c onc rs '́, value12);

\section{Stage 2:}

ocorrect the Zero Calibration Standard

oThis script looks through all the raw intesnties for the minimum intensity ofor each element in the run. This is then copied into the intensity for the ostd zero sample.

othen the new Std_Zero intensity (for each element) is subtracted from the ostdB intensities - essentially subtracting the instrument oblank(background/minimum possible intesnity for that run), from the ostandards prior to recalibrating them. So column 1 in stdB.intensity is opopulated with zeros, and the other columns (other standard samples) have ohad the minimum intensity for each element subtracted from them.

oThis is in order to ensure that all the calibration samples have positive ovalues.

oYou are prompted to save the workspace as'New_zero_std_workspace.mat' after

oremoving the temporary variables.

Find the Minimum intensity measured for each element from all the odifferent analytes (samples, blanks, standards), and set those minimum ointensities to the zero standard - so that the calibration standards have opositive values.

load 'ImportedFiles run6.mat';

$\operatorname{smin}=\operatorname{zeros}(50,1)$;

for iso=1:50;

min temp=nanmin (RICE II 6rem Sample.intensity ( (iso), 1 :end));

end

$\operatorname{smin}($ iso $)=\operatorname{vertcat}\left(\min _{-}\right.$temp);

bmin=zeros $(50,1)$;

for iso=1:50;

min_temp=nanmin (RICE_II_6rem_RunBlank.intensity ( (iso), 1 : end)) ;

bmin $(i s o)=\operatorname{vertcat}\left(\min \bar{n}_{-}\right.$émp) ;

end

Amin=zeros $(50,1)$;

for iso=1:50;

min temp=nanmin (RICE II 6rem StdA.intensity ( (iso), 1 : end));

end

$\operatorname{Amin}(i s o)=\operatorname{vertcat}(\operatorname{mi} \bar{n}$ temp) ;

Bmin=zeros $(50,1)$;

for iso=1:50; 


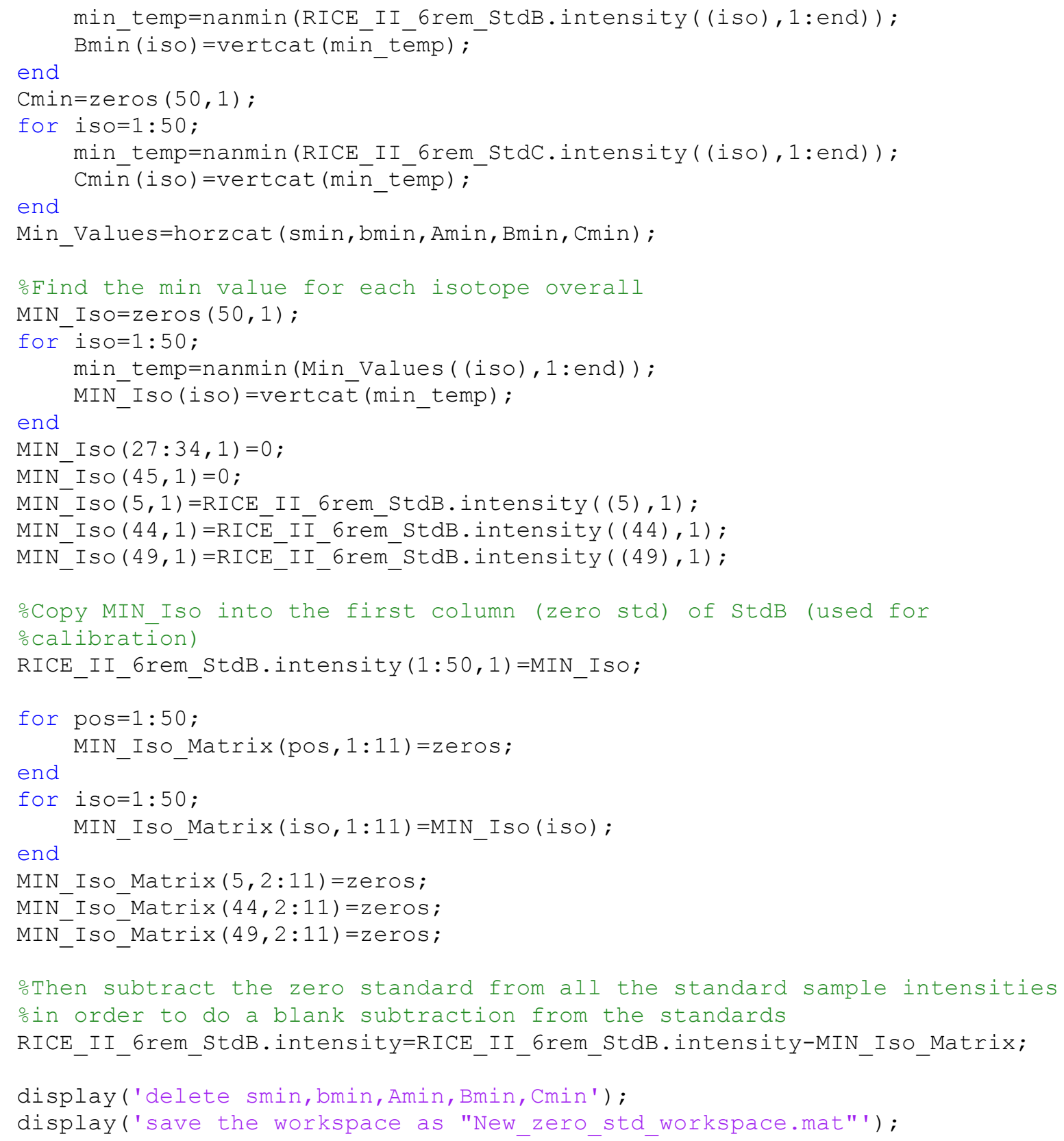

\section{Stage 3:}

oRecalibration script

oThe recalibration script calculates the Indium Corrected (IScorr) values ofor the Standard B samples, using the Thermo equation:

oInternal standardization is performed for each run value. ㅇ=Imeas. cIS/IIS

을

\%I = internal standardized value for isotope of interest

\%Imeas = measured intensity of isotope of interest

ocIS = concentration of the internal standard (500ppt)

\%IIS = measured intensity of internal standard

oThen the 'robustfit' function is used to calculate a line of best fit through othe IScorr Standard Sample values. The default option (bisquare) is used to oweight the points, and the intercept is turned 'off' to ensure 
the line ostarts at 0,0 (the start has already been corrected for the minimum 으tensity).

oThe slope of the robustfit line for each element is concatenated into the variable 'b'.

oThe slope is then used to re-calibrate the IScorr values of the Samples, oBlanks, Dupl/QCs to concentration values in ppt. These new re-calibrated omatrices are saved as variables: e.g. run\# recal sample(blank/duplqc) concs

oNo new workspace is saved, the Blank_Correction_run\#.m script is opened and orun next.

oThis script takes the intensity of the calibration samples from the oimported (but colated) raw files (saved in the NewStd Zero_Workspace), and othen uses the "robustfit" function based on the Bisquare method to produce a new calibration line.

-Standard B was chosen because it is in the middle of the run, and least oaffected by instrument drift over the run; after checking that there are ono significant issues between calibrations

\%I had to split up the isotopes so that it would process them all, then oconcatenate them back together to produce a matrix of the corrected olement calibration lines.

oStandard B

음 This is to standardise the calibration samples to In - the internal \%ostandard - so that they are compatable with the IScorr sample numbers ofrom the Element software.

LRIn_ISO $=[]$;

LRIn=500./RICE_II_6rem_StdB.intensity ( (5), 1 : end) ;

iso $=1: 34$;

for pos=1:34;

LRIn_Iso (pos, $1: 11)=$ LRIn;

end

MRIn ISO $=[]$;

MRIn=500./RICE_II_6rem_StdB.intensity ( (44), 1:end);

iso $=35: 45$;

for $p o s=1: 11$;

end

MRIn Iso (pos, $1: 11)=$ MRIn;

HRIn_ISO $=[]$;

HRIn=500./RICE II 6rem StdB.intensity ( (49), 1 : end);

is $\mathrm{O}=46: 50$;

for pos=1:5;

end

HRIn Iso (pos, $1: 11)=$ HRIn;

IScorr_StdB=vertcat (LRIn_Iso, MRIn_Iso, HRIn_Iso);

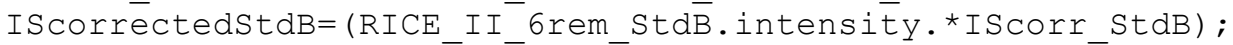

IScorrectedStdB $(1: 50, \overline{1})=\bar{z}$ eros $\overline{\text {; }}$

\%Apply a robustfit method to the IS corrected StdB samples, to produce a onew calibration line.

corr concA $=[]$;

corr_concB=[];

run6_corr_BConC $=[]$;

$\mathrm{b}=[]$;

for iso $=[1: 24]$ 


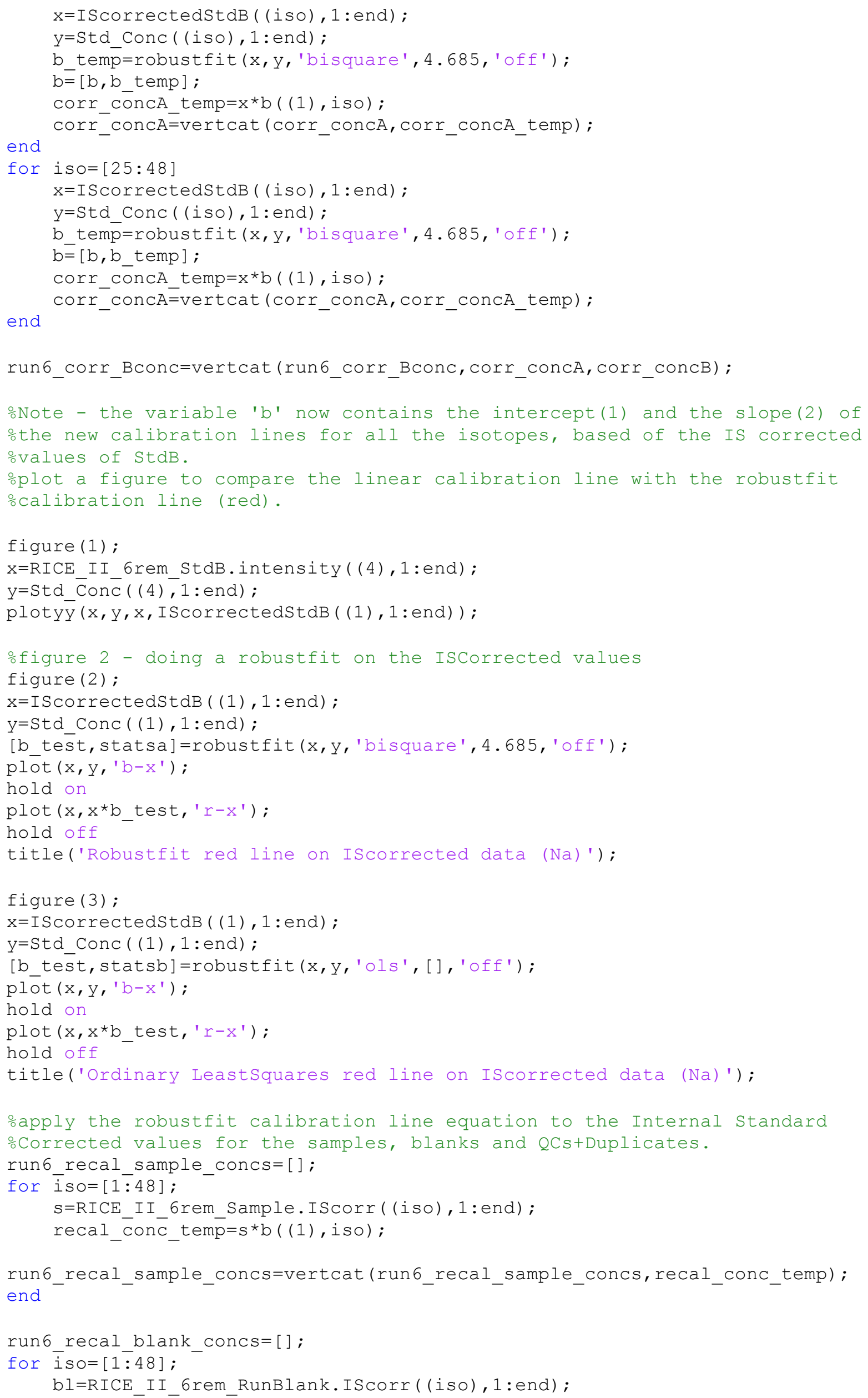




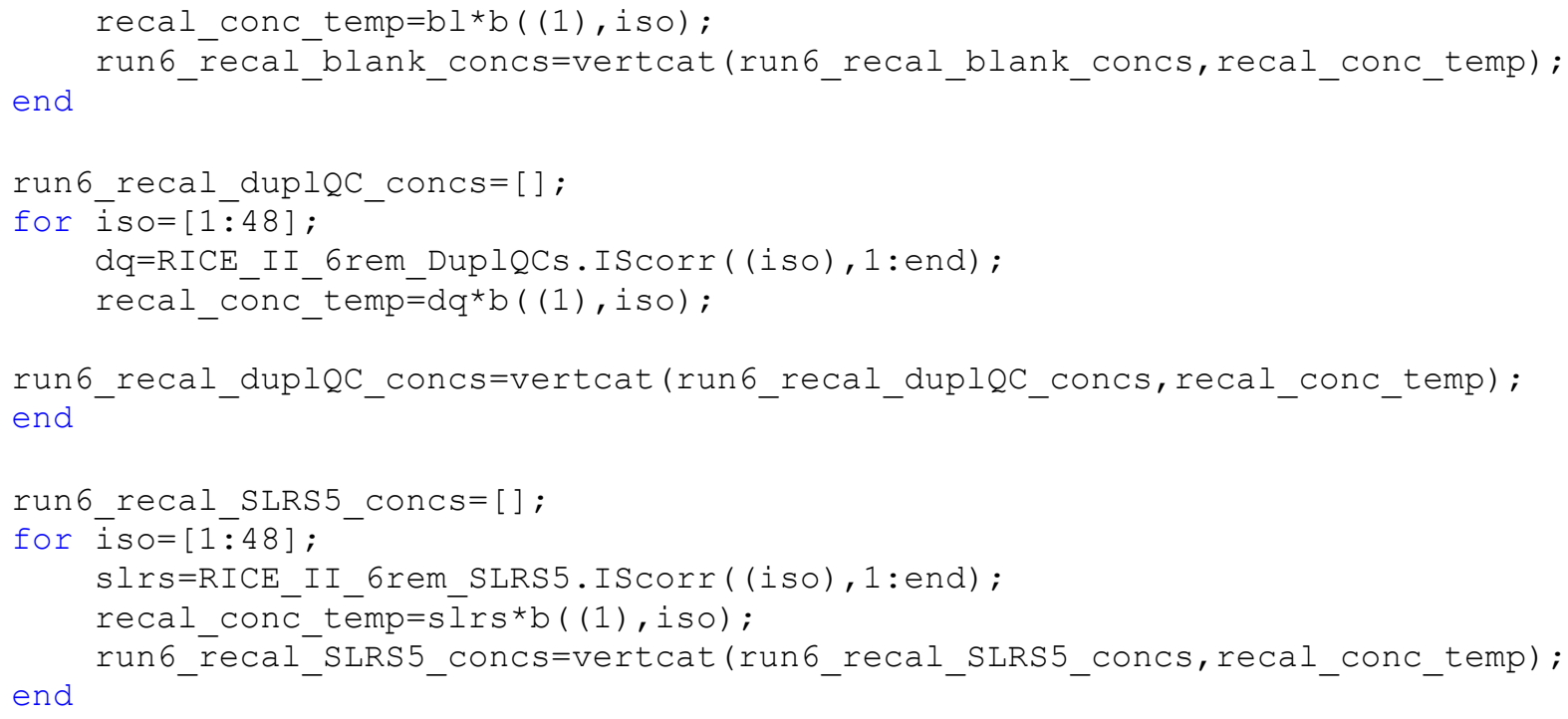

\section{Stage 4:}

oBlank Correction Script to remove instrument background oRun through several times

othe first part of the script should work (for Na and Rb) . oActivate breakpoints just after each "plot" line, to check the fit of the oline. First time through, I removed any obvious outliers from the blank oconcentrations, and chose either a linear fit or a quadratic fit to best oapproximate the blank correction for each element.

oplot the blank concentrations then open the editor and use the interactive oGUI for basic curve fitting. When you save a new variable it returns a ostructure array with the equation coefficients in it.

osecond time through, check the fit of each line through the blank oconcentrations, and ensure the approximate fit is ok.

oThe fit through the blanks for each isotope in each run is used to ocalculate a blank correction based on the time of each sample in the run.

$\mathrm{x} 1=\mathrm{RICE}$ II 6 rem RunBlank.time;

$\mathrm{y} 1=\operatorname{run} 6 \_r e \bar{c} a l \_b \bar{l} a n k \_c o n c s((1), 1$ : end ) ;

plot $(\mathrm{x} 1, \mathrm{y} 1, ' \mathrm{~b}-\mathrm{x} ')$;

ofrom the interactive curve fitting I selected linear fit, and saved the onew variables for the coefficients to the workspace under the name 'Na'. oThis creates a structure array with the type of equation and the ocoefficients in it.

$\mathrm{p} 1=\mathrm{Na} \cdot \operatorname{coeff}((1), 1) ;$

$\mathrm{p} 2=\mathrm{Na} \cdot \operatorname{coeff}((1), 2)$;

$\mathrm{p} 3=\mathrm{Na} \cdot \operatorname{coeff}((1), 3)$;

$\mathrm{Na}$ temp $=\mathrm{p} 1{ }^{*} \mathrm{RICE}$ II $6 \mathrm{rem}$ Sample.time.^2+p2*RICE II 6 rem Sample.time+p3; $\mathrm{Na}{ }^{-} \mathrm{dqC}=\mathrm{p} 1 * \mathrm{RICE} \overline{\mathrm{I} I} \overline{6} \mathrm{rem}$ DuplQCs.time.^2+p2*RICE_II-6rem_DuplQCs.time+p3;

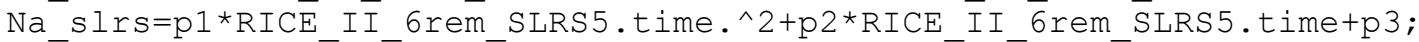
onote point 4 and $\overline{9}$ deleted after checking for outliers

xI=RICE_II_6rem_RunBlank.time; 
y1=run6_recal_blank_concs $((2), 1$ : end $)$;

plot $(\mathrm{x} 1, \mathrm{y} 1, \mathrm{~b}-\mathrm{x}$ ') ;

ofgain, from the interactive basic curve fitting window I selected

oquadratic curve, and saved the new variables as 'Rb'. For this one I

ohighlighted and deleted the first point which was way above the others.

$\mathrm{p} 1=\mathrm{Rb} \cdot \operatorname{coeff}((1), 1) ;$

$\mathrm{p} 2=\mathrm{Rb} \cdot \operatorname{coeff}((1), 2)$;

$\mathrm{p} 3=\mathrm{Rb}$. coeff $((1), 3)$;

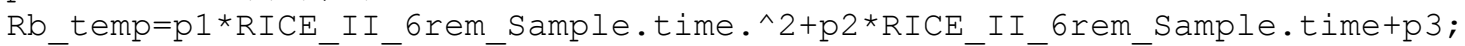

onote point 1 dēleted

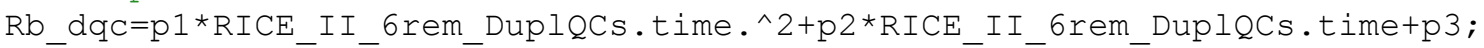

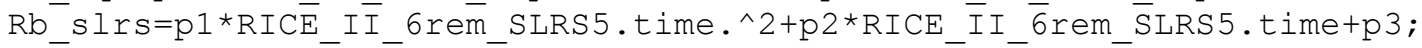

$\mathrm{xI}=\mathrm{RICE} I I$ 6rem_RunBlank.time;

$\mathrm{y} 1=\operatorname{run} 6 \_$recal_bīank_concs $((3), 1$ : end $)$;

$\mathrm{plot}(\mathrm{x} 1, \mathrm{y} 1, \mathrm{~b}-\mathrm{x}$ ') ;

$\mathrm{p} 1=\operatorname{Sr} \cdot \operatorname{coeff}((1), 1)$;

$\mathrm{p} 2=\operatorname{Sr} \cdot \operatorname{coeff}((1), 2)$;

Sr_temp $=\mathrm{p} 1 *$ RICE_II_6rem_Sample.time+p2 ;

onote point 1 déleted

Sr_dqC $=\mathrm{p} 1 * \mathrm{RICE} I I \_6 r e m \_D u p l Q C s . t i m e+p 2$;

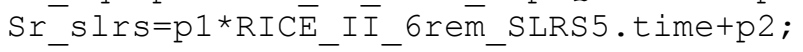

$\mathrm{x} 1=\mathrm{RICE} I \mathrm{I}$ 6rem_RunBlank.time;

y1=run6_recal_blank_concs ( (4), 1 : end) ;

plot $(x 1, y 1, ' b-x ')$;

$\mathrm{p} 1=\mathrm{Y} \cdot \operatorname{coeff}((1), 1)$;

$\mathrm{p} 2=\mathrm{Y} \cdot \operatorname{coeff}((1), 2)$;

$\mathrm{Y}$ temp $=\mathrm{p} 1 * \mathrm{RICE} I \mathrm{I} 6 \mathrm{rem}$ Sample.time+p2;

$\mathrm{Y}{ }^{-} \mathrm{dqC}=\mathrm{p} 1 * \mathrm{RICE} \overline{\mathrm{I} I} \overline{6} \mathrm{rem}$ DuplQCs.time+p2;

Y_slrs=p1*RICE_I ${ }_{-}{ }_{-} 6 r e \bar{m} \_S L R S 5$. time $+\mathrm{p} 2$;

$\operatorname{InLR}(1: 190)=\mathrm{NaN}$;

InLRdqC $(1: 24)=\mathrm{NaN}$;

InLRslrs $(1: 2)=\mathrm{NaN}$;

$\mathrm{x} 1=\mathrm{RICE} I I$ I 6 rem_RunBlank.time;

y1=run6_recal_b̄ank_concs ( (6), 1 : end) ;

$\mathrm{plot}(\mathrm{x} 1, \mathrm{y} 1, \mathrm{~b}-\mathrm{x}$ ') ;

$\mathrm{p} 1=\operatorname{Cs} \cdot \operatorname{coeff}((1), 1)$;

$\mathrm{p} 2=\operatorname{Cs} \cdot \operatorname{coeff}((1), 2)$;

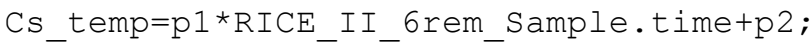

Cs_dqC $=\mathrm{p} 1 * \mathrm{RICE} \overline{\mathrm{I} I} \overline{6} \mathrm{rem} \_\overline{\mathrm{D}} \mathrm{p} 1 \mathrm{QCs}$. time+p2;

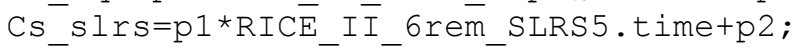

onote first point deleted

x1=RICE_II_6rem_RunBlank.time;

$\mathrm{y} 1=\operatorname{run} 6$ recal_blank_concs $((7), 1$ : end ) ;

$\mathrm{plot}\left(\mathrm{x} 1, \mathrm{y} 1, \mathrm{~b}-\mathrm{x}^{\prime}\right)$;

$\mathrm{p} 1=\mathrm{Ba} \cdot \operatorname{coeff}((1), 1)$;

$\mathrm{p} 2=\mathrm{Ba} \cdot \operatorname{coeff}((1), 2)$;

$\mathrm{p} 3=\mathrm{Ba} \cdot \operatorname{coeff}((1), 3)$;

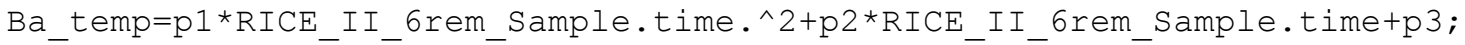

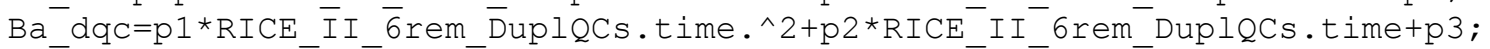

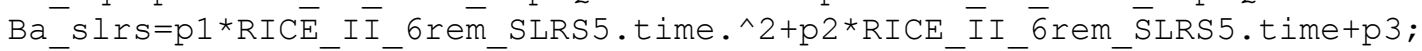

$\times 1=R I C E \_I I \_6 r e m \_R u n B l a n k . t i m e ;$

y1=run6_reçal_b̄ank_concs $((8), 1$ : end $)$;

plot $(x 1, y 1, ' b-x ')$;

$\mathrm{p} 1=\mathrm{La} \cdot \operatorname{coeff}((1), 1)$;

$\mathrm{p} 2=\mathrm{La} \cdot \operatorname{coeff}((1), 2)$;

La_temp $=p 1 * R I C E \_I I \_6 r e m \_S a m p l e . t i m e+p 2$; 


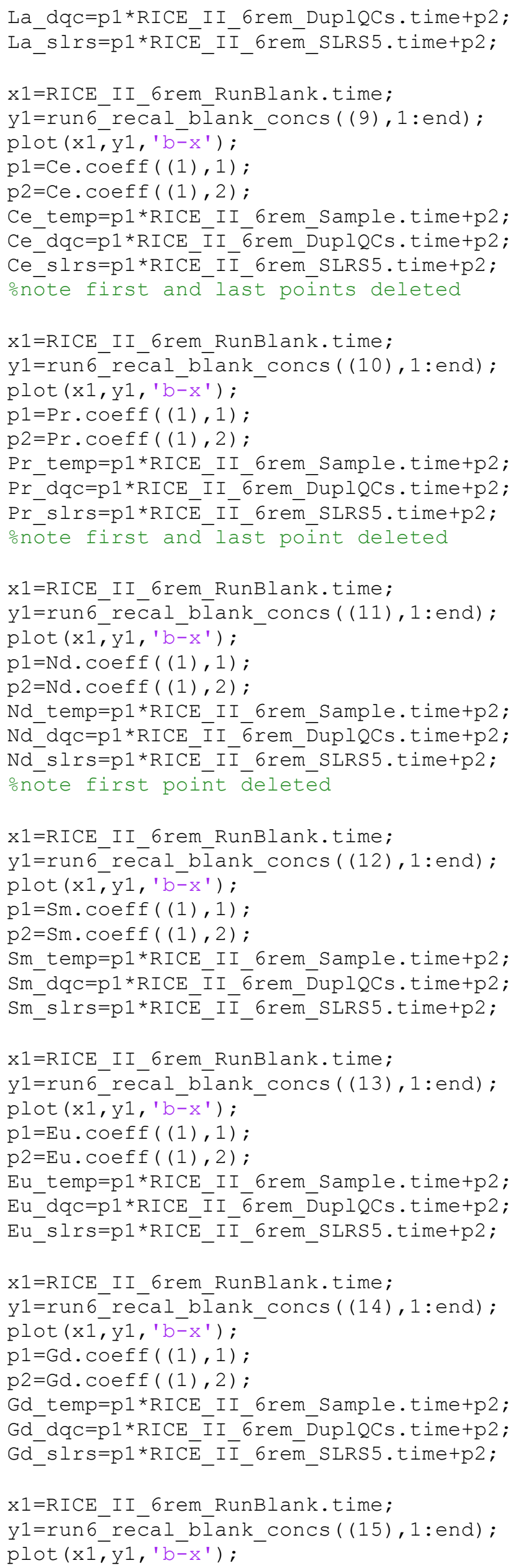


$\mathrm{p} 1=\mathrm{Tb} \cdot \operatorname{coeff}((1), 1)$;

$\mathrm{p} 2=\mathrm{Tb}$. coeff $((1), 2)$;

Tb temp $=\mathrm{p} 1 * \mathrm{RICE}$ II 6 rem Sample.time+p2;

$\mathrm{Tb}-\mathrm{dqC}=\mathrm{p} 1 * \mathrm{RICE} \overline{\mathrm{I} I} \overline{6} \mathrm{rem}$ DuplQCs.time+p2;

Tb_slrs=p1*RICE_I I _6rem_SLRS5.time+p2;

othird to last point de $\bar{l}$ eted

$\mathrm{x} 1=\mathrm{RICE}$ II 6 rem RunBlank.time;

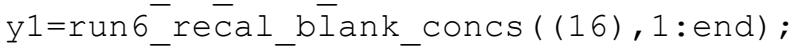

$\mathrm{plot}(\mathrm{x} 1, \mathrm{y} 1, \mathrm{~b}-\mathrm{x}$ ') ;

$\mathrm{p} 1=\operatorname{Dy} \cdot \operatorname{coeff}((1), 1)$;

$\mathrm{p} 2=\operatorname{Dy} \cdot \operatorname{coeff}((1), 2)$;

Dy_temp $=\mathrm{p} 1 * \mathrm{RICE}$ II 6 rem Sample.time+p2;

Dy_dqC $=\mathrm{p} 1 * \mathrm{RICE} \overline{\mathrm{I}} \mathrm{I} \overline{6} \mathrm{rem}$ DuplQCs.time+p2;

Dy_slrs=p1*RICEE_II_6rem_SLRS5.time+p2;

$x 1=R I C E$ II 6 rem RunBlank.time;

$\mathrm{y} 1=\mathrm{run} 6$ recal_blank_concs $((17), 1$ : end) ;

$\mathrm{plot}(\mathrm{x} 1, \mathrm{y} 1, \mathrm{~b}-\mathrm{x}$ ') ;

$\mathrm{p} 1=$ Ho. coeff $((1), 1)$;

$\mathrm{p} 2=$ Ho. coeff $((1), 2)$;

Ho_temp $=\mathrm{p} 1 *$ RICE_II_6rem_Sample.time+p2 ;

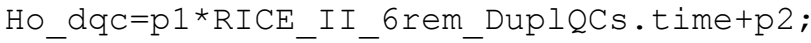

Ho_slrs=p1*RICE

$\mathrm{x} 1=\mathrm{RICE}$ II_6rem_RunBlank.time;

y1=run6_recal_blank_concs ( (18), 1 : end) ;

plot $(\mathrm{x} 1, \mathrm{y} 1, \mathrm{~b}-\mathrm{x}$ ') ;

$\mathrm{p} 1=\mathrm{Er}$. coeff $((1), 1)$;

$\mathrm{p} 2=\operatorname{Er} \cdot \operatorname{coeff}((1), 2)$;

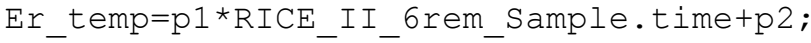

Er_dqC $=\mathrm{p} 1 *$ RICE_II_ $\overline{6}$ rem_DuplQCs.time+p2;

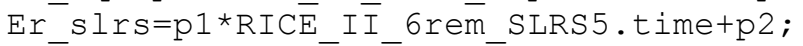

$\mathrm{xI}=\mathrm{RICE} I I$ 6rem RunBlank.time;

$\mathrm{y} 1=\operatorname{run} 6$ recal_b̄̄ank_concs ( (19), 1 : end) ;

$\mathrm{plot}(\mathrm{x} 1, \mathrm{y} 1, \mathrm{~b}-\mathrm{x}$ ') ;

$\mathrm{p} 1=\mathrm{Tm} \cdot \operatorname{coeff}((1), 1)$;

$\mathrm{p} 2=\mathrm{Tm}$. coeff $((1), 2)$;

$\mathrm{p} 3=\mathrm{Tm}$. coeff $((1), 3)$;

Tm_temp $=\mathrm{p} 1 *$ RICE_II_6rem_Sample.time.^2+p2*RICE_II_6rem_Sample.time+p3;

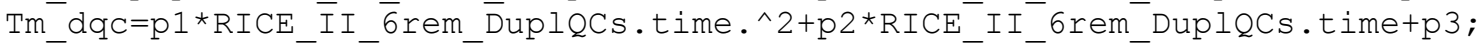

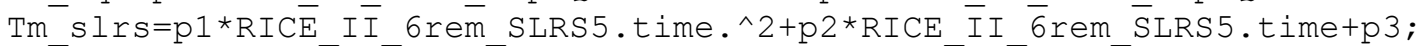

№te first point deletēd

$\mathrm{x} 1=\mathrm{RICE} I \mathrm{I} \_6 \mathrm{rem}$ RunBlank.time;

y1 $=$ run6_recal_b $\bar{l}$ ank_concs $((20), 1$ : end $)$;

plot $(x 1, y 1, ' b-x ')$;

$\mathrm{p} 1=\mathrm{Yb} \cdot \operatorname{coeff}((1), 1)$;

$\mathrm{p} 2=\mathrm{Yb} \cdot \operatorname{coeff}((1), 2)$;

$\mathrm{Yb}$ temp $=\mathrm{p} 1$ * RICE II 6 rem Sample.time+p2;

$\mathrm{Yb}-\mathrm{dqC}=\mathrm{p} 1 * \mathrm{RICE} \overline{\mathrm{I} I} \overline{6} \mathrm{rem}$ DuplQCs.time+p2;

$\mathrm{Yb} \_\mathrm{s} I \mathrm{rs}=\mathrm{p} 1 * \mathrm{RICE} \_\mathrm{I} \overline{\mathrm{I}} \_6 r e \bar{m} \_\mathrm{SLRS} 5$. time+p2;

$\mathrm{x} 1=\mathrm{RICE}$ II 6 rem RunBlank.time;

y1=run6 re $\bar{c} a l \_\bar{l}$ ank_concs ( (21), 1 : end) ;

$\mathrm{plot}(\mathrm{x} 1, \mathrm{y} 1, \mathrm{~b}-\mathrm{x}$ ') ;

$\mathrm{p} 1=\mathrm{Lu} \cdot \operatorname{coeff}((1), 1)$;

$\mathrm{p} 2=\mathrm{Lu} \cdot \operatorname{coeff}((1), 2)$;

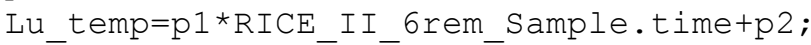

onote point 12 deleted

Lu_dqc $=\mathrm{p} 1 * \mathrm{RICE} I I \_6 r e m \_D u p l Q C s . t i m e+p 2$;

Lu_sIrs=p1*RICE_I $\bar{I} \_6 r e \bar{m} \_S L R S 5 . t i m e+p 2$; 
$\mathrm{xI}=\mathrm{RICE} I I \_6 r e m \_R u n B l a n k . t i m e ;$

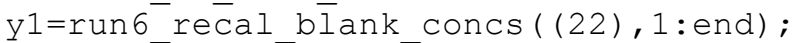

plot $(\mathrm{x} 1, \mathrm{y} 1, \mathrm{~b}-\mathrm{x}$ ') ;

$\mathrm{p} 1=\mathrm{T} 1 \cdot \operatorname{coeff}((1), 1)$;

$\mathrm{p} 2=\mathrm{T} 1 . \operatorname{coeff}((1), 2)$;

T1 temp $=\mathrm{p} 1$ *RICE II 6 rem Sample.time+p2;

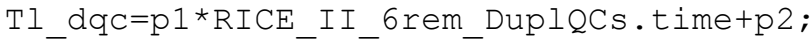

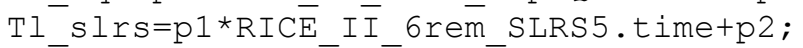

$\mathrm{x} 1=\mathrm{RICE}$ II_6rem_RunBlank.time;

y1=run6_recal_blank_concs ( (23), 1 : end) ;

$\mathrm{plot}(\mathrm{x} 1, \mathrm{y} 1, \mathrm{~b}-\mathrm{x}$ ') ;

$\mathrm{p} 1=\mathrm{Pb} . \operatorname{coeff}((1), 1)$;

$\mathrm{p} 2=\mathrm{Pb} \cdot \operatorname{coeff}((1), 2)$;

$\mathrm{p} 3=\mathrm{Pb} \cdot \operatorname{coeff}((1), 3)$;

$\mathrm{Pb}$ temp $=\mathrm{p} 1{ }^{*} \mathrm{RICE} I I$ 6rem_Sample.time.^2+p2*RICE_II_6rem_Sample.time+p3;

oNote deleted third to last point.

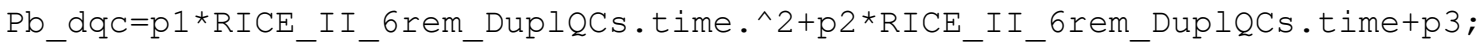

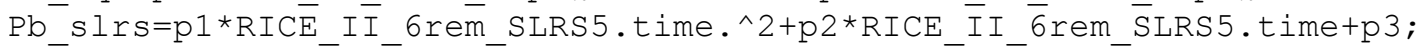

$\mathrm{x} 1=\mathrm{RICE} I \mathrm{I}$ 6rem RunBlank.time;

$\mathrm{y} 1=\operatorname{run} 6$ re $\bar{c} a l \_b \bar{l} a n k \_c o n c s((24), 1$ :end );

$\mathrm{plot}(\mathrm{x} 1, \mathrm{y} 1, \mathrm{~b}-\mathrm{x}$ ') ;

$\mathrm{p} 1=\mathrm{Bi}$. coeff $((1), 1)$;

$\mathrm{p} 2=\mathrm{Bi} \cdot \operatorname{coeff}((1), 2) ;$

p3=Bi. coeff $((1), 3)$;

Bi temp $=\mathrm{p} 1{ }^{*} \mathrm{RICE}$ II 6 rem Sample.time.^2+p2*RICE II 6 rem Sample.time+p3;

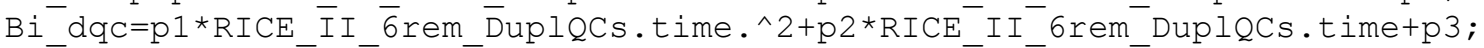

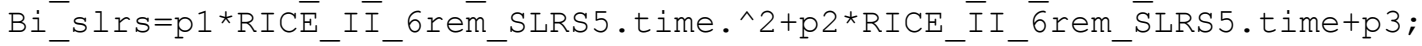

onote deleted pōint 13

$\mathrm{x} 1=\mathrm{RICE}$ II 6 rem RunBlank.time;

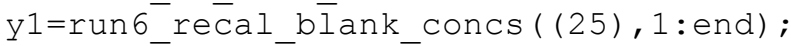

$\mathrm{plot}(\mathrm{x} 1, \mathrm{y} 1, \mathrm{~b}-\mathrm{x}$ ') ;

$\mathrm{p} 1=\mathrm{Th} . \operatorname{coeff}((1), 1)$;

$\mathrm{p} 2=\mathrm{Th} . \operatorname{coeff}((1), 2)$;

Th_temp $=\mathrm{p} 1 *$ RICE_II_6rem_Sample.time+p2;

onote first point and $1 \overline{0}$ th deleted

Th_dqC $=\mathrm{p} 1 * \mathrm{RICE}$ II $6 \mathrm{rem}$ DuplQCs.time+p2;

Th_slrs=p1*RICEEIII_6rem_SLRS5.time+p2;

$\mathrm{x} I=\mathrm{RICE}$ II 6 rem RunBlank.time;

y1=run6_recal_b $\bar{l}$ ank_concs $((26), 1$ : end ) ;

plot $(\mathrm{x} 1, \mathrm{y} 1, \mathrm{~b}-\mathrm{x}$ ') ;

$\mathrm{p} 1=\mathrm{U} \cdot \operatorname{coeff}((1), 1)$;

$\mathrm{p} 2=\mathrm{U} \cdot \operatorname{coeff}((1), 2)$;

$\mathrm{p} 3=\mathrm{U}$. coeff $((1), 3)$;

U temp $=\mathrm{p} 1 * \mathrm{RICE}$ II $6 \mathrm{rem}$ Sample.time.^2+p2*RICE II 6 rem Sample.time+p3;

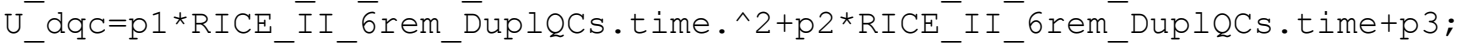

$\mathrm{U}^{-} \mathrm{s} I \mathrm{rS}=\mathrm{p} 1 * \mathrm{RICE} \mathrm{I} \overline{\mathrm{I}} 6 \mathrm{rem}$ SLRS5.time.^2+p2*RICE $\bar{I} I \overline{6}$ rem SLRS5.time+p3;

oñote second pōint and secondtolast point de $\bar{l} e \bar{e} \bar{d}$

$\operatorname{Pu} 239(1: 190)=\mathrm{NaN}$;

$\operatorname{Pu} 239$ dqc $(1: 24)=\mathrm{NaN}$;

Pu239sirs $(1: 2)=\mathrm{NaN}$;

$\mathrm{Pu} 242(1: 190)=\mathrm{NaN}$;

Pu242dqc $(1: 24)=\mathrm{NaN}$;

Pu242slrs $(1: 2)=\mathrm{NaN}$;

Pu24 $4(1: 190)=\mathrm{NaN}$;

Pu244dqC $(1: 24)=\mathrm{NaN}$;

Pu244slrs $(1: 2)=\mathrm{NaN}$;

$\operatorname{SnLR}(1: 190)=\mathrm{NaN}$; 


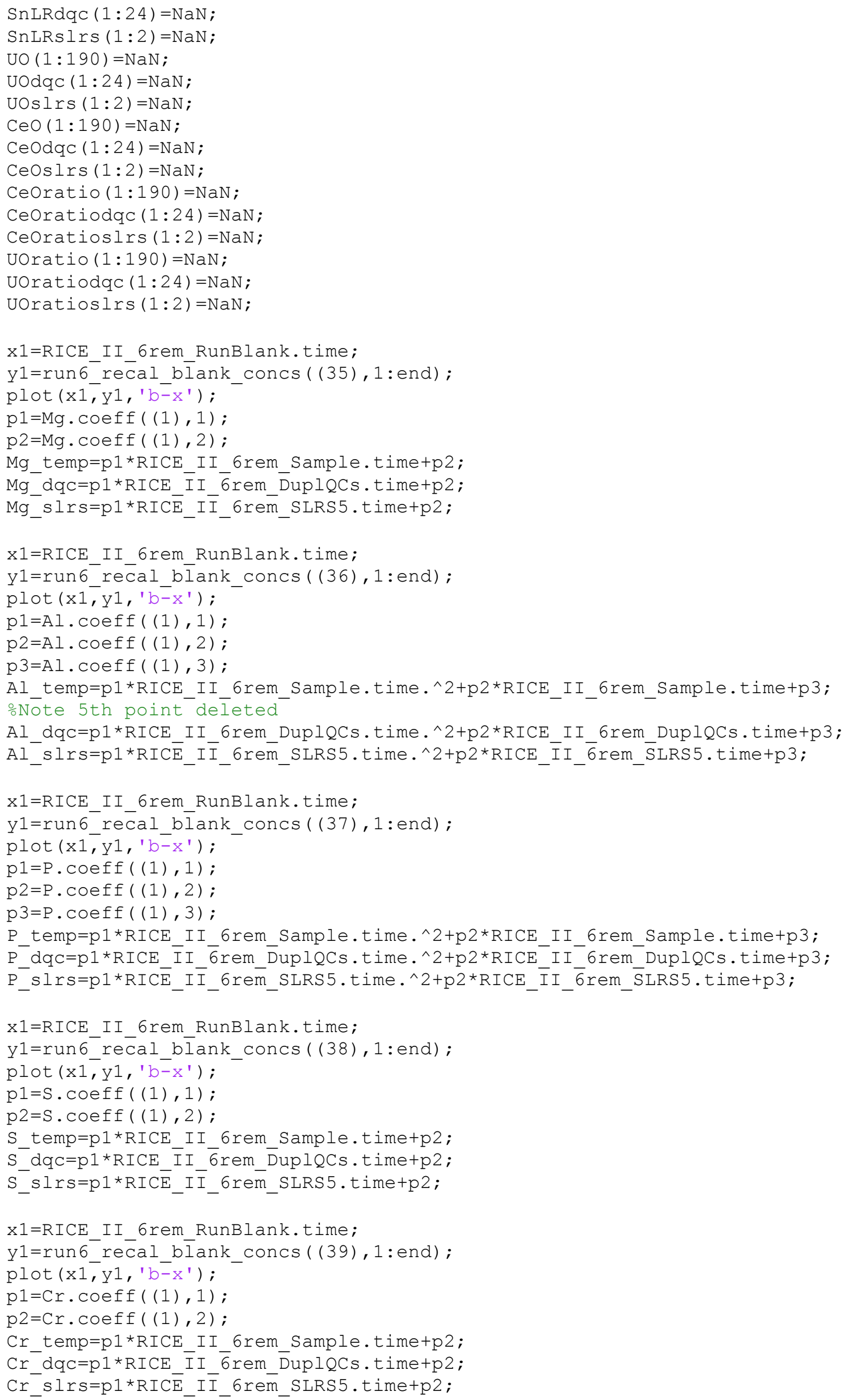


$\mathrm{x} 1=\mathrm{RICE}$ II 6 rem RunBlank.time;

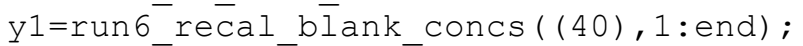

$\mathrm{plot}(\mathrm{x} 1, \mathrm{y} 1, \mathrm{~b}-\mathrm{x}$ ') ;

$\mathrm{p} 1=\mathrm{Mn} \cdot \operatorname{coeff}((1), 1)$;

$\mathrm{p} 2=\mathrm{Mn}$. coeff $((1), 2)$;

p3 $=$ Mn . coeff $((1), 3)$;

Mn_temp=p1*RICE_II_6rem_Sample.time.^2+p2*RICE_II_6rem_Sample.time+p3;

oNote second to last point deleted

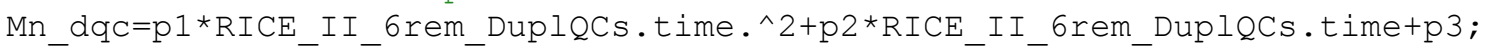

Mn_slrs=p1*RICE_II_6rem_SLRS5.time.^^2+p2*RICE_II_6rem_SLRS5.time+p3;

$\mathrm{xI}=\mathrm{RICE} I I \_6 r e m \_R u n B l a n k . t i m e ;$

y1=run6_re $\bar{c} a l \_b \bar{l}$ ank_concs $((41), 1$ : end );

plot $(x 1, y 1, ' b-x ')$;

$\mathrm{p} 1=\mathrm{Fe} \cdot \operatorname{coeff}((1), 1)$;

$\mathrm{p} 2=\mathrm{Fe}$. coeff $((1), 2)$;

Fe_temp $=p 1 *$ RICE_II_6rem_Sample.time+p2;

$\mathrm{Fe}{ }^{-} \mathrm{dqC}=\mathrm{p} 1 * \mathrm{RICE} \overline{\mathrm{I}} \mathrm{I} \overline{6} \mathrm{rem}$ DuplQCs.time+p2;

$\mathrm{Fe}$ - $\mathrm{SIrS}=\mathrm{p} 1 * \mathrm{RICE} \_\mathrm{I} \overline{\mathrm{I}} \_6 r \mathrm{e}{ }_{-}$SLRS5.time+p2;

onote first two points deleted

$\mathrm{x} 1=\mathrm{RICE}$ II 6 rem RunBlank.time;

yl=run6_recal_b̄ank_concs ( (42), 1 : end) ;

plot $(\mathrm{x} 1, \mathrm{y} 1, \mathrm{~b}-\mathrm{x}$ ') ;

$\mathrm{p} 1=$ Co. $\operatorname{coeff}((1), 1)$;

$\mathrm{p} 2=$ Co. coeff $((1), 2)$;

Co_temp $=\mathrm{p} 1 *$ RICE_II_6rem_Sample.time+p2;

Co-dqC $=\mathrm{p} 1 * \mathrm{RICE} \overline{\mathrm{I}} \mathrm{I} \overline{6} \mathrm{rem}$ DuplQCs.time+p2;

Co_slrs=p1*RICE_I I _6rem_SLRS5.time+p2;

$\mathrm{xI}=\mathrm{RICE} I \mathrm{I}$ 6rem RunBlank.time;

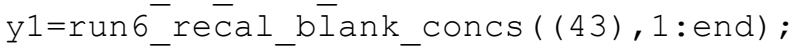

$\mathrm{plot}(\mathrm{x} 1, \mathrm{y} 1, \mathrm{~b}-\mathrm{x}$ ') ;

$\mathrm{p} 1=\mathrm{Cu} \cdot \operatorname{coeff}((1), 1)$;

$\mathrm{p} 2=\mathrm{Cu} \cdot \operatorname{coeff}((1), 2) ;$

$\mathrm{p} 3=\mathrm{Cu} \cdot \operatorname{coeff}((1), 3)$;

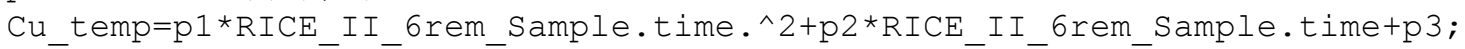

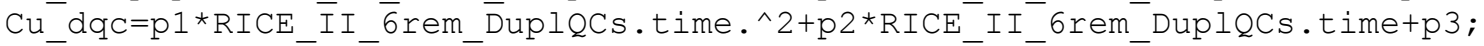

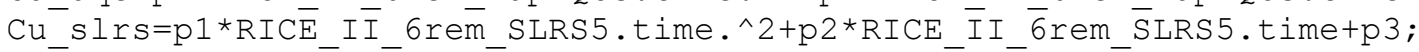

$\operatorname{InMR}(1: 190)=\mathrm{NaN}$;

InMRdqc $(1: 24)=\mathrm{NaN}$;

InMRslrs $(1: 2)=\mathrm{NaN}$;

$\operatorname{SnMR}(1: 190)=\mathrm{NaN}$;

SnMRdqC $(1: 24)=\mathrm{NaN}$;

SnMRslrs $(1: 2)=\mathrm{NaN}$;

$\mathrm{x} 1=\mathrm{RICE}$ II 6 rem RunBlank.time;

y1=run6_recal_blank_concs ( (46), 1 : end) ;

$\mathrm{plot}(\mathrm{x} 1, \mathrm{y} 1, \mathrm{~b}-\mathrm{x} ')$;

$\mathrm{p} 1=\mathrm{K}$. coeff $((1), 1)$;

$\mathrm{p} 2=\mathrm{K}$. coeff $((1), 2)$;

K_temp $=p 1 * R I C E$ II_6rem_Sample.time+p2;

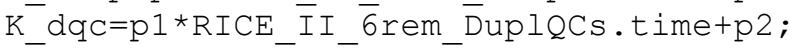

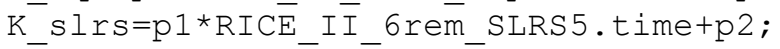

oñote first point deleted

$\mathrm{x} 1=\mathrm{RICE} I I$ 6rem_RunBlank.time;

y1=run6_recal_b̄̄ank_concs $((47), 1$ : end) ;

$\mathrm{plot}(\mathrm{x} 1, \mathrm{y} 1, \mathrm{~b}-\mathrm{x}$ ') ;

$\mathrm{p} 1=\mathrm{Ca} \cdot \operatorname{coeff}((1), 1)$;

$\mathrm{p} 2=\mathrm{Ca} \cdot \operatorname{coeff}((1), 2)$;

p3=Ca. coeff $((1), 3)$; 
Ca temp $=\mathrm{p} 1 * \mathrm{RICE}$ II 6 rem Sample.time.^2+p2*RICE II 6 rem Sample.time+p3;

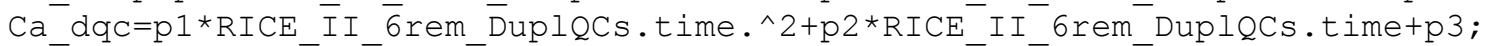

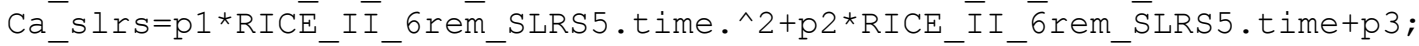

$\mathrm{xI}=\mathrm{RICE}$ II_6rem_RunBlank.time;

$\mathrm{y} 1=\operatorname{run} 6$ recal blank concs $((48), 1$ : end $)$;

plot $(\mathrm{x} 1, \mathrm{y} 1, \mathrm{~b}-\mathrm{x}$ ') ;

$\mathrm{p} 1=\mathrm{As} \cdot \operatorname{coeff}((1), 1)$;

$\mathrm{p} 2=\mathrm{As} \cdot \operatorname{coeff}((1), 2)$;

As_temp $=\mathrm{p} 1 * \mathrm{RICE} I I$ rem_Sample.time+p2;

As_dqc $=\mathrm{p} 1 * \mathrm{RICE} \overline{\mathrm{I} I} \overline{6} \mathrm{rem}$ DuplQCs.time+p2;

As_slrs=p1*RICE_I $\bar{I}_{-} 6 r e \bar{m} \_S L R S 5 . t i m e+p 2$;

oMake a new blank array that will hold all the new blank values created ofrom the chosen curve/line.

Blank_Corrections_Samp=vertcat (Na_temp, Rb_temp, Sr_temp, Y_temp, InLR, Cs_temp,

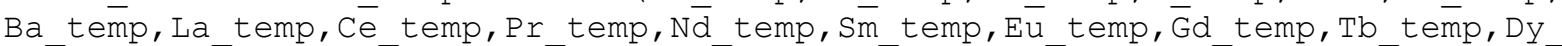

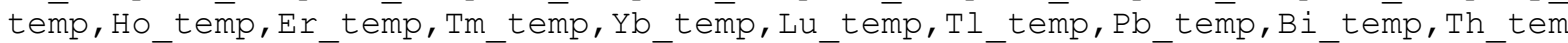

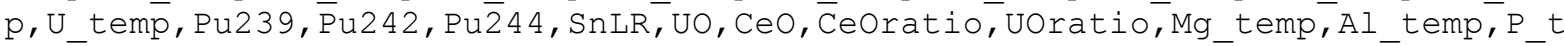
emp, S_temp, Cr_temp, Mn_temp, Fe_temp, Co_temp, Cu_temp, InMR, SnM̄R, K_temp, Ca_temp , As_tèmp);

Blank Corrections $\mathrm{DQC}=$ vertcat $(\mathrm{Na}$ dqc, $\mathrm{Rb}$ dqc, $\mathrm{Sr}$ dqc, $\mathrm{Y}$ dqc, InLRdqc, $\mathrm{Cs}$ dqc, $\mathrm{Ba}$

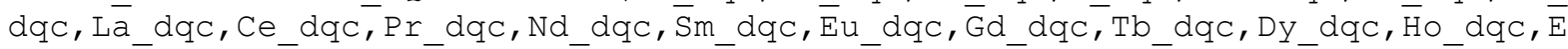

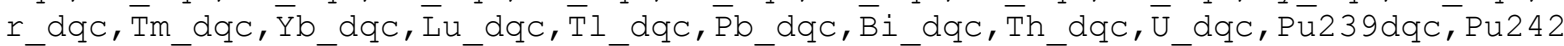

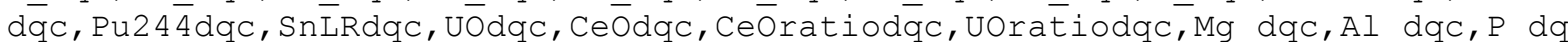
C, S_dqc, Cr_dqc, Mn_dqc, Fe_dqc, Co_dqc, Cu_dqc, InMRdqc, SnMRdqc , $\bar{K} \_d q c, C \bar{a} \_d q c, \bar{A} s$ $\mathrm{dqc}^{\bar{T}}$;

Blank_Corrections_SLRS=vertcat (Na_slrs, Rb_slrs,Sr_slrs, Y_slrs, InLRslrs, Cs_s

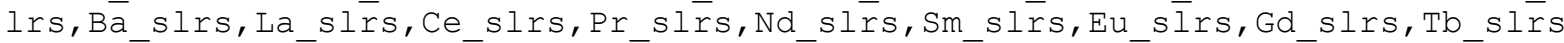

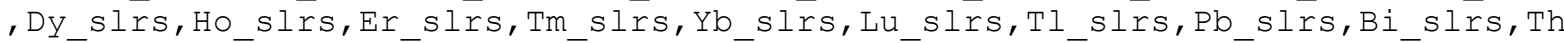

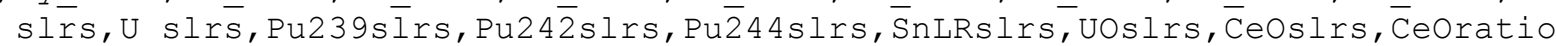
slrs, UOratioslrs, Mg slrs, Al slrs, P slrs, S slrs, Cr slrs, Mn slrs, Fe slrs, Co s lrs, Cu_slrs, InMRslrs, SnMRslīs,K_slērs, Ca_sīrs, As_sìrs);

ofinally, subtract the Blank Corrections from the recalibrated sample oconcentrations - these are the Final, Internal Standard corrected, oRecalibrated, and Blank Subtracted Concentrations of Samples, Duplicate oand Quality Control Samples, and any External Standards.

FINAL Corrected Sample=run6 recal sample concs-Blank Corrections Samp;

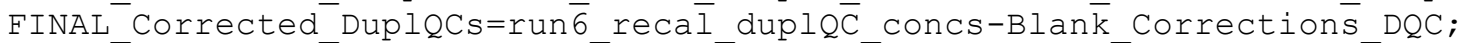

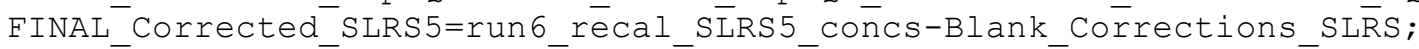

oplot figures to check sample concentrations before and after blank osubtraction

figure (1);

plot (Run_Order_Samples,FINAL_Corrected_Sample((23), 1:190),'r-x') ;

hold on

plot (Run_Order_Samples,run6_recal_sample_concs( (23), 1:190), 'b-x') ; hold on

plot (Run_Order_Blanks, run6_recal_blank_concs ( (23), 1 : end), 'g-x') ; hold off

ylabel ('Concentration ppt');

figure (2);

plotyy (Run_Order_QCs,FINAL_Corrected_DupleCs ( (3), 1 : end), Run_Order_SLRS, FINA

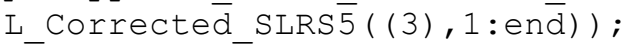

oThe 'FINAL Corrected \#' variables can be exported to an xls spreadsheet oand worked with separately from there. 